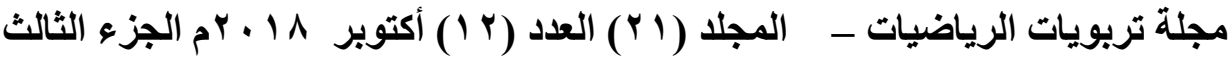

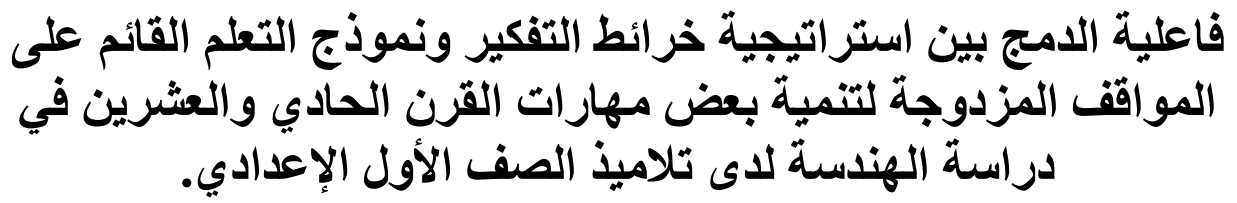

The Eeffectiveness of Integration of the Strategy of Thinking Maps and the Dual Situated Learning Model to Develop of some of the 21st Century Skills in the Geometry Study for the Students of the Frist Prep Stage.

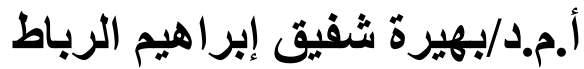

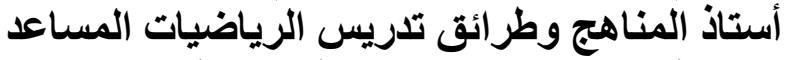

كلية الدراسات العليا للتربية/ جامعة التربية الرامبات الترة. 


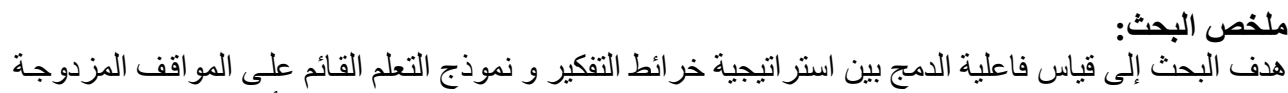

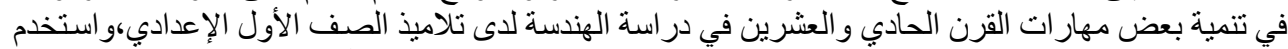

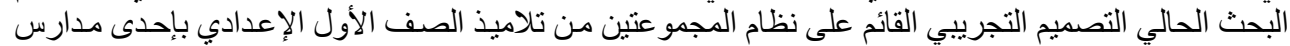

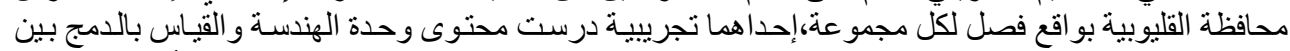

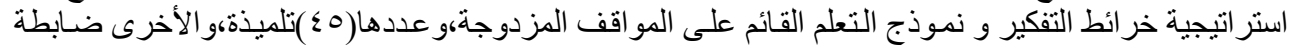

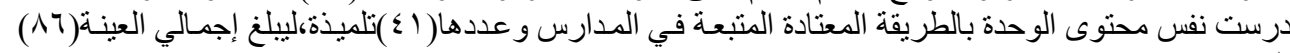
تلميذة. و قد توصل البحث للنتائج التالية:

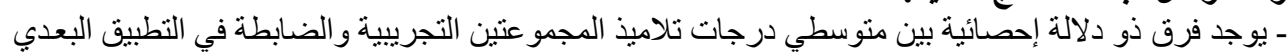

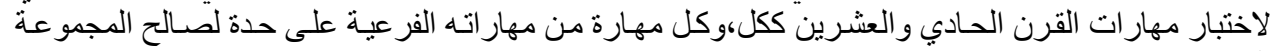
التجريبية.

- يوجد فرق ذو دلالة إحصـائية بين متوسطي درجات تلاميذ المجموعة التجريبية في التطبيقين القبلي و البعدي لاختبار مهار ات القرن الحادي و العشرين ككل،وكل مهارة من مهار اته الفرعية على حدة لصالح التطبيق البعدي الفي لتحي

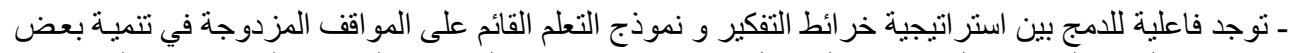

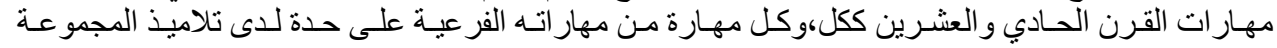

\section{Abstract of The Resarch:}

التجريبية.

A Research Aimed to Measure of The Effectiveness of Integration of the Strategy of Thinking Maps and the Dual Situated Learning Model to Develop of some of the 21st Century Skills in the Geometry Study for the Students of the Frist Prep Stage, The Present Research Used Experimental Design Based on The System Two Groups of Students of The Frist Prep Stage at A school Governorate Qalyoubiya by Classroom for Each Group, One Experimental Group Studied The Content of of the Unit of Geometry and Measurement by Integration of the Strategy of Thinking Maps and the Dual Situated Learning Model and Number of(45) Schoolgirls, and Other Control Studied The Same Content of Unit by Being Traditionally in Schools, and Number of(41) Schoolgirls, for a Total Sample(86)Schoolgirls.

\section{FIndings of The Resarch:}

The Present Searcsh bore out The Following Results:

-There is a Statistically Significant Difference Between Scores Mean of The Students in The Experimental Group and The Control Group Concerning The Posttest of the 21st Century Skills (Total Score and Individual skill) in Favor of The Experimental Group.

-There is a Statistically Significant Difference Between The Mean Scores of The Experimental Group on Pretesting and Post testing on the 21st Century Skills (Total Score and Individual skill)in favor of Post testing Mean Scores.

-There is Effectiveness of Integration of the Strategy of Thinking Maps and the Dual Situated Learning Model to Develop of some of the 21st Century Skills (Total Score and Individual Skill)for The Students of The Experimental Group. 


\section{المقدمة والإحساس بالمشكلة:}

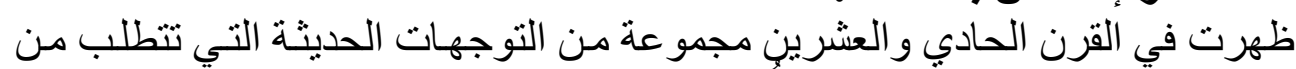

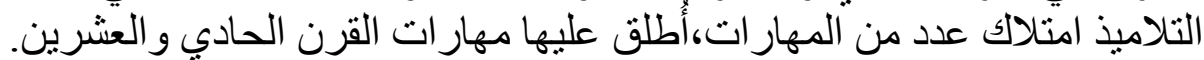

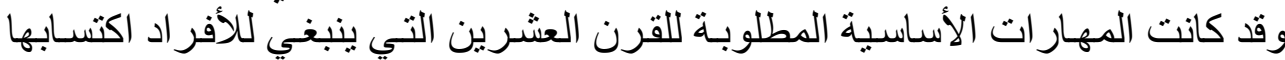

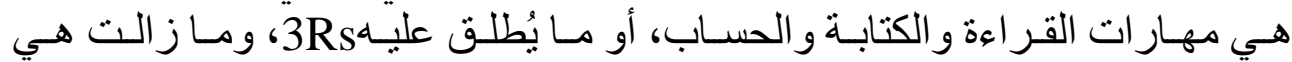

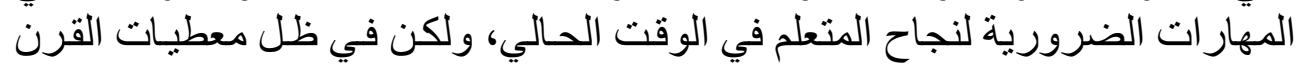

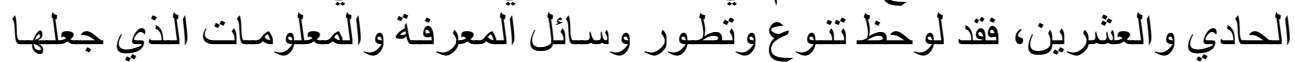

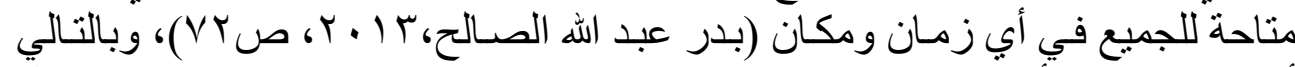

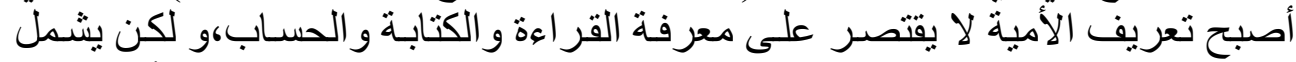

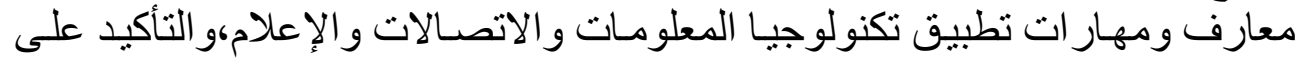

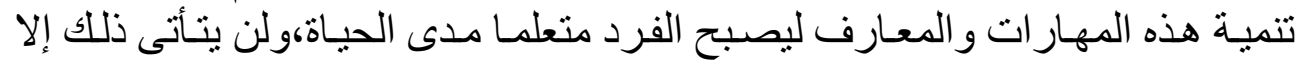

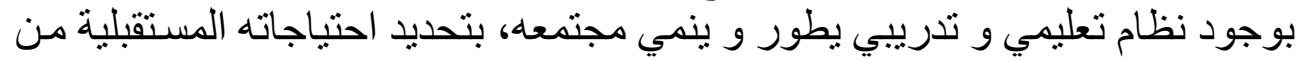

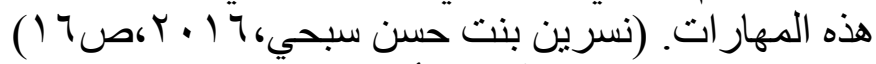

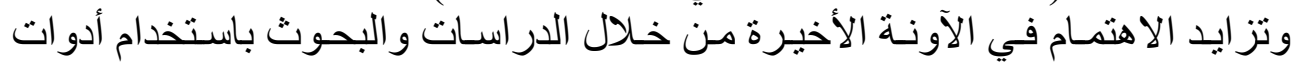

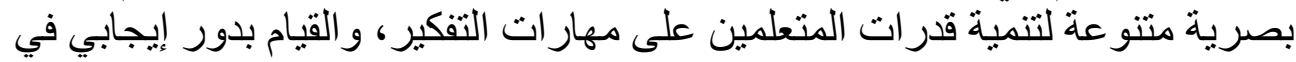

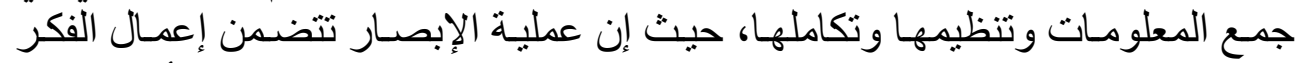

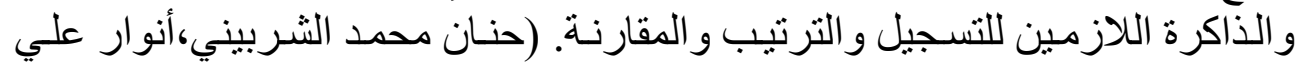

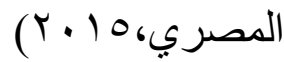

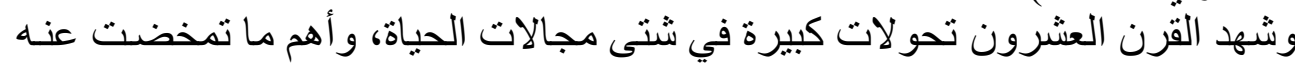

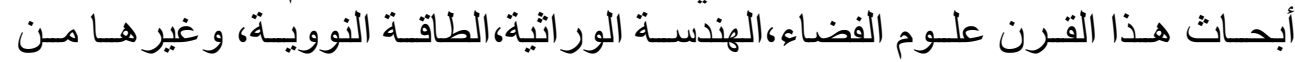

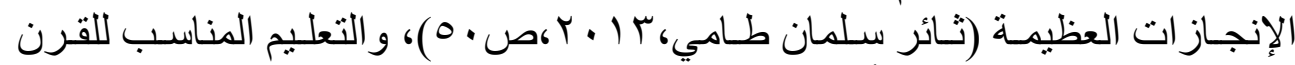

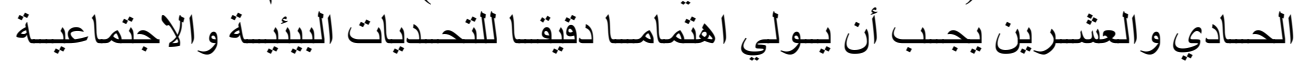

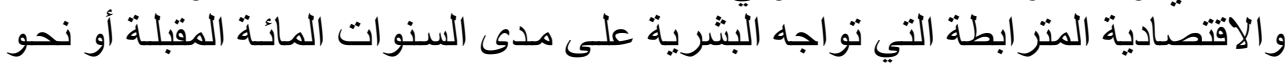
ذلك. (Bell,2016)

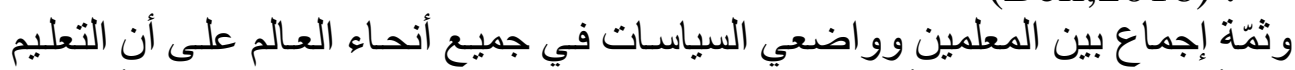

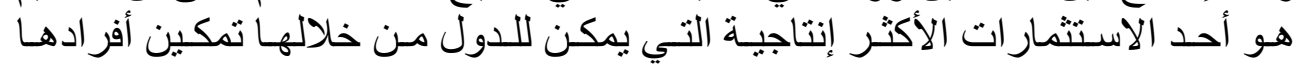

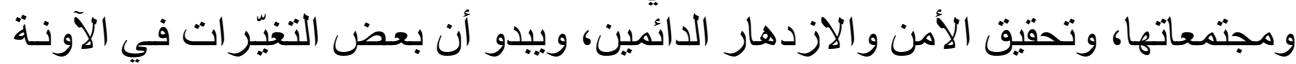

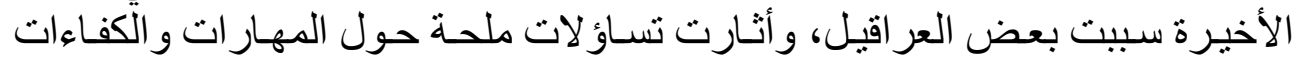

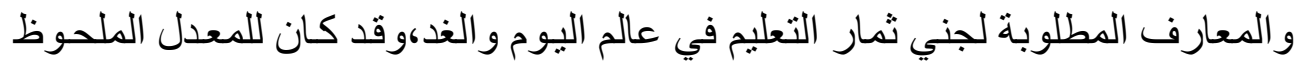

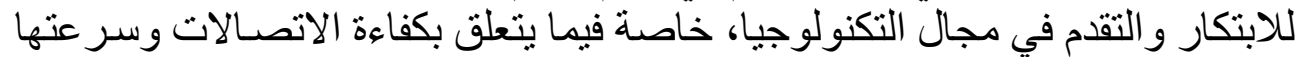

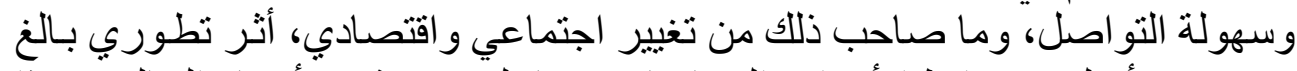

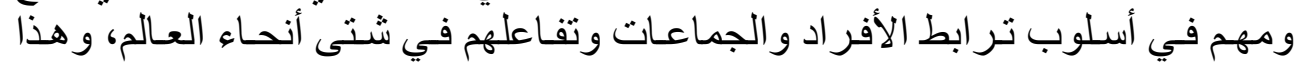




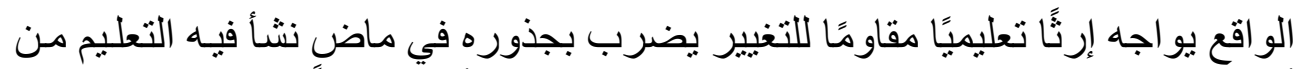

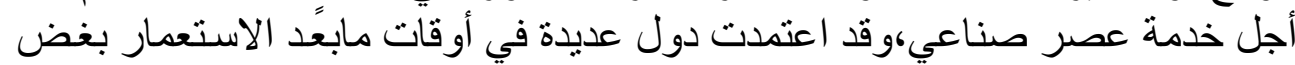

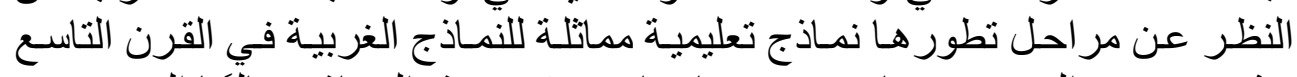

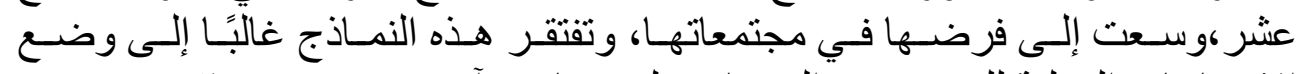

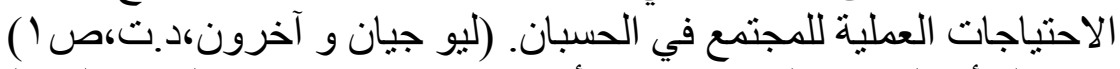

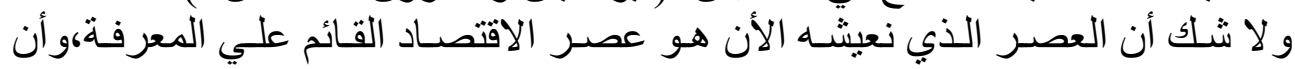

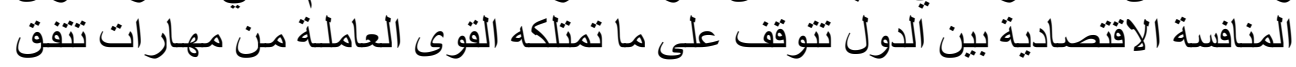

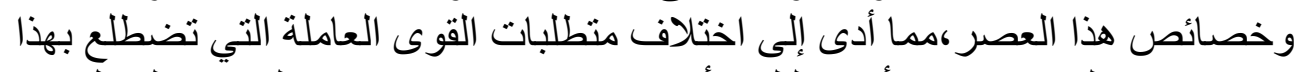

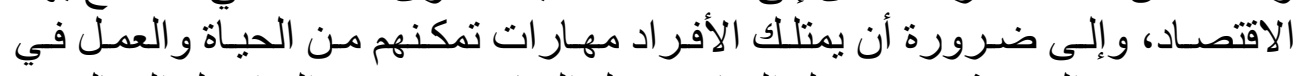

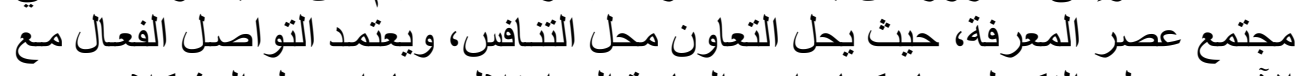

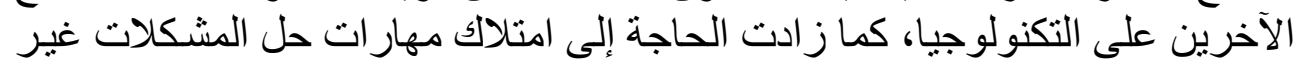

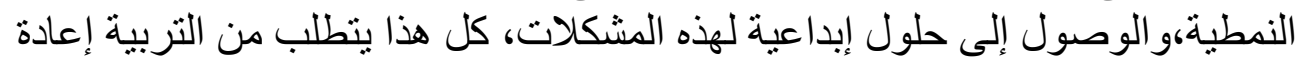

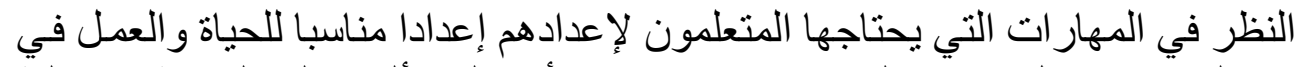

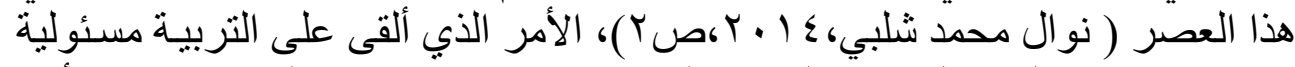

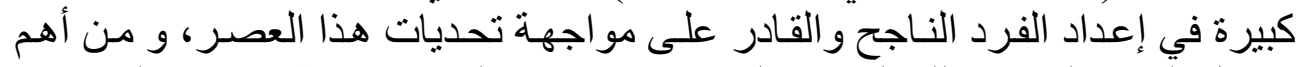

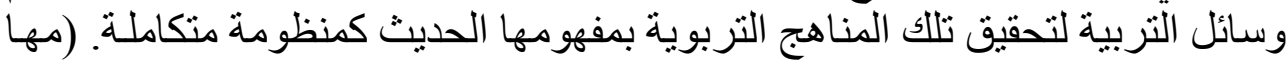

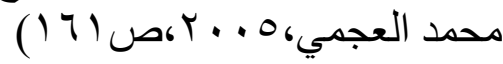

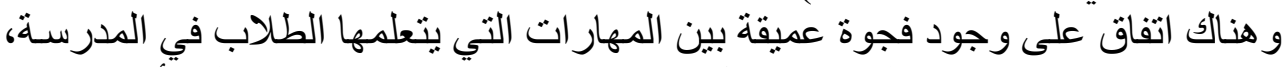

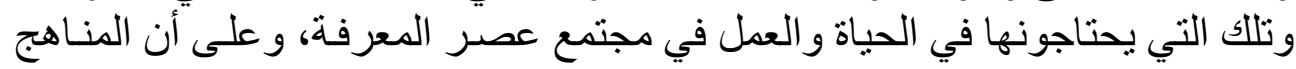

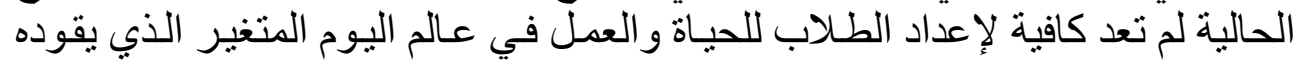

التطور التكنولوجي. (Bybee,2010)

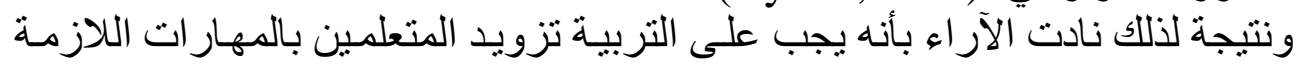

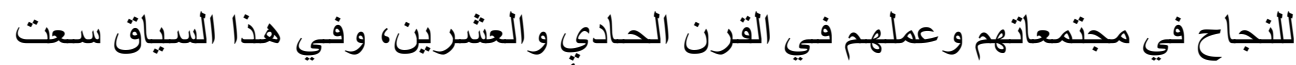

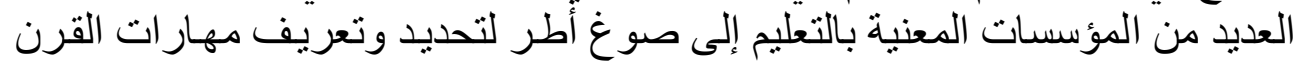

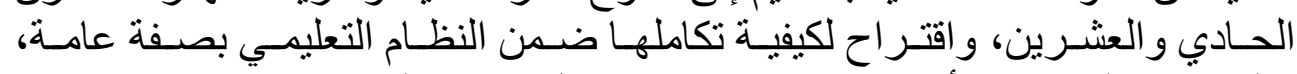

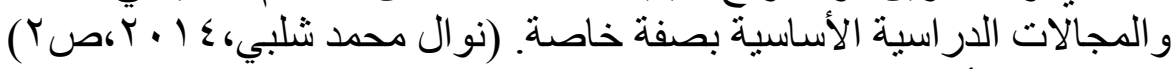

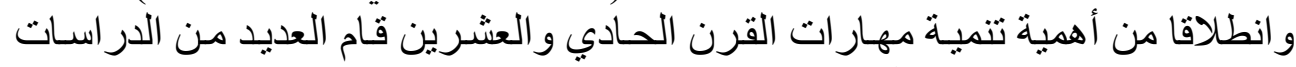

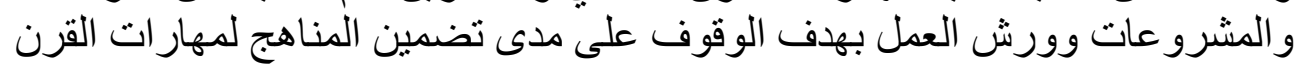

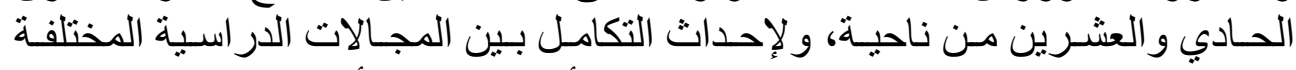

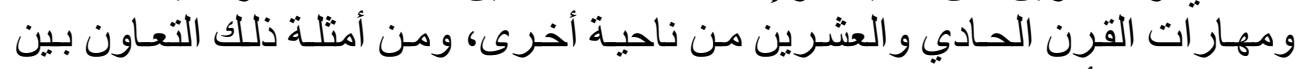

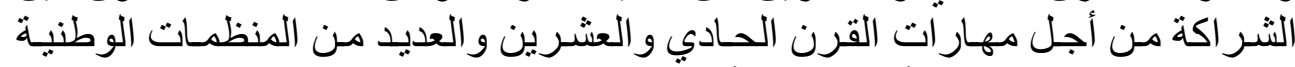

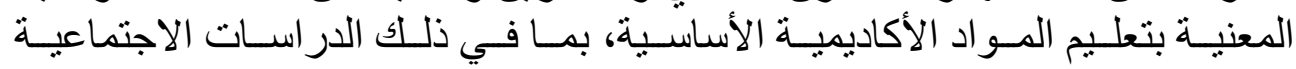




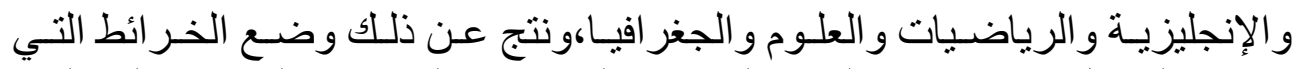

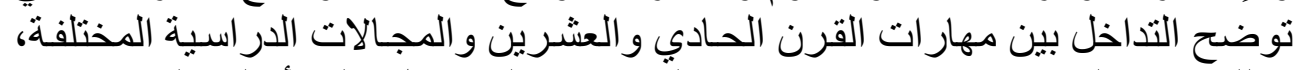

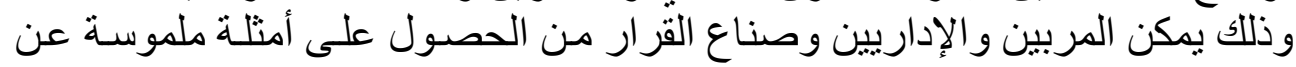

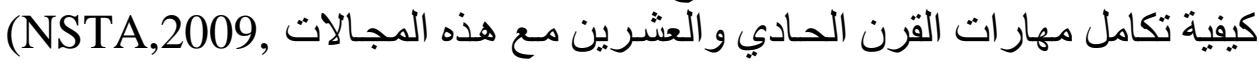

وترتكز أهداف تنميـة مهـار ات القرن إب على جعل الطـلاب قـادرين على: التفكير

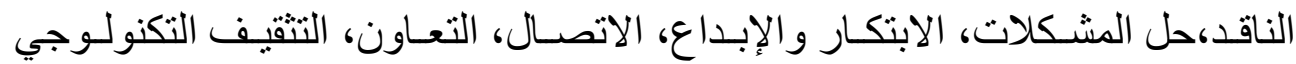

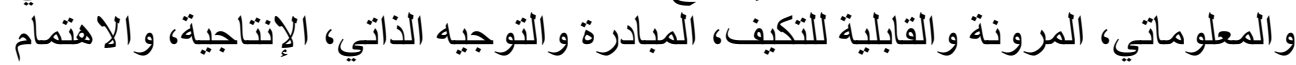

بالثـئون العالميـة، التثقيف الإعلامسي. Partnership for 21st Century

Skills, 2009)

ويعتبر التفكير مطلبا أساسيا لجميع أفر اد المجتمع عندما يو اجهون مشكلات أو تحديات

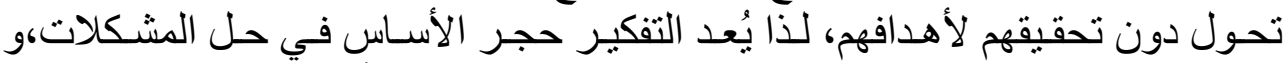

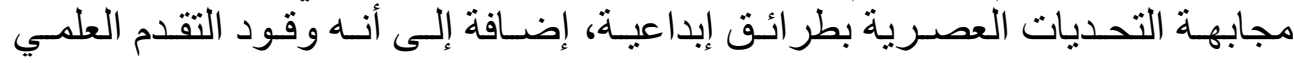

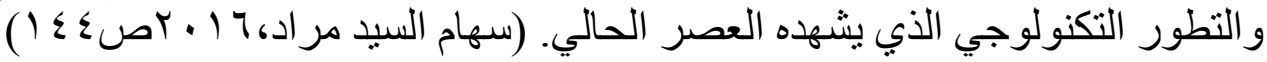

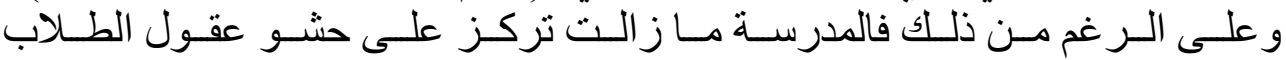

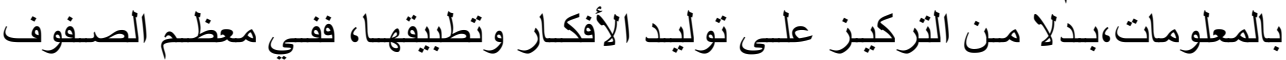

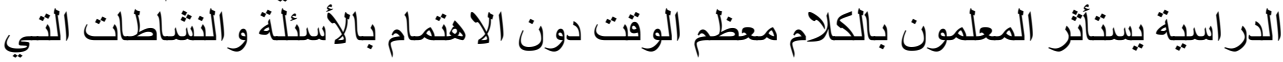

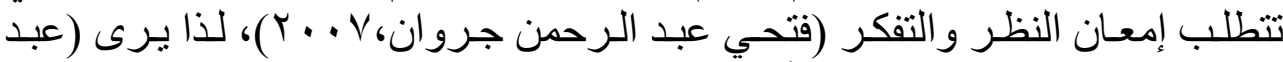

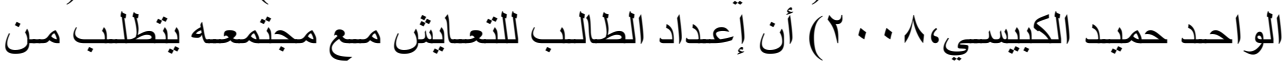

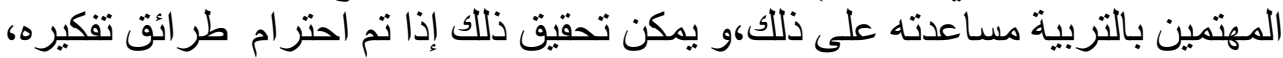

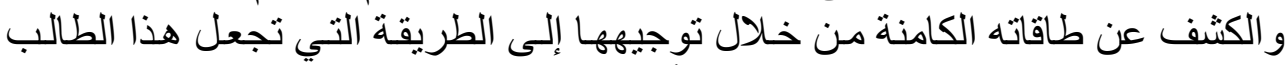

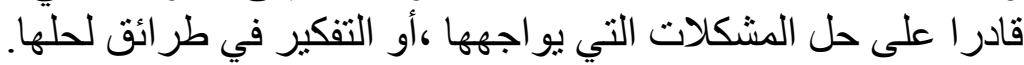

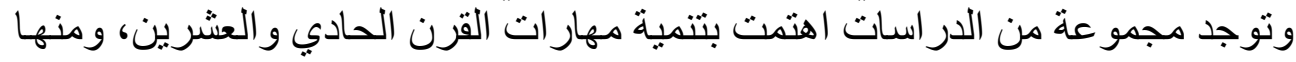

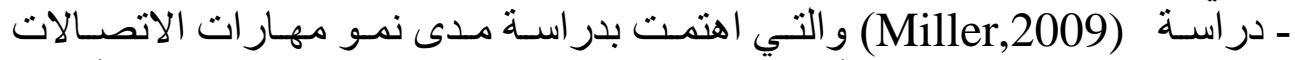

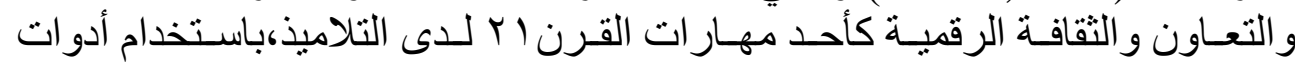

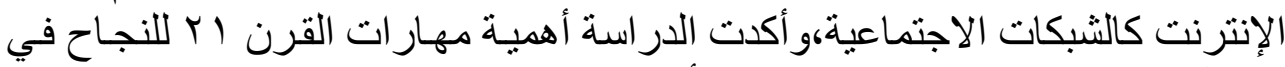

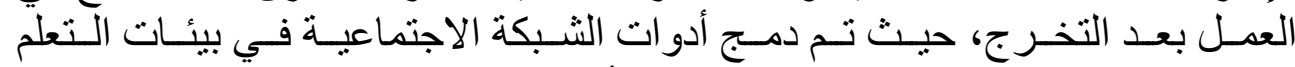

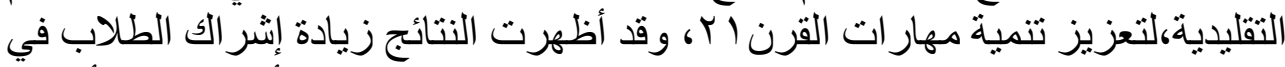

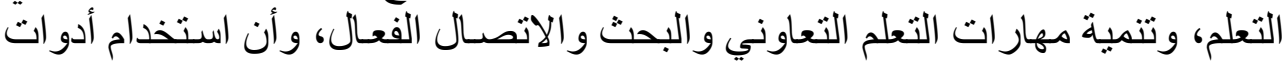

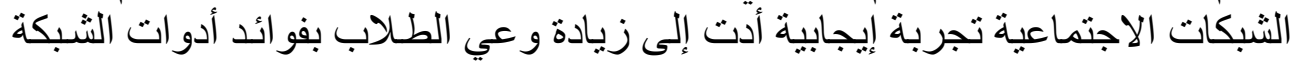

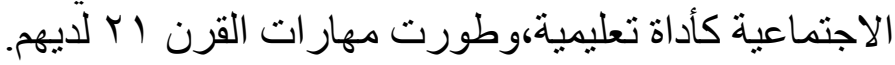




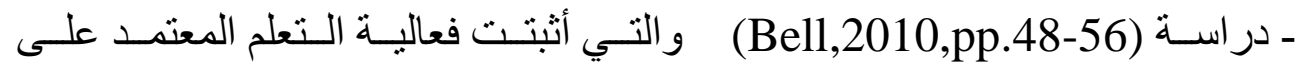

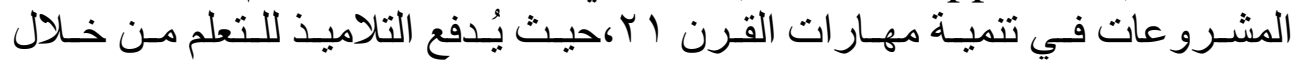

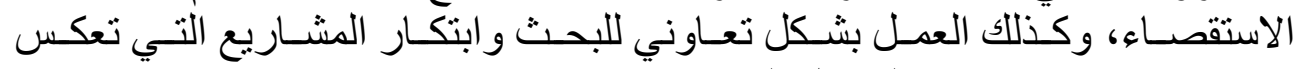
معرفتهم، وتنمي قدرتهم على حل المشكلات.

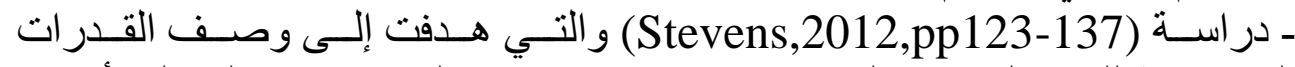

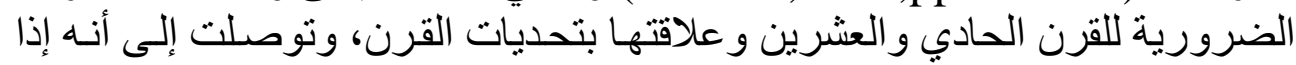

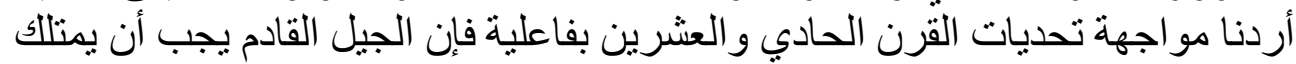

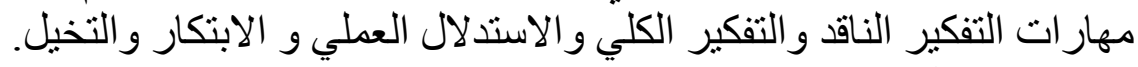

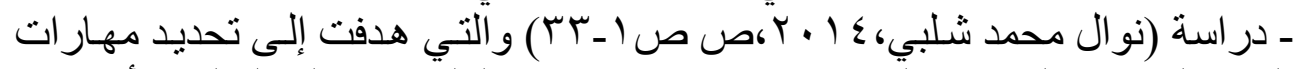

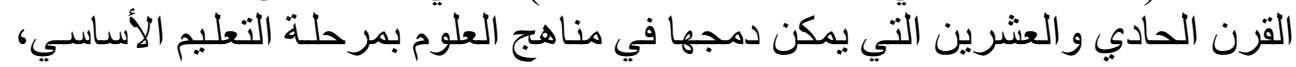

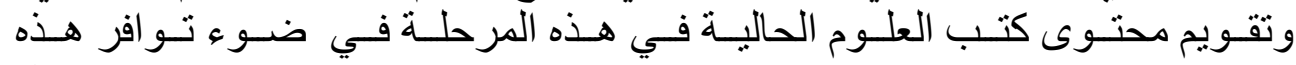

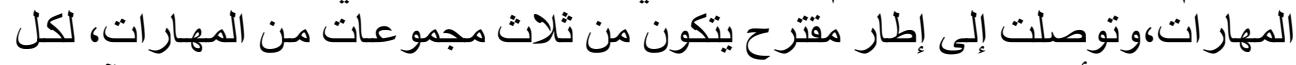

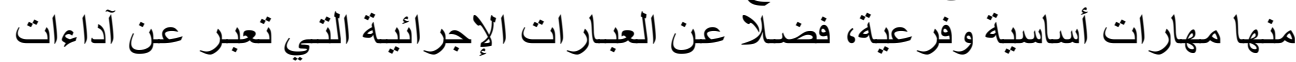

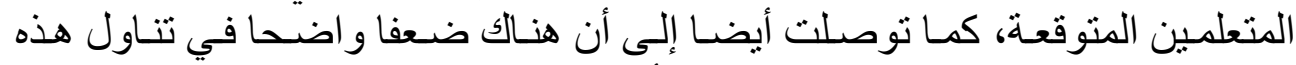

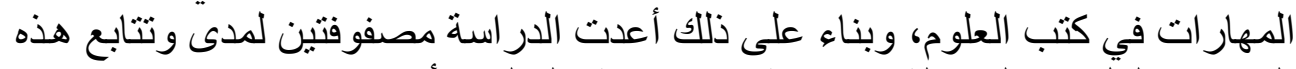

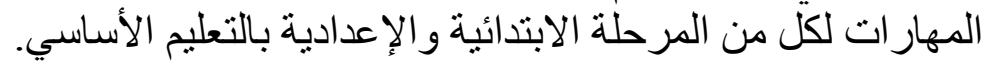

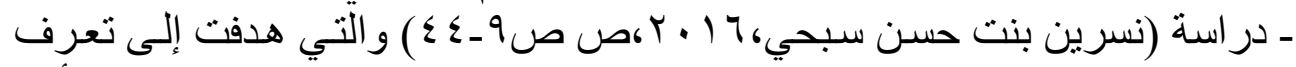

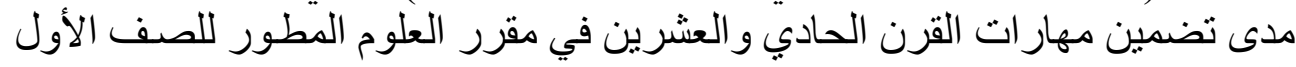

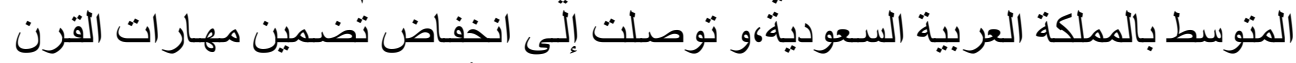
الحادي والعشرين في مقرر العلوم المطور للصف الأول المتوسط بالمملكة العربية العزية

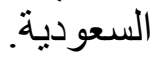

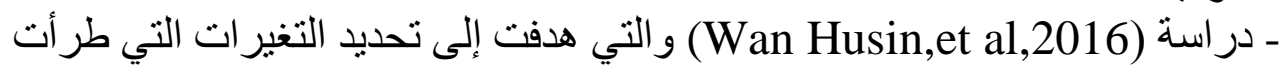

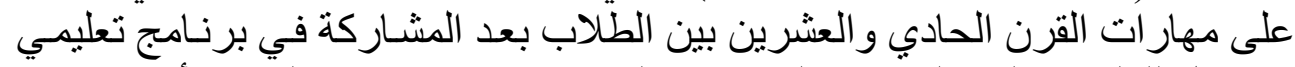

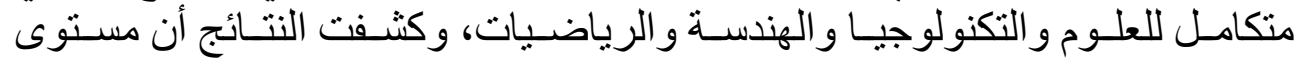

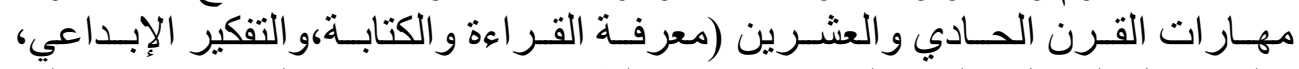

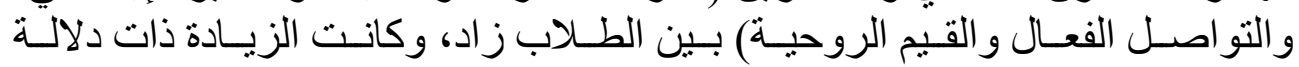
إحصائية.

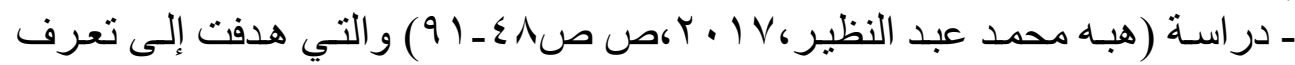

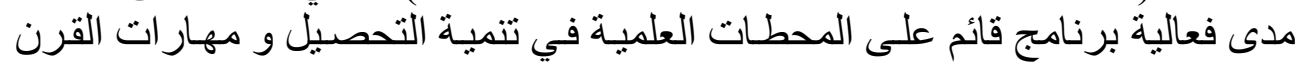

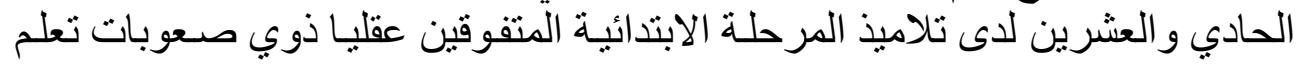
الرياضيات، وتوصلت إلى وجود فرق ذي دلي دلالة إحصائية بين متوسطي رنب رنب درجيات 
المجموعتين التجريبية و الضابطة في التطبيق البعدي لمقياس مهار ات القرن الحـادي

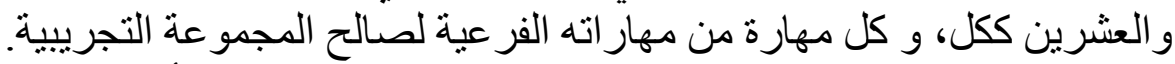

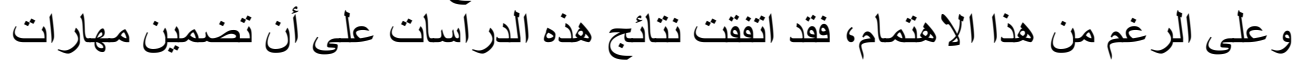

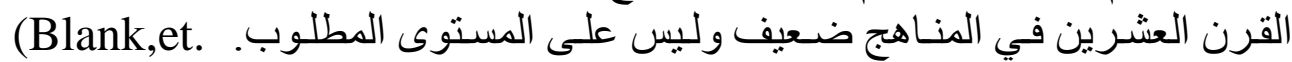
al,2001)

ونتيجة لمر اجعة الدر اسات التي اهتمت بتحليل الأعمال التي بتطلبها سوق العمل في في إني

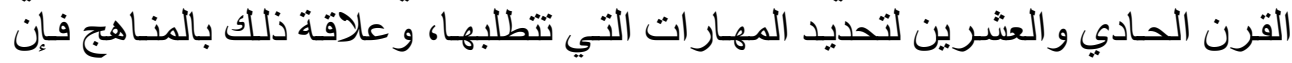

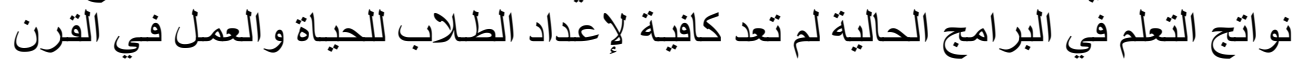

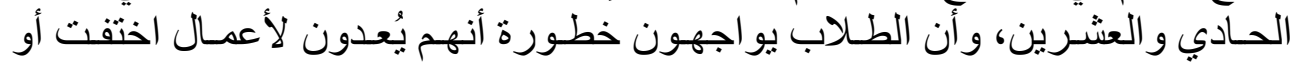

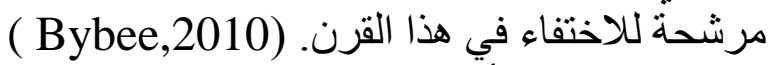

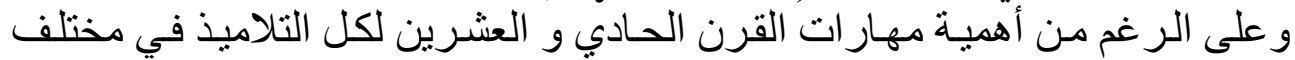

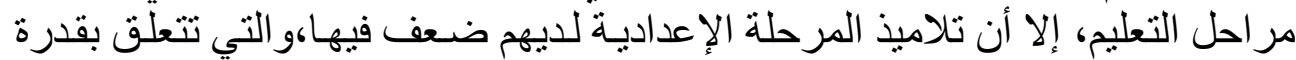

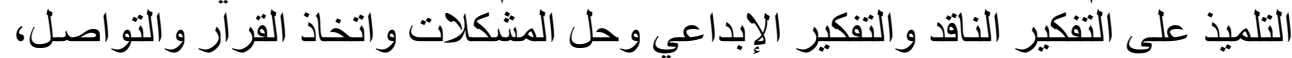

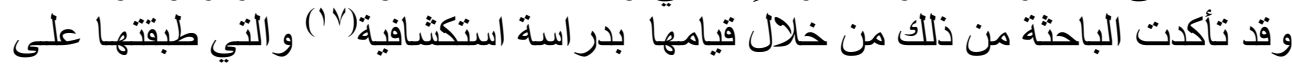

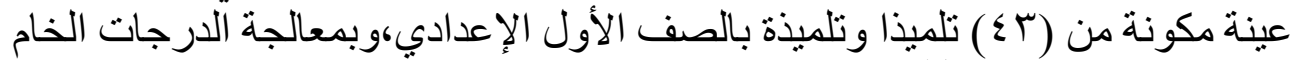

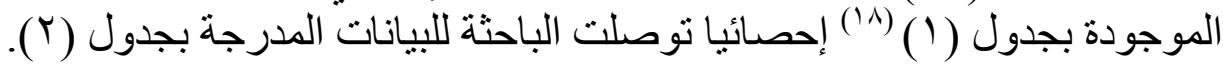

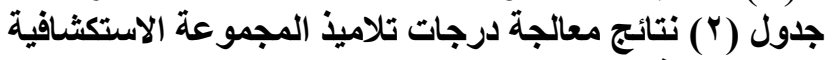
في مهارات القرن الحادي والعشرين

\begin{tabular}{|c|c|c|c|c|c|c|}
\hline \multirow[t]{2}{*}{ الاختبار ككل } & \multirow[t]{2}{*}{ التواصل } & \multirow[t]{2}{*}{ اتخاذ القرار } & ح & التفكيـــــر & التفكيـــر & \multirow{2}{*}{ البيان } \\
\hline & & & المشكلات & الإبداعي & 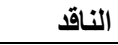 & \\
\hline \multicolumn{6}{|c|}{$\varepsilon \psi$} & عدد التلاميذ \\
\hline rq & 9 & r & 7 & 7 & 7 & درجة الاختبار \\
\hline 11.091 & r.qvV & $\because 9 \cdot v$ & $Y .0 \wedge 1$ & r.\&1q & $r .9 \cdot v$ & المتوسط \\
\hline$\varepsilon . \wedge r \Lambda$ & $1 . r .0$ & - & I.YY. & 1.109 & $1 . \leqslant Y \Lambda$ & الانحراف المعياري \\
\hline
\end{tabular}

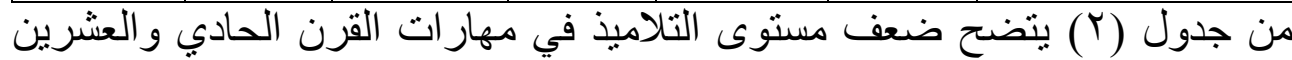

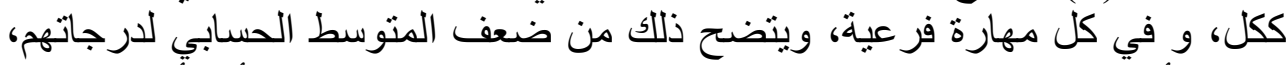

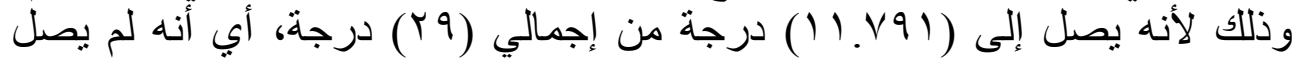

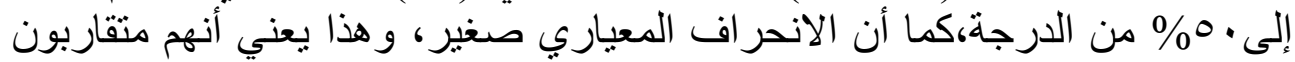

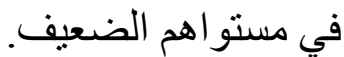

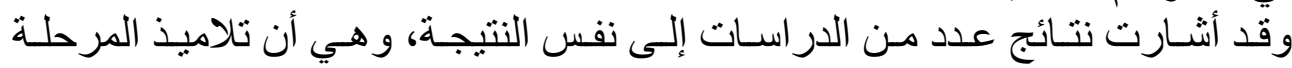

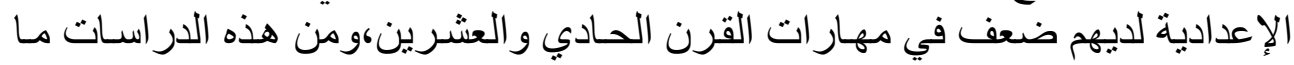




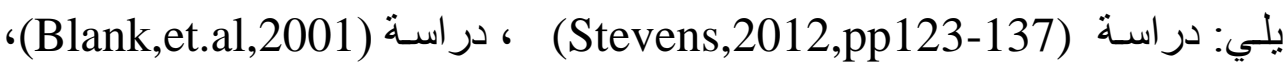

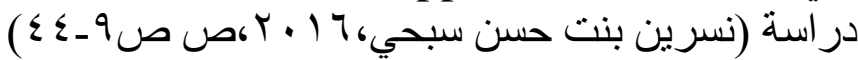

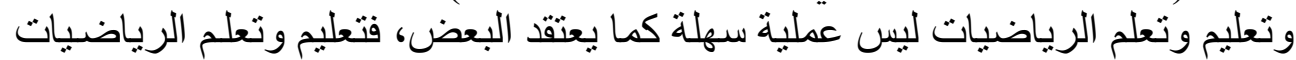

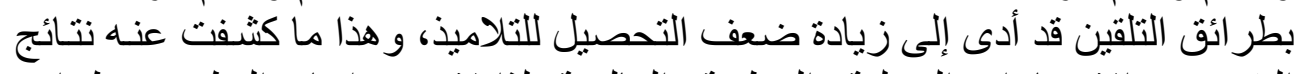

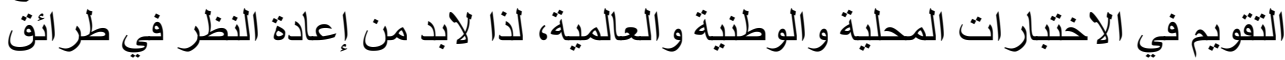

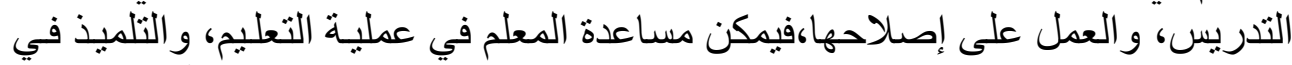

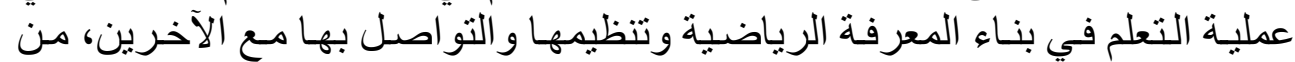

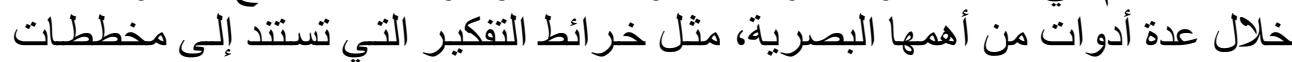

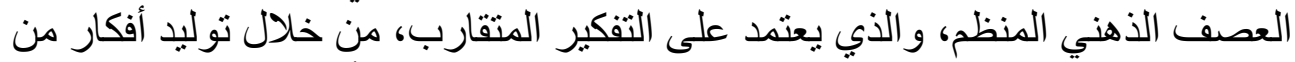

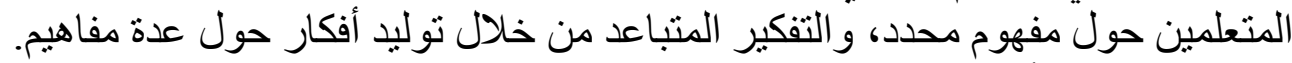

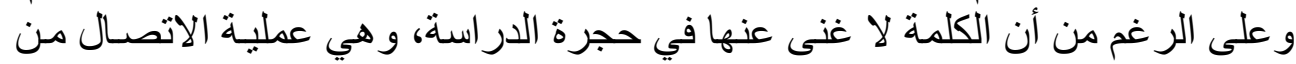

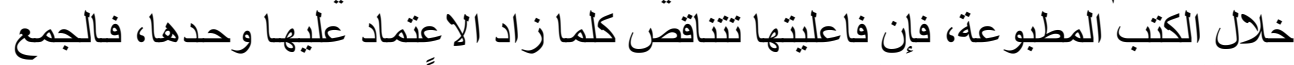

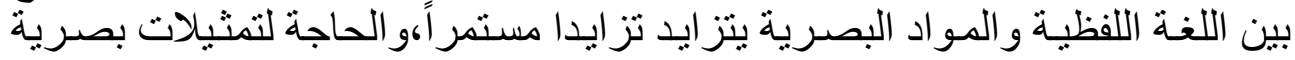

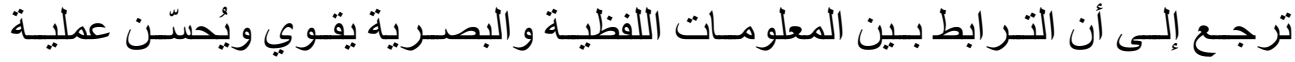

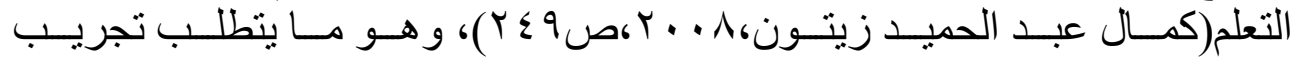

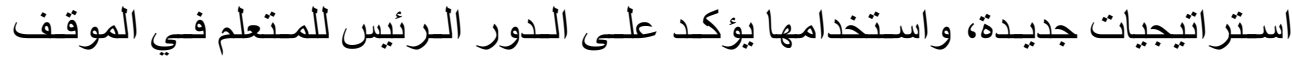

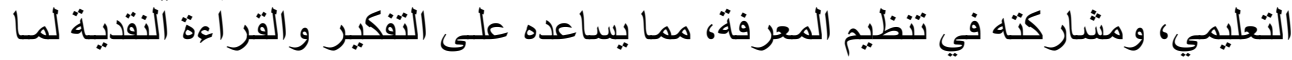

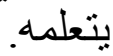
وقد ظهرت عدة استر اتيجيات وطر ائق ترتبط بالمنظمـات البصرية أو التخطيطية

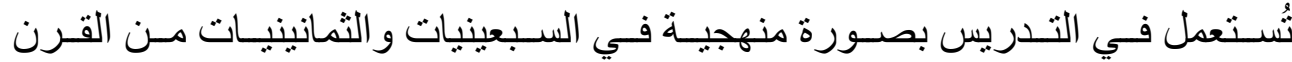

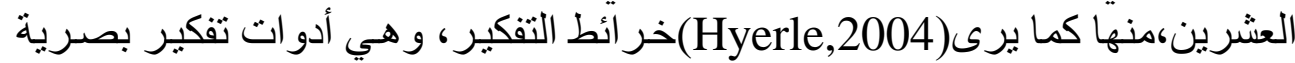

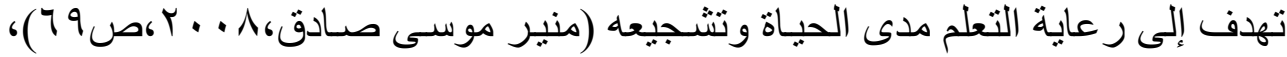

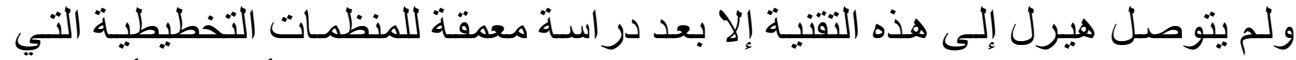

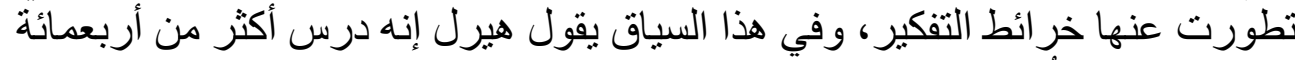

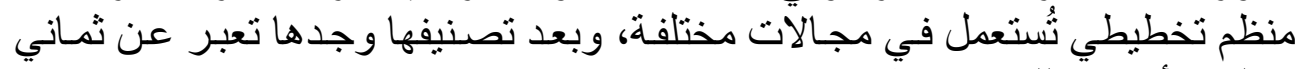
عمليات أساسية للتفكير فقط. وخر ائط التفكير تُعد من أدو ات التفكير البصري التي تحمل لغة مشتركة بين المعلمين

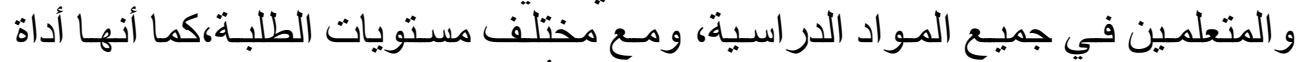

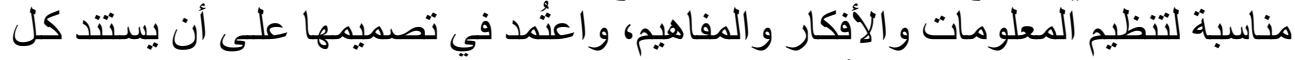

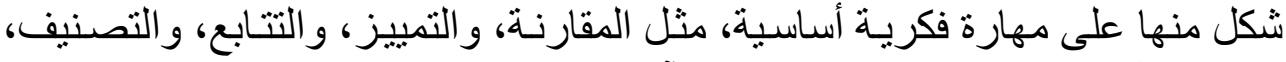

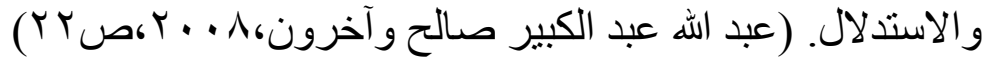




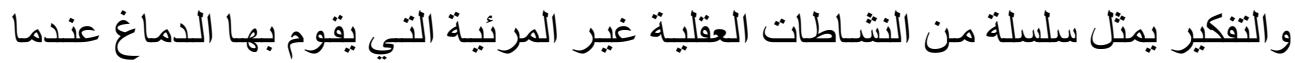

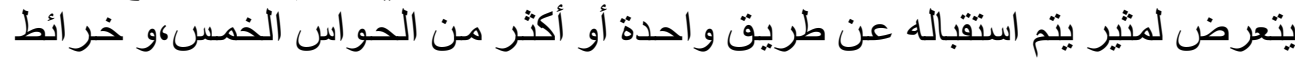

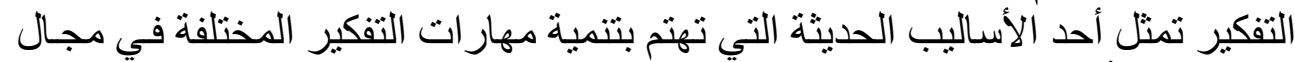

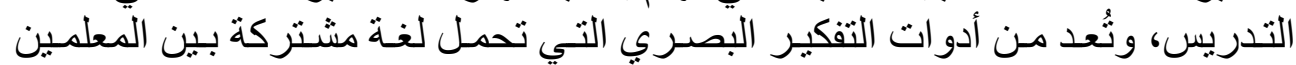

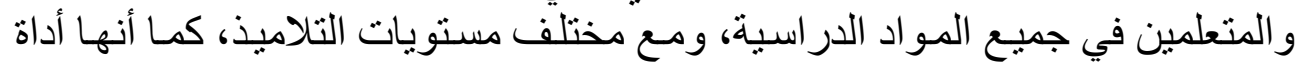
مناسبة لتنظيم المعلومات و والأفكار و المفاهيم.

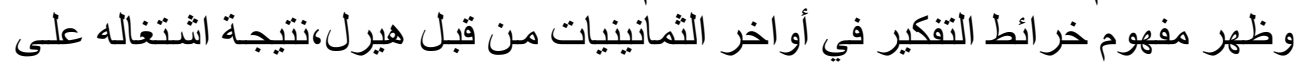

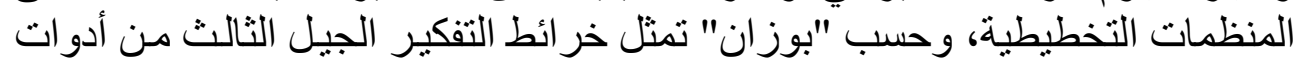

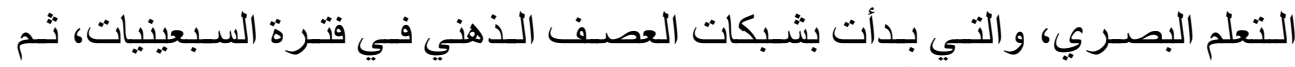

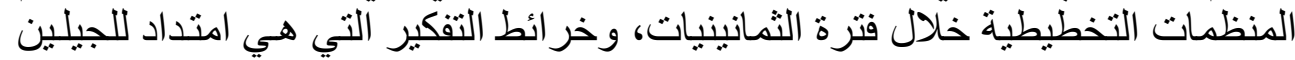

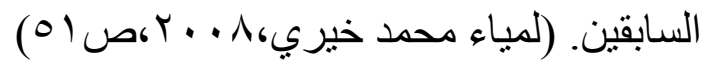
وقد تم تطوير ها كي تساعد الطلاب على تطويل تطوير قدرتهم في حل المشكلات، حيث إنها إنها

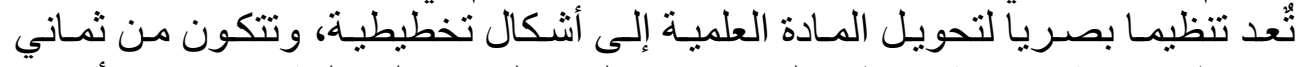

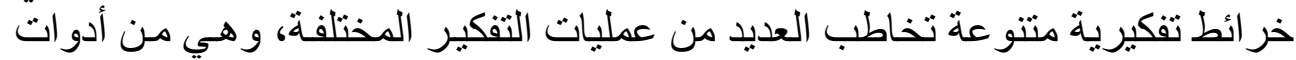

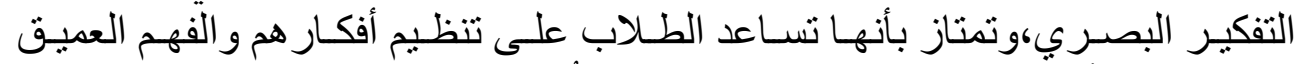

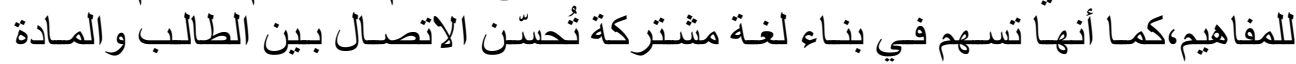

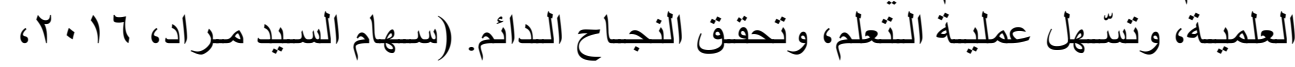
( )

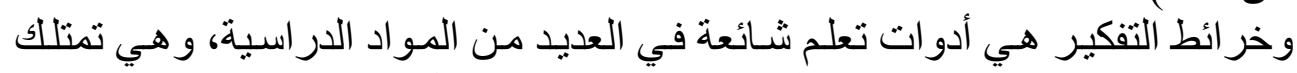

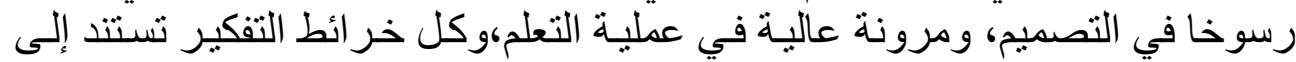

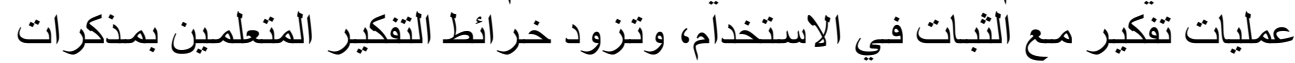

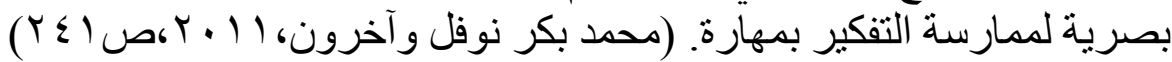

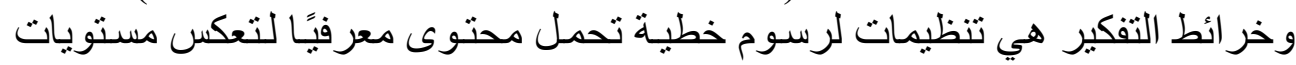

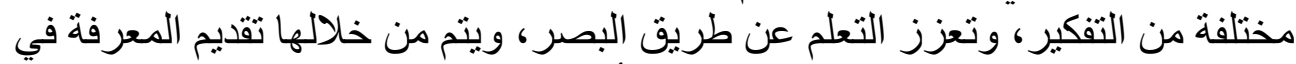

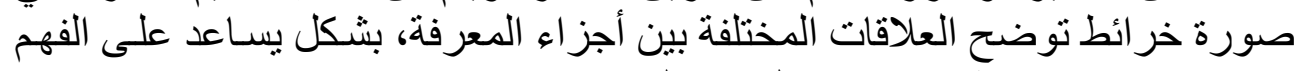

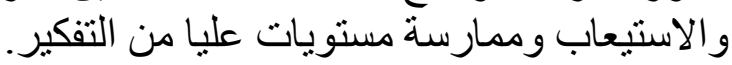
وتوجد مجمو عة من الدر اسات اهتمت باستخدام خر ائط التفكير في التدريس،ور منها مـا ـ دراسة (Yvtte,2002) التي توصلت إلى فعالية استخدام خر ائط التفكير في تحصبل المعرفة العلمية في العلوم لدى طلاب المرحلة المتوسطة.

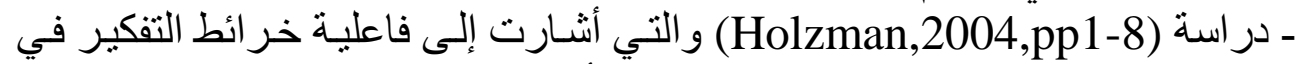
تتمية تحصيل الطلاب في اللغة الإنجليزية،كما أسفرت عن فاعليتها في إعطاء صسورة 
و اضحة للمعلمين عن كيفية تفكير طلابهم،وذللك بإعدادهم الخر ائط التي تعكس طريقة

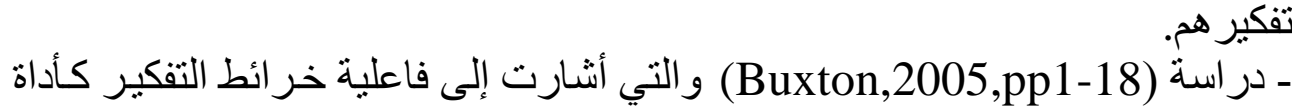

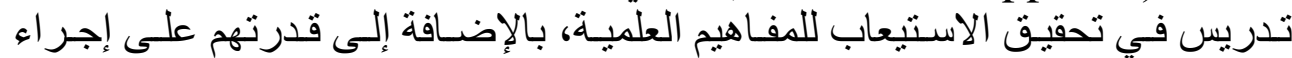
عمليات المقارنة. ـ دراسـة (Sylvia,2007) و التي هدفت إلى تحديد فعاليـة خر ائط التفكير في تنميـة التهية

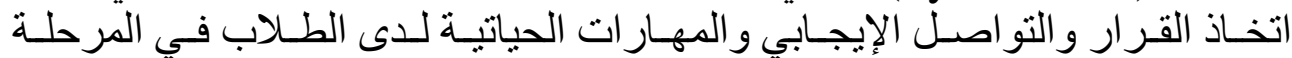

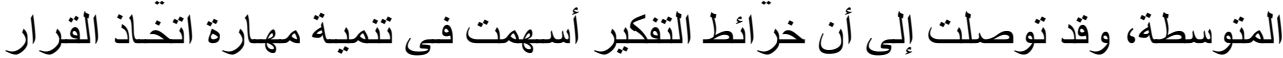

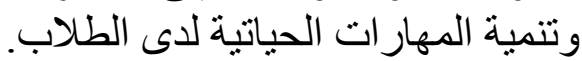

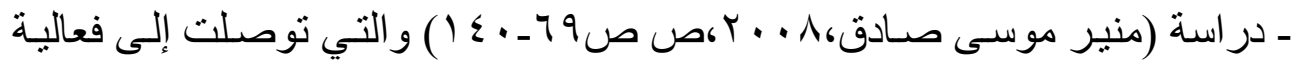

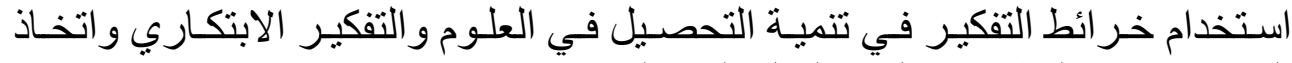

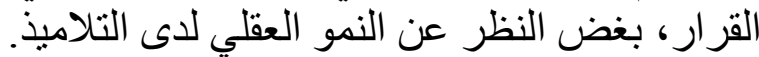

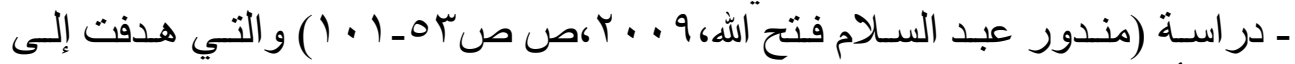

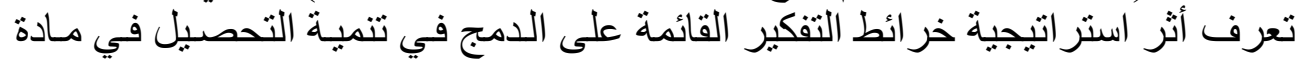

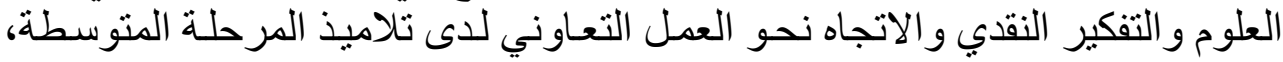

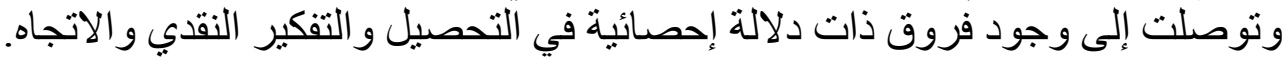

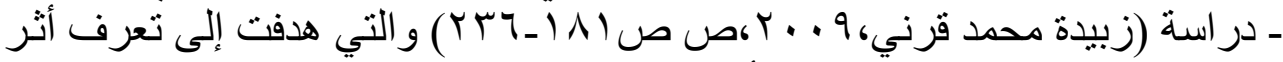

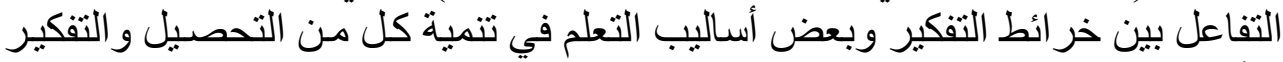

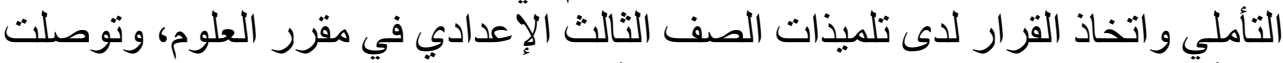
إلى أن التفاعل بين خر ائط التفكير وبعض أسـاليب التعلم يسـاعد على تنميـة التفكير التأملي.

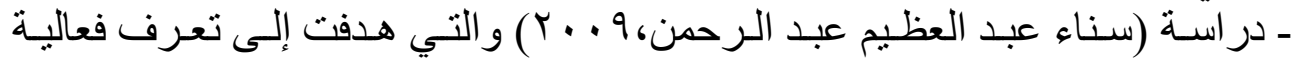

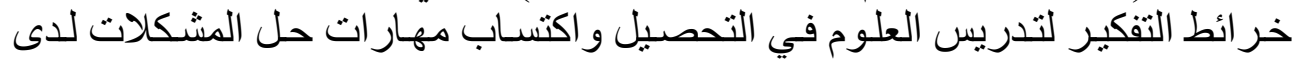

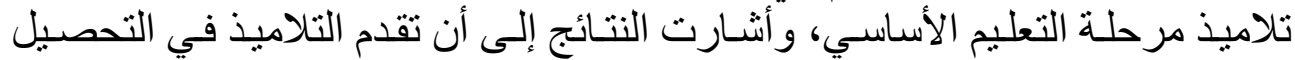

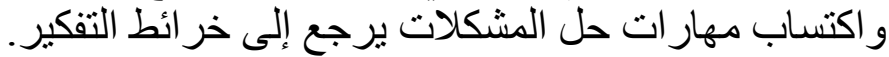

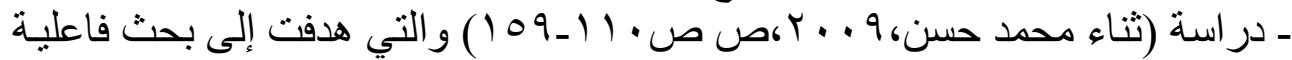

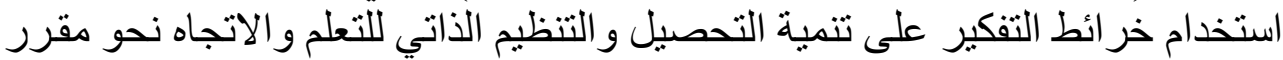

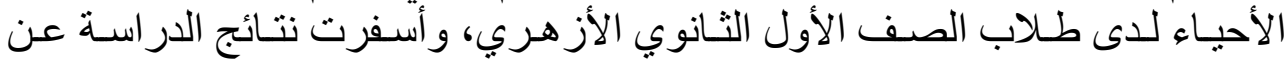

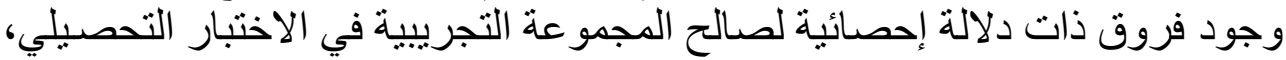

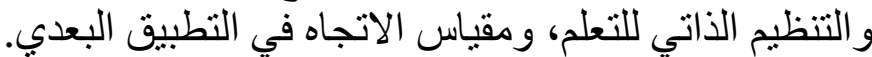

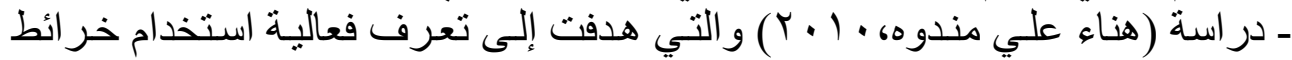

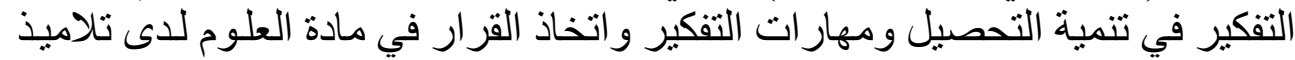


المرحلـة الإعداديـة، وقد أظهرت النتائج فعاليـة خر ائط التفكير في تنميـة التحصيل

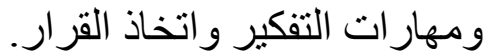

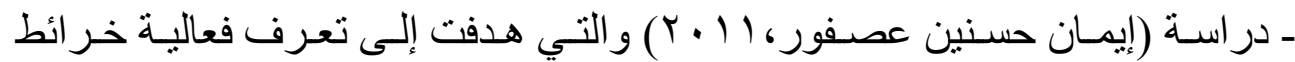

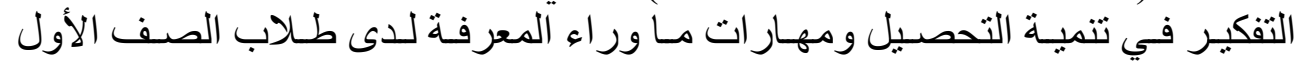

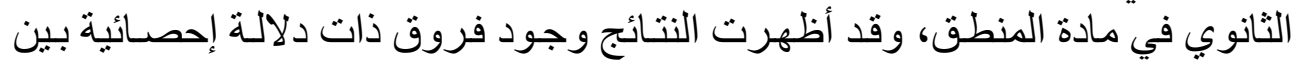

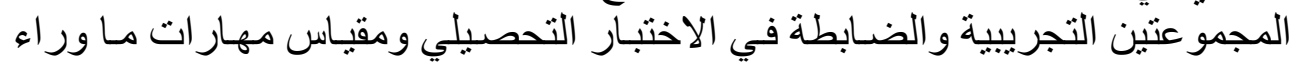
المعرفة، ولصالح المجمو عة التجريبية.

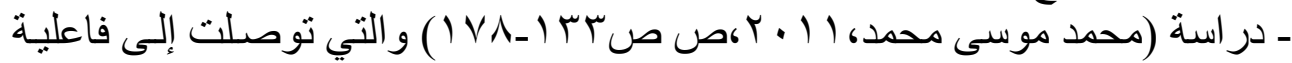

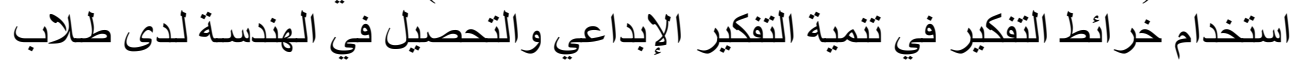
الصف الأول الثنانوي. ـ در اسة (Sunseri,2011) و التي هدفت إلى تعرف أثر خر ائط التفكير في الكتابـات

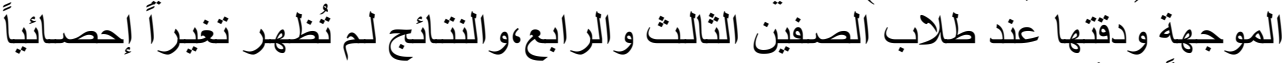

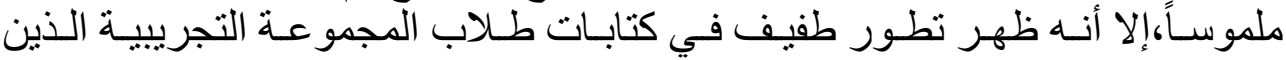

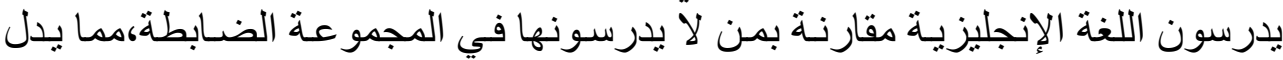

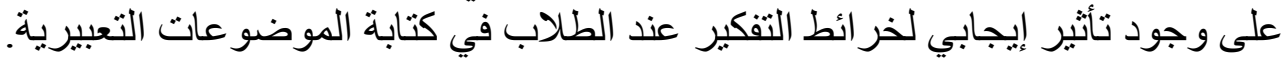

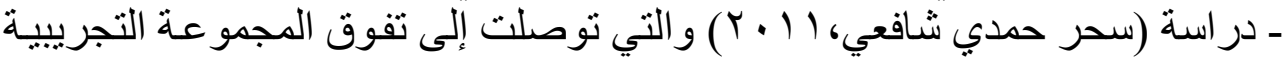

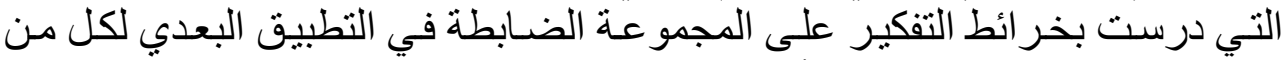

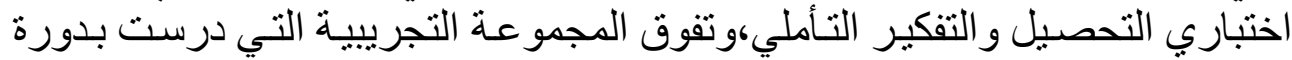

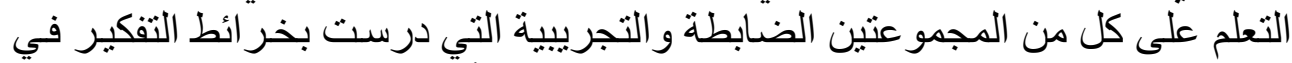

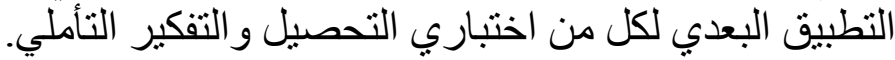

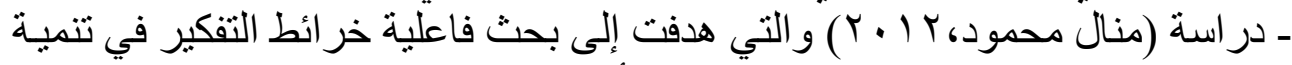

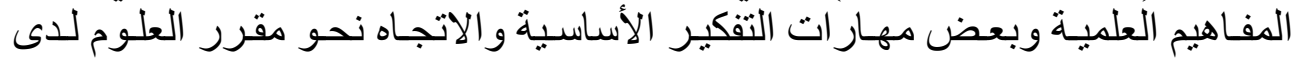

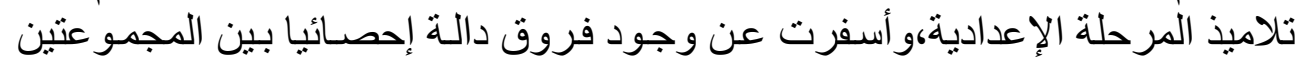
التجريبية والضابطة لصالح التجريبية في التطبيق البعدي.

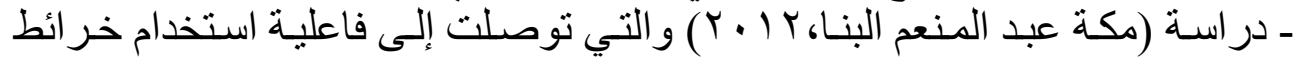

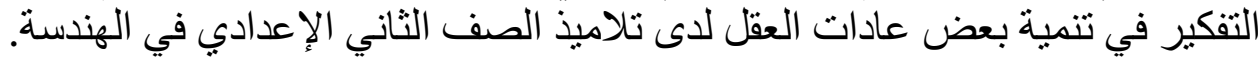

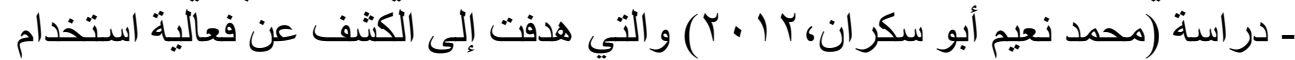

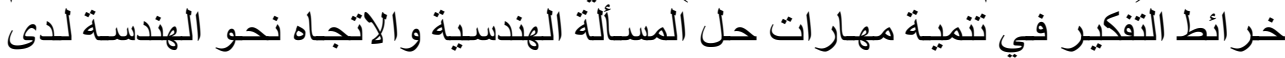

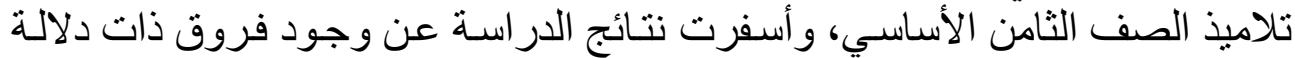

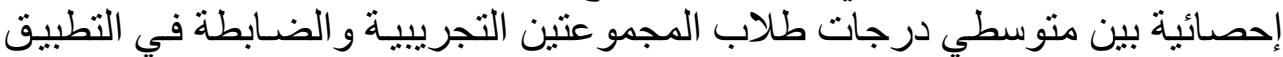

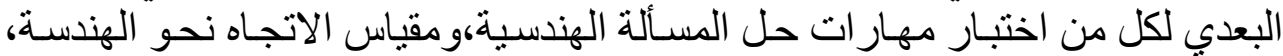
وذللك لصالح المجمو عة التجريبية. 


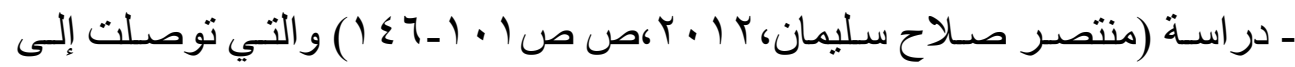

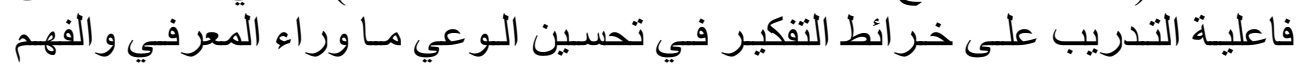

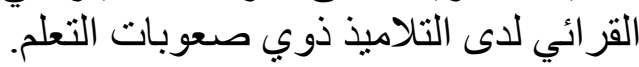

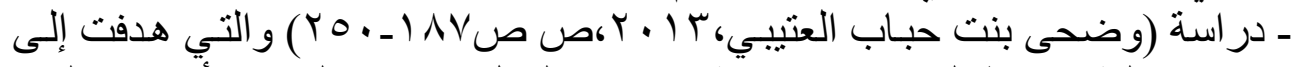

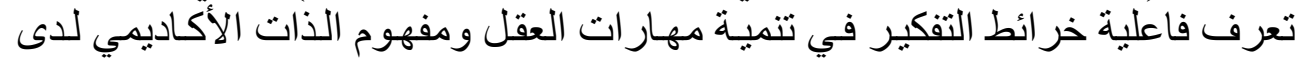

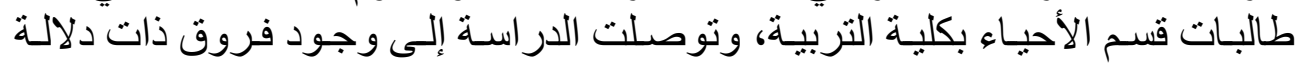

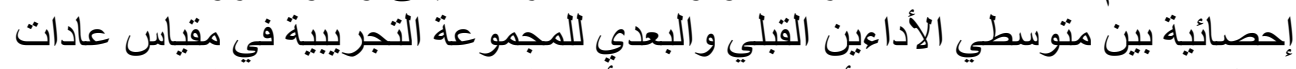

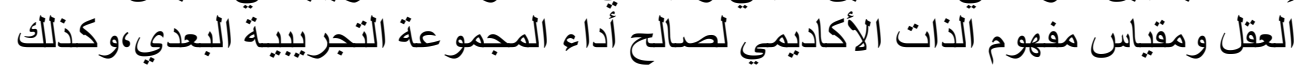

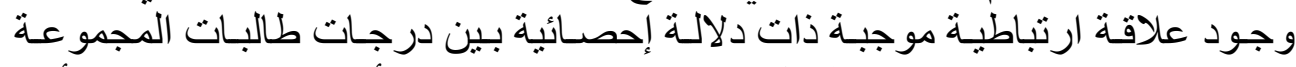

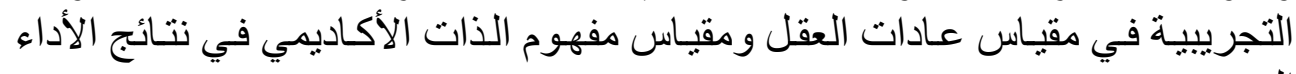

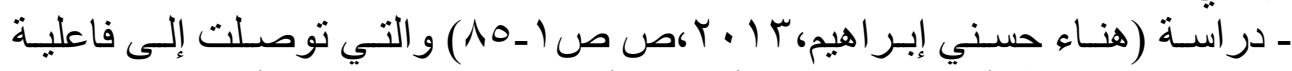

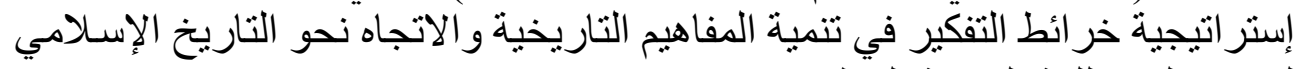

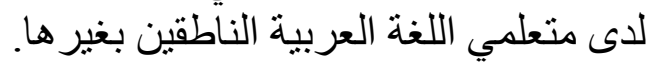

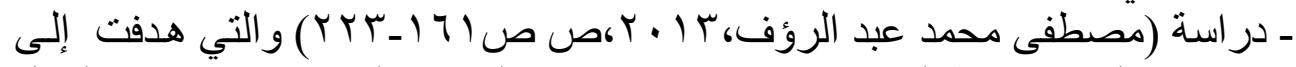

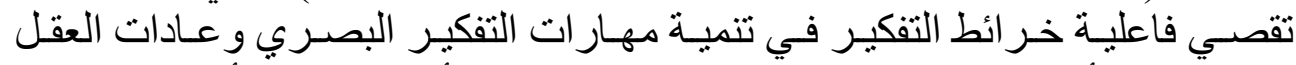

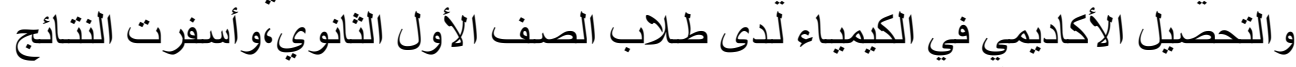

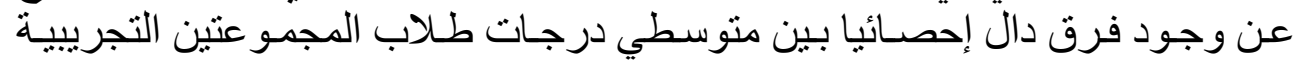

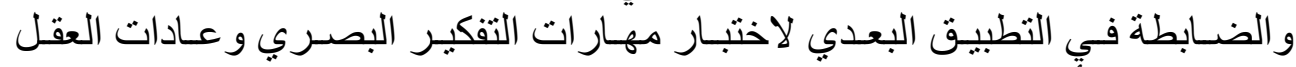

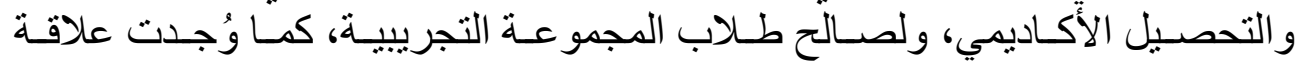

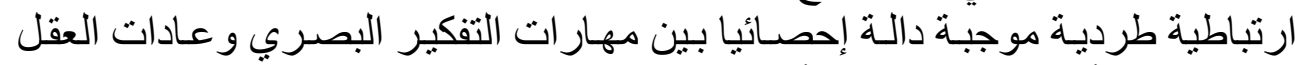

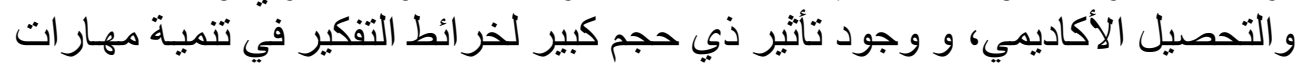

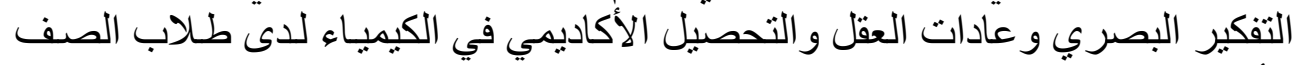
الأول الثنانوي.

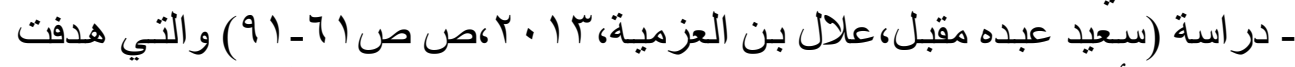

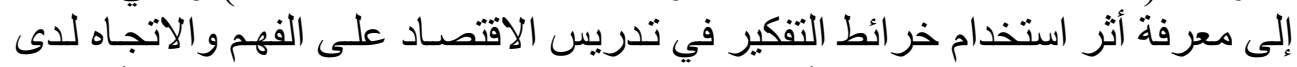

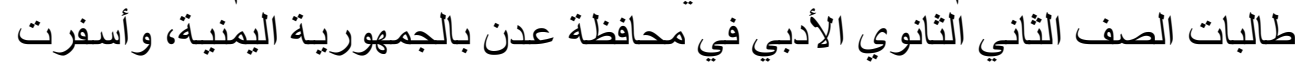

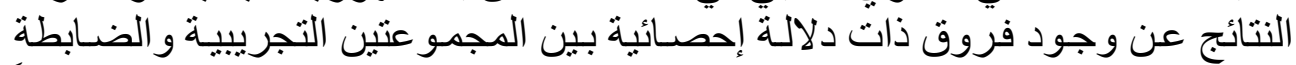

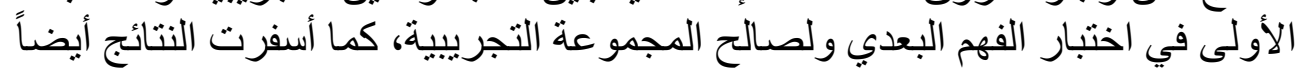

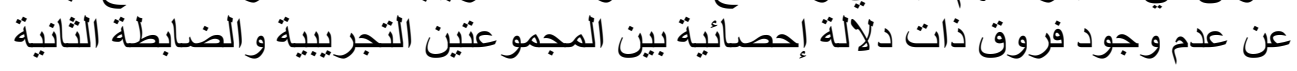
في اختبار الفهم ومقياس الاتجاه البعدي. 


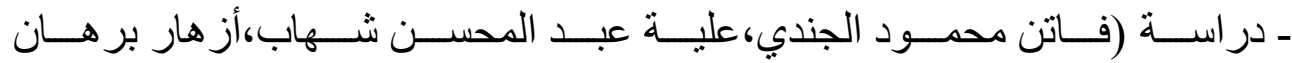

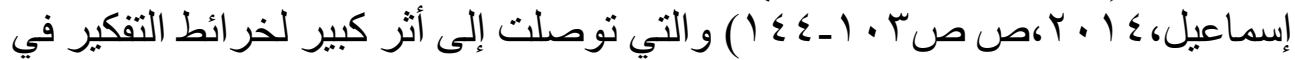

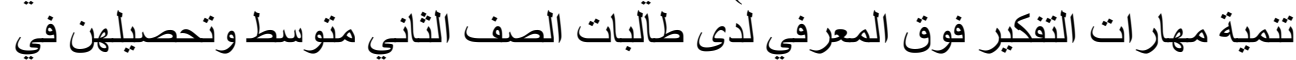
مادة الفيزياء.

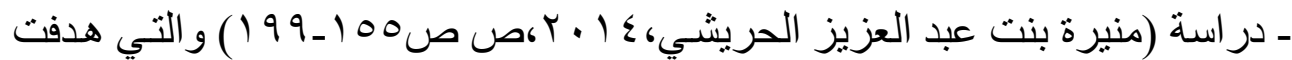

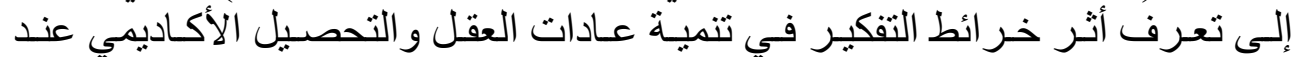

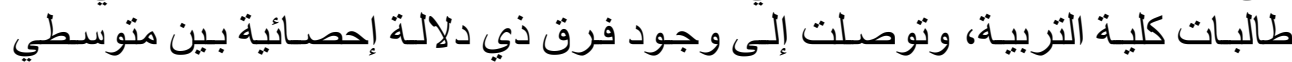
الأداعين القبلي و البعدي للمجمو عة التجريبية في كل من التحصيل الأكاديمي ومقياس دئس

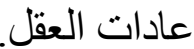

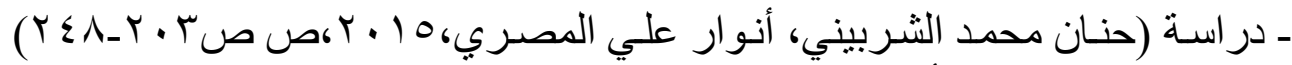

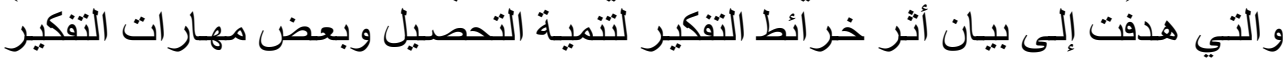

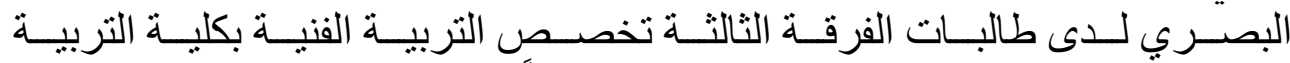

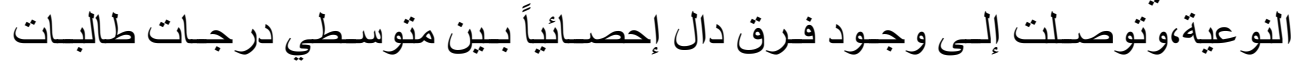

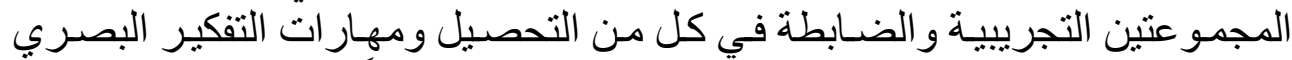

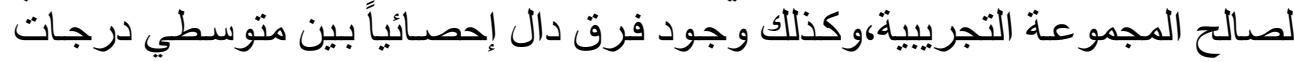

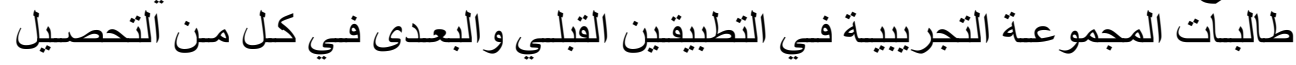
ومهار ات التفكير البصري لصالح التطبيق البعدي.

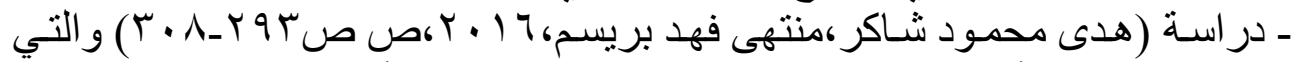
هدفت إلى تعرف أثنر استر اتيجيتي خر ائط التفكير وحدائق الأفكار في تحصيل طالبات التيات

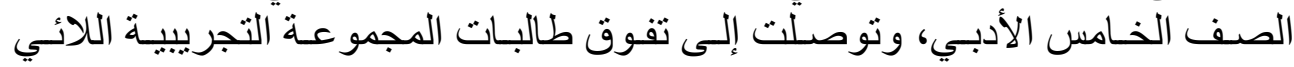

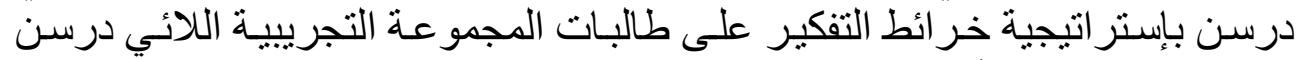
باسترتيجية حدائق الأفكار في التحصيل.

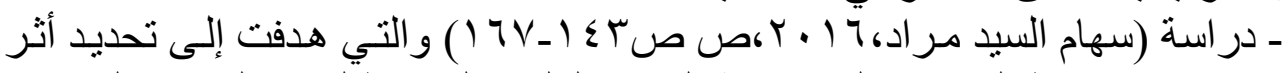

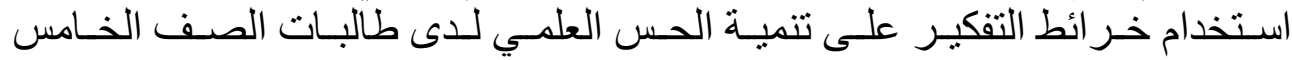

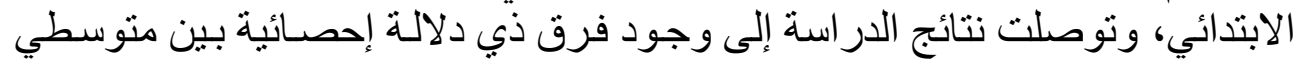

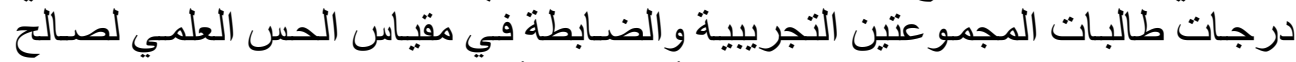

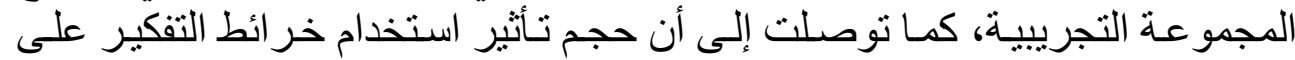

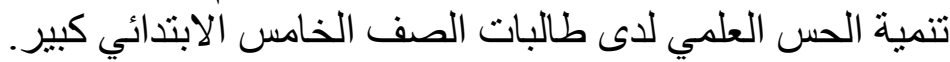

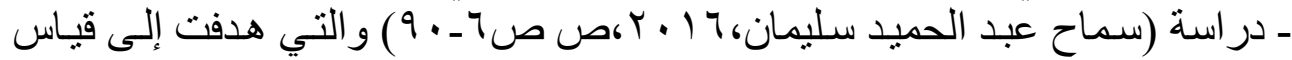

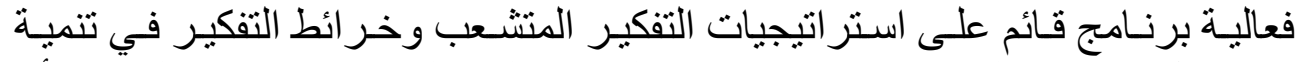
التحصيل والتفكير البصري في الرياضيات لطلاب المرحلة الثانوية، وتوصلت التيات إلى أن لنية 
حجم تأثير خر ائط التفكير على تنمية التحصيل والتفكير البصري لاى طلاب المرحلة الثانوية كبير.

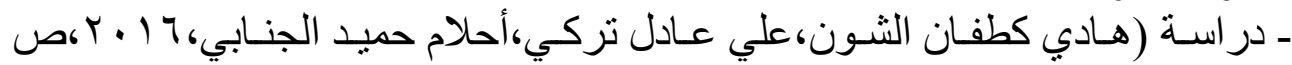

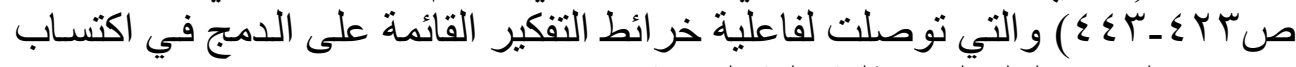
مهار ات التفكير العليا لدى طلى والبة كلية التربية.

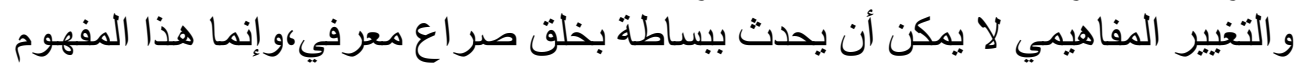

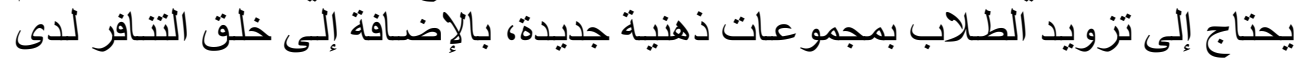

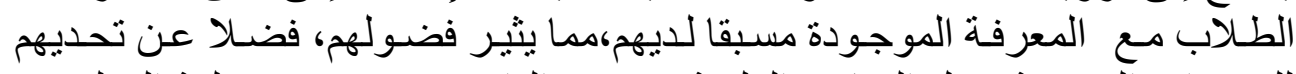

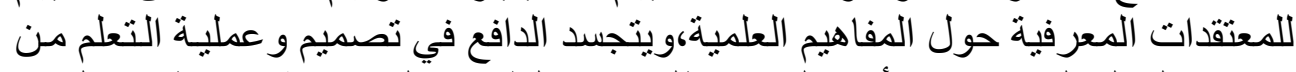

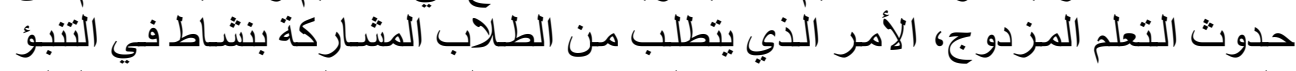

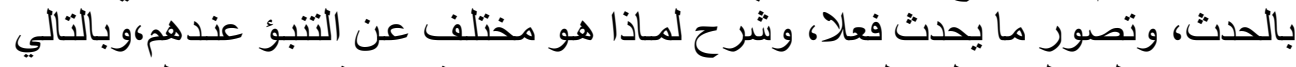

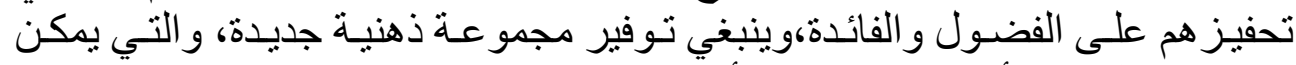

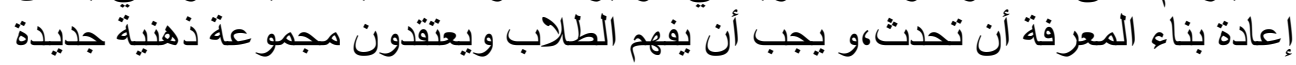

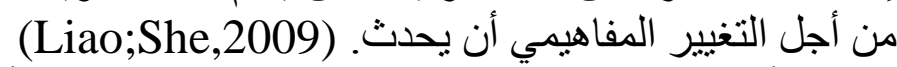

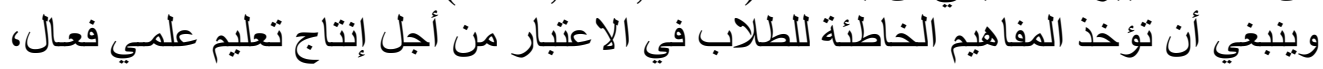

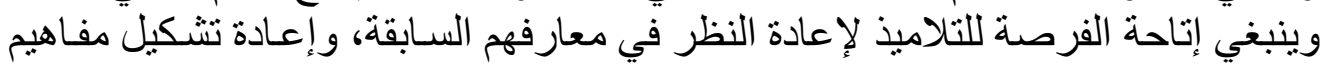
جديدة. (Akpinar,2007)

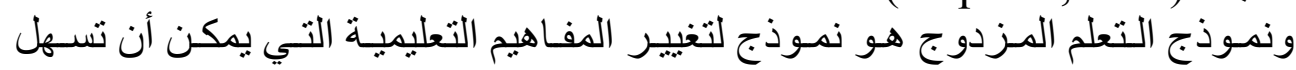

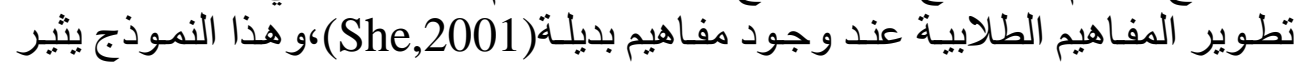

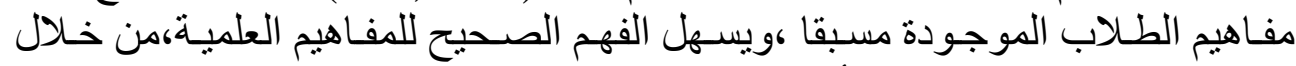

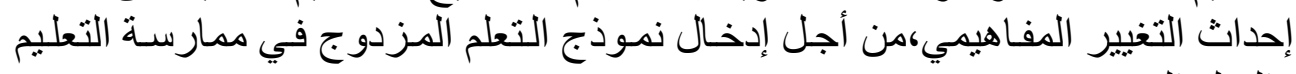
و والتعلم الحقيقي. ويعني التعلم القائم على المو اقف أن عملية التغير المفاهيمي واقعة بين طبيعـة المفاهيم

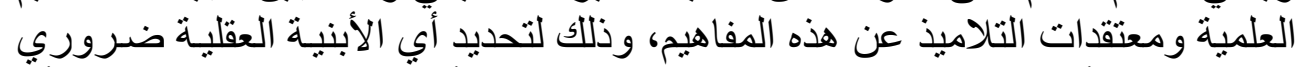

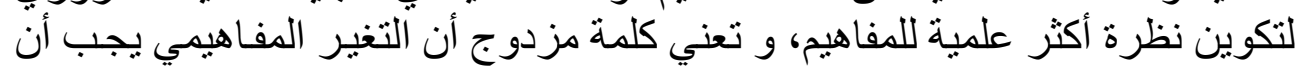

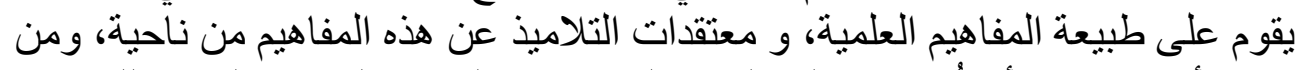

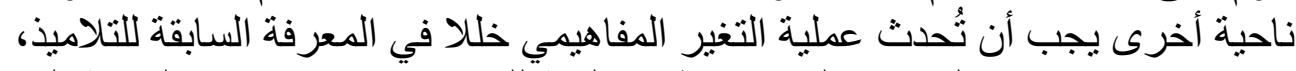

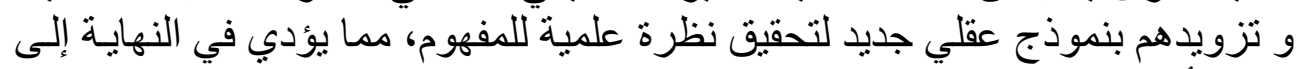

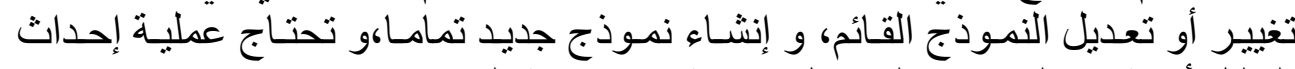

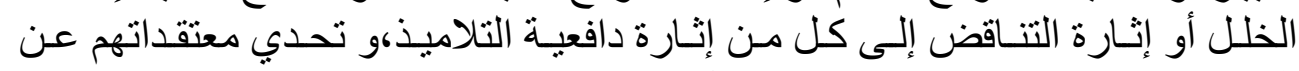

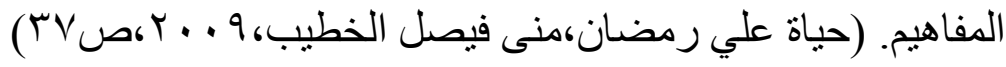


وتوجد مجموعة من الدراسات التي اهتمت بنموذج التعلم القائم على المواقف

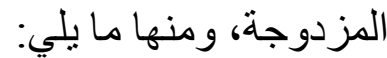
ـ در اسة (She,2001) و التي أظهرت أن نموذج التعلم القائم على المو اقف المزدوجـة

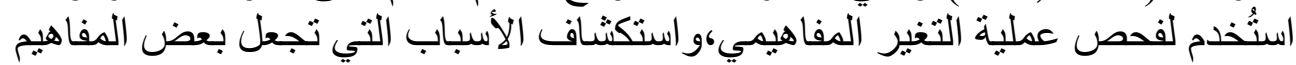
أكثر صعوبة من غير ها. ـ در اسـة (She,2002,pp981-996) و التـي أظهرت أن مفهومًا منثل الطفو يتطلب

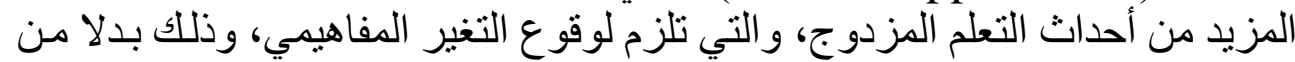

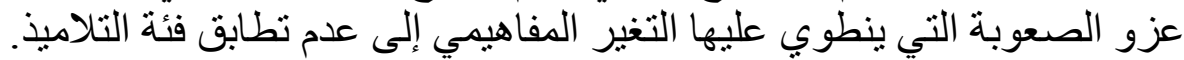

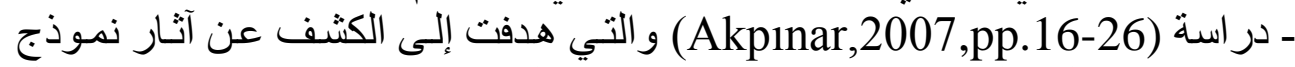

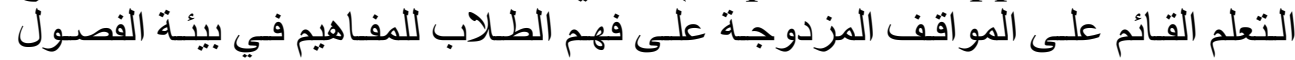

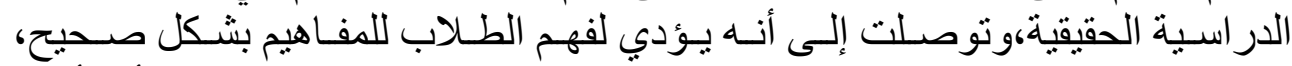

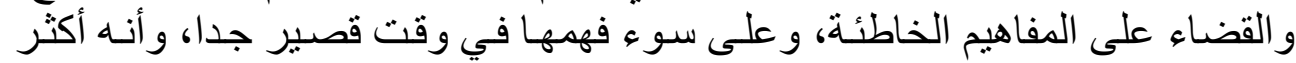
فعالية من التعليم التقليدي.

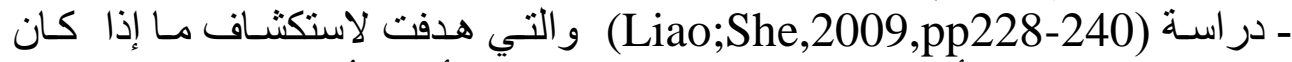

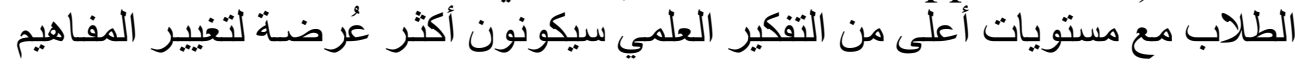

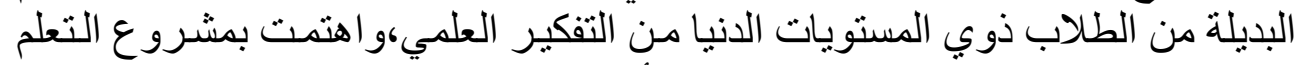

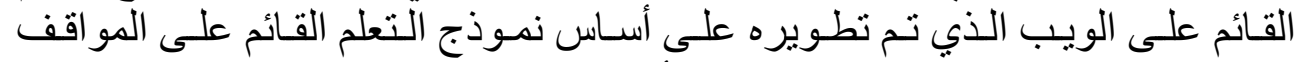

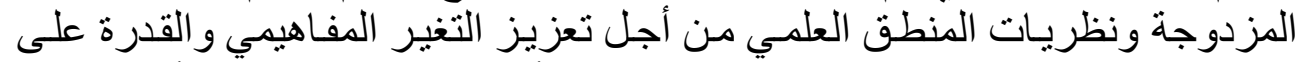

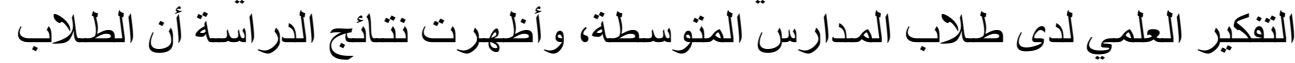

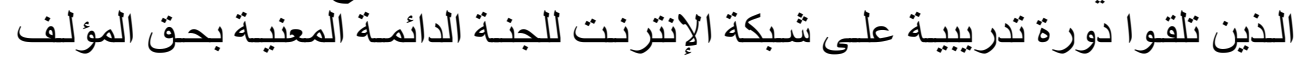

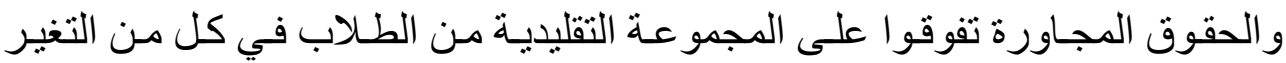
المفاهيمي و القدرة على التفكير العلمي.

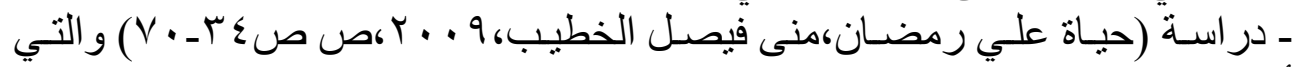

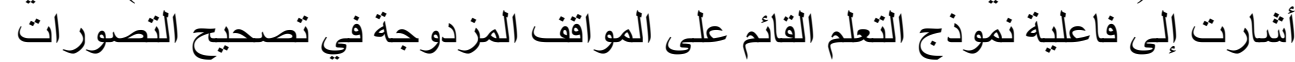
البديلة، وتنمية التفكير العلمي في مادة العلوم لدى الدي تلاميذ المرحلة الابتدائية.

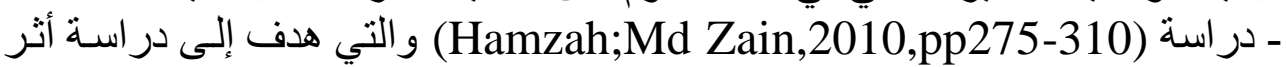

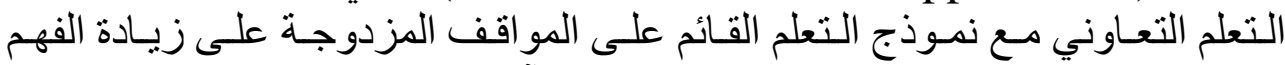

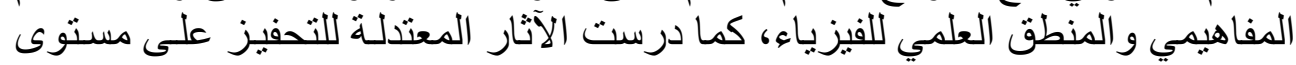

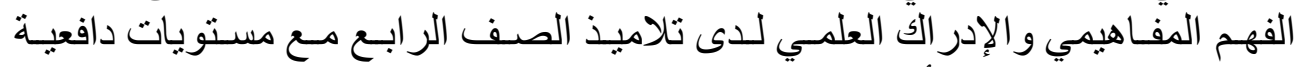

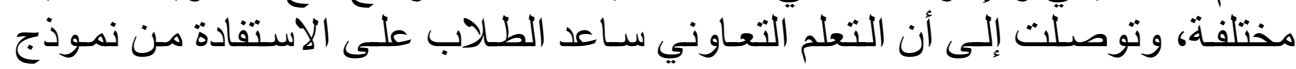

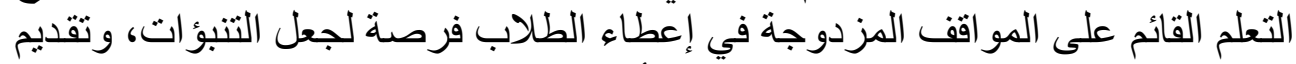

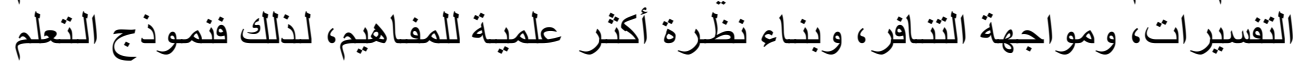


القائم على المو اقف المزدوجة طريقة غير كافية دون التعلم التعـاوني، أو نموذج التعلم

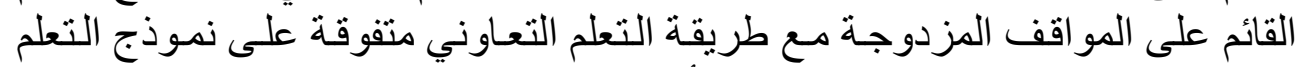

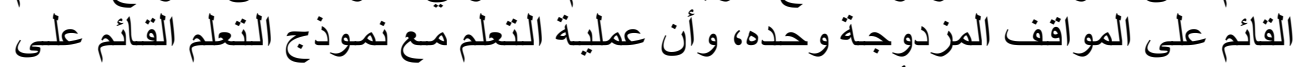
المو اقف المزدوجة ينبخي أن يكون سقالة بشكل مناسب من خلانل التعلم التح التعاوني.

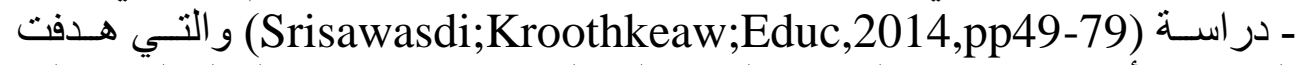

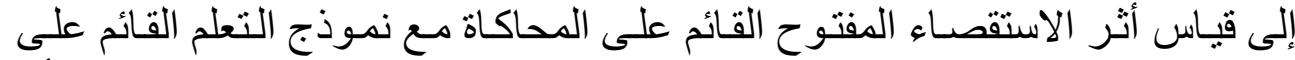

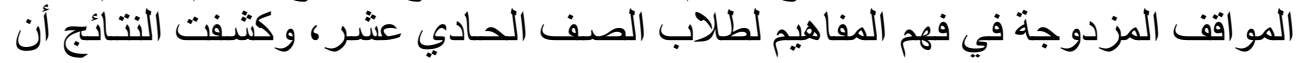

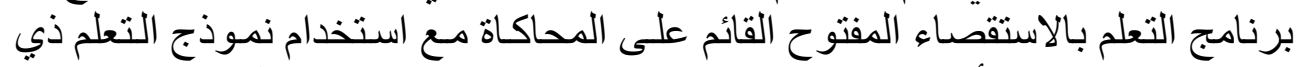

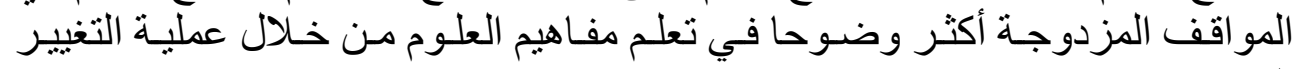
المفاهيمي.

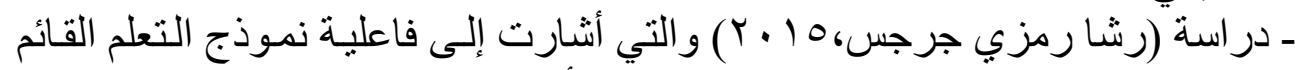

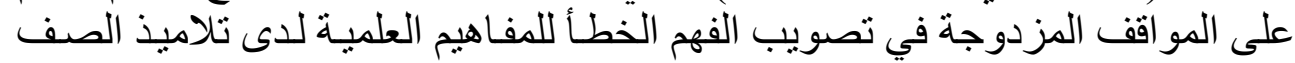

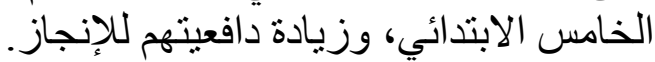
ـ در اسة (Senthilkumar,2016,pp76-80) و التي أشارت إلى التى أن التعلم بالمحاكاة

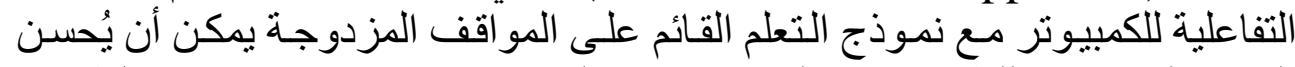

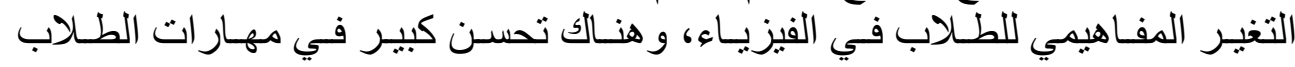
المعرفية. ـ در اسة (Hwa;Karpudewan,2017) والتي هدفت إلى التحقق من فعالية نموذج التحون

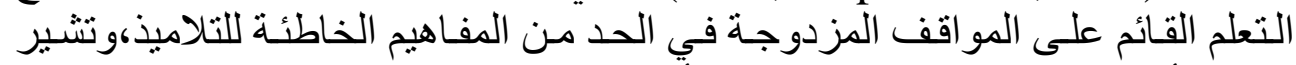

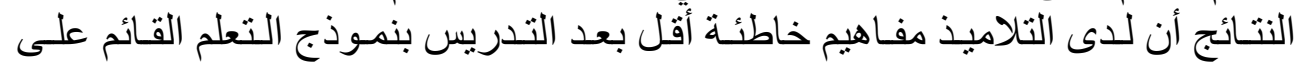

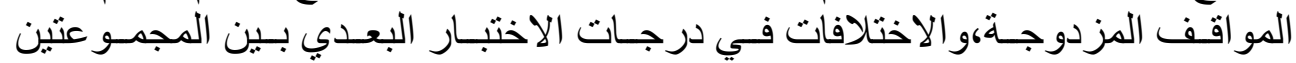

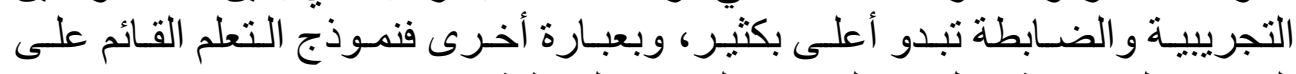
المو اقف المزدوجة فعال في الحد من المفاهيم الخاطئة. تحديد مشكنة البحث:

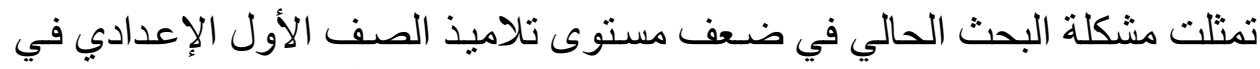

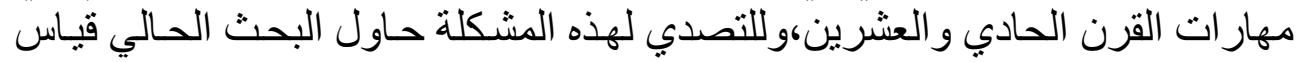

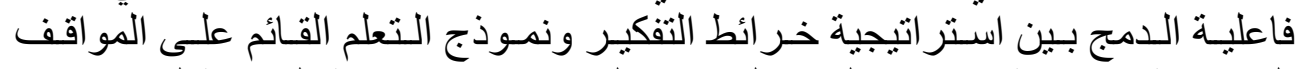

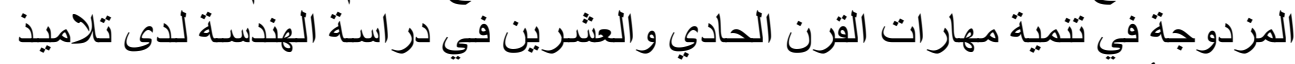

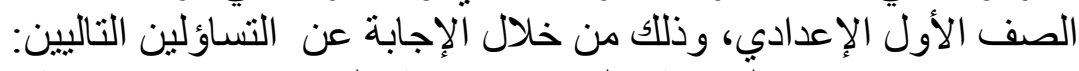

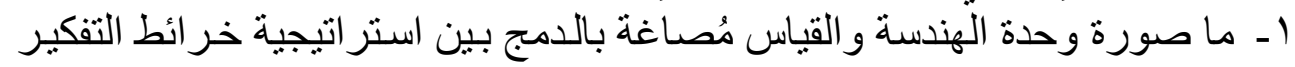

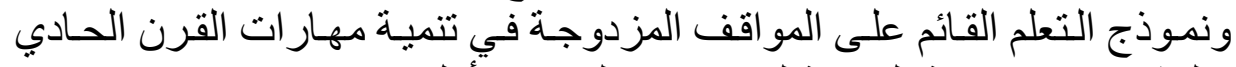

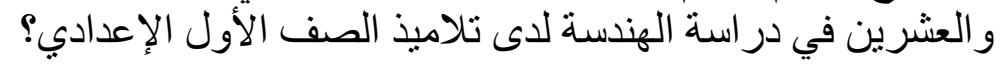




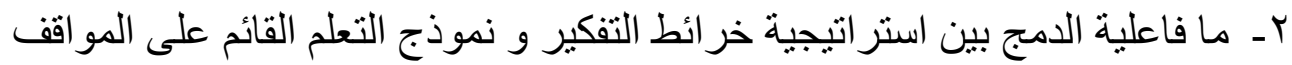

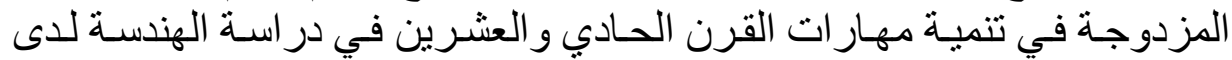

1 ـ ـتمية بعض مهار ات القرن الحادي و العشرين لدى تلاميذ الصف الأول الإعدادي

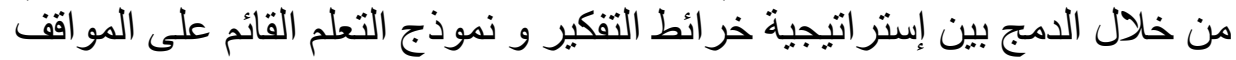

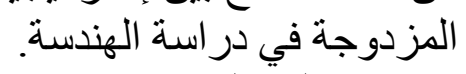

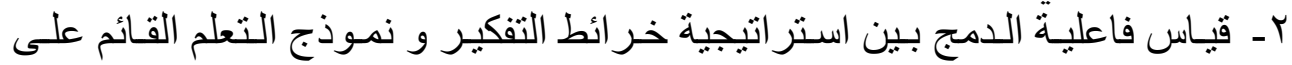

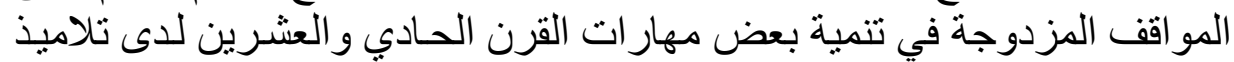

$$
\text { الصف الأول الإعدادي. }
$$
أهمية البحث: البه:

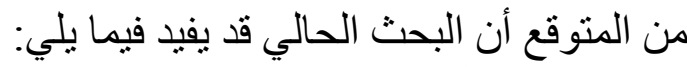
1 ـ توجيه نظر المعلمين إلى كيفية قيادة تلاميذّهم في ظل البـ استر اتيجية خر ائط التفكير

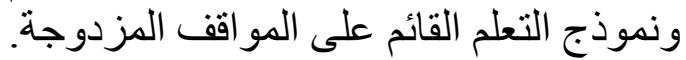

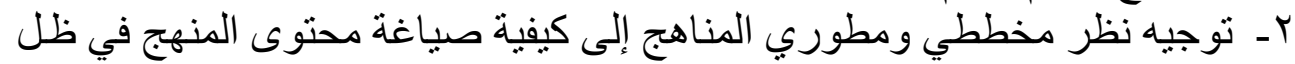

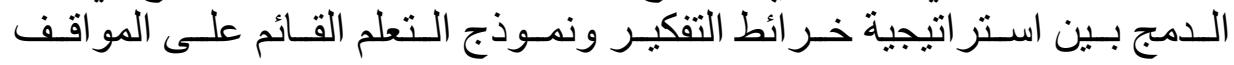

$$
\text { المزدوجة. }
$$

rـ توجيه نظر الباحثين إلى إجر اء در اسـات مماتلـة على مر احل در اسية أخرى أو

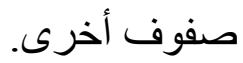
ع - جعل التلاميذ نشيطين و إيجابيين أثناء عملية التعلم.

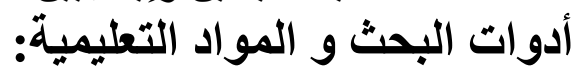
ا ـ اختبار مهار ات القرن الحادي والعشئ العرين في الهندسة.(من إعداد الباحثة)

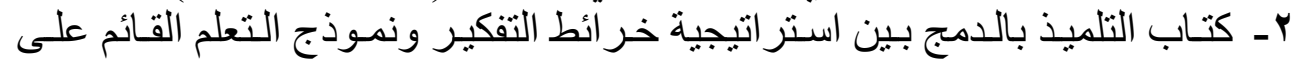

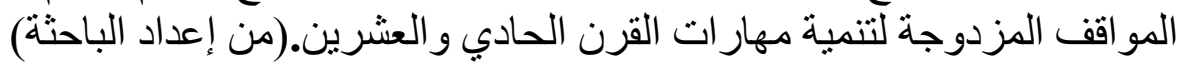

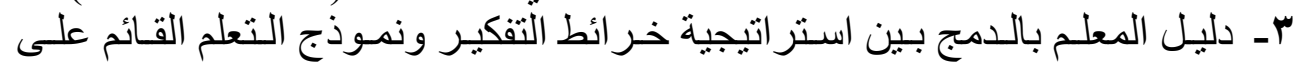

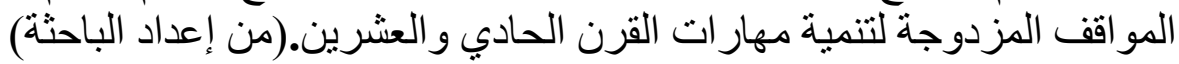
حدود البحث: ا ـ مجمو عة من تلاميذ الصف الأول الإعدادي بإحدى مدارس محافظة القليوبية.

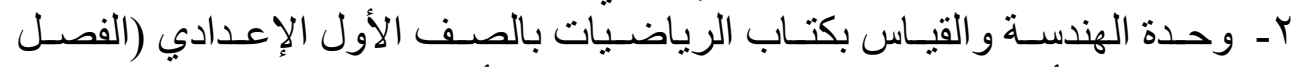

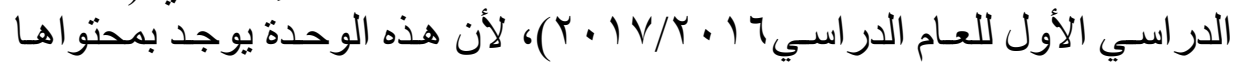

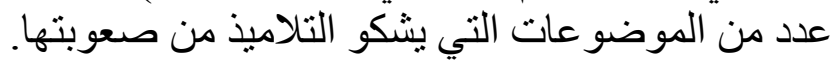


rـ قياس بعض مهار ات القرن الحادي و العشرين لدى تلاميذ الصف الأول الإعدادي

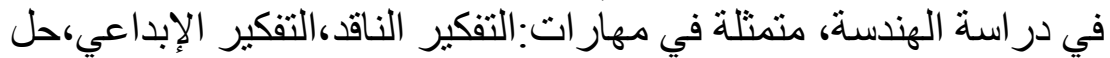

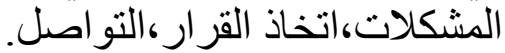

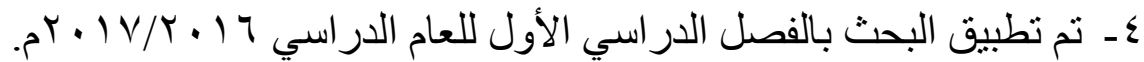

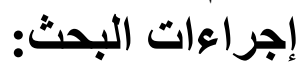

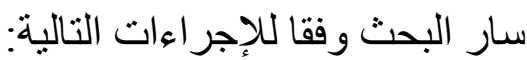

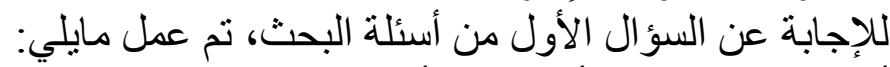

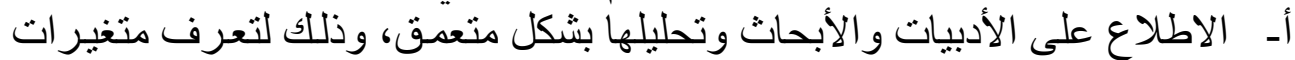

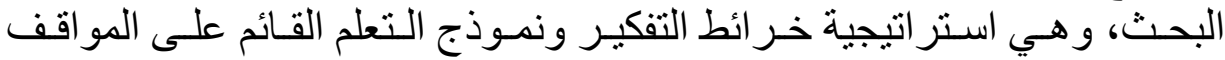

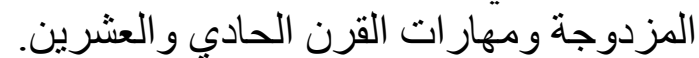

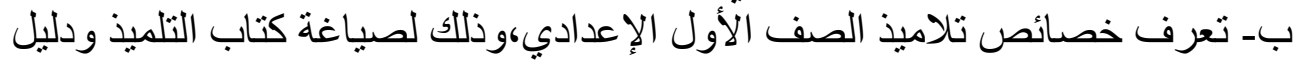

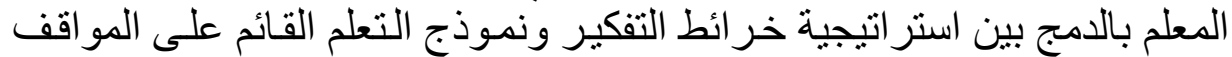

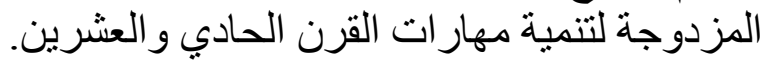

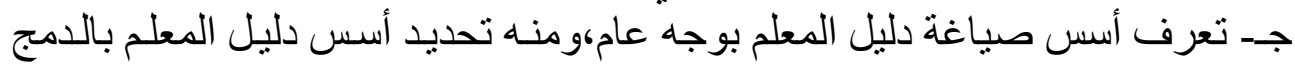

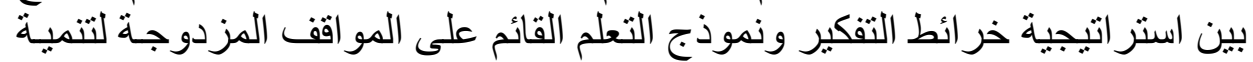

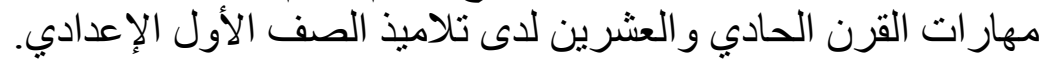

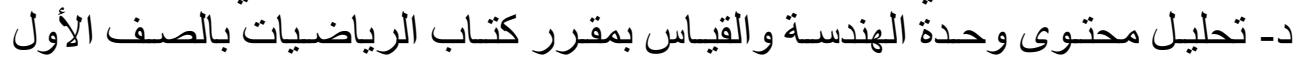

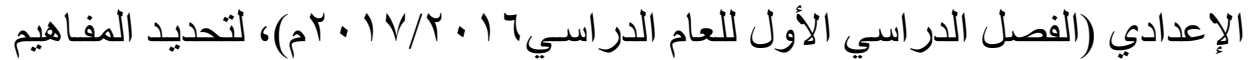

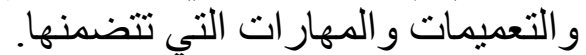

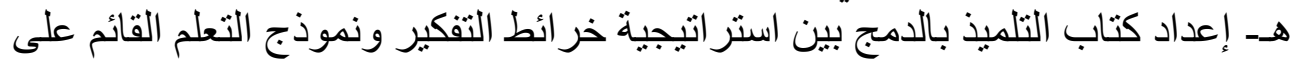

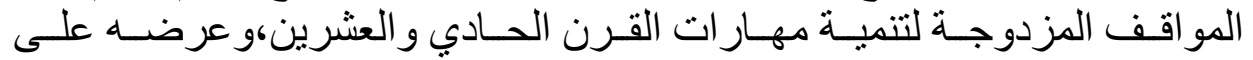

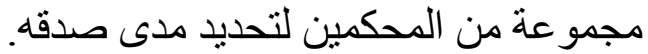

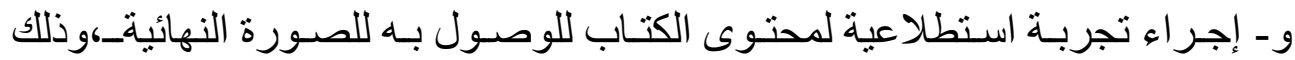
لتفادي الأخطاء أثناء التطبيق.

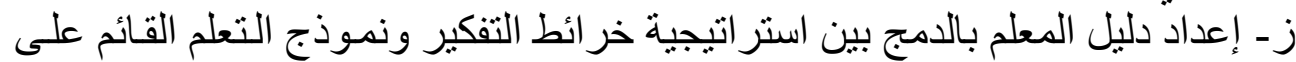

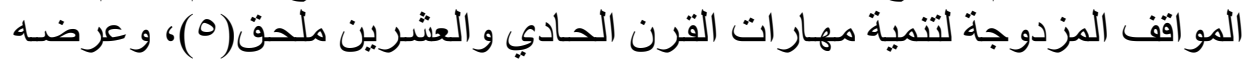
على مجمو عة من المحكمين لتحديد مدى صدو صدقه.

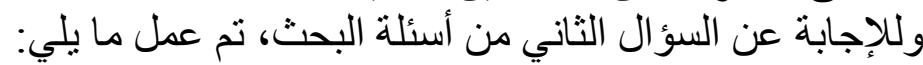

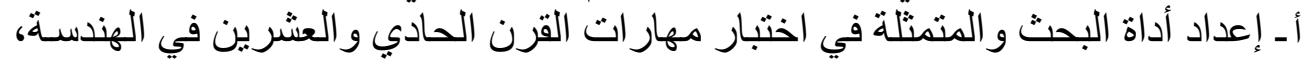

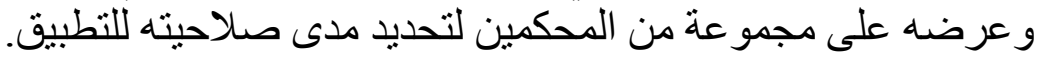




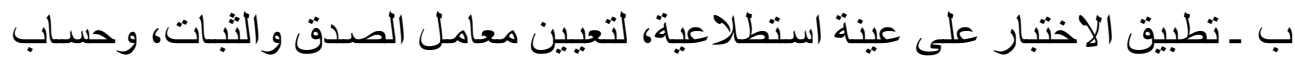

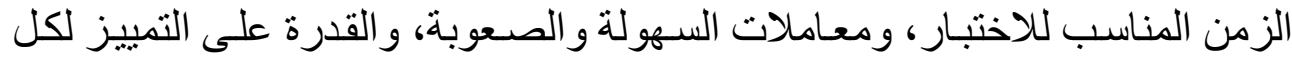
مفردة من مفردات الاختبار ، وكذللك حساب الاتساق الداخلي لكل مفردة من مفرداته.

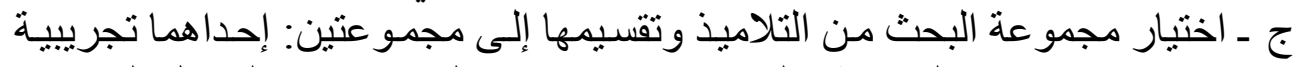

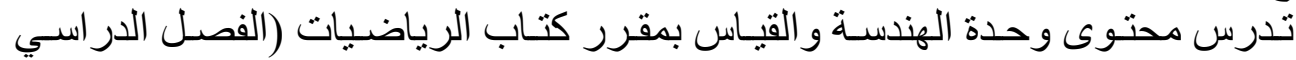

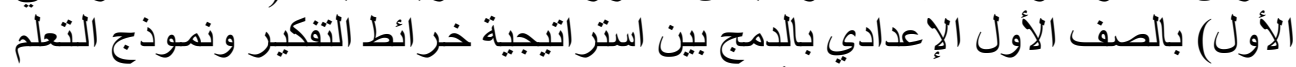

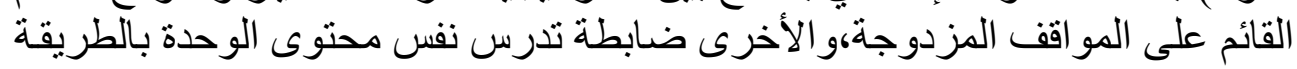
المعتادة. دـ ـ التطبيق القبلي لاختبار مهار ات القرن الحـادي و العشـرين في الهندسـة على تلاميذ المجمو عتين،للتأكد من تكافئهما. هـ ـ التدريس للمجمو عة التجريبية من التلاميذ بالدمج بين استر اتيجية خر ائط التفكير و

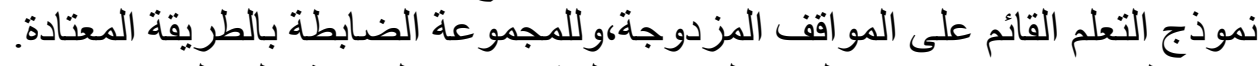

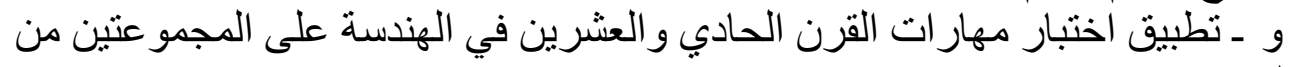

التنامبذ بعديا.

ز - رصد النتائج وتحليلها وتفسير ها. ط ـ تقديم التوصيات و المقترحات. تحديد مصطلحات البحث: تون:

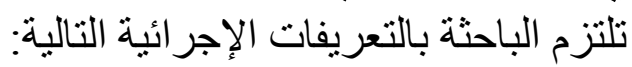

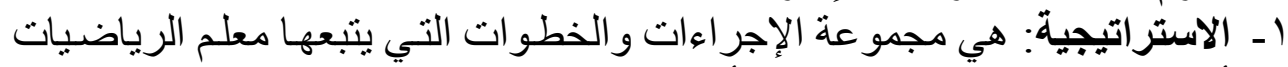

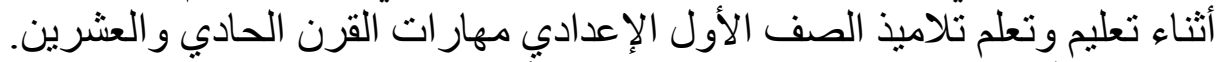

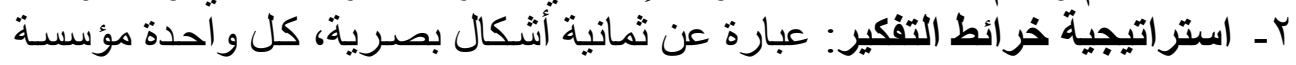

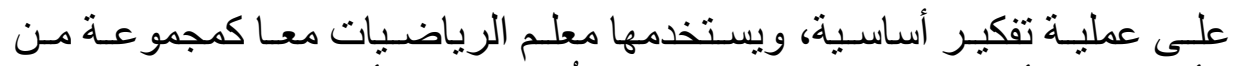

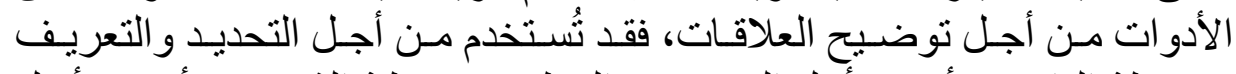

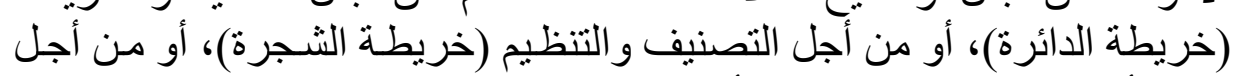

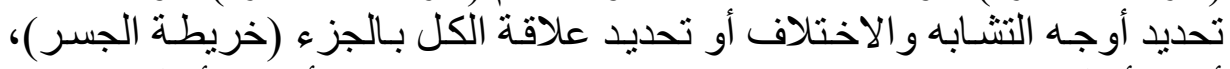

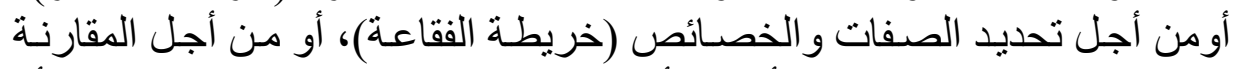

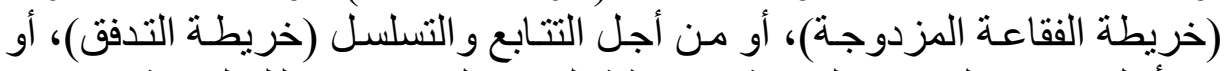

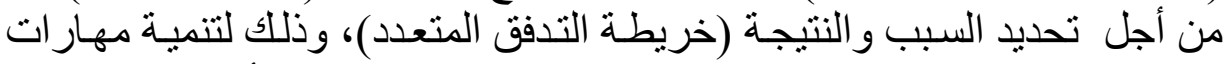

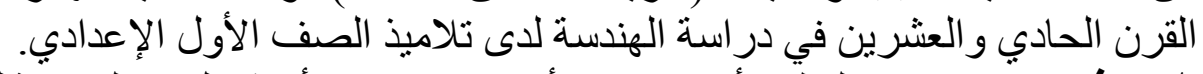

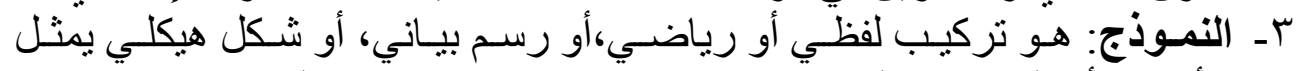

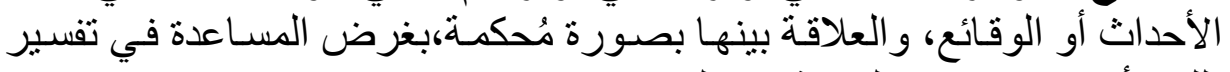

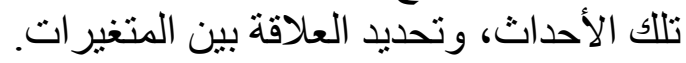




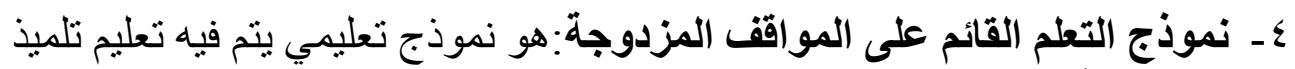

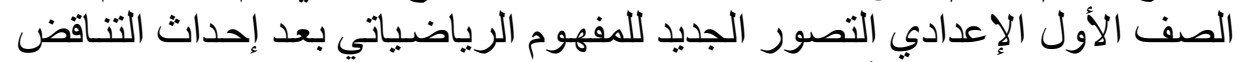

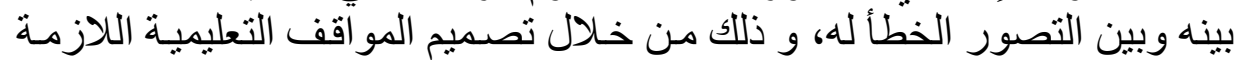

لذلك

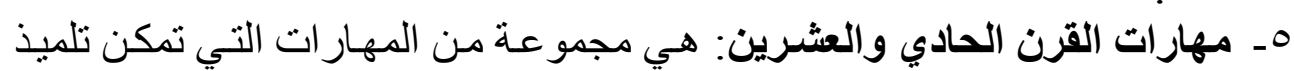

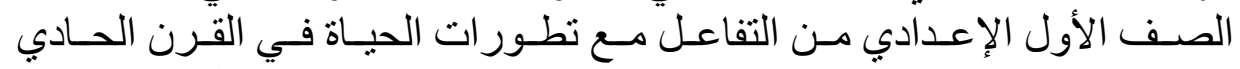

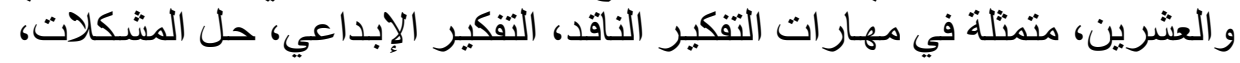

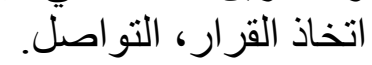

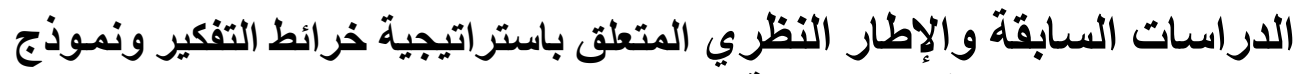

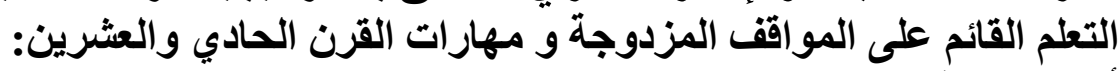

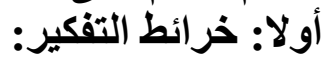

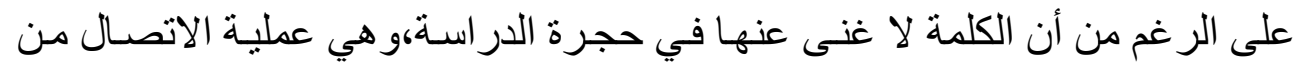

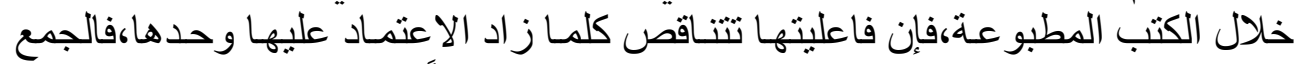

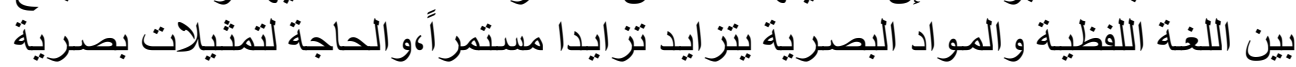

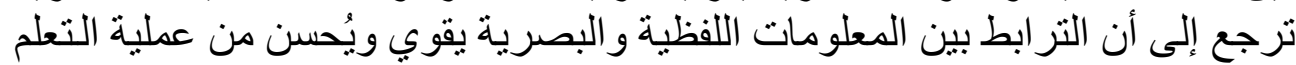

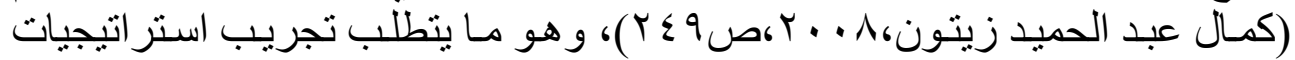

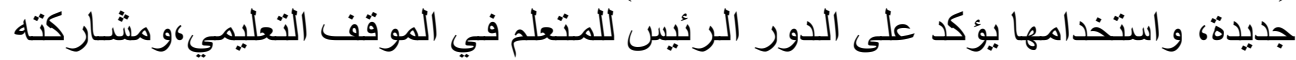

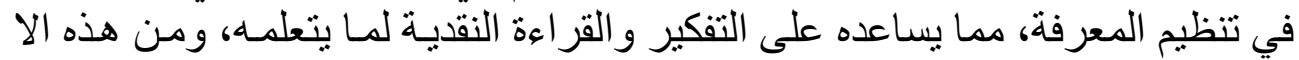

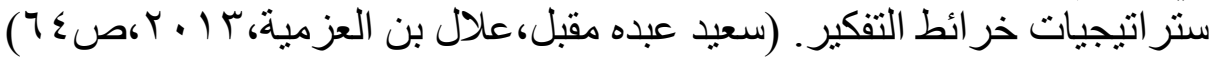

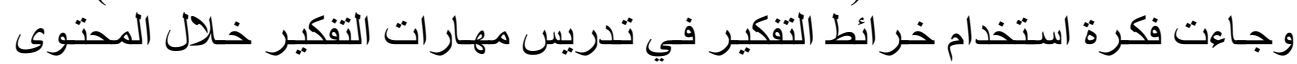

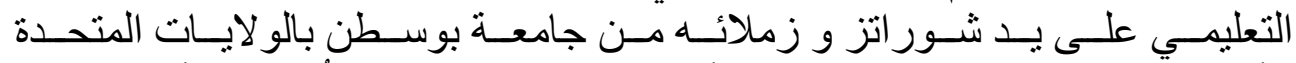

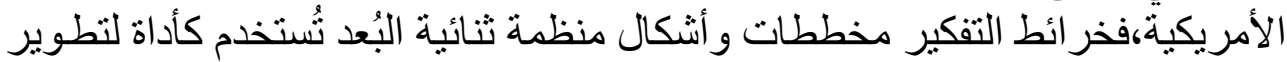

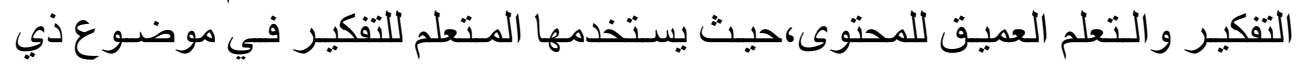

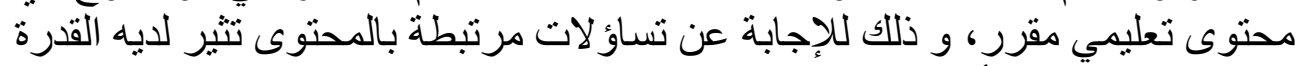

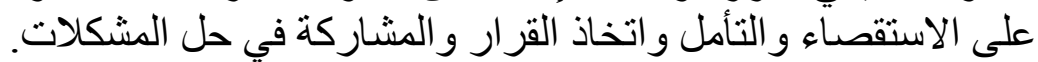

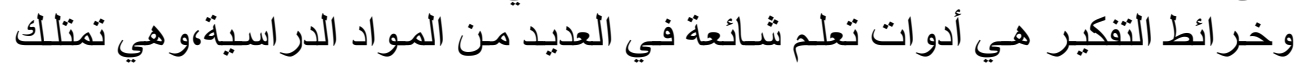

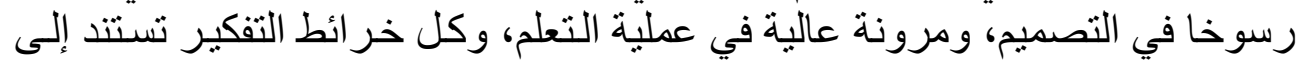

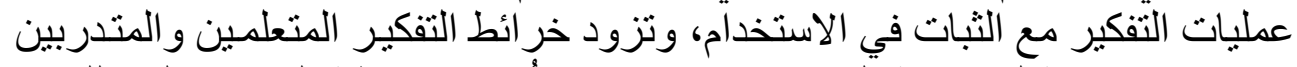

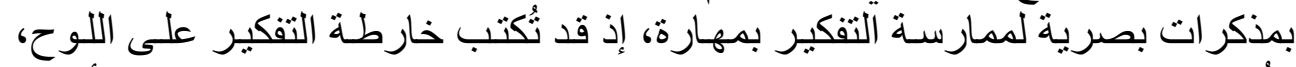

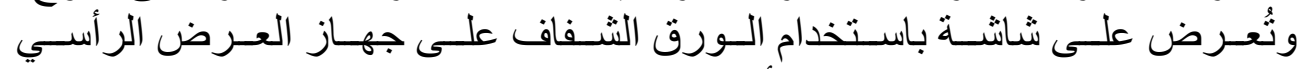
Overhead Projector 
قبل المعلم على المتعلمين كي تكون مرشدا و هاديا في ممارسة تطبيق عمليات التفكير.

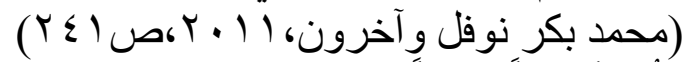

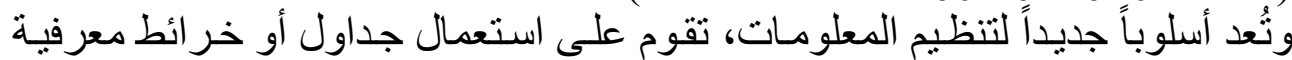

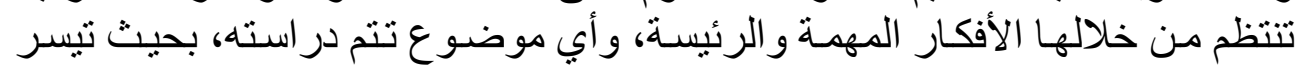
للمتعلم استر جاعها وتفسير ها وتحليلهار الافيلها.

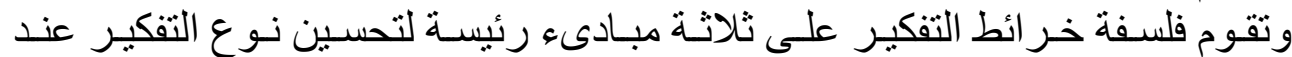

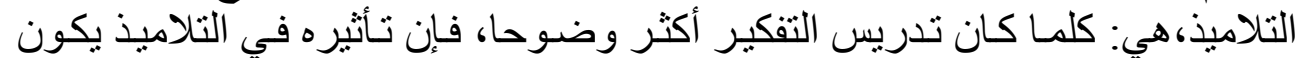

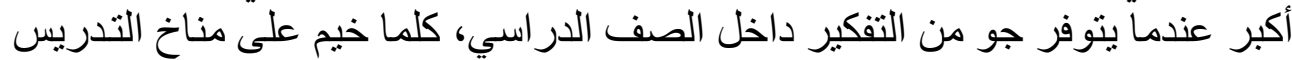

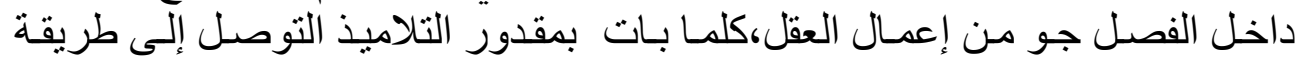

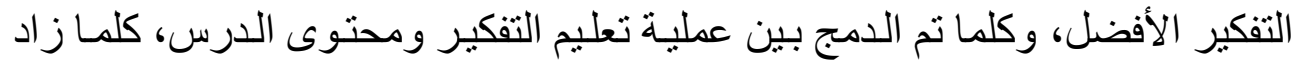

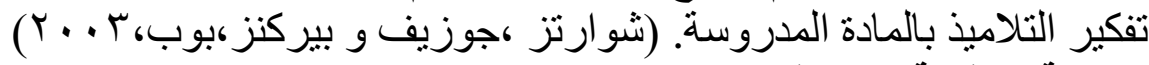

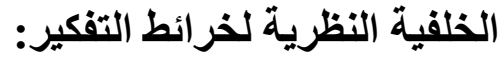

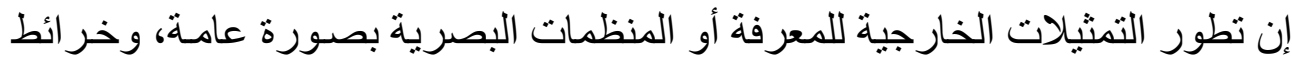

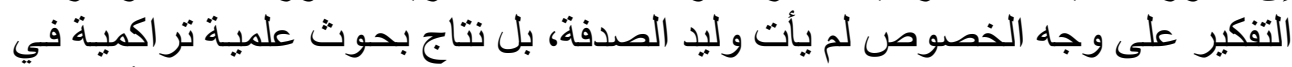

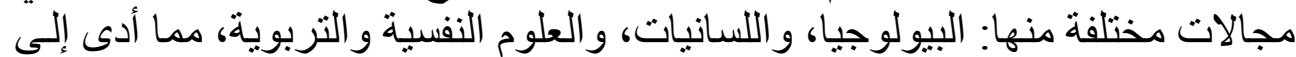

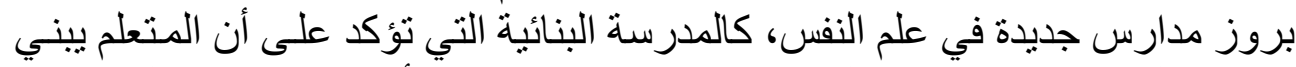

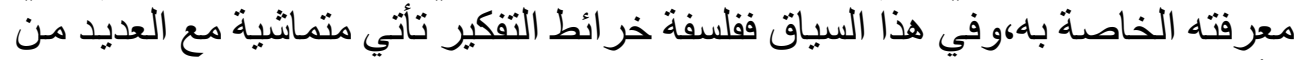

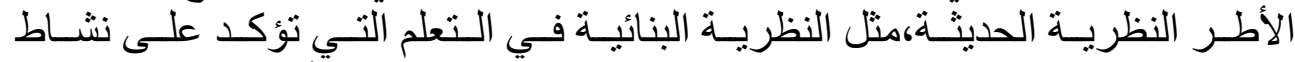

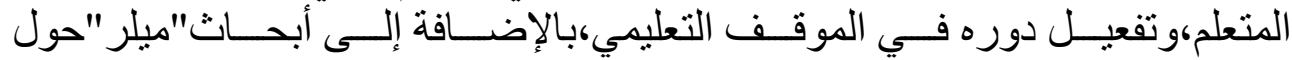

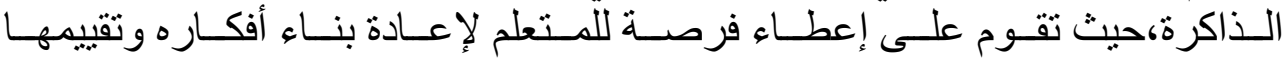

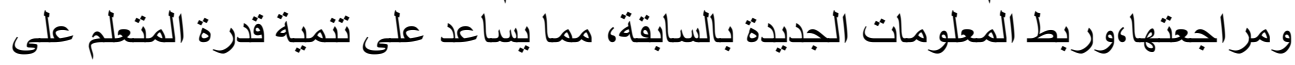

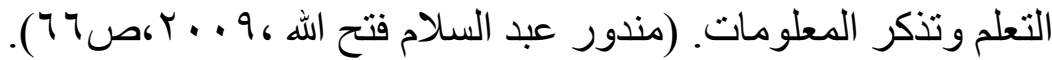

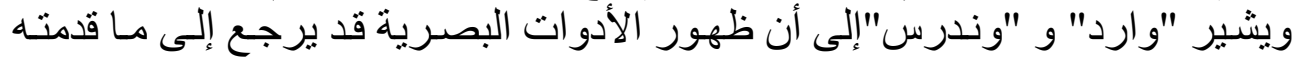

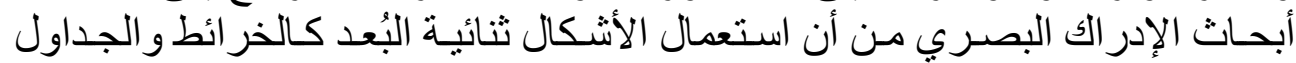

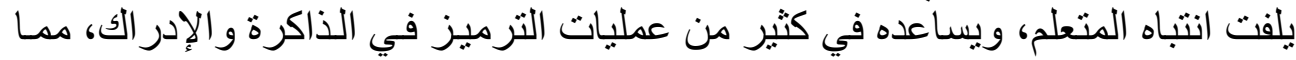

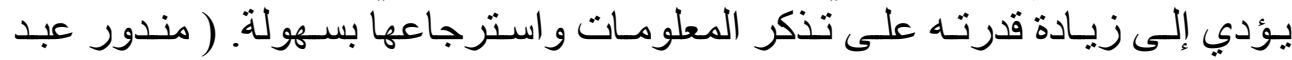

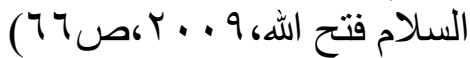

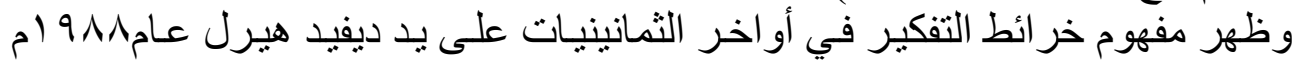

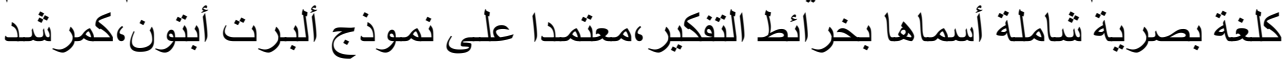

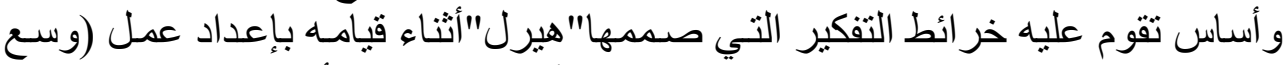
تفكيرك Expand your Thinking)، و الذي يُعد المصدر الأول للتدريس بخر ائط 


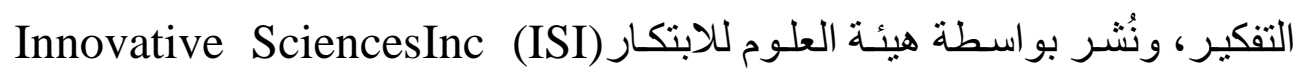

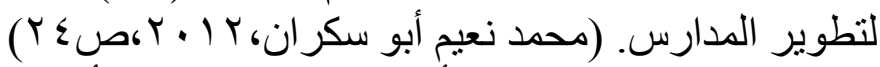

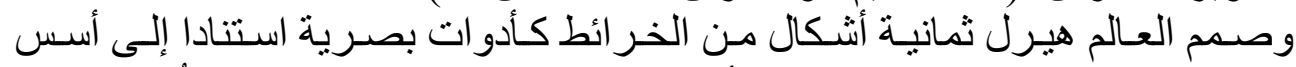

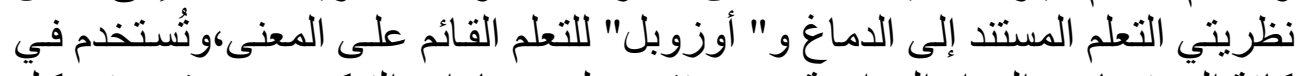

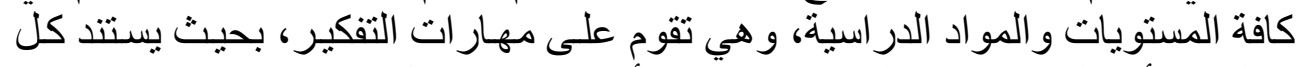

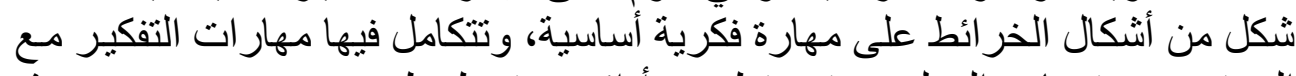

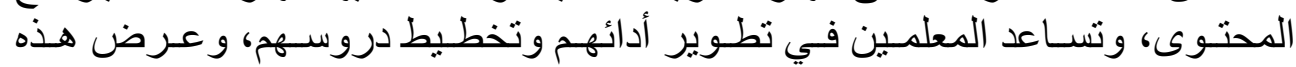

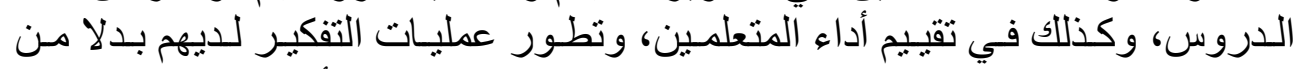

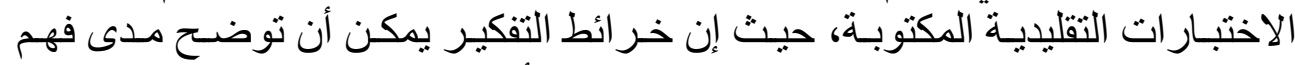

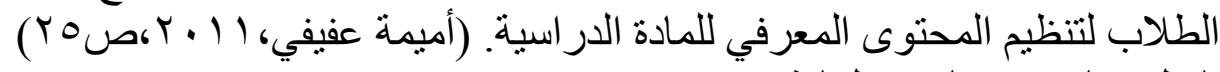

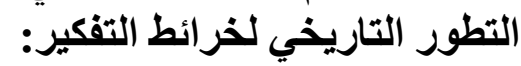

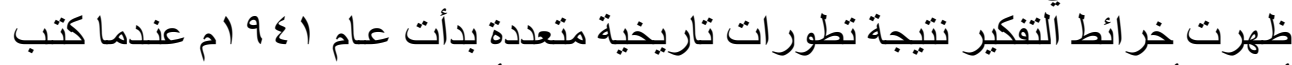

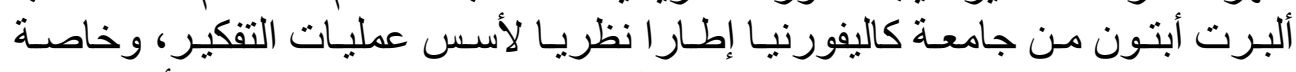

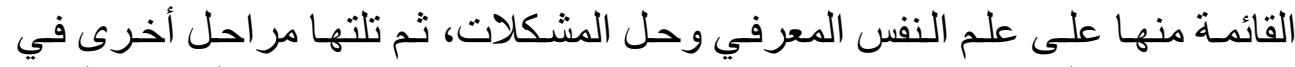

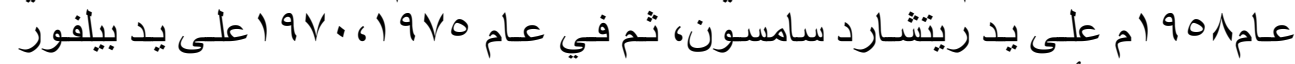

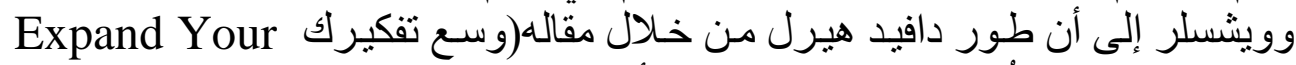
Thinking

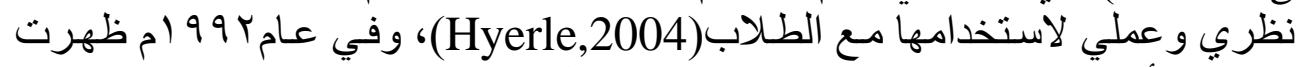

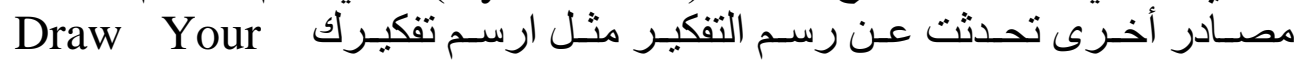
Map Thinking Your Thinking

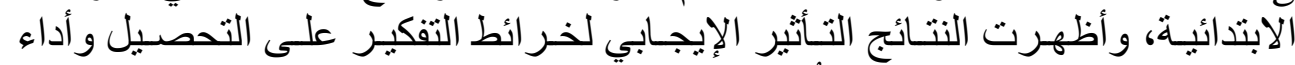

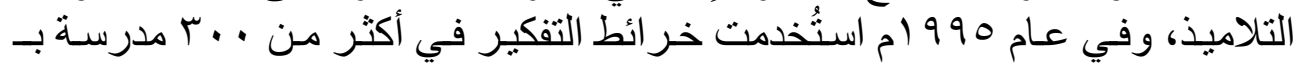

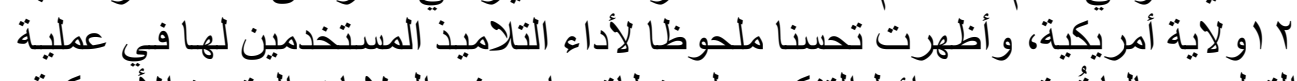

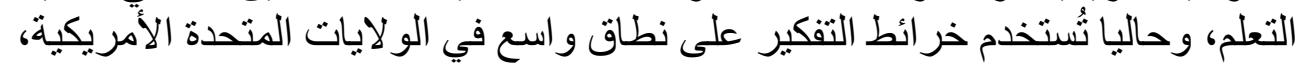

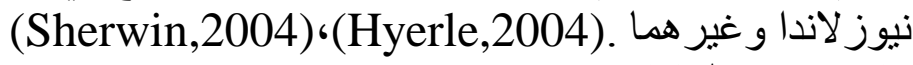

مفهوم خرائط التفكير: عرفها "هيلر" بأنها ثمانية أشكال (مخططات) للتعلم البصري اللفظي، يقوم كل شكل شيكل

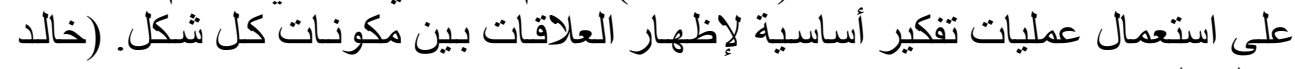

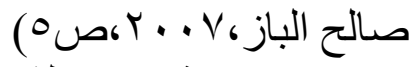

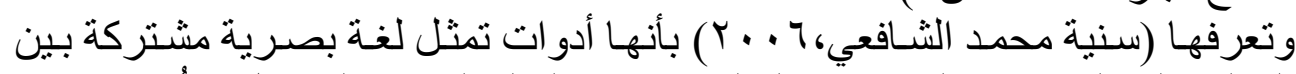

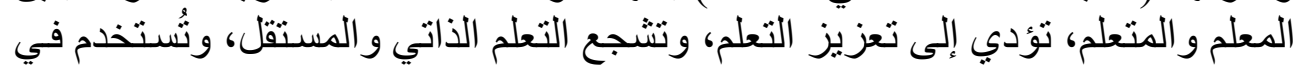




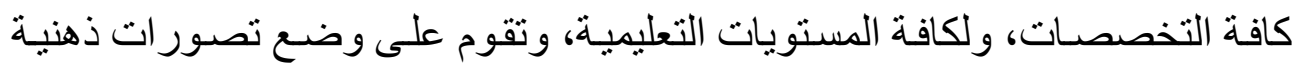

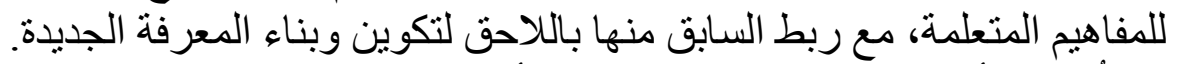

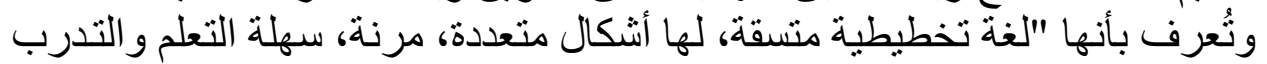

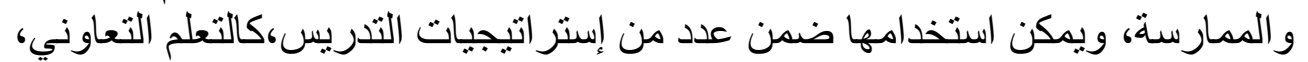

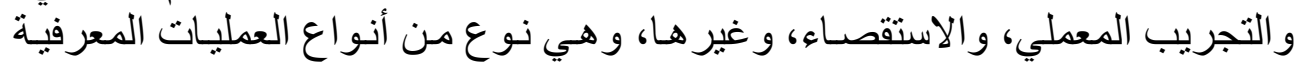

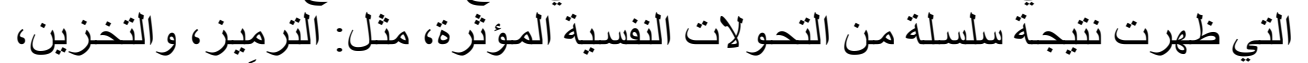

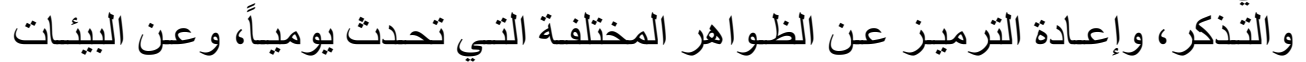

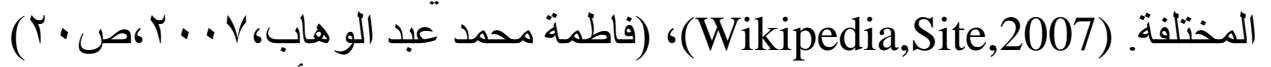

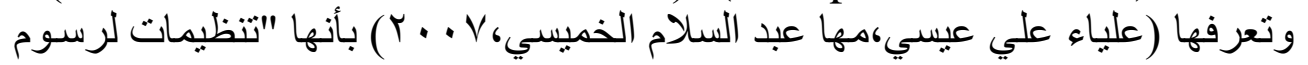

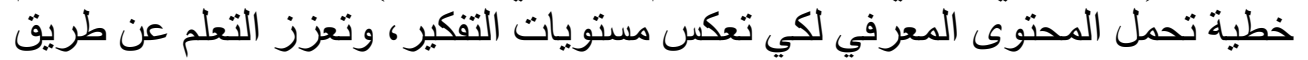

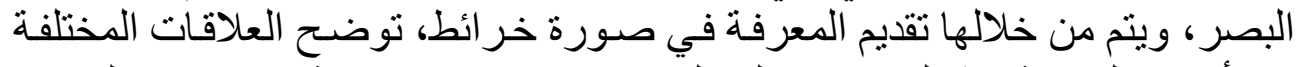

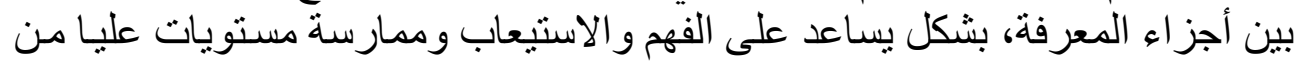
التفكير."

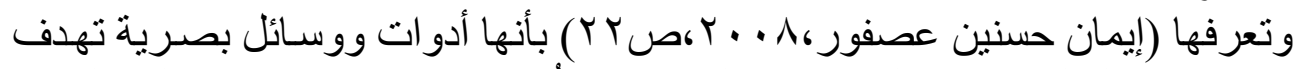

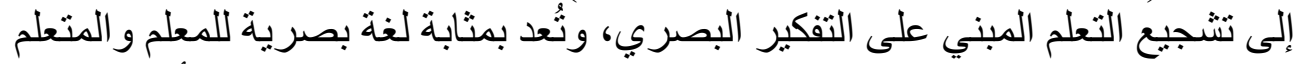

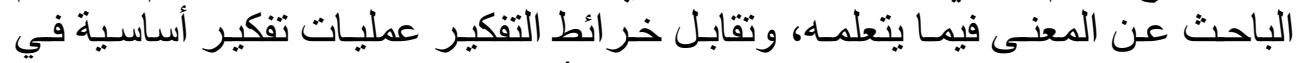

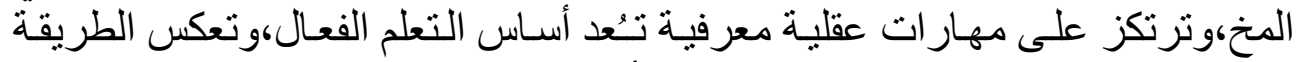

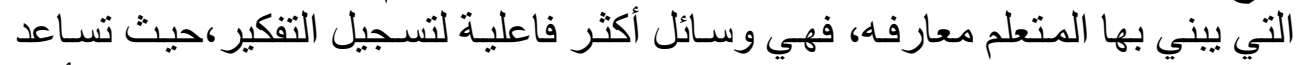

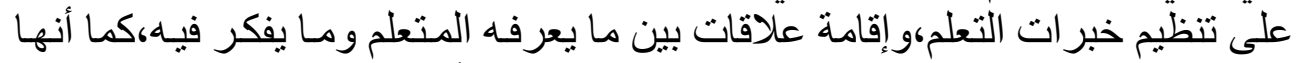

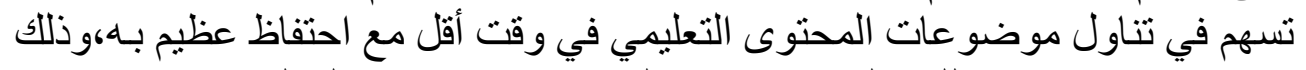

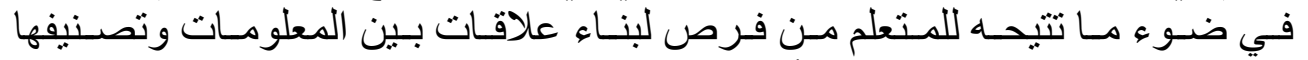

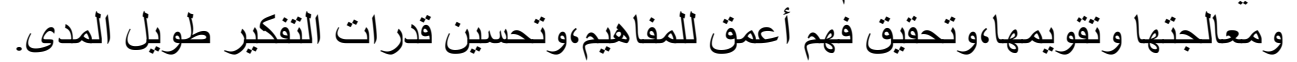

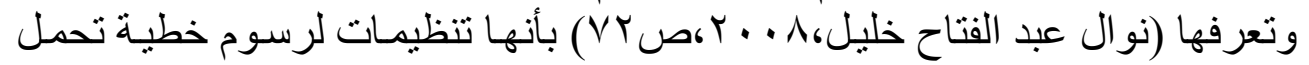

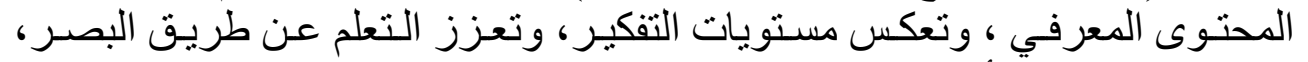

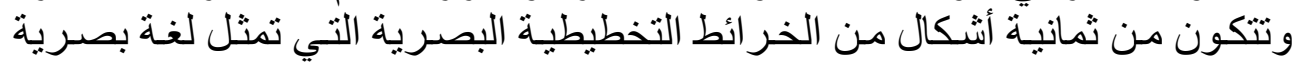

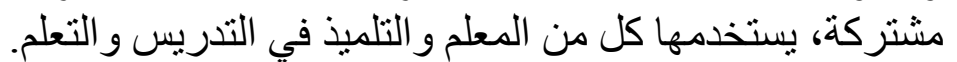

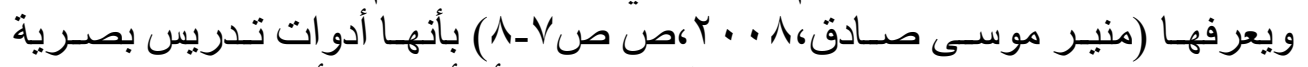

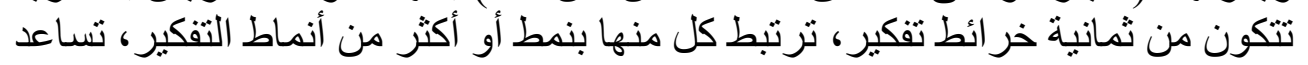

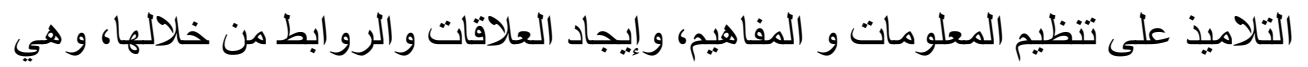

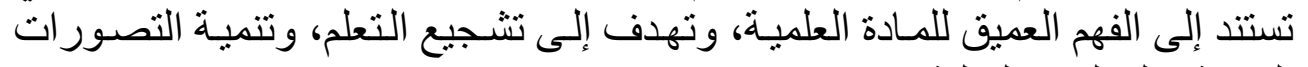
الذهنية و العمليات العقلية. 


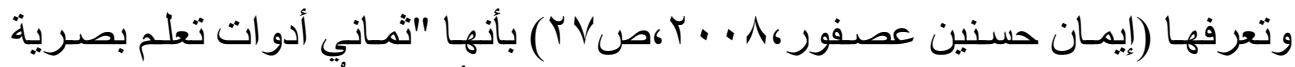

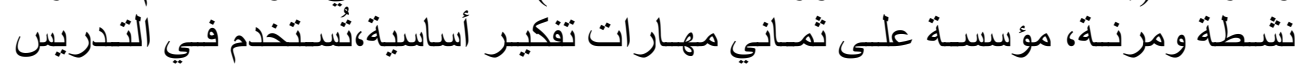

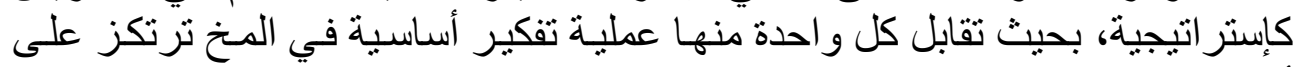
أساس مهاري معرفي.

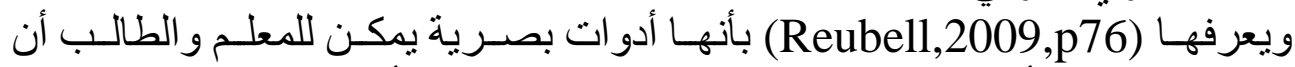

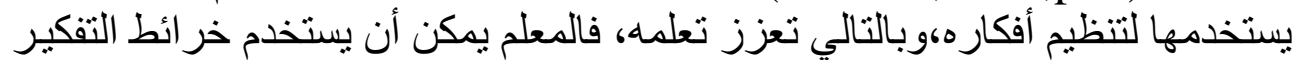

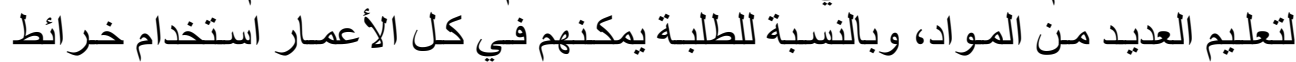

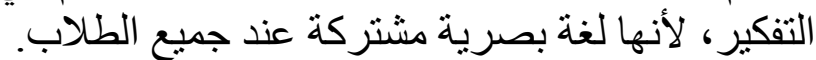

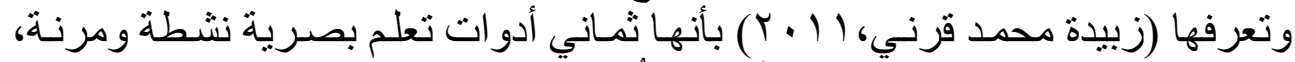

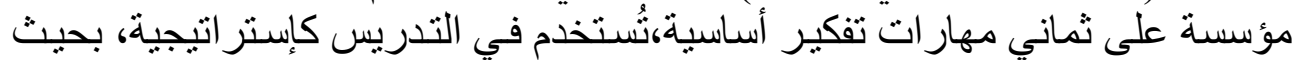

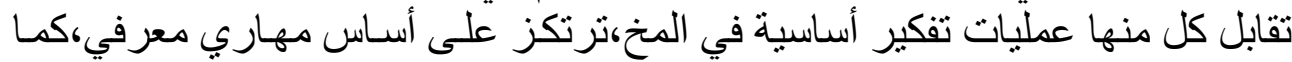

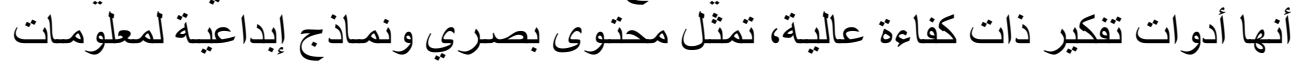

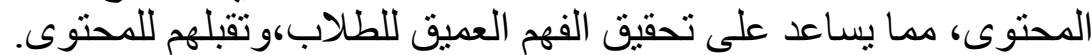

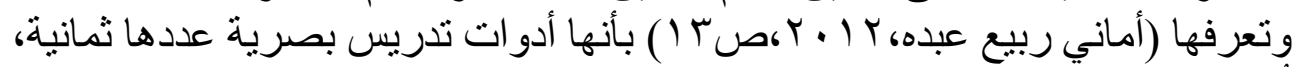

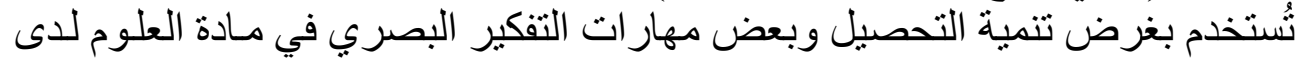

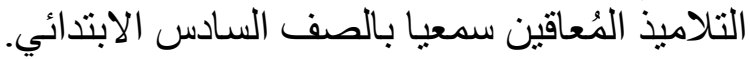

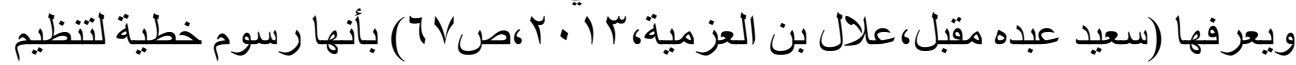
محتوى وحدتي المشكلة الاقتصادية وعناصر الإنتاج، وتعكس بعض مض مهار ات ات التفكير الأساسية.

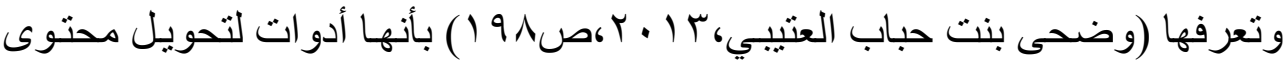

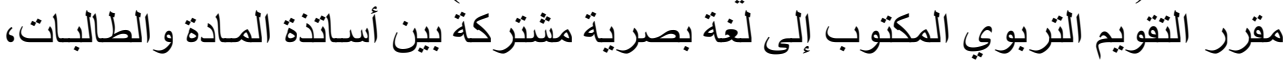

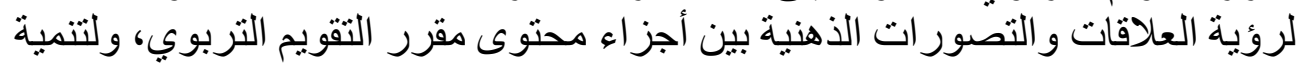

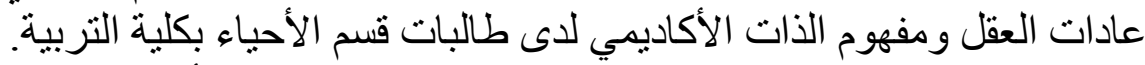

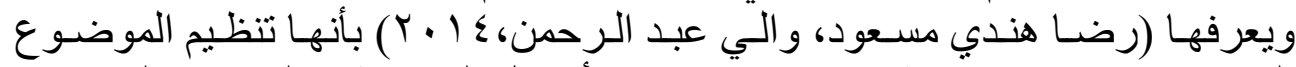

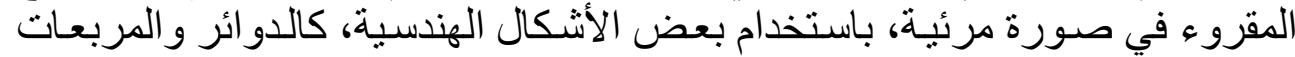

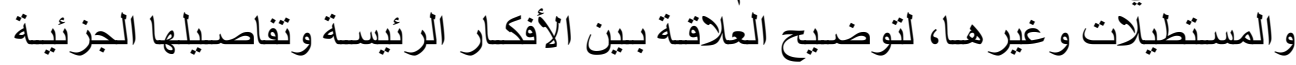

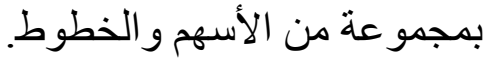

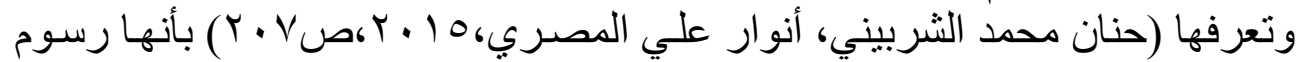

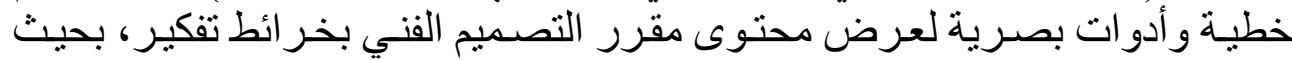

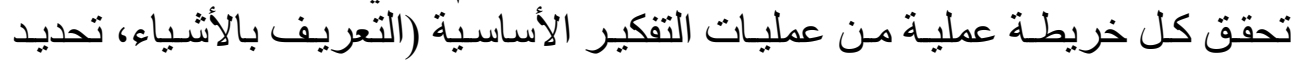
خصائص الأشياء، مقارنة ومقابلة الأشياء، و التصنيف و إدر الك العلاقات) . 


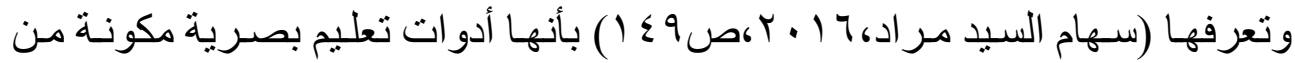

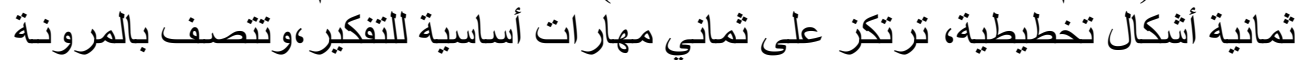
وسهولة التعلم. أهمية خرائط التفكيز

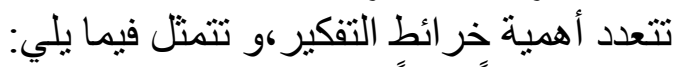

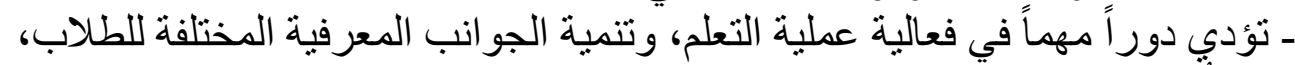

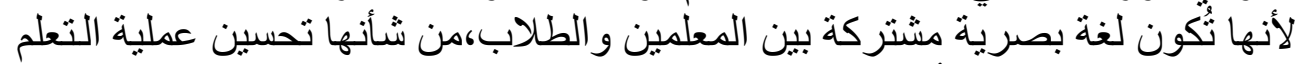

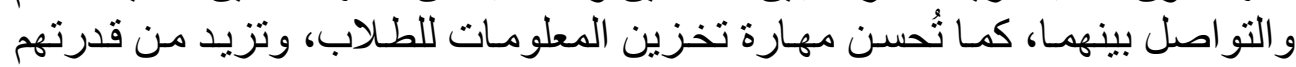

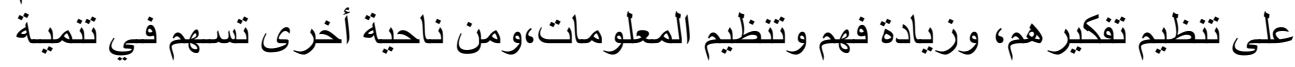

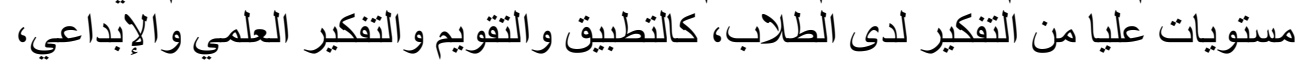

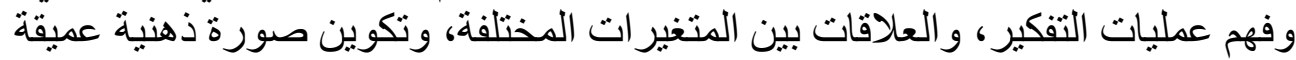

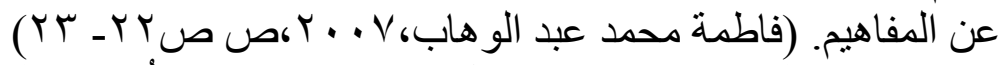

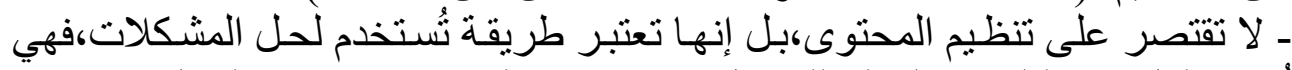

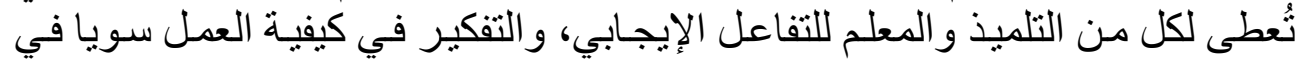

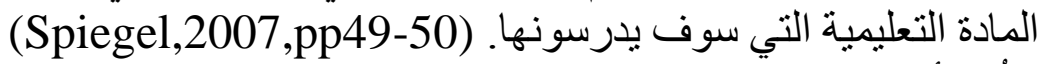

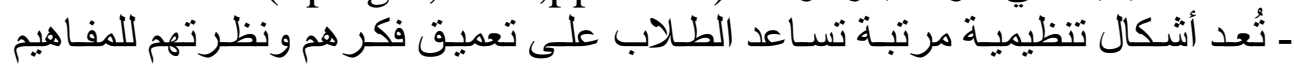

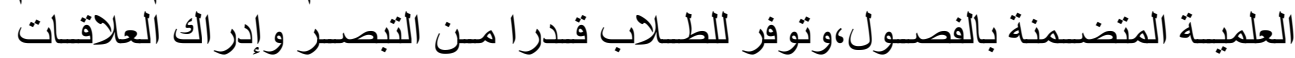

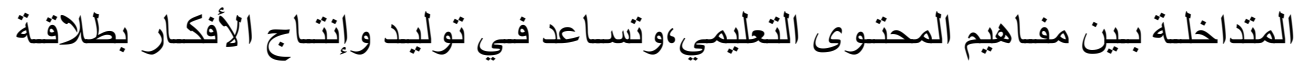

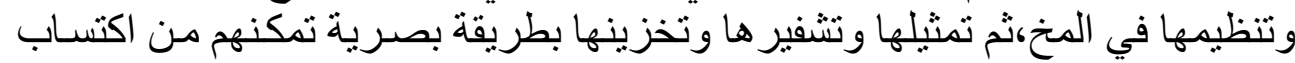

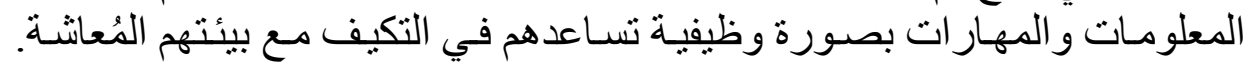

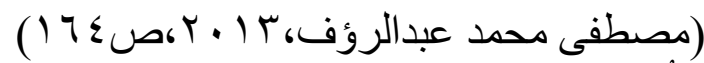

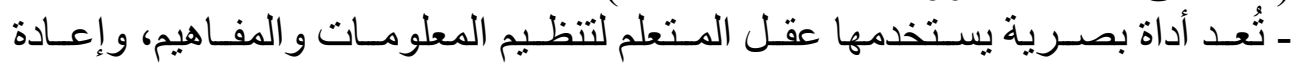

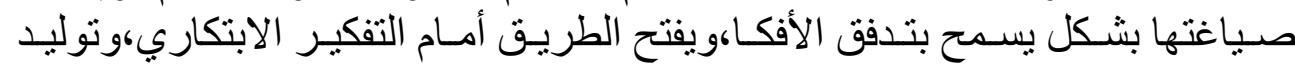

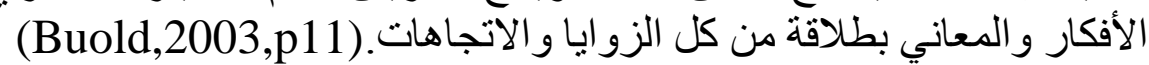

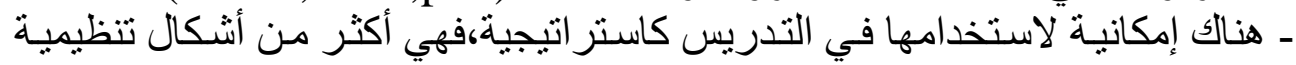

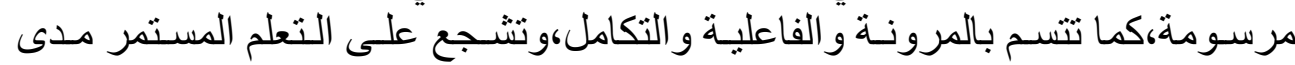

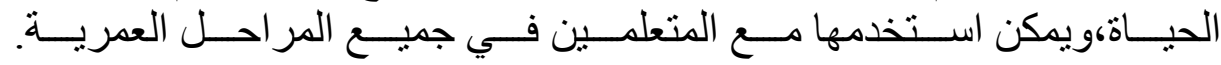

(Hyerle,2004,p6)

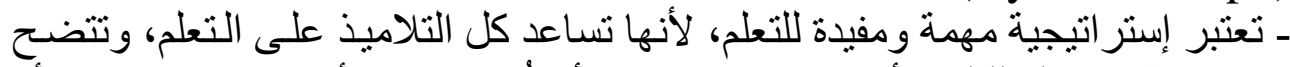

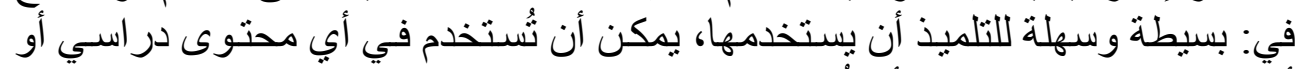

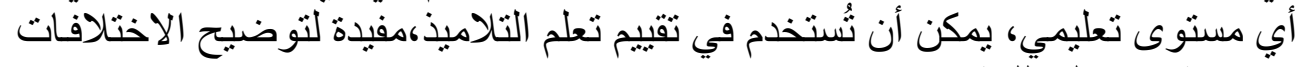
وخاصة في تعلم اللغة. (Holzman,2004) 


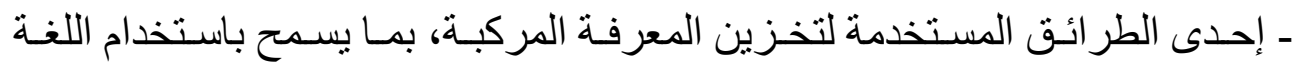

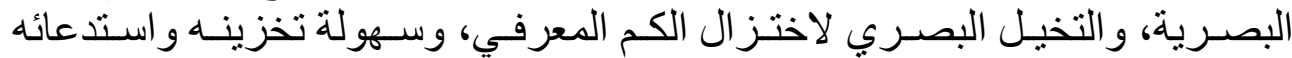
و التعامل معه. (John;Cecilia,2003)

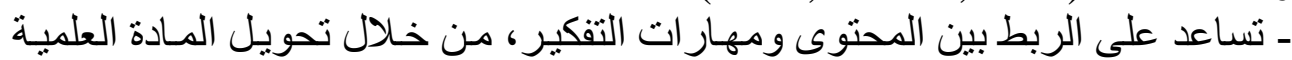

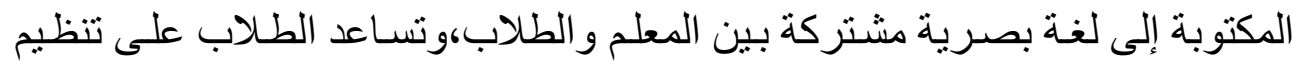

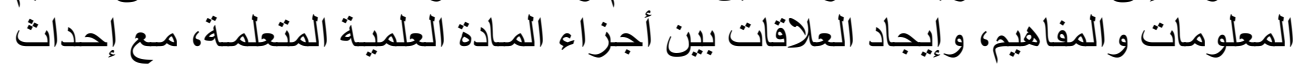

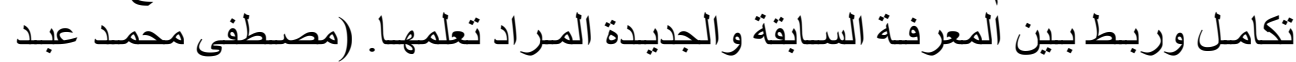

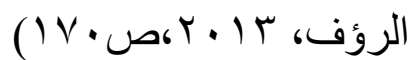

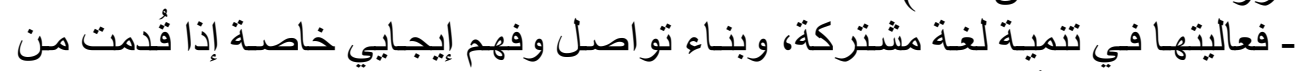
خلال التجارب وأمثلة للطلاب، مما يزيد من فهم الطلاب واستئيعابهم للمفاهيم العلمية.

(Hortencia,2007) ـ هي أحد أدوات التفكير البصري،و هي تمثنل لغـة بصرية للمعلم و التلميذ،يبني بها

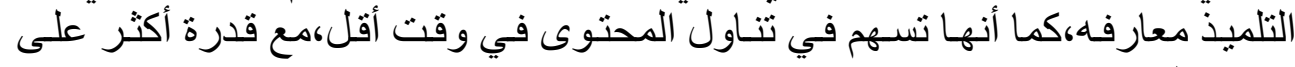
الاحتفاظ.Russel,2010,p3)

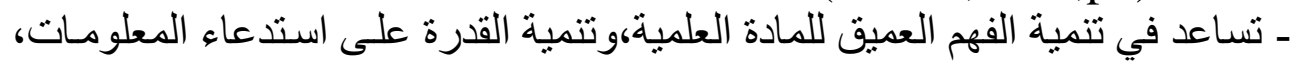

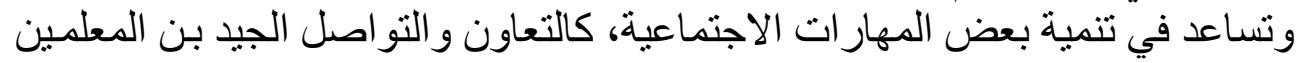

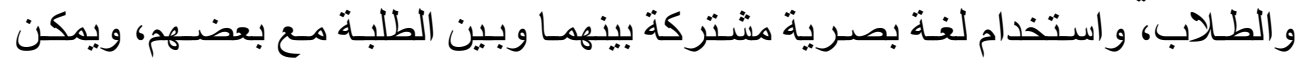

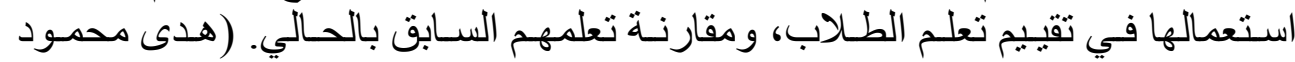

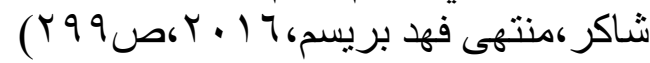

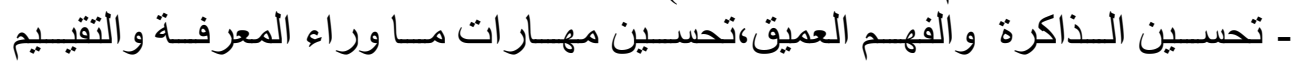

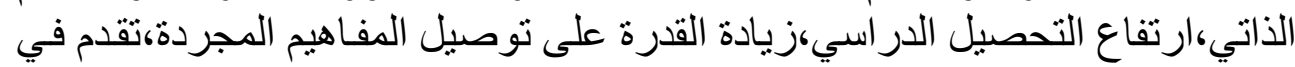

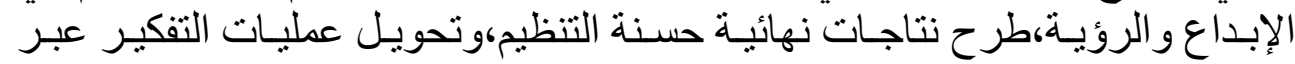
التخصصات إلى خارج إطار المدرسة. (Hyerle,2004)

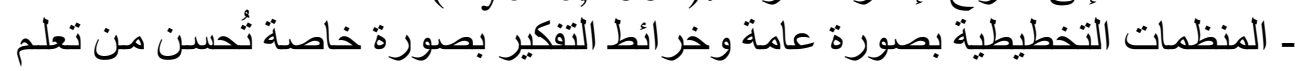

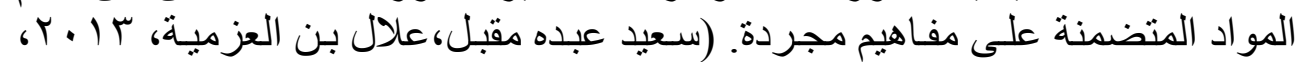
ـ تُُعد من أدو ات التفكير البصري التي توفر لغة مشتركة لكل من المعلمين و المتعلمين

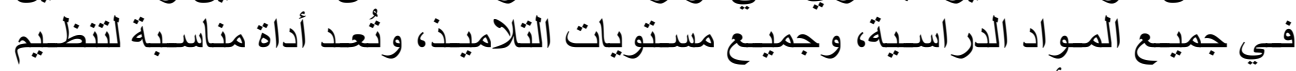
المعلومات، و الأفكار ، و المفاهيم ـ (Burden; Silver,2006)

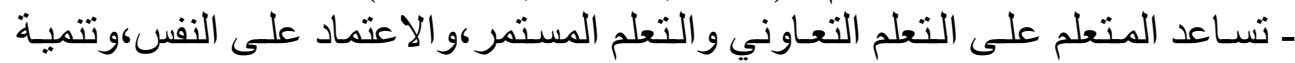

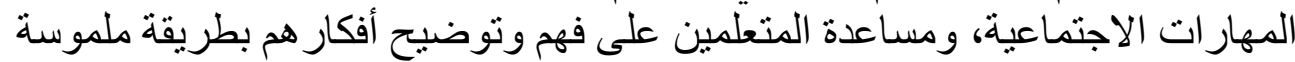

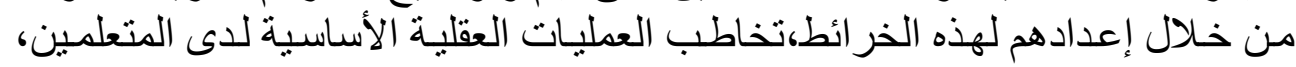




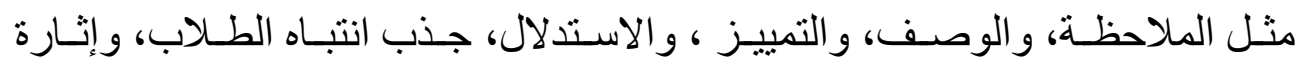

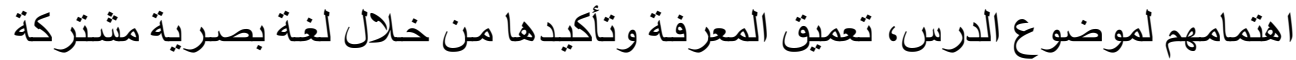

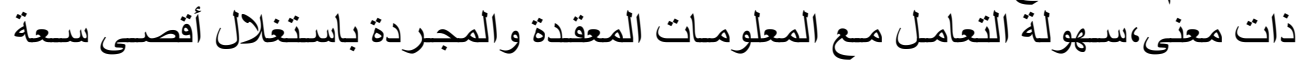

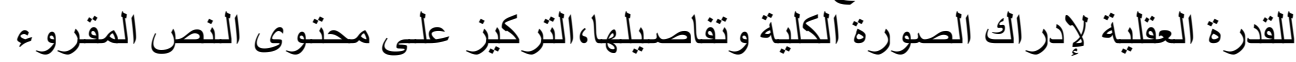

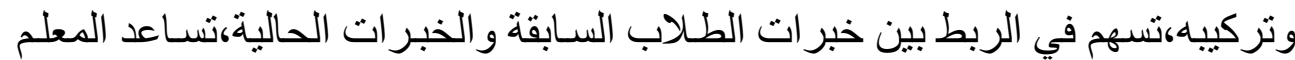

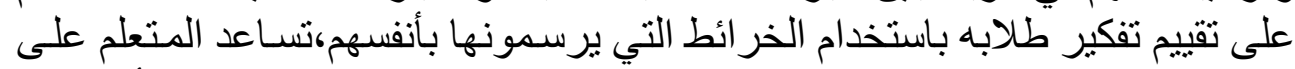

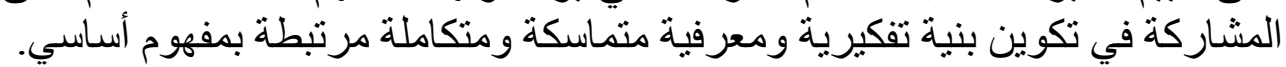

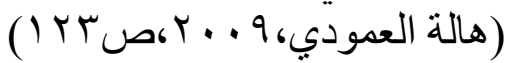

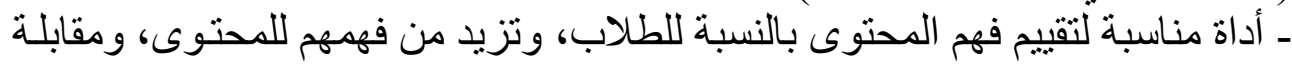
الفروق الفردية بينهم، وربط التعلم السابق بالتعلم الجديد. (Hyerle,2007)

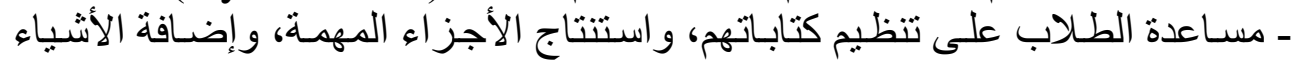

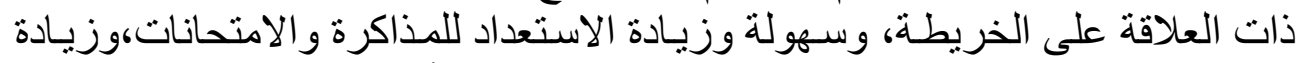

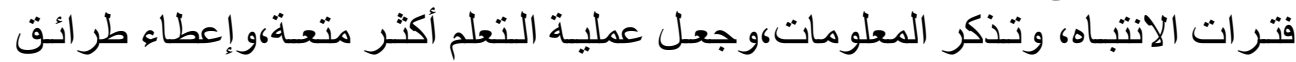

متعددة وفر صا متنو عة للتعلم. (Sylvia,2007)

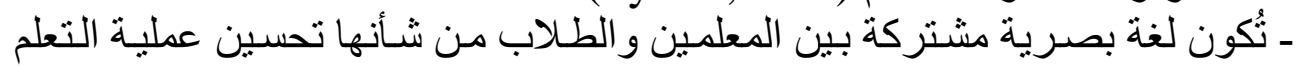

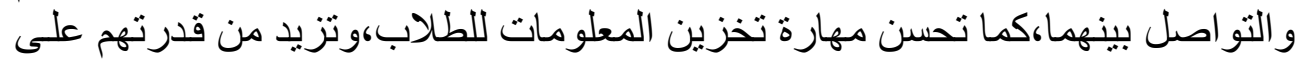

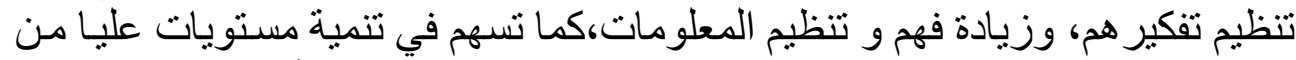

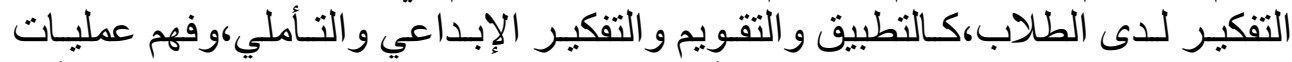

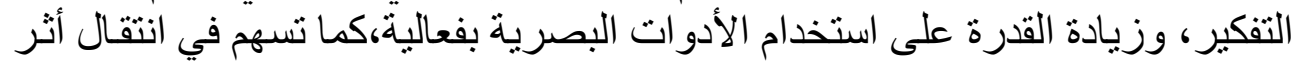

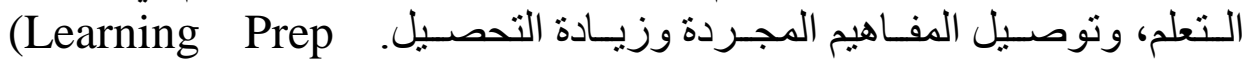
School,2007) ـ تزيد من مسئولية الطلاب و الاعتماد على النفس، وتتمية بعض المهار ات الاجتماعية

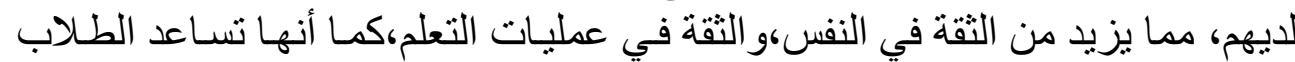

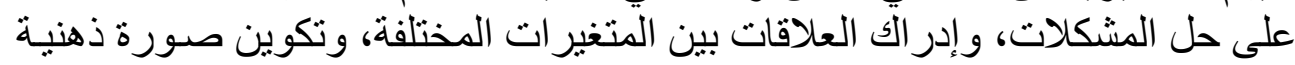

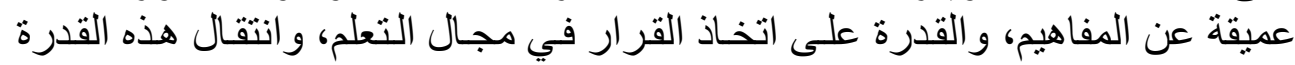
للحياة. (Sylvia,2007) ـ تُعد من أدوات التفكير البصري التي توفر لغة مشتركة لكل من المعلمين و المتعلمين

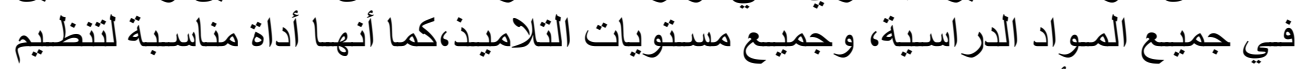

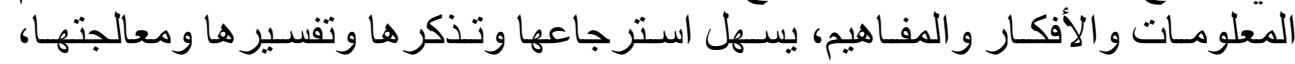

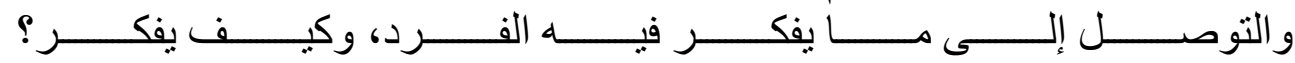
(Hyerle;Curtis;Alper,2004,p106)،(Gallagher,2011) 
ـ تعتبر خر ائط التفكير أدوات تفكير بصرية ولغة مهمة في تخطيط الأفكار وتنظيهها،

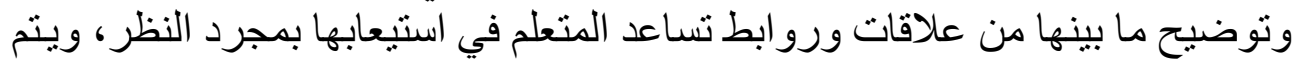

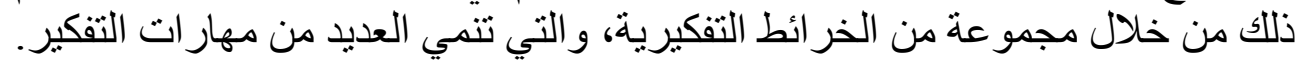

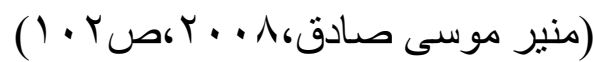

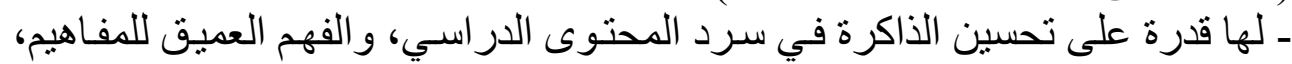

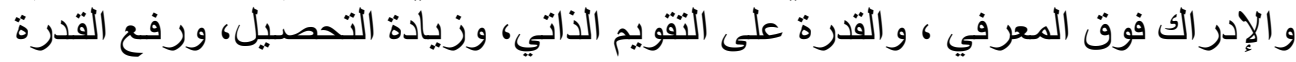

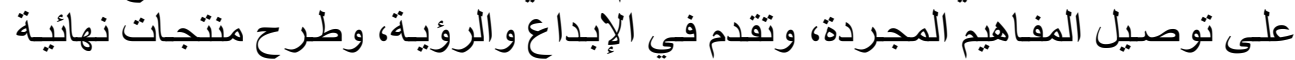

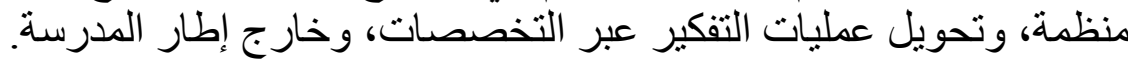

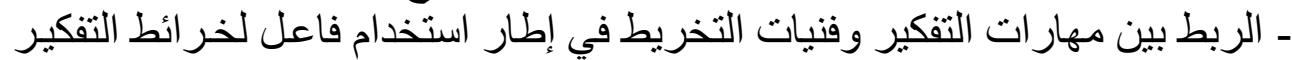

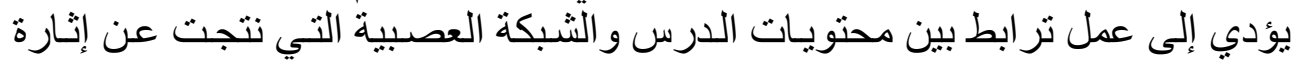

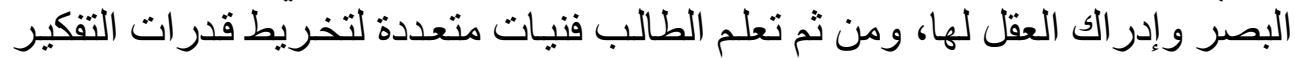

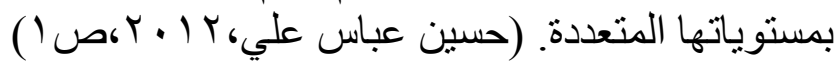

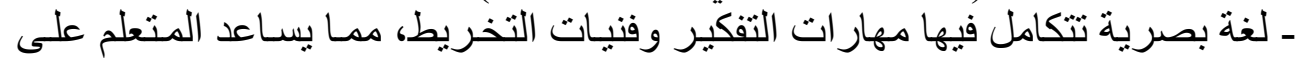

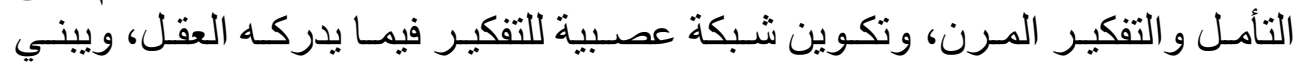

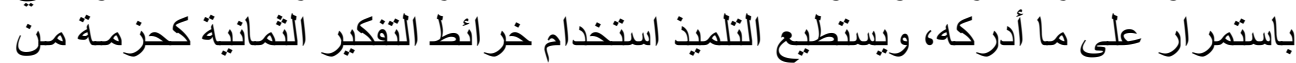
الأدوات لبناء المعرفة، وتنمية قدر ات التهات التفير العليا. (Piercy, 2007,p69)

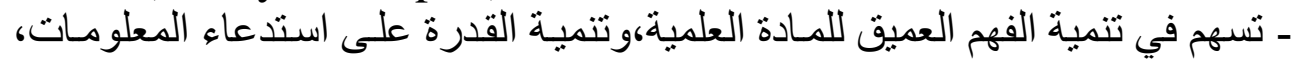

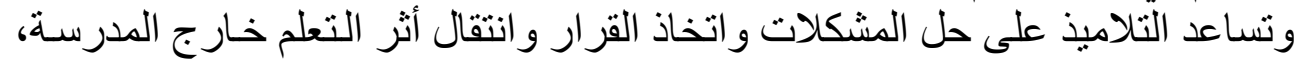

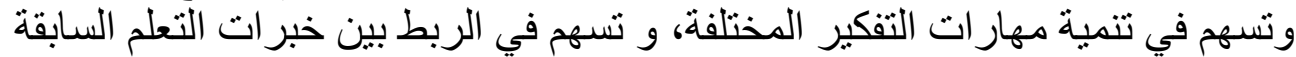

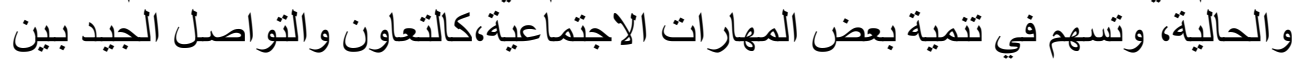

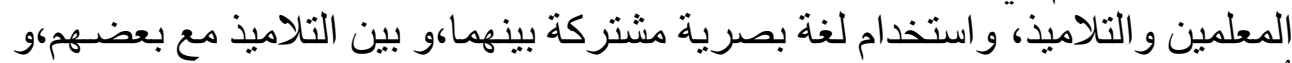

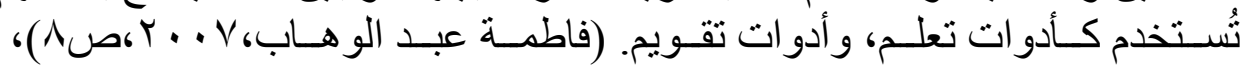
(Holzman,2004,p3)

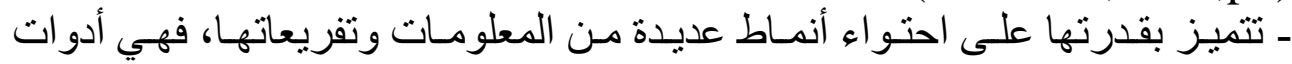

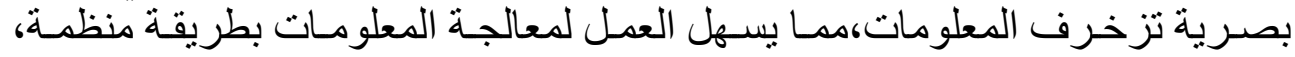

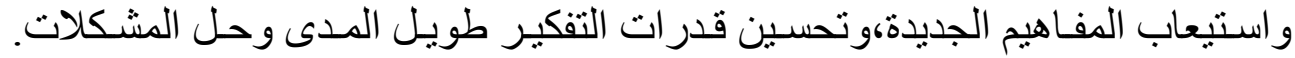

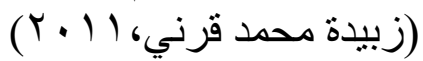

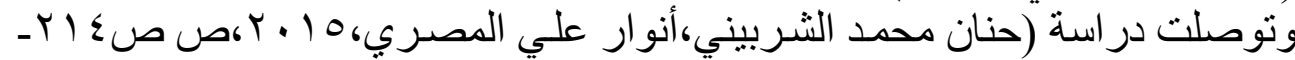

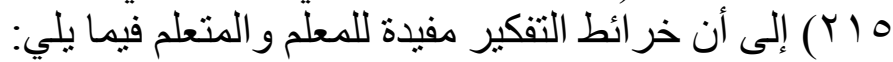

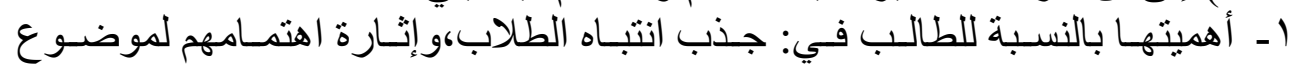

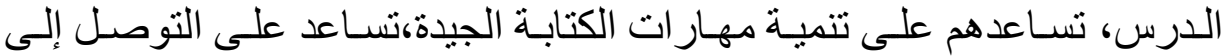

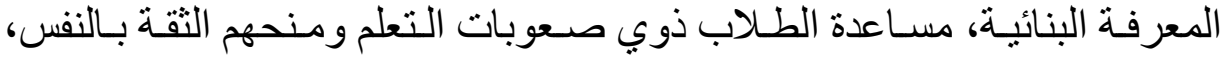


التفكير المستقل لتنظيم الأفكار وتحقيـق الاعتمـاد على النفس،تسـاعد على توليد

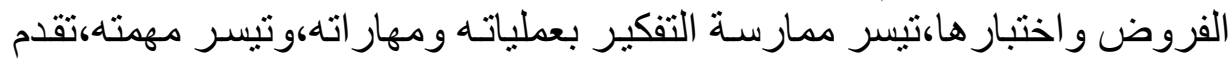

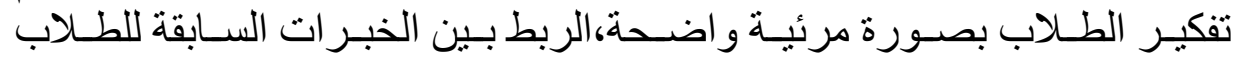
و الحالية، تشجع على الإبداع، الاحتفاظ بالمعرفة (بقاء أثر التعلم)، وفاعلية المتعلم

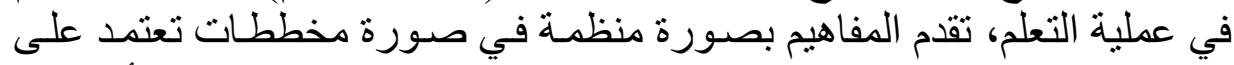

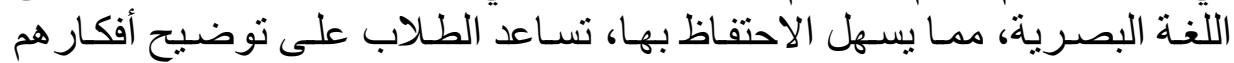

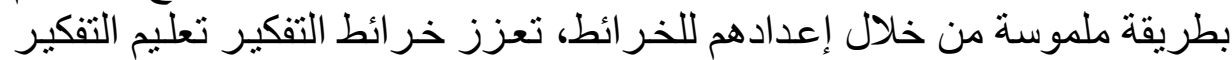

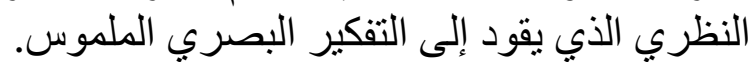

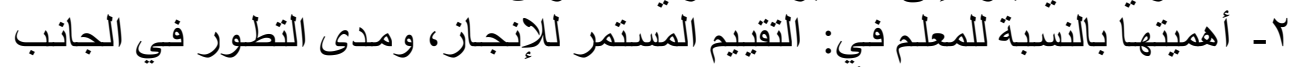

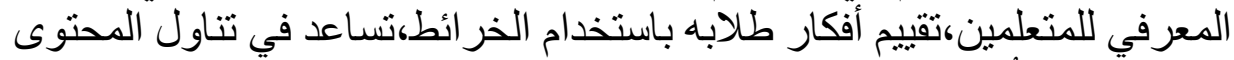

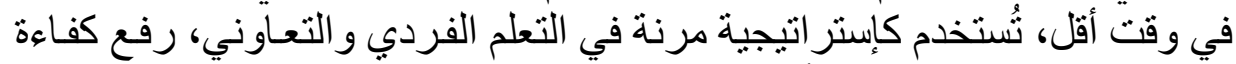

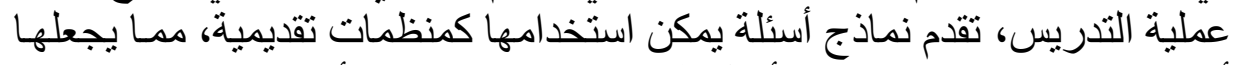

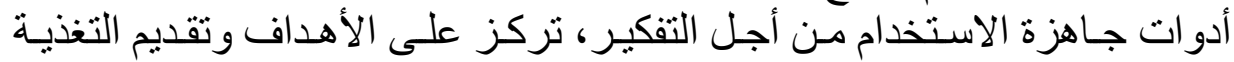

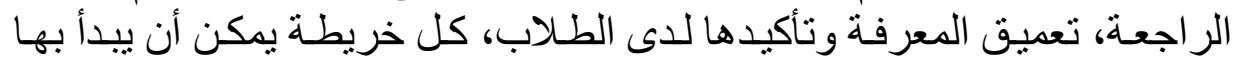

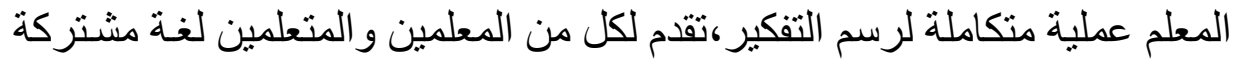

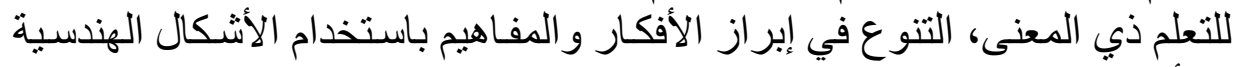

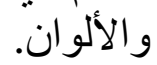
خصائص خرائط التفكير:

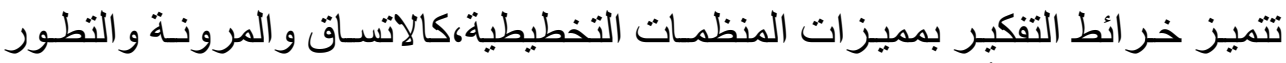

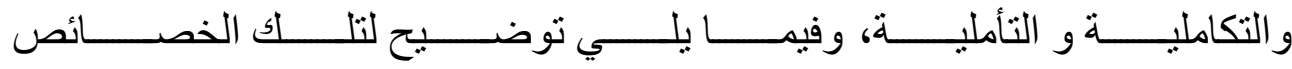
:(Diaz,2010,p38)،(Hyerle,2004,p8)

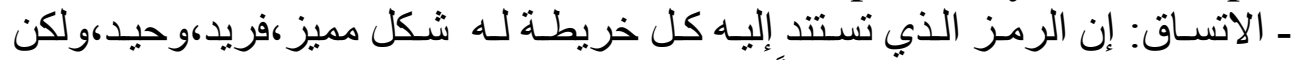

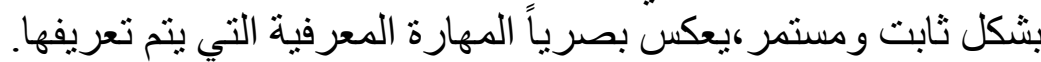

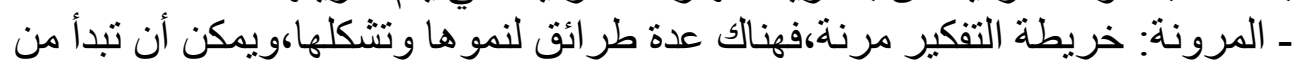

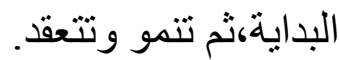
ـ القابلية للنمو والتطور : بسبب الرسوم البسيطة و الثابتة،والاستخدام السهل،فأي متعلم

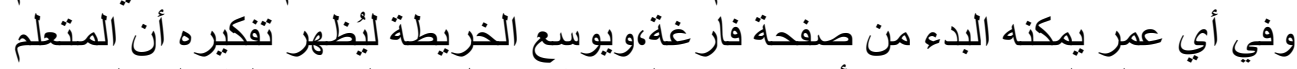

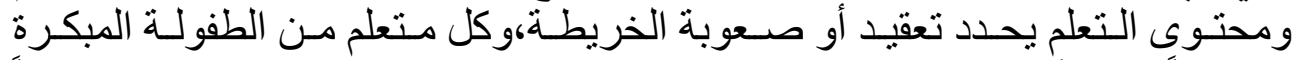

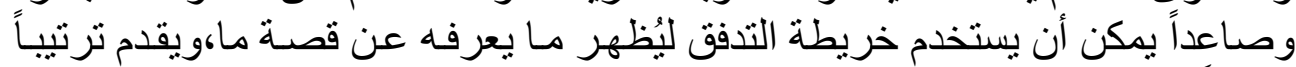
مختلفاً للمحتوى. 


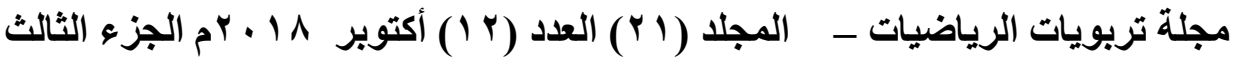

ـ التكاملية: هنالك بُعدان أساسيان للتكامل هما:عملية التفكير ،ومعرفة المحتوى:أو لاً:كل

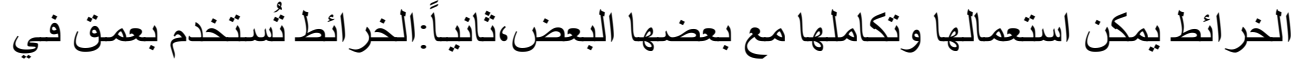

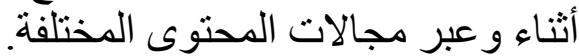

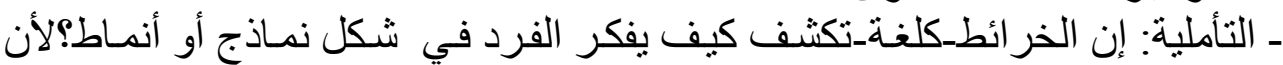

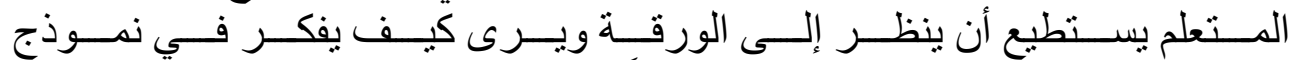

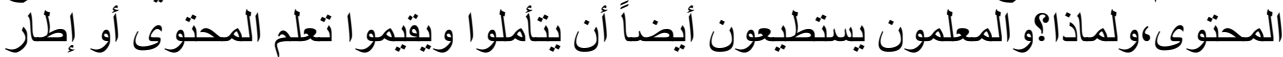
ما ور اء المعرفةوهةو عمليات تفكير المتعلم. و شكل (1) يوضح خصائص خر ائط التفكير.

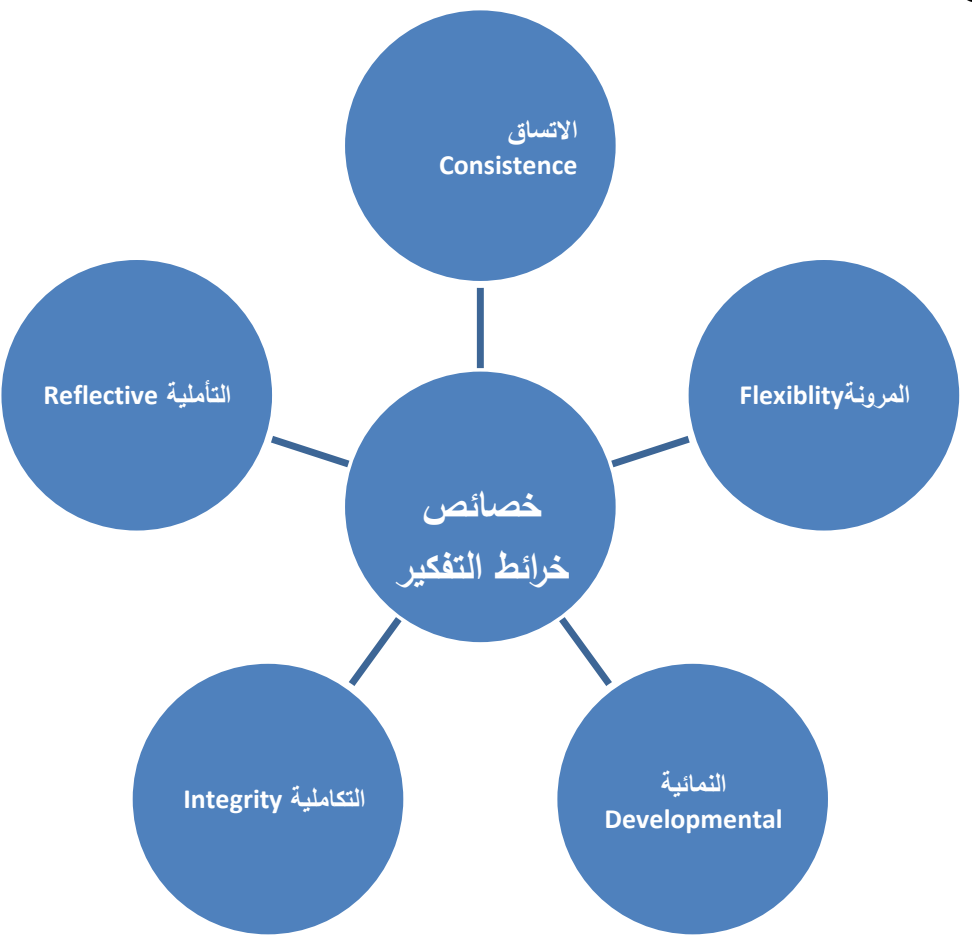

شكل (1 ) خصائص خرائط التفكير

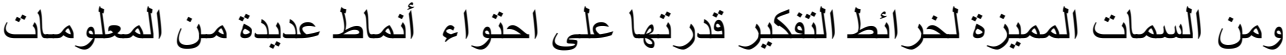

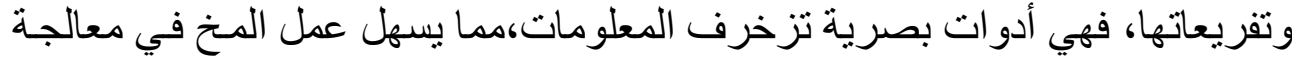

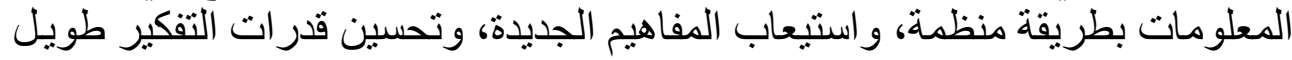

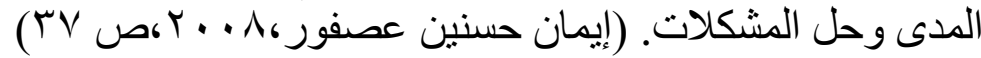
أنواع الأدوات البصرية: 
صنف ديفيد هيرل الأدوات البصرية إلى أربعة أنواع،هي(سهام السيد مر اد، 1 • ب؟،

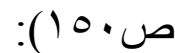
ـ مخططات (شبكات) العصف الذهني:وتتبنى الإبداع سو اء للفرد و المجمو عة، ومنها

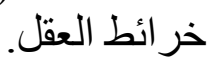
ـ المنظمات البيانية:وتتبنى المهار ات الأساسية ومحتوى التعلم،ومنها شكل ثن.

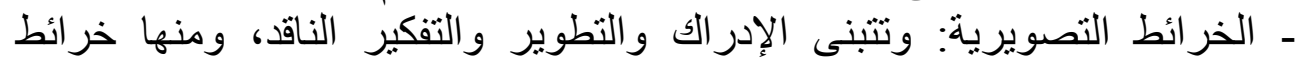

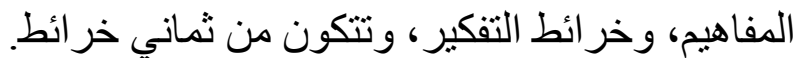

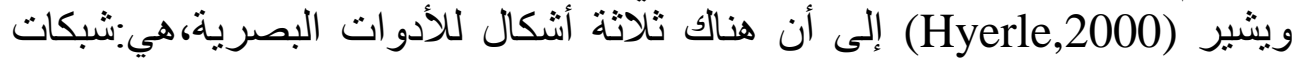

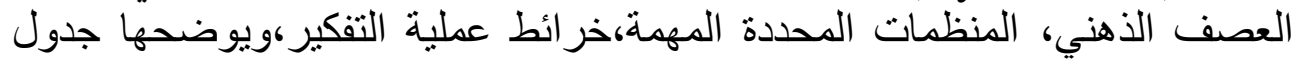

جدول (r) أشكال الأدوات البصرية

\begin{tabular}{|c|c|c|}
\hline خرائط عمليات التفكير & المنظمات المحددة المهمة & شبكات العصف الذهني \\
\hline خرائط المفاهيم & الخطوط الزمنية & الشبكات \\
\hline الأشكال المنظمة & حل المشكلات & خر ائط العقل \\
\hline خرائط التفكير & & الشبكات العنقودية \\
\hline
\end{tabular}

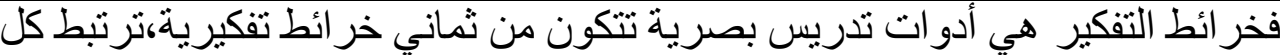

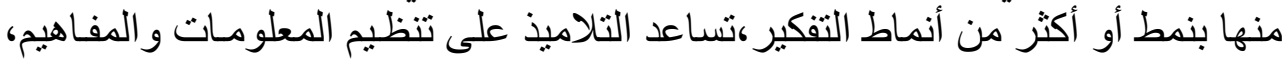

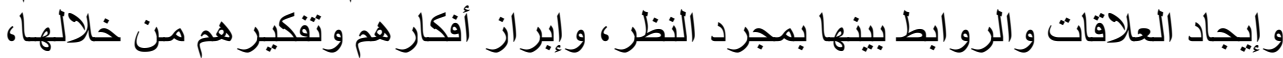

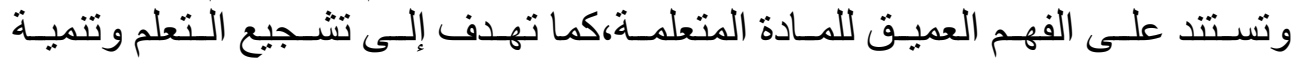

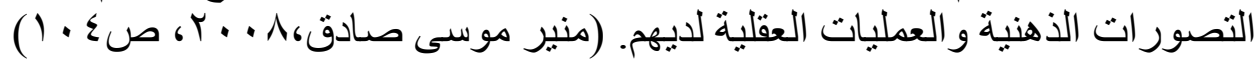
أنواع خر ائط التفكير: ظهرت خر ائط التفكير وتم توظيفها في التدريس، وقد تم تطوير ها على يد ديفيد هيرل

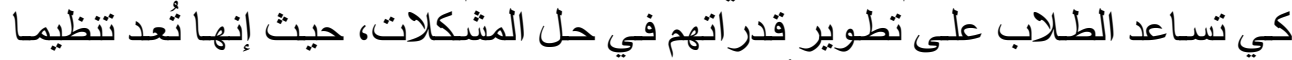

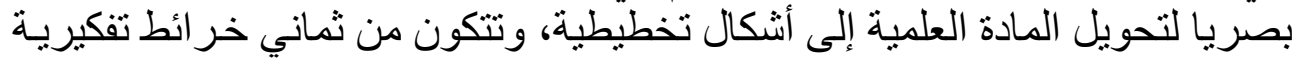

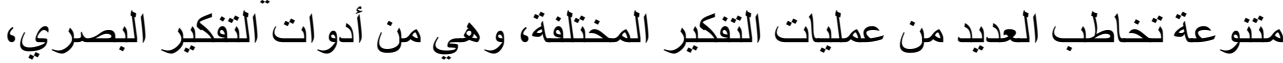

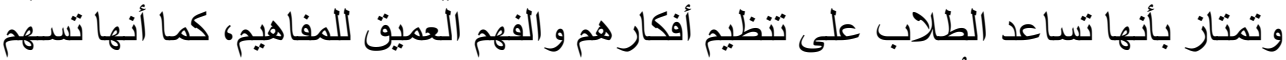

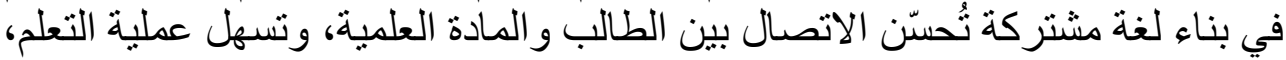

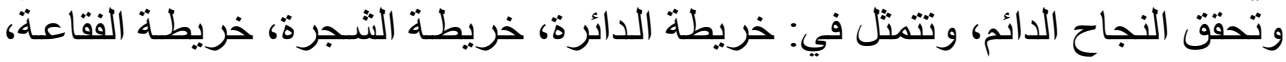

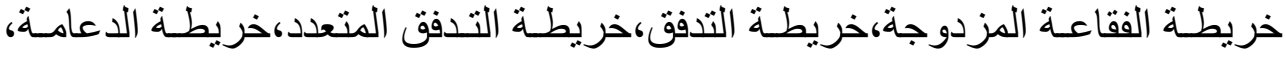

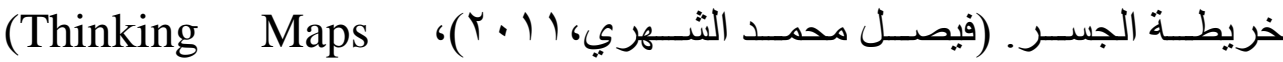

( Hyerle,2004)، Organization,n.d)

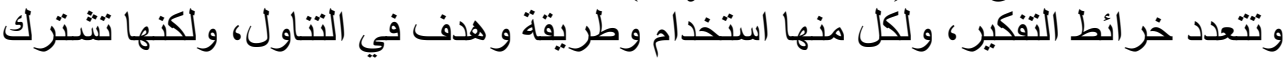

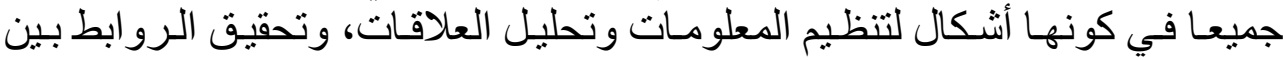




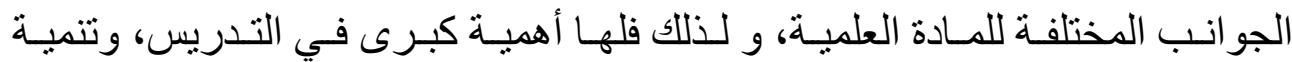

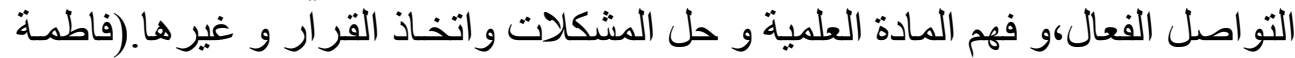

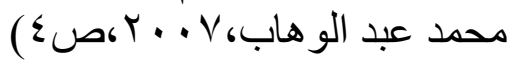

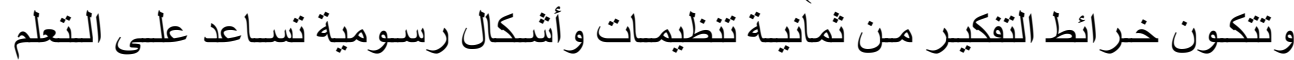

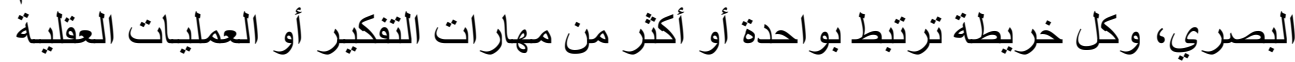

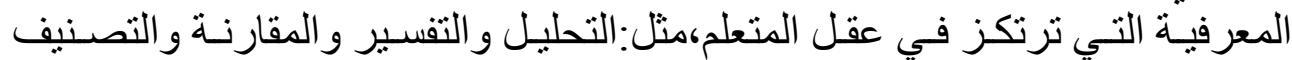

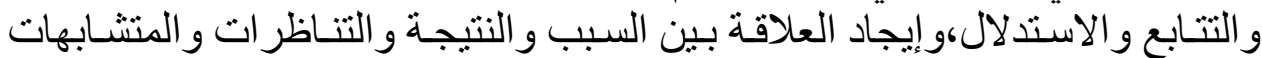

(Thinking Maps,INC,2004)

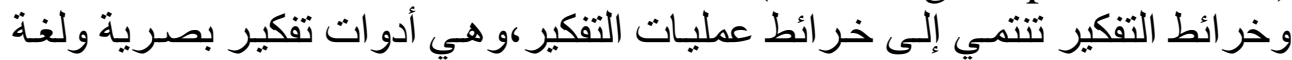

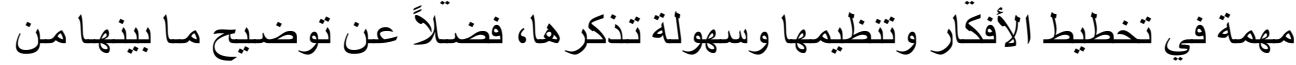

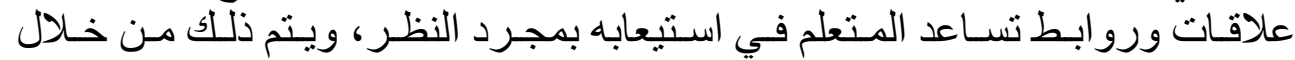

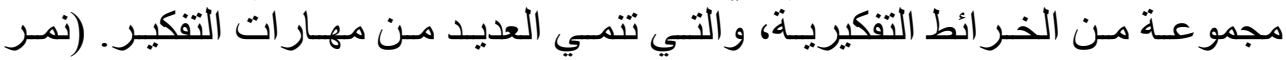

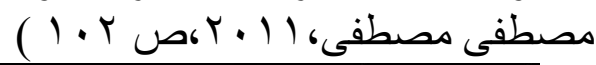

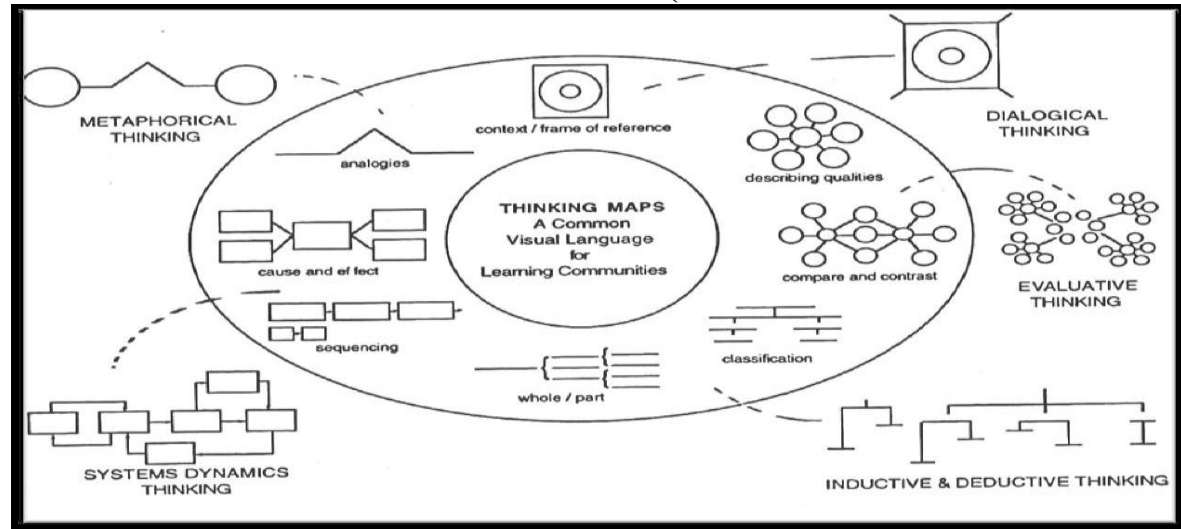

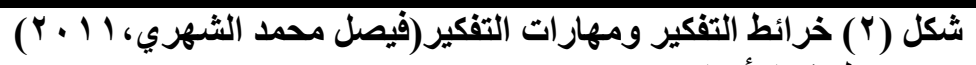

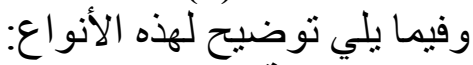

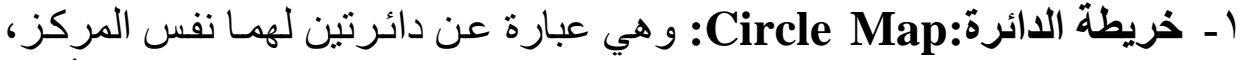

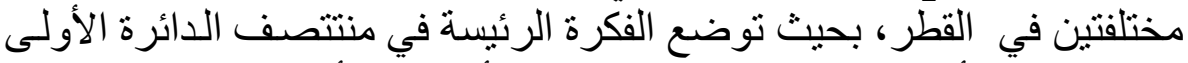

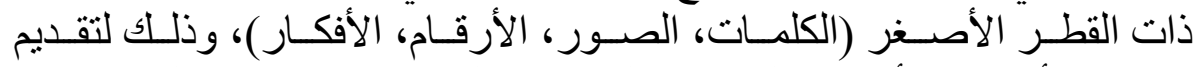

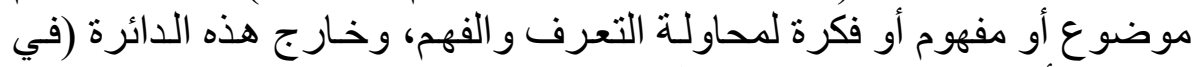

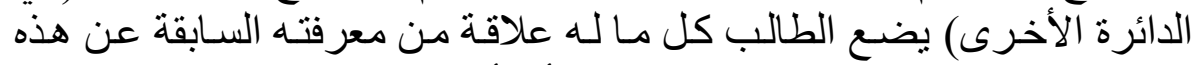

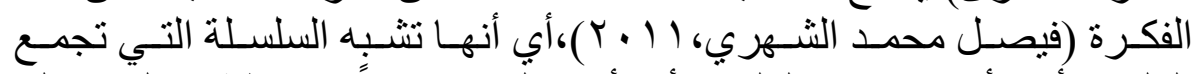

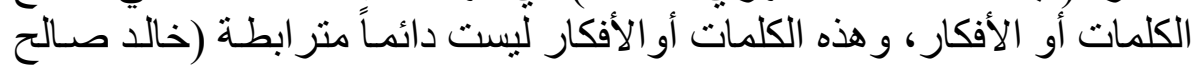




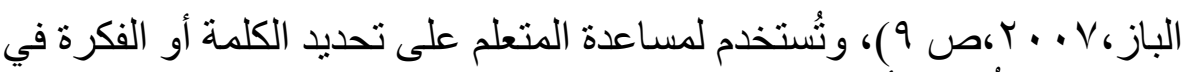

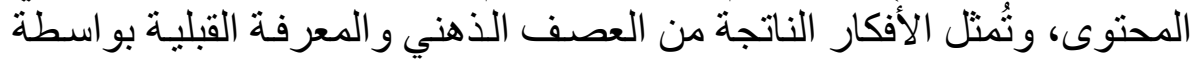

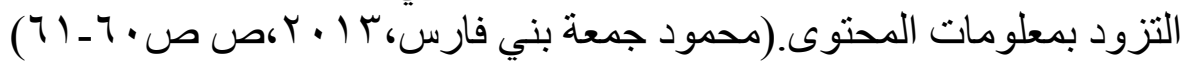

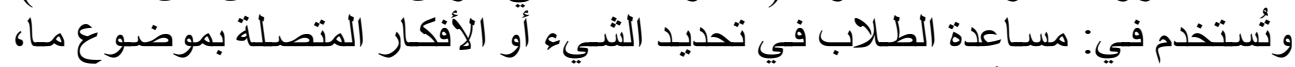

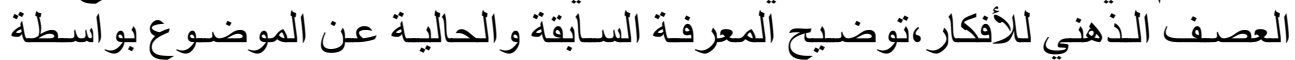

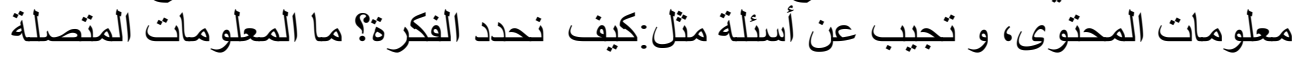

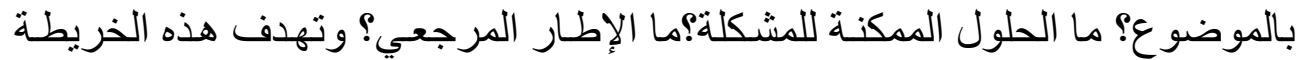

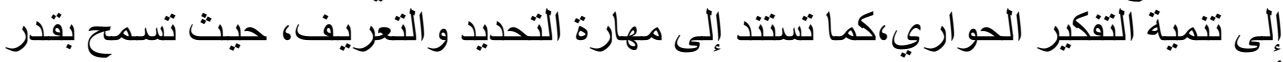

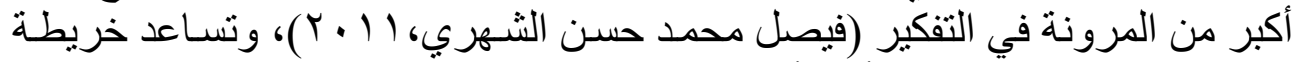

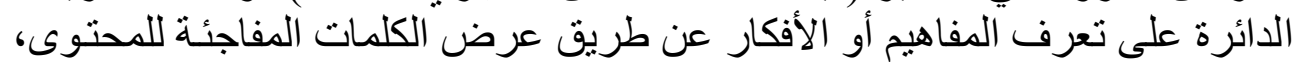

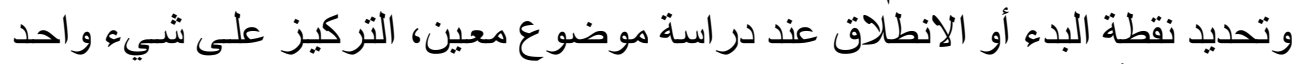
فقط لجذب أنظار الطلاب عليه.

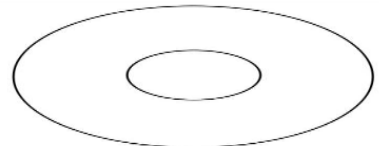

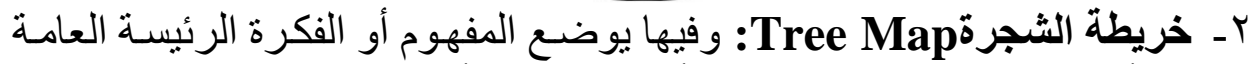

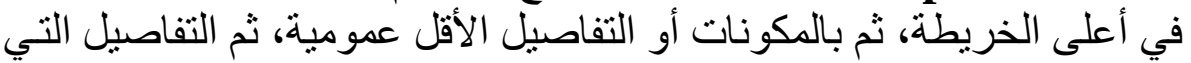

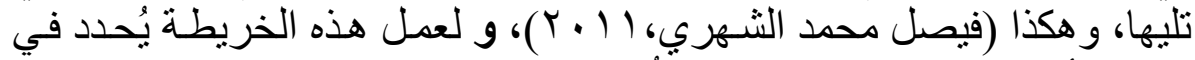

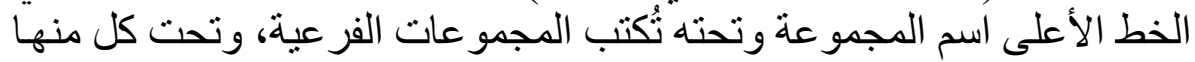

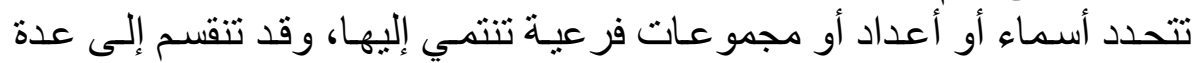

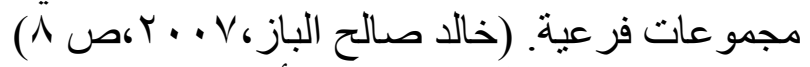

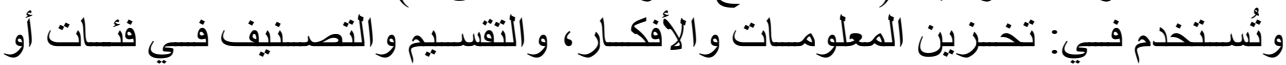

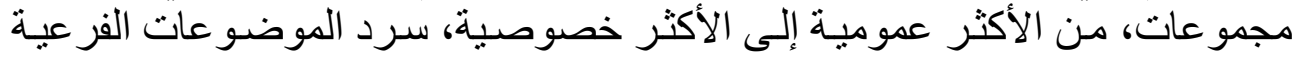

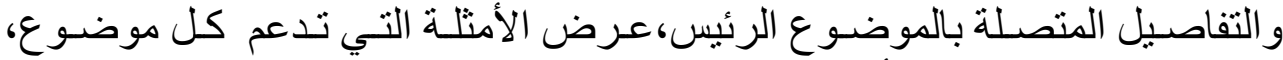

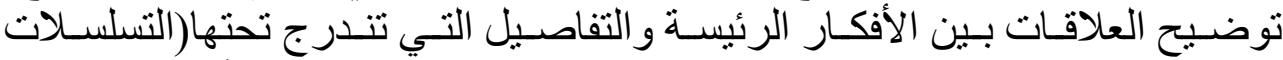

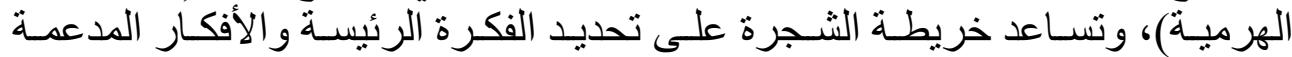

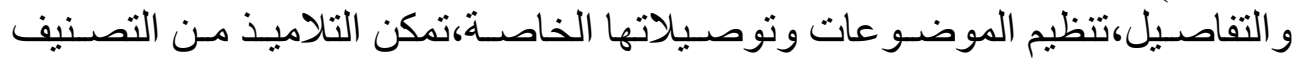

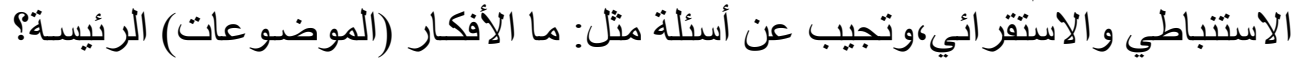

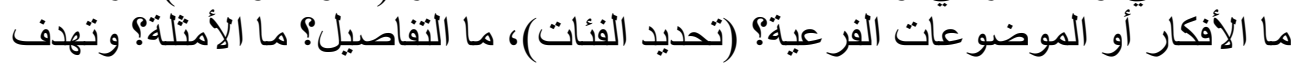

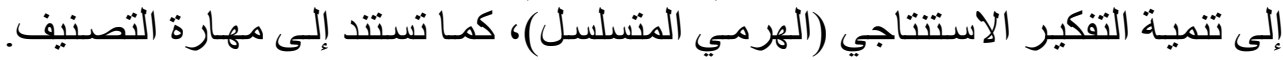

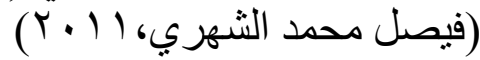




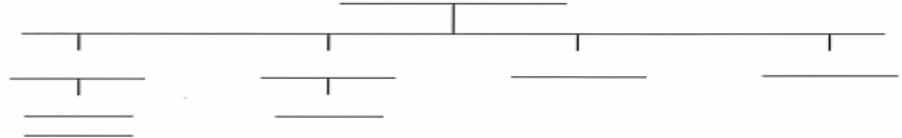

r- خريطة الفقاعةBubble Map:هي خريطة عنقودية مفتوحة النهاية، وتتكون

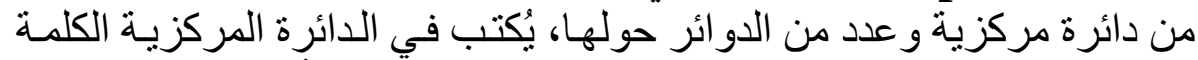

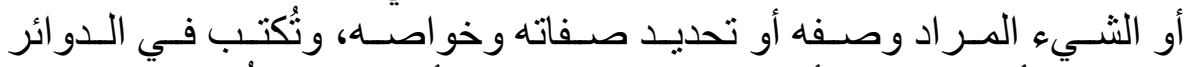

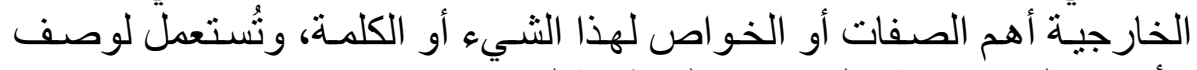

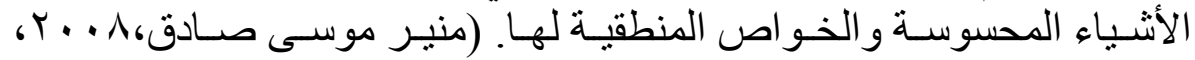

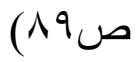

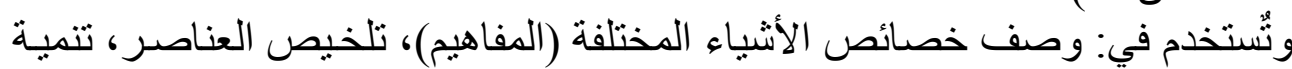

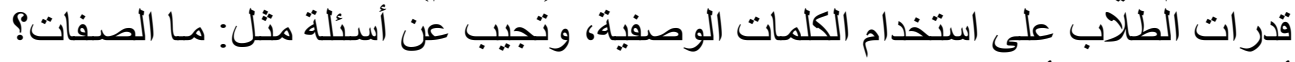

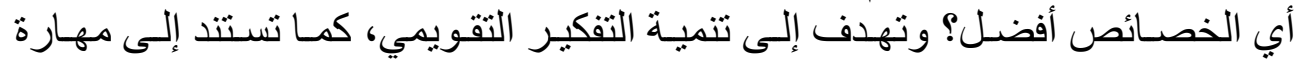

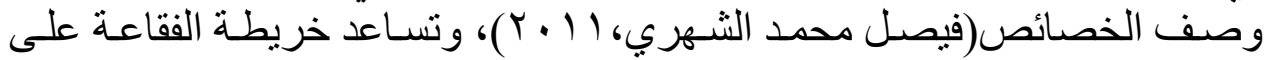

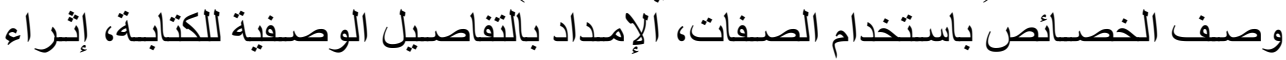
قدرات الطلاب لامتداد عملية الوصف وتحديد الخصائص.

\section{ع- خريطة الفقاعة المزدوجة Double Bubble Map: تنكون هذه الخريطة}

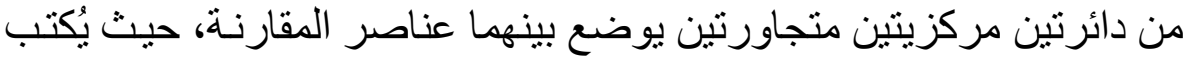

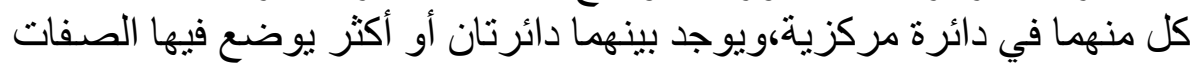

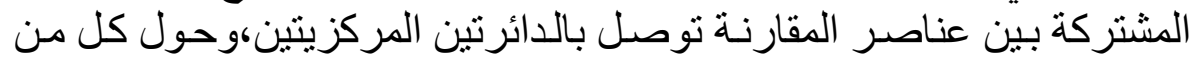

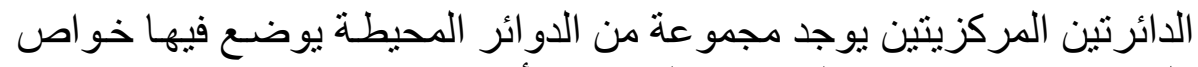

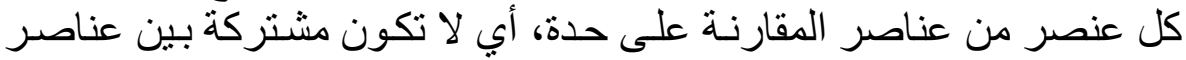

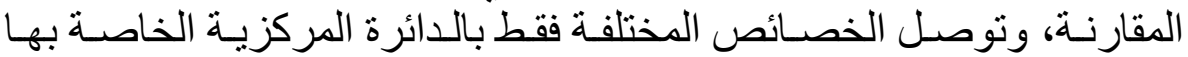

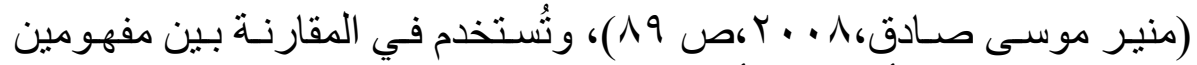

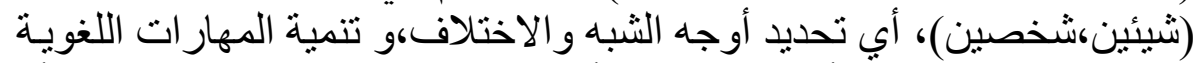

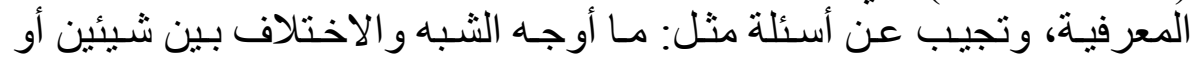

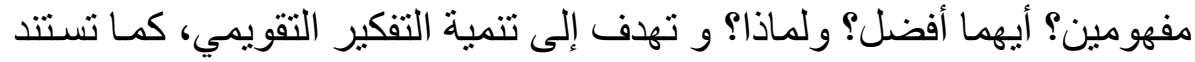

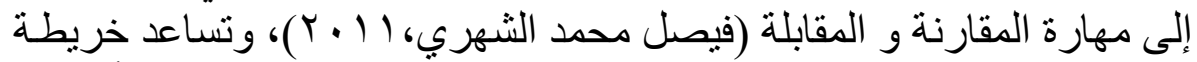

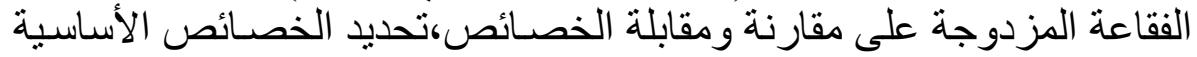
لعنصرين، تنظيم عملية المقارنة بسهولة. 


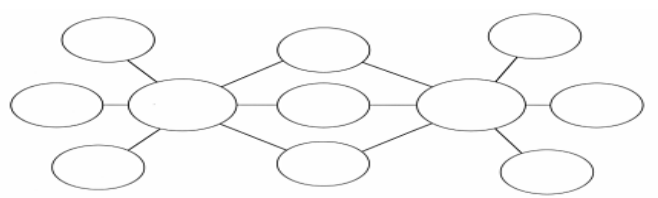

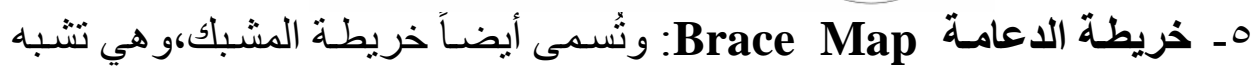

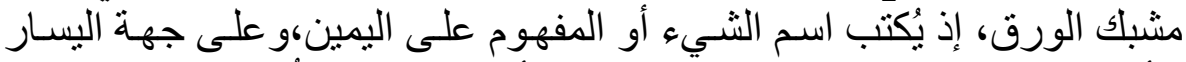

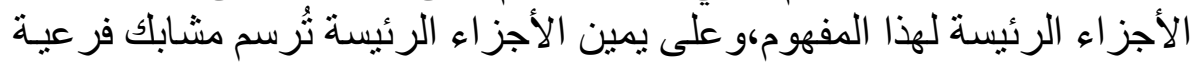

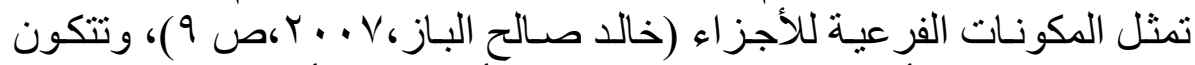

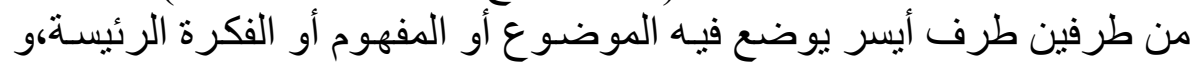

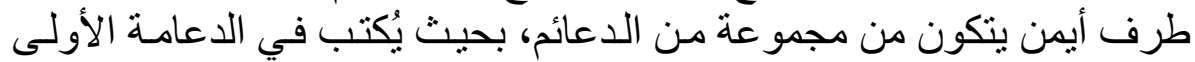

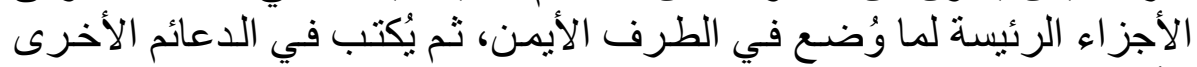

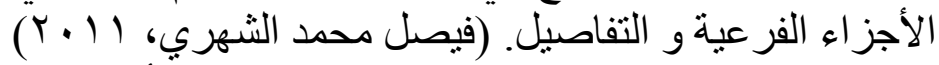

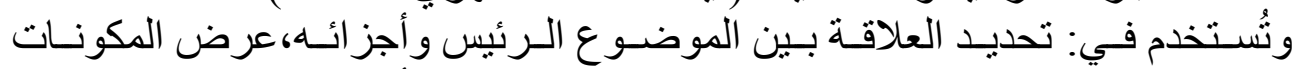

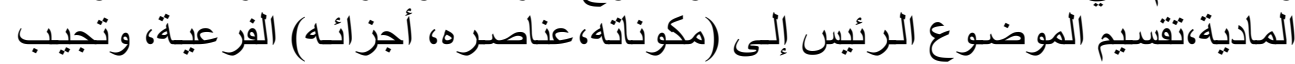

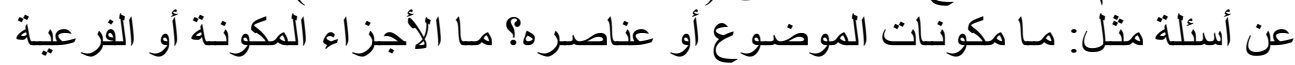

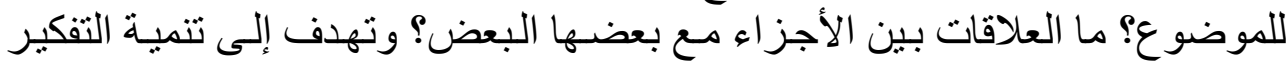

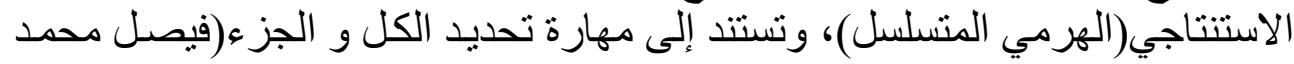

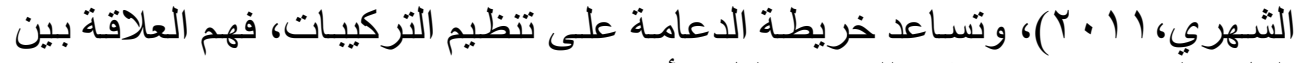

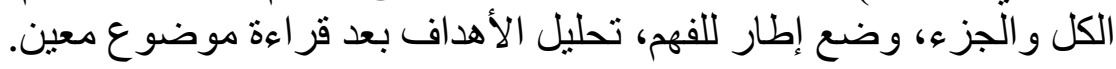

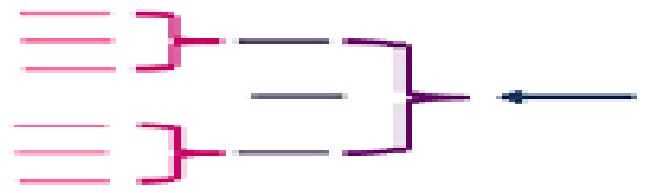

7- خريطة الجسر (القطرة)Bridge Map: تنكون خريطة الجسر من طرفين،

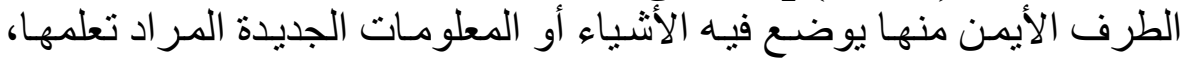

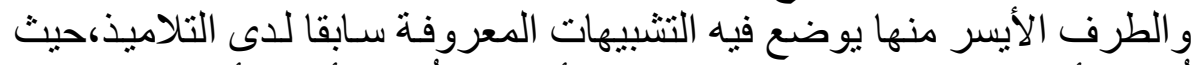

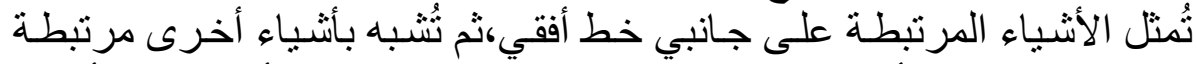

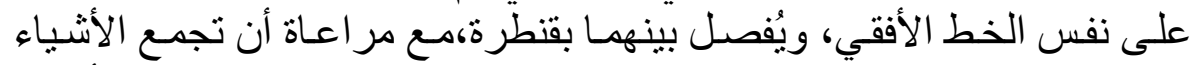

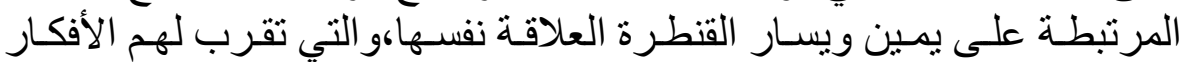

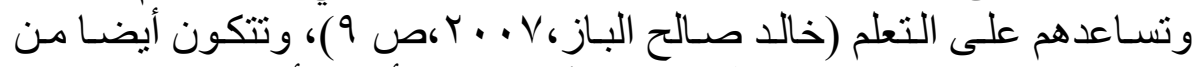

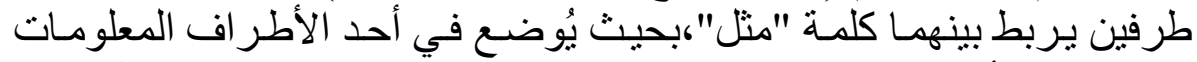

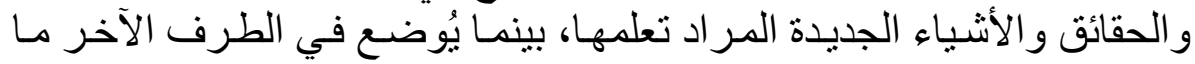




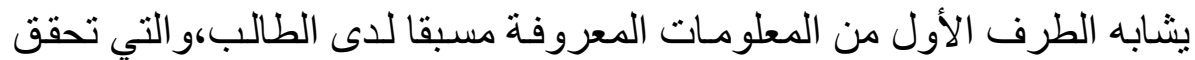

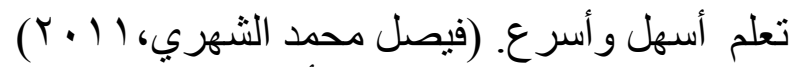

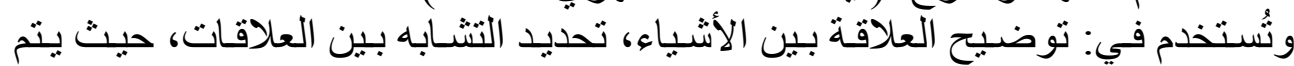

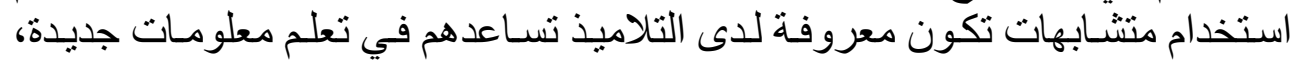

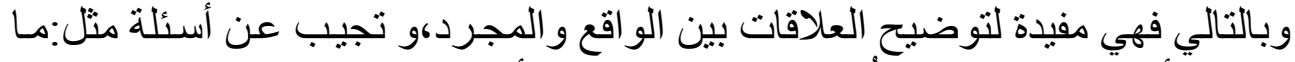

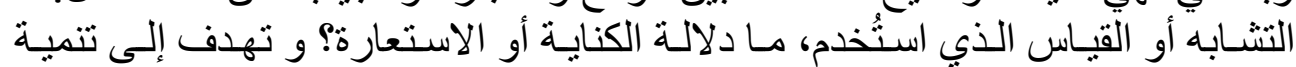

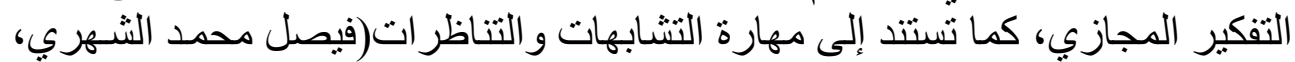

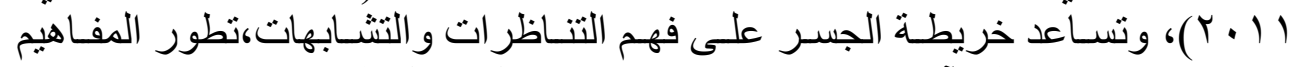

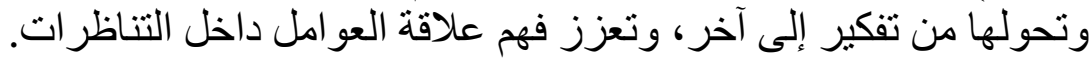

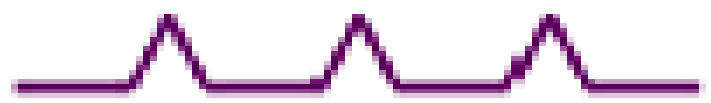

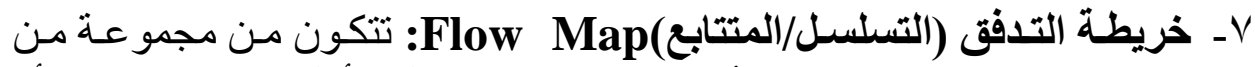

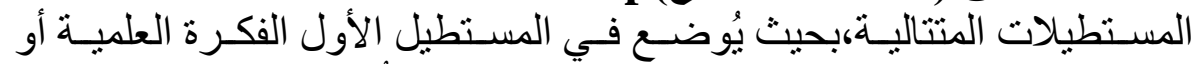

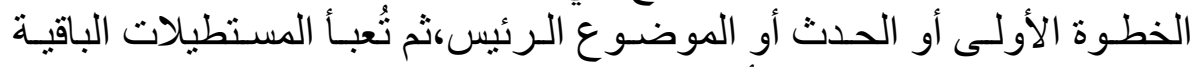

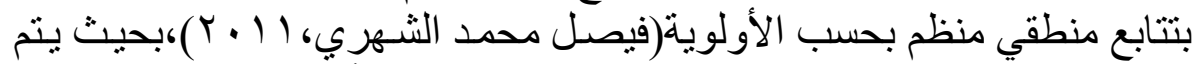

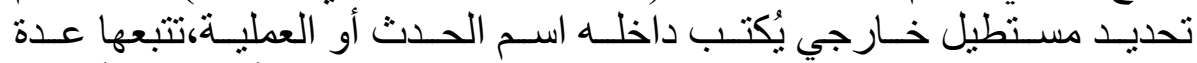

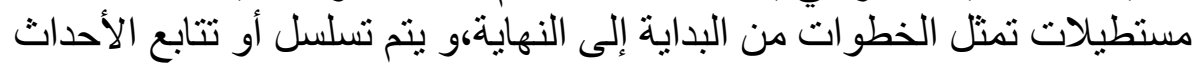

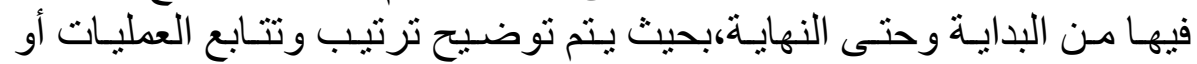

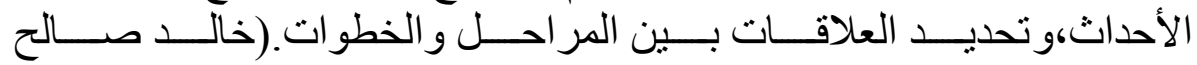

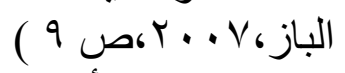

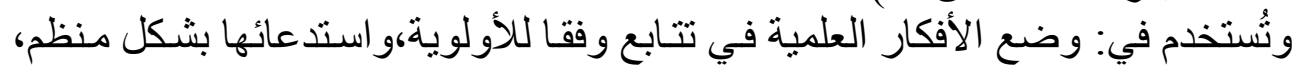

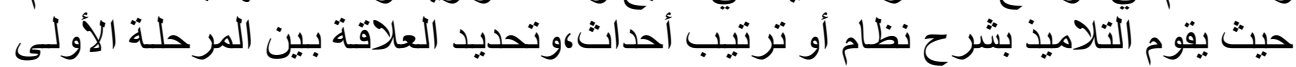

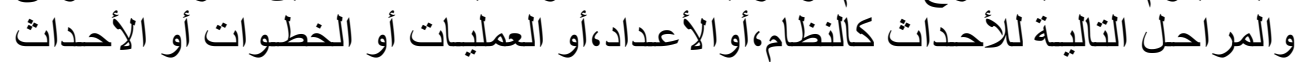

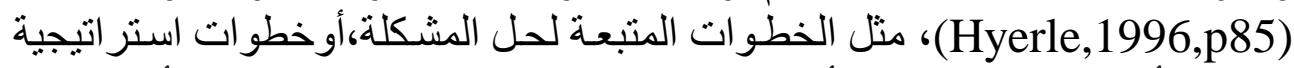

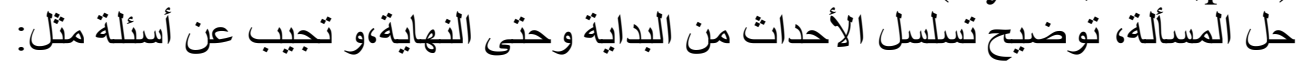

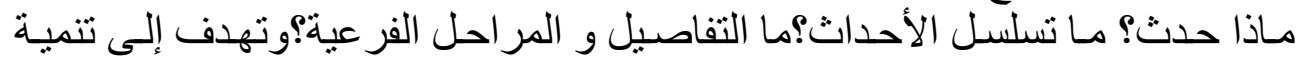

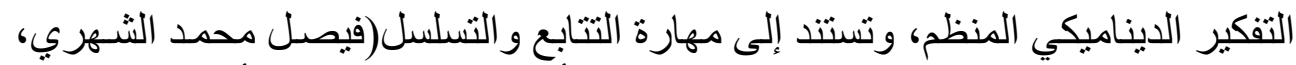

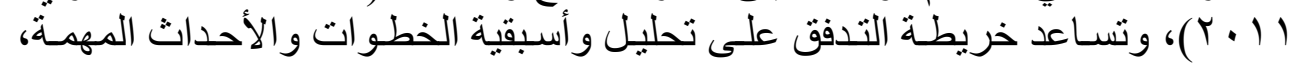

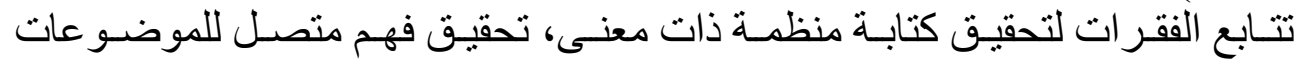
المعقدة. 


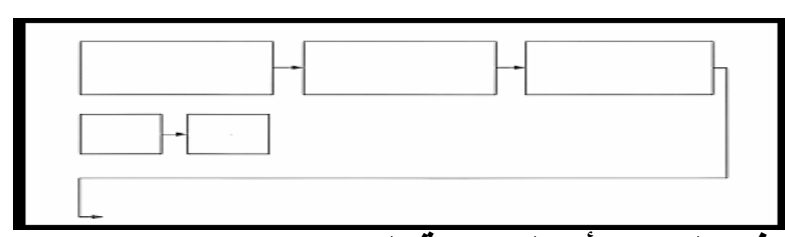

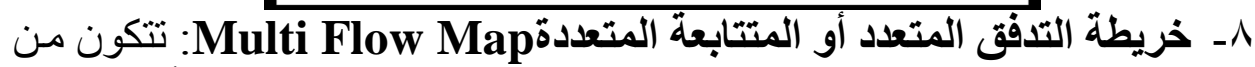

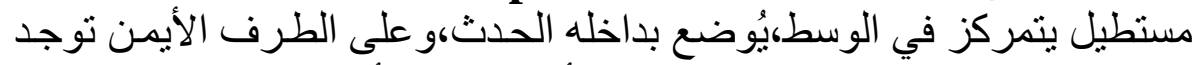

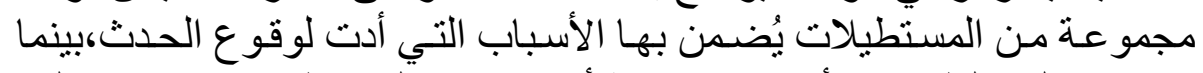

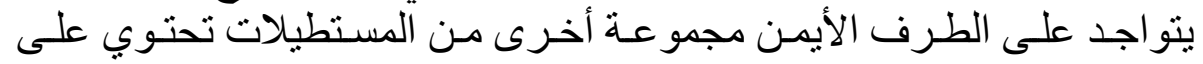

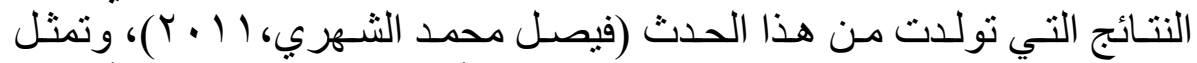
علاقات السبب والنتيجة، وتوضنح عملية تتابع الأسباب التي تؤدي إنى إلى أحداث

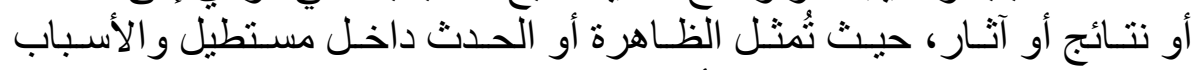

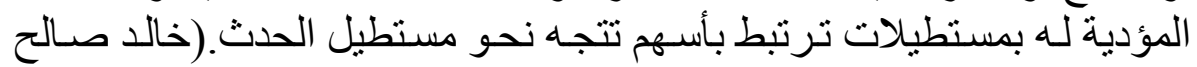

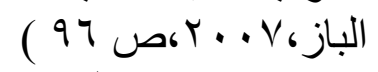

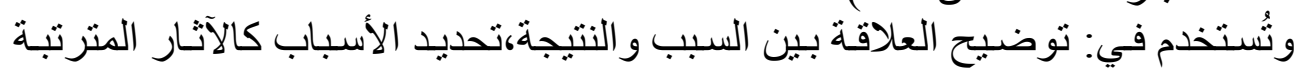

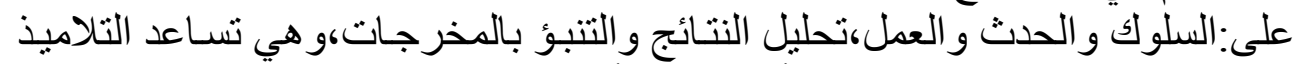

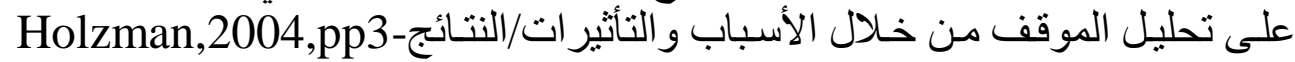

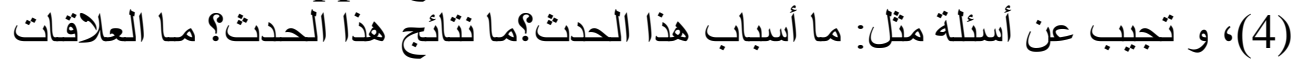

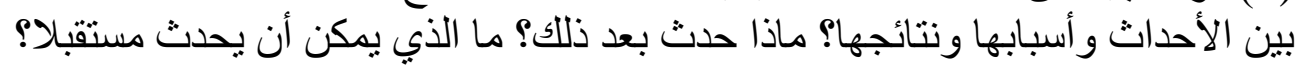

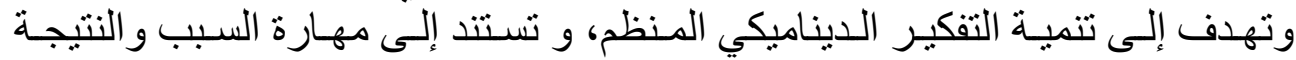

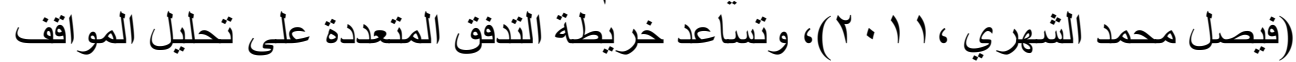

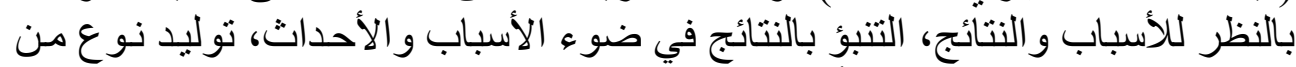

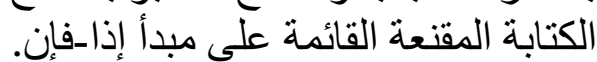

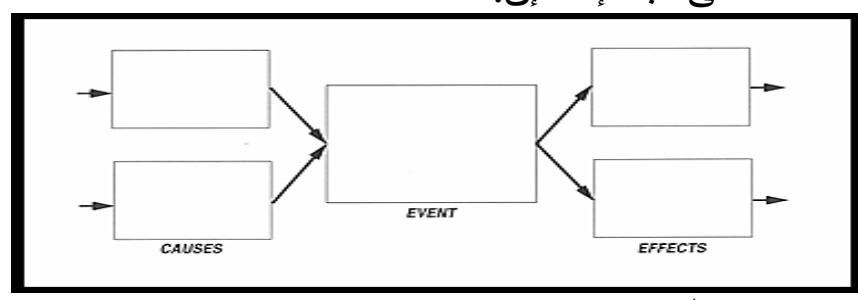

متطلبات التدريس بخرائط التفكير:

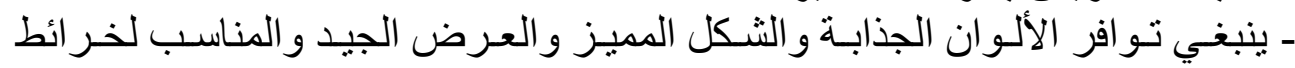

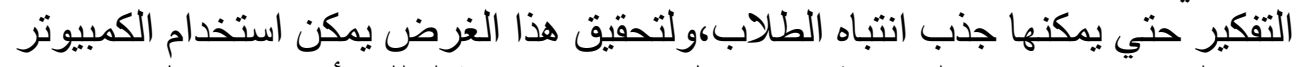

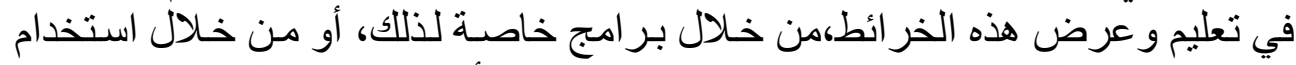

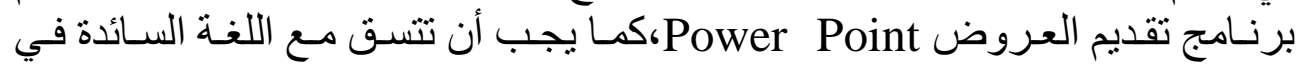


المدرسة وفي المناهج،ومن ثم سهولة فهمها،و استخدامها،وتصميمها من جانب الطلاب سو اء بشكل جماعي أو بشكل فردي.)(Thinking Maps Information,2004)

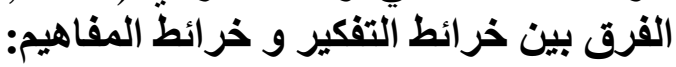

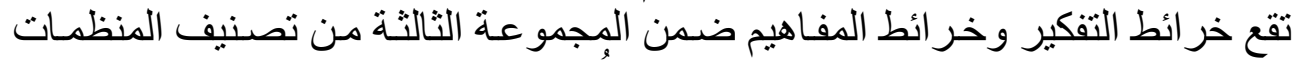

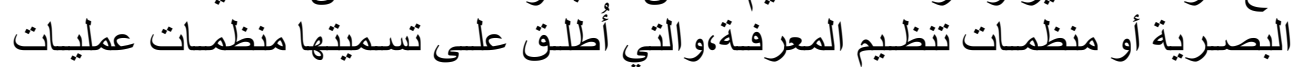

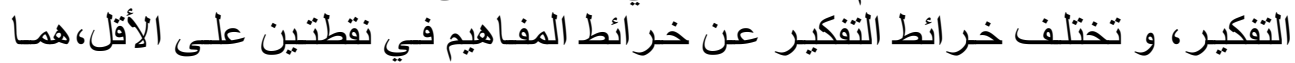

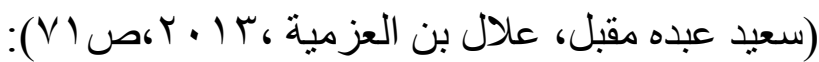

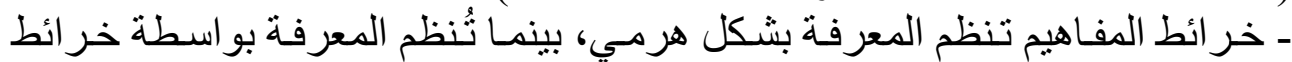
التفكير بشكل هرمي و غيط النفير هرمي. ـ تُنظ كل خريطة من خر ائط التفكير الثمانية على أساس مهارة تفكير أساسية حسب

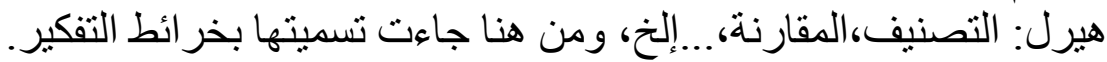
الفرق بين خرائط التفكير والمنظمات البئنة البيانية:

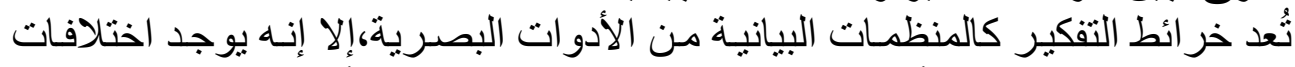

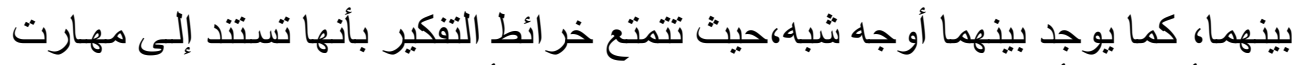

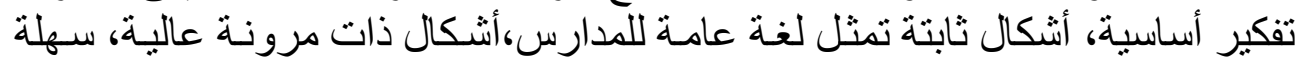

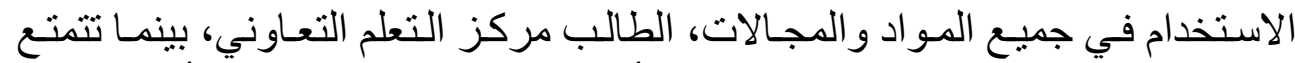

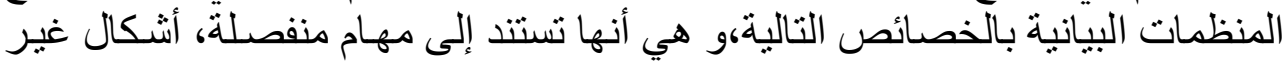

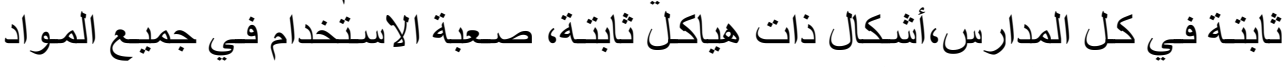

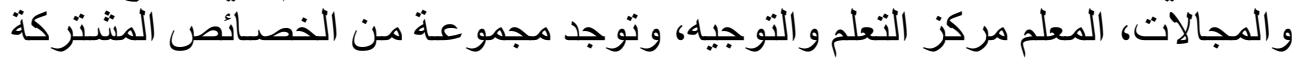

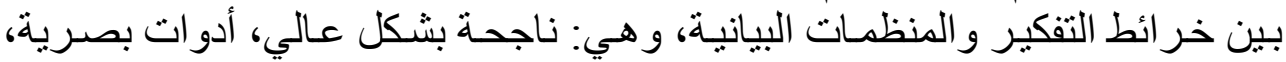

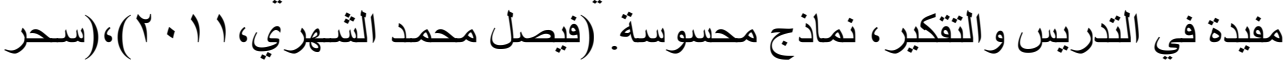

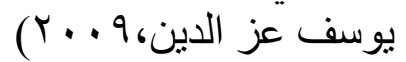
وتمثل خر ائط التفكير الجيل الثالث من أدو ات التعلم البصري، و التي بدأت بمخططات

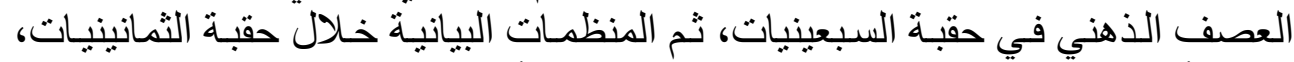

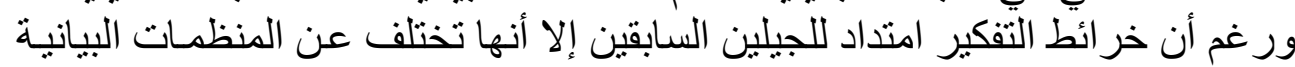

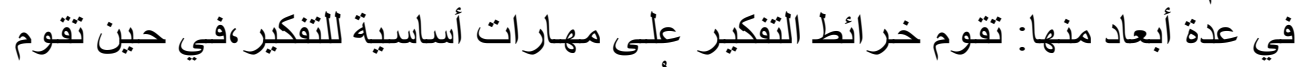

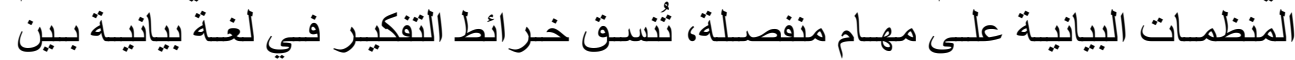

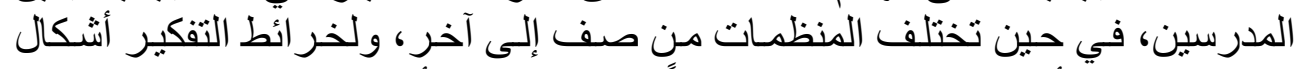

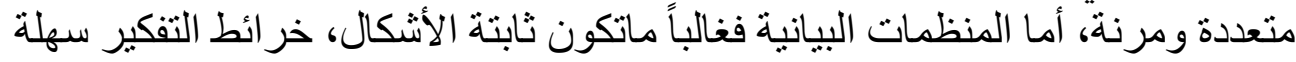

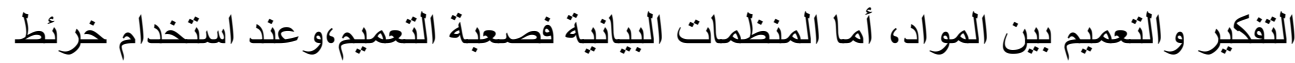

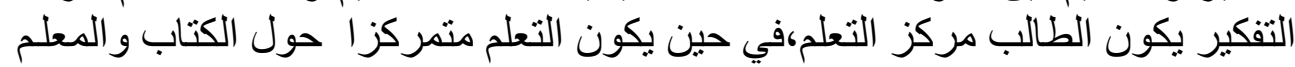

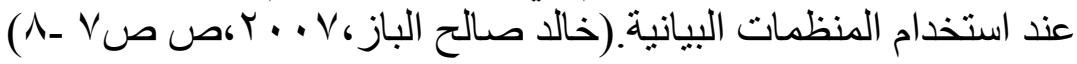


حالات المتعلم عند استخدام خرائط التفكير:

يمر المتعلم عند استخدامه لخر ائط التفكير بمر احل هل هي: (Hyerle,2000,p104)

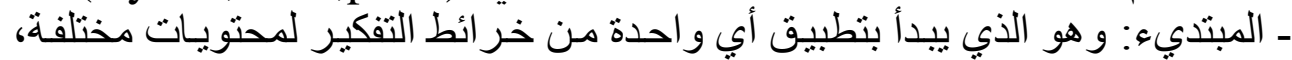

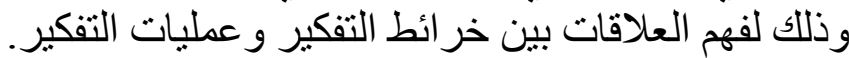

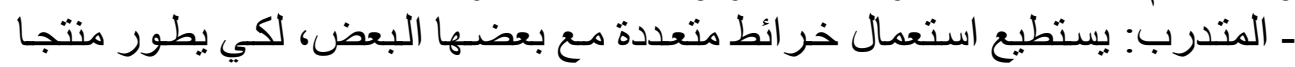

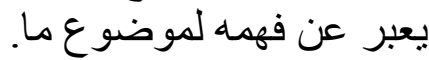
ـ الممارس: ويكون قادرا على اختيار الخر ائط بحريـة، وتطبيق الخر ائط بطلاقة في مجمو عات تعاونية. ـ الخبير: ويكون قادر ا على استخدام الخرائط بحرية، وقادرا على التخطيط وتقييم

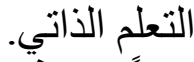
ثual Situated (DSLM) ثانياً: نموذج التعلم القائم على المواقف المزدوجة :Learning Model نموذج التعلم القائم على المواقف المزدوجة يعني أن التعلم المفاهيمي للطلاب يجعلهم

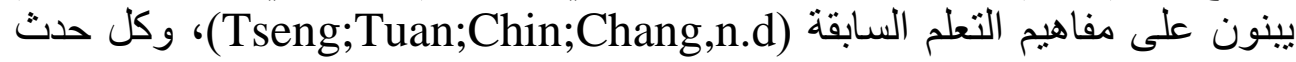

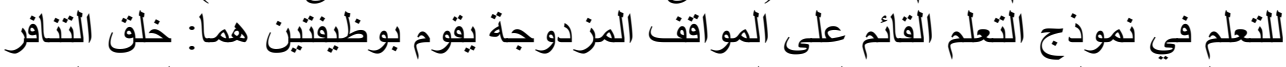

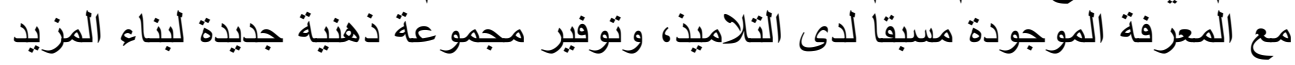

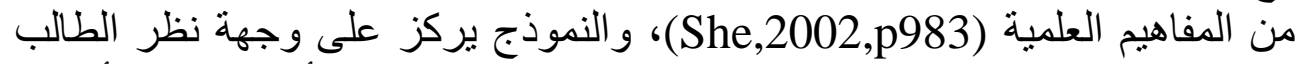
حول المفهوم، وخصائص ذلك المفهوم، مع الاستفادة من هذا كأسس لتطور النس أحداث

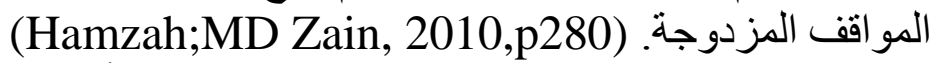
ولقد طورت (She,2001) نموذج التعلم المزدوج من أجل التغير المفـاهيمي، ويستند

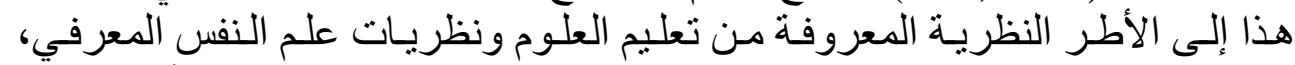

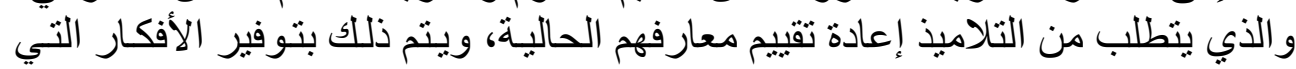

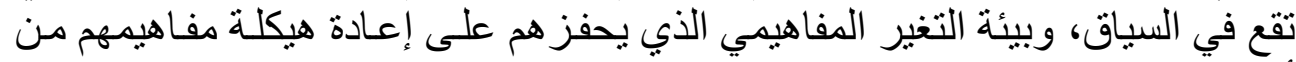
أجل تغيير ها.

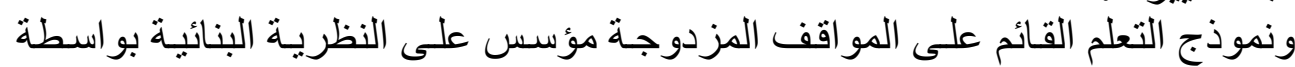

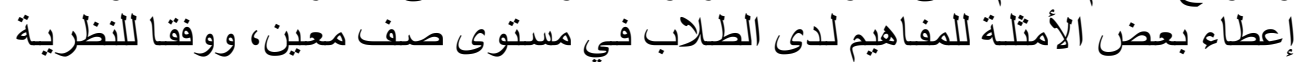

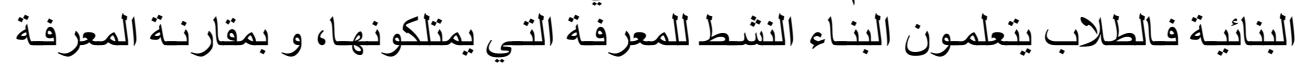

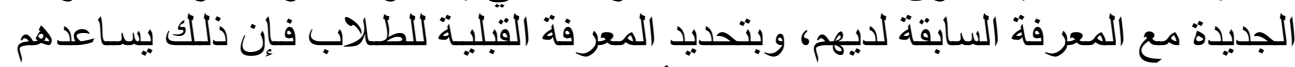

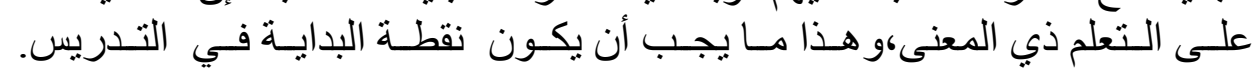
(Akpinar;Ergin,2007,p390) وقد وضع نموذج التعلم القائم على المو اقف المزدوجة مصطلح "التعلم القائم"، ويعني

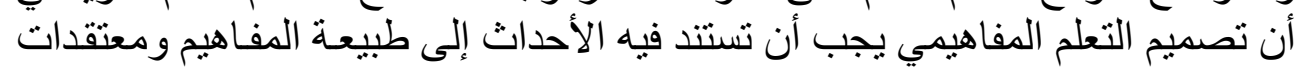


الطلاب للمفاهيم، من أجل تحديد ما العقلية الأسـاسية اللازمـة لبنـاء نظرة أكثر علميـة

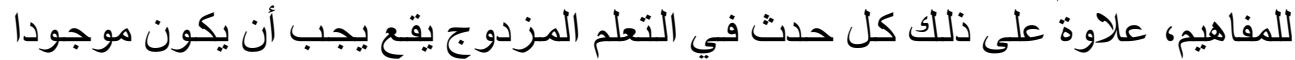

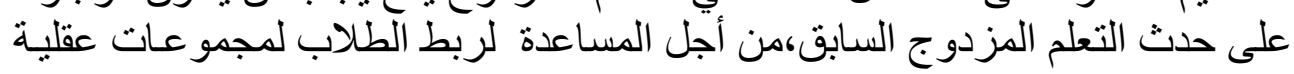

مختلفة. (She,2002)

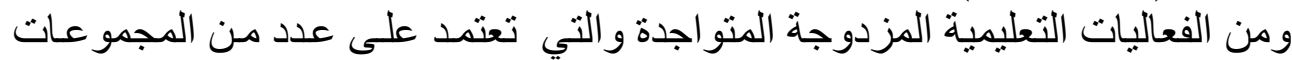

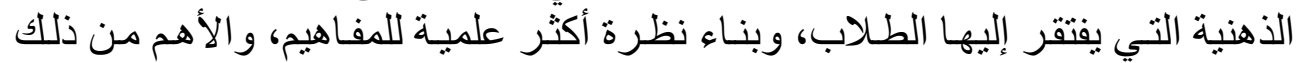

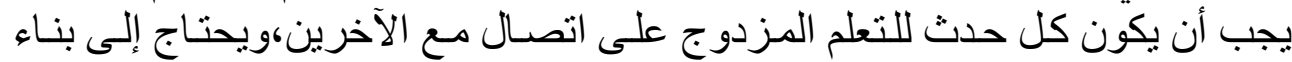
أحداث التعلم المزدوجة السابقة من أجل تنفيذ هذه النظرية. (Liao;She,2009)

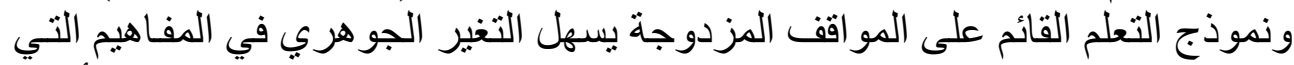

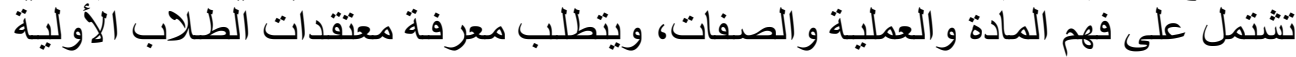

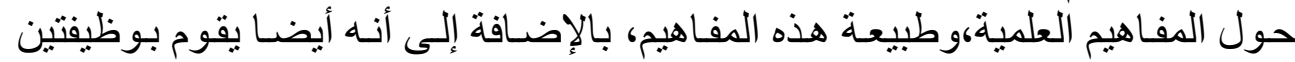

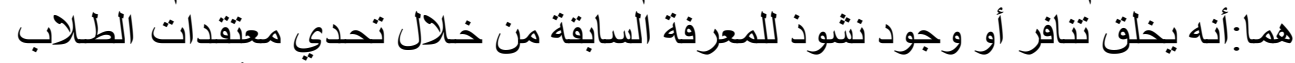

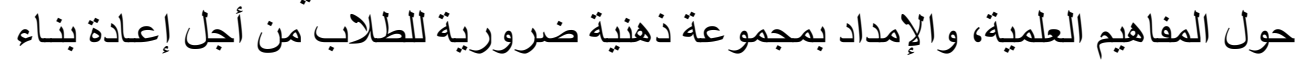

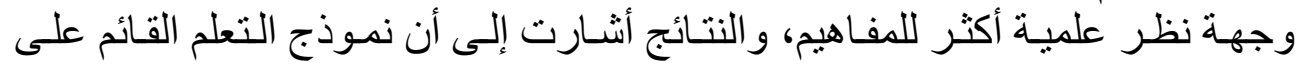

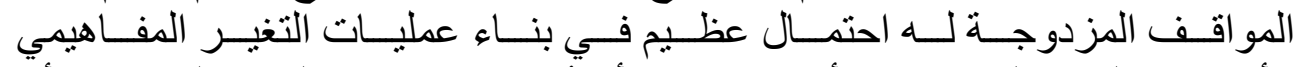

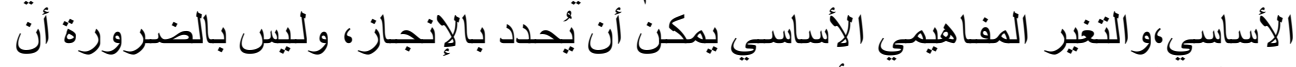
يشتمل على العمليات البطيئة أو التدريجية. الأينية

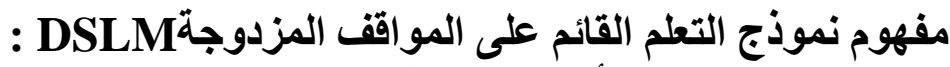

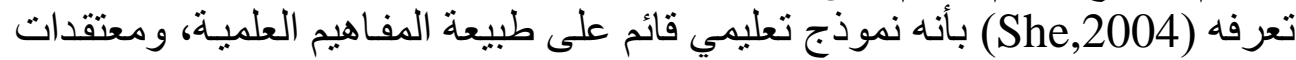

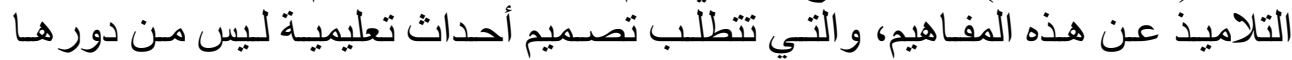

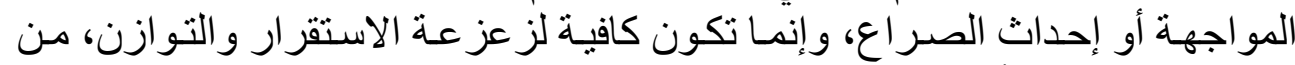

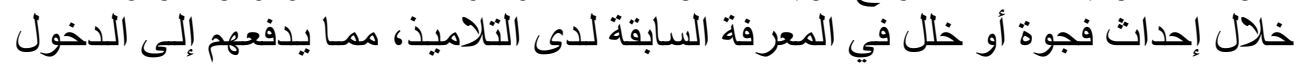

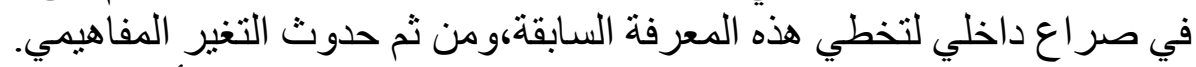

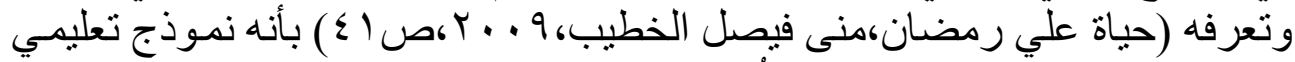

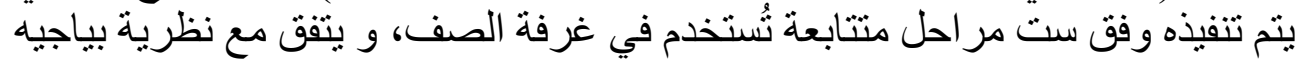

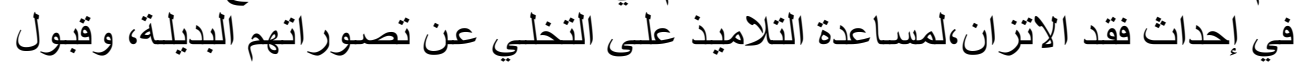

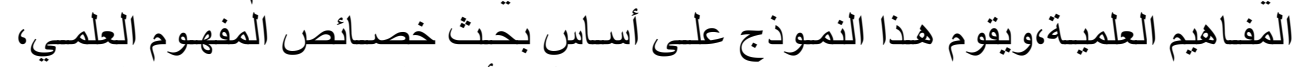

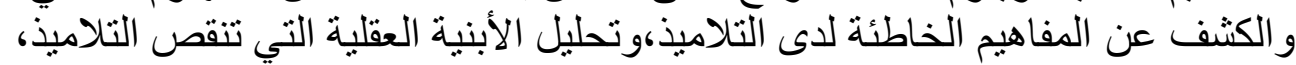

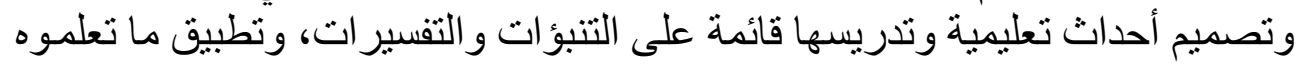
في مو اقف جديدة تؤكد حدوث عملية التغير المفاهيمي. 


\section{القلسفة التي يقوم عليها نموذج التعلم القائم على المواقف المزدوجة:}

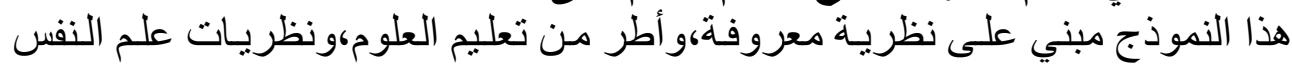

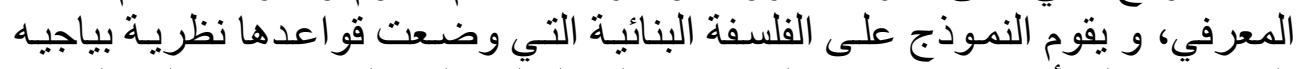

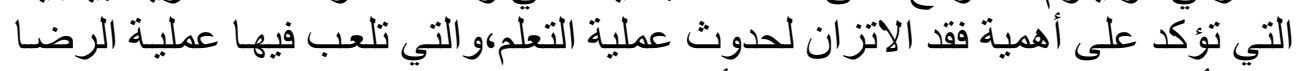

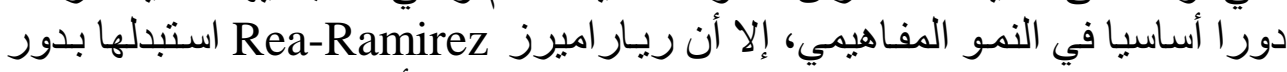

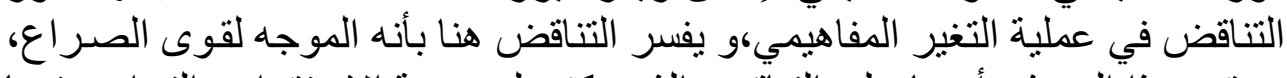

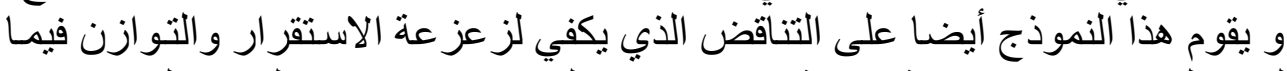

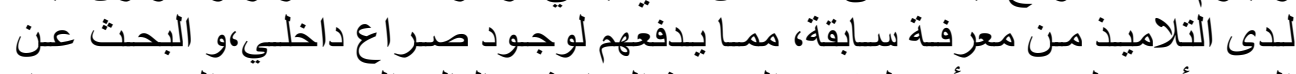

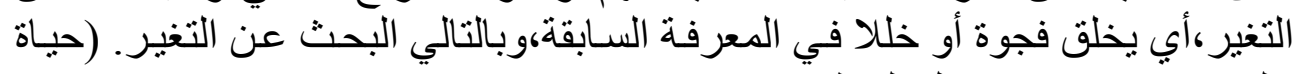

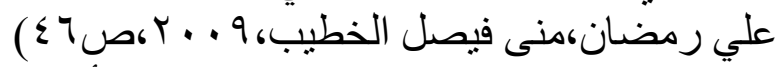
ويمكن إيجاد تفسير بديل لماذا بعض فيل المفاهيم أكثر صعوبة في التهي التغيير من غير ها،فهذه

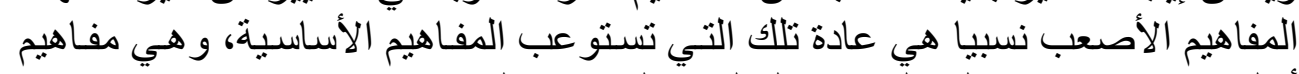

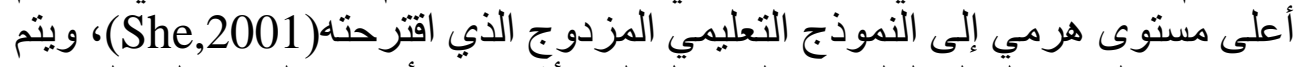

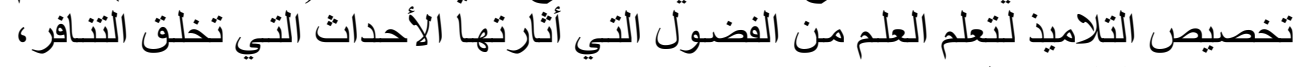
وتقديم مخطط جديد لهم.

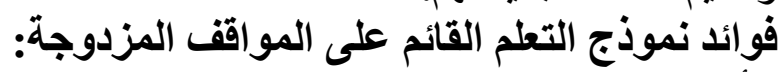

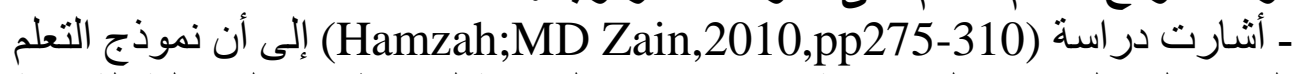

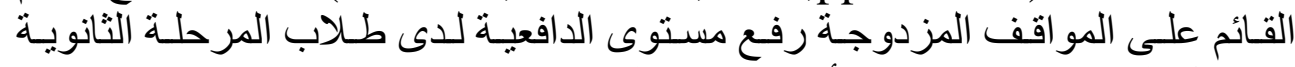

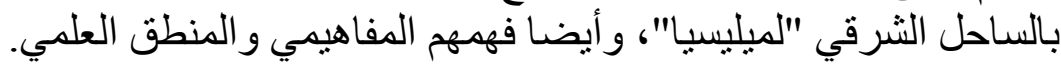

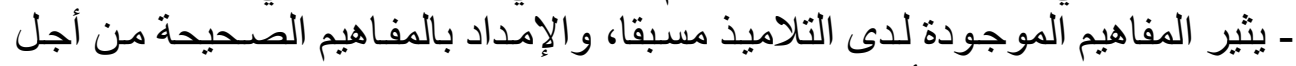

التغير المفاهيمي" الو اقع أو الكائن"(Tseng;Tuan;Chin;Chang,n.d)

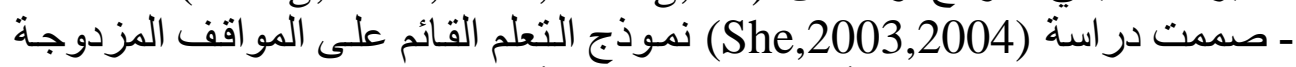

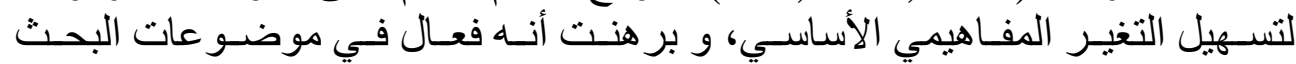

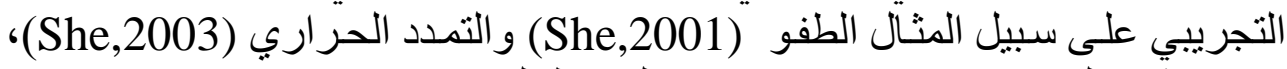
وفي انتشار الحرارة (She,2004) و في الضغط الجوي(She,2001) (She).

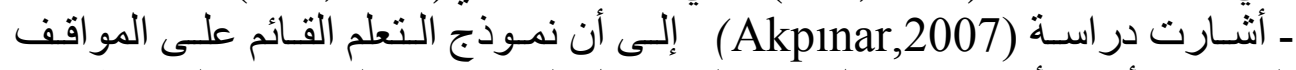

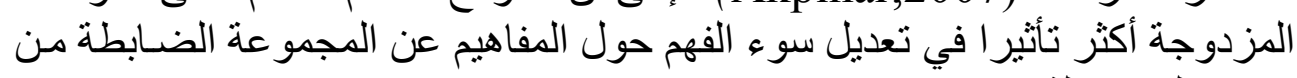

تلاميذ الصف الثامن بتركيا. ـ در اسة (Tseng;Tuan;Chin;Chang,n.d) أثبتت فعالية نموذج التعلم القائم على الثى المو اقف المزدوجة و المتعلق بالعلاقة بين دافعية الطلاب و التغير المفاهيمي. 


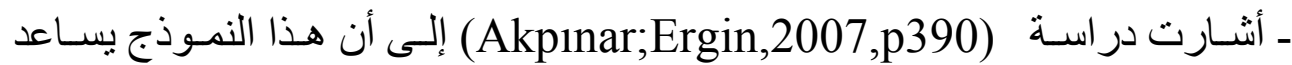

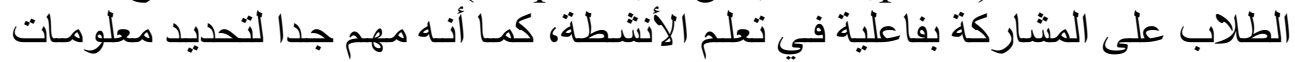

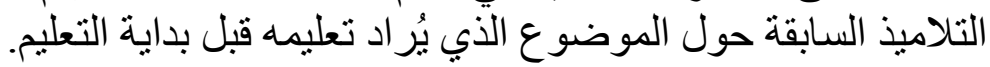

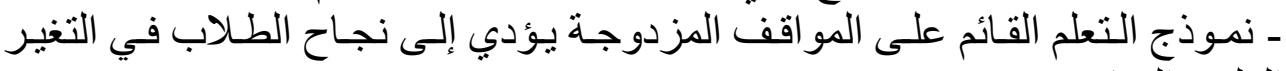
العلمي المفاهيمي. ـ نموذّج التعلم القائم على المو اقف المزدوجة يمكن أن يسهل التغير الأساسي للمفاهيم

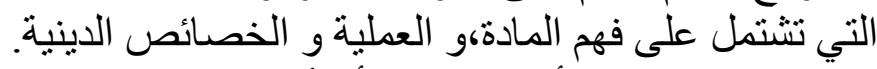

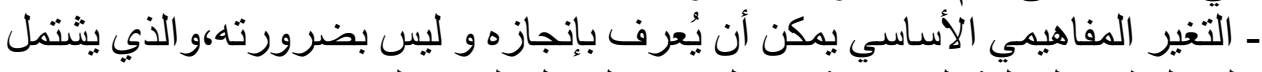

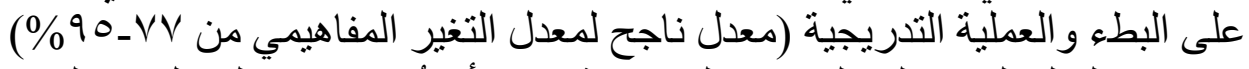

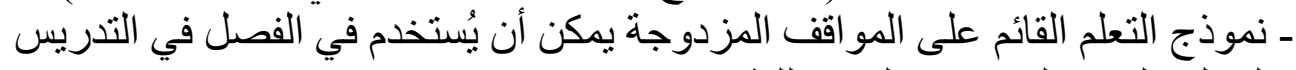

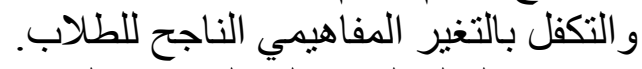

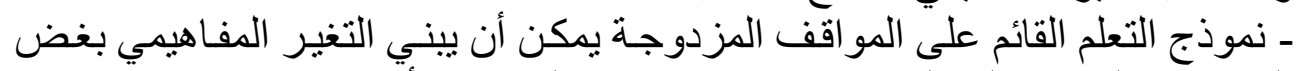

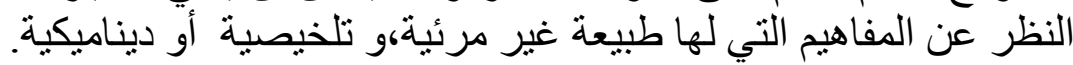

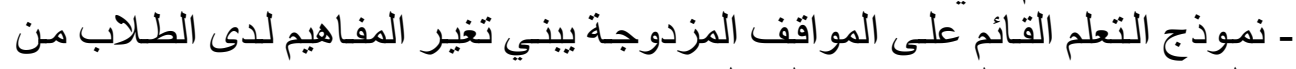
خلال استخدامه في التندريس في الفصل.

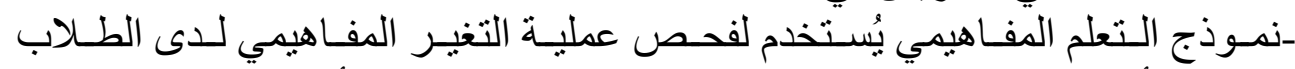

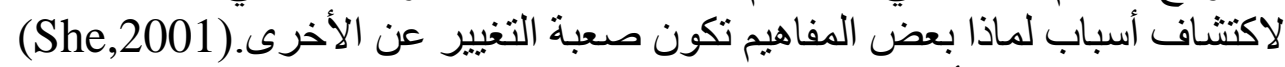

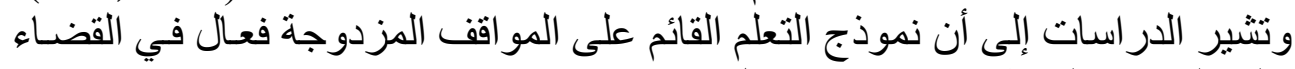

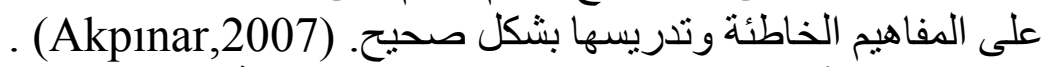

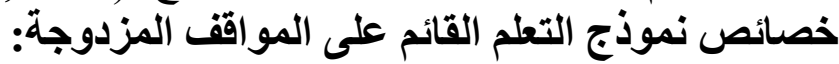

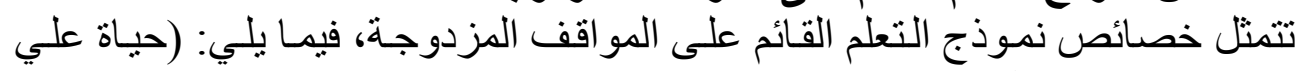

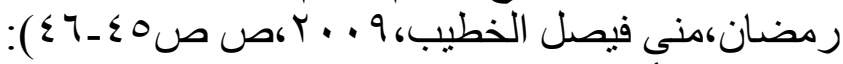

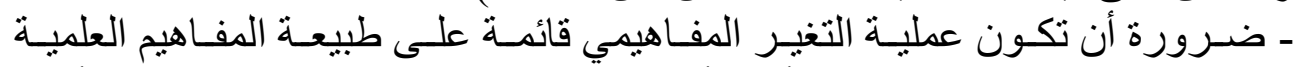

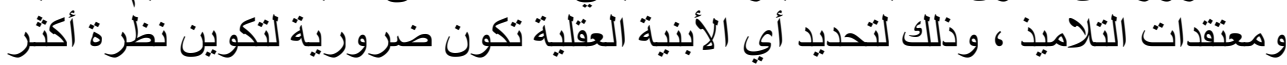

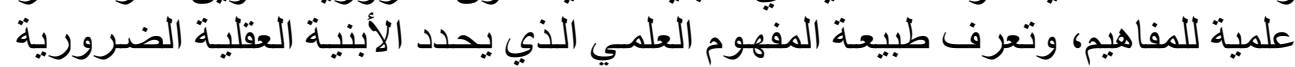

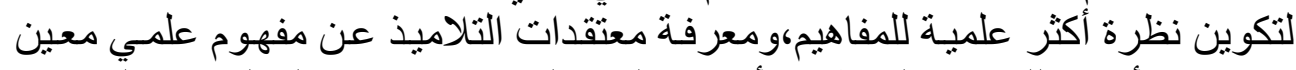

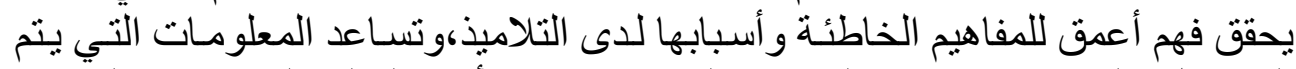

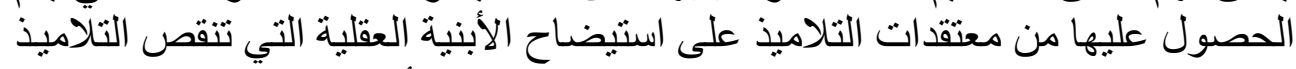

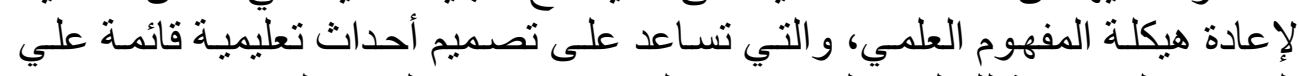

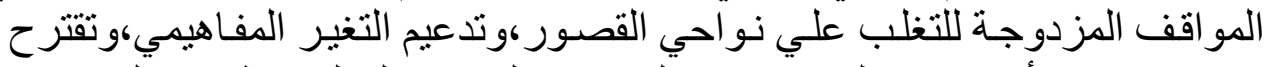

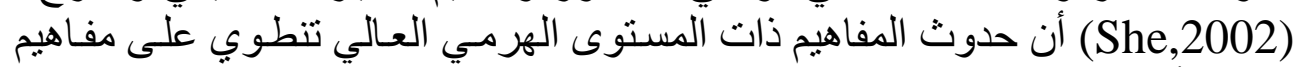

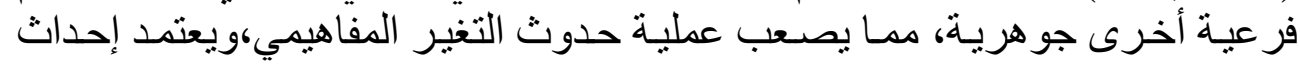


التعلم القـائم على المواقف المزدوجـة على عدد الأبنيـة العقليـة التي تـنقص التلاميذ

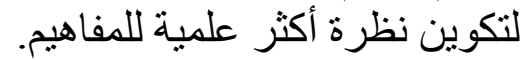

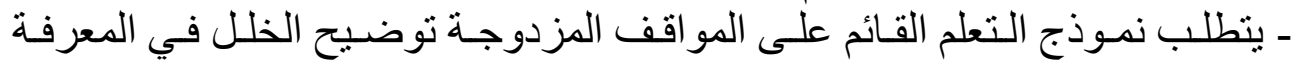

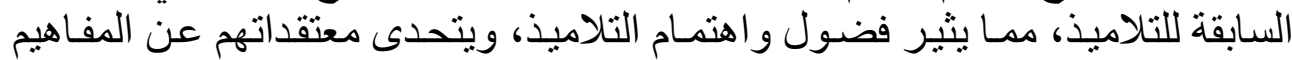

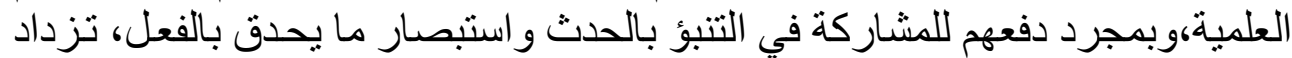

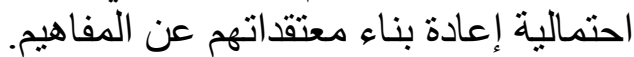

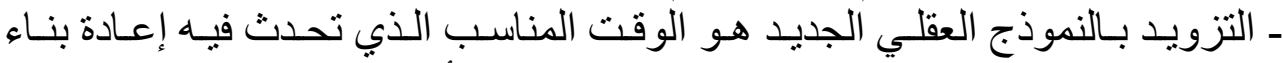

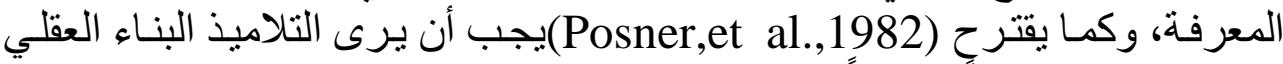

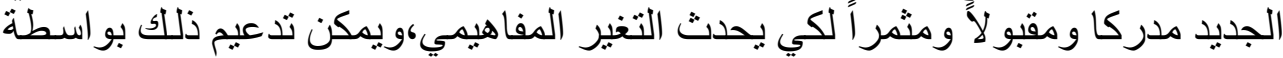

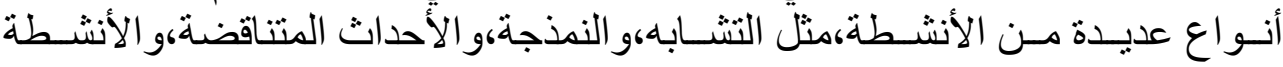
الاستقصائية.

الأنثطة التعليمية المناسبة للتدريس بنموذج التعلم القائم على المواقف المزدوجة:

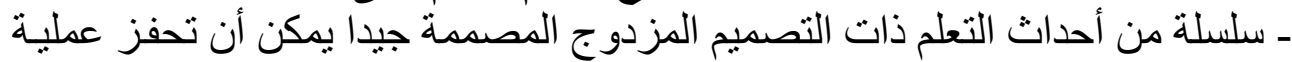

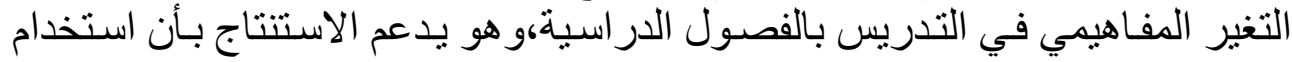

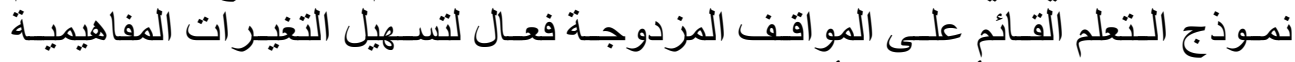

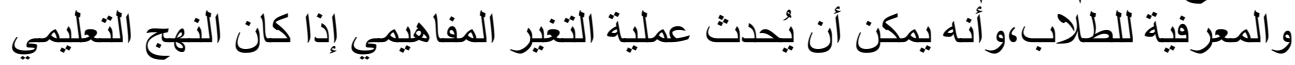
مدعوما بنماذج تعليمية منطورة. (She;Liao,2010)

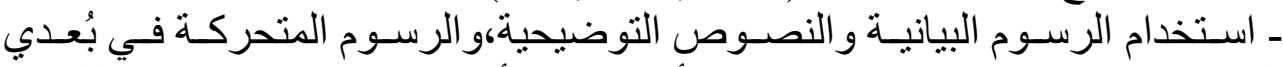

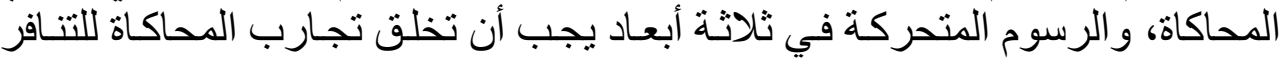

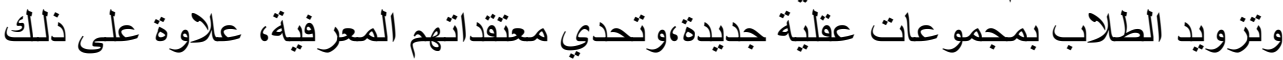

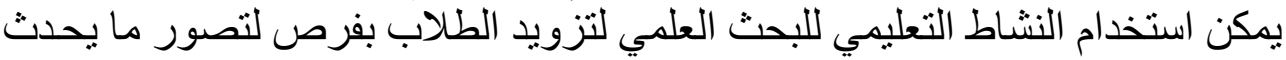

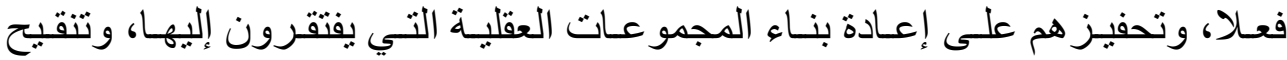

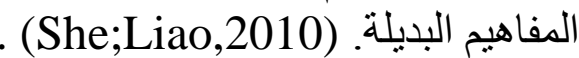

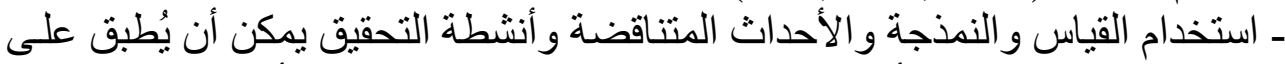

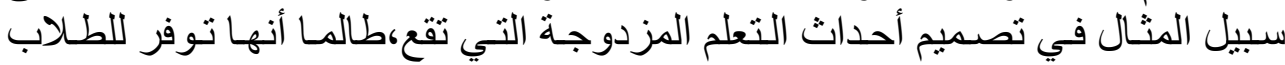

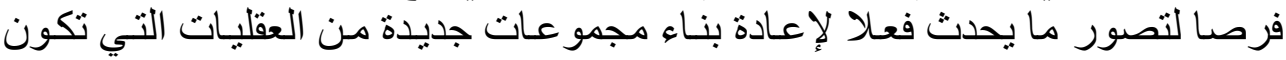

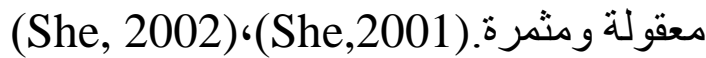

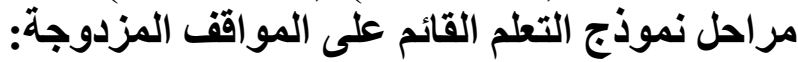

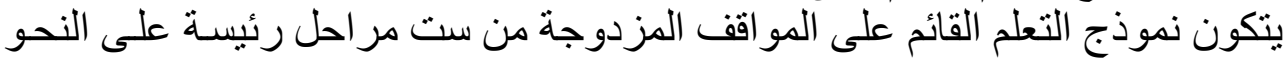

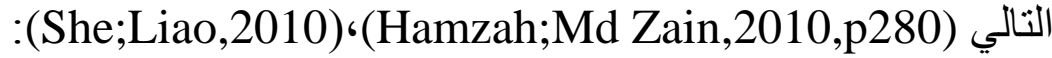

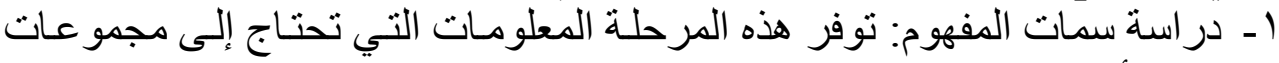
عقلية أساسية لبناء نظرة علمية عن المفهوم. 


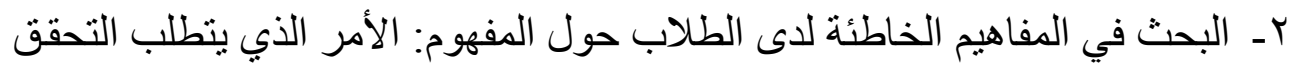

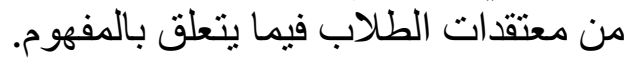

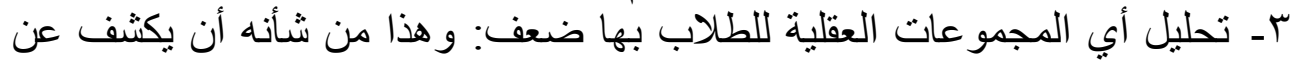

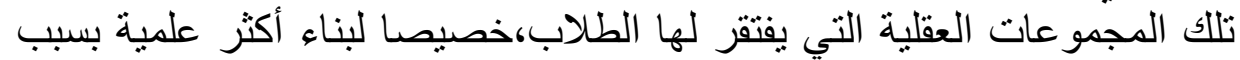

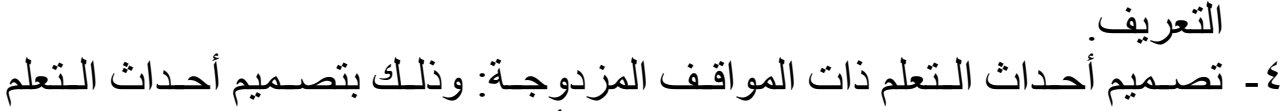

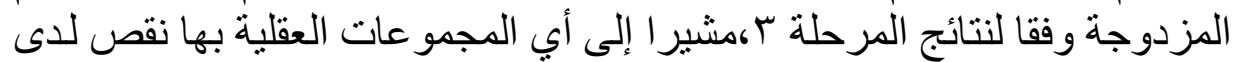

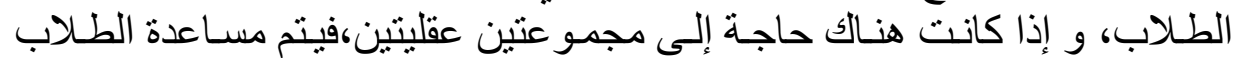

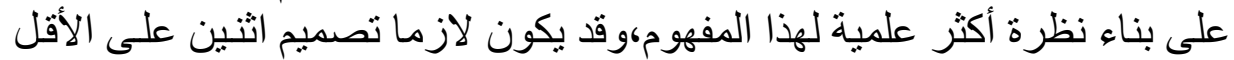

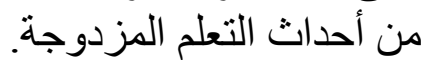

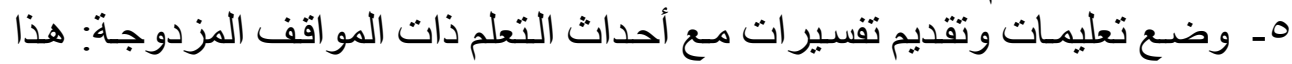

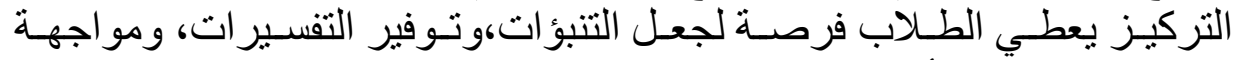

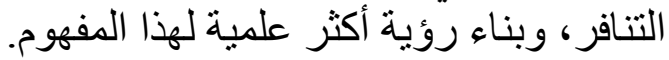

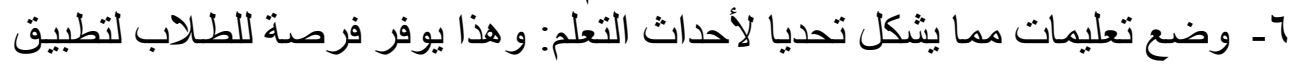

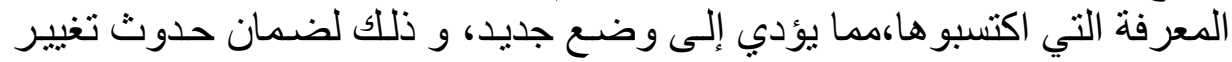
مفاهيمي ناجح. كما أن هنالك ست مر احل رئيسة لنموذج التعلم القائم على المواقف المزدوجة، هي:

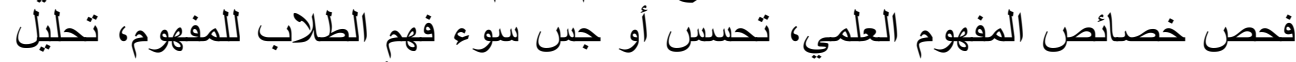

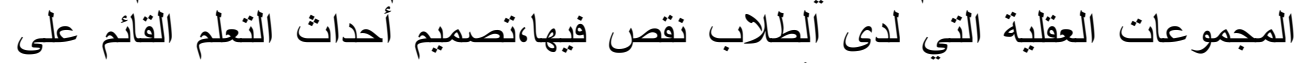

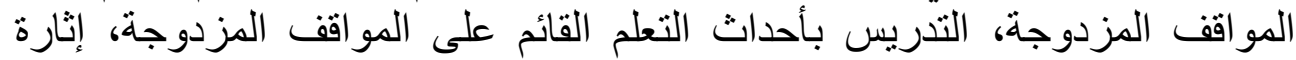

التحدي لأحداث التعلم الموقفي. (Tseng;Tuan;Chin;Chang,n.d) كما أن نموذج التعلم القائم على المواقف الفق المزدوجة مكون من ست مر احل أساسية (Hamzah;MD Zain,2010,p280) (She,2002,pp483-486) 1 ـ فحص خصائص المفهوم العلمي: هذه المرحلة تمد بالمعلومات حول الأوضاع

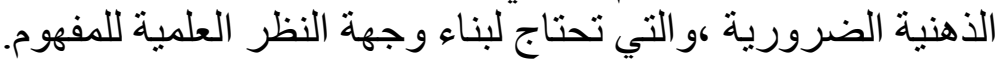

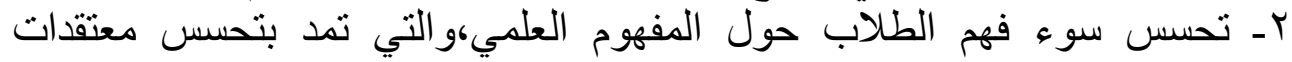

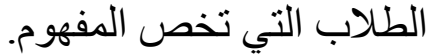

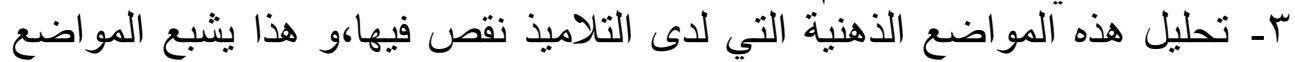

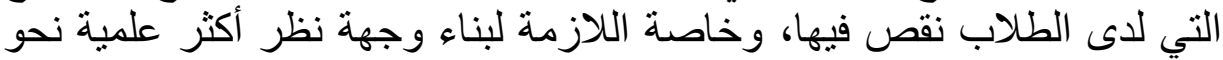

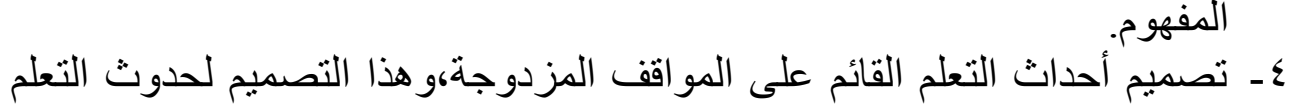

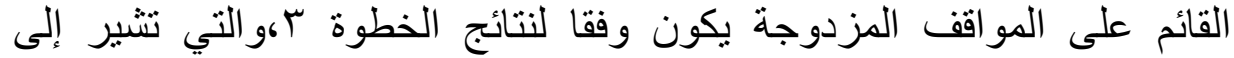




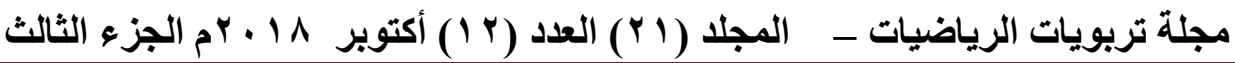

المواضع الذهنية التي لدى الطلاب نقص فيهاهو إذا كان هناك موضعان ذهنيان

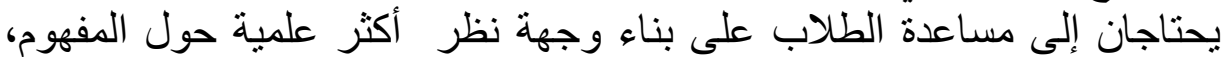

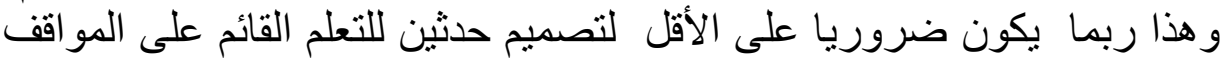
المزدوجة.

0ـ التدريس مع أحداث التعلم القائم على المواقف المزدوجة، هذا يركز على إعطاء

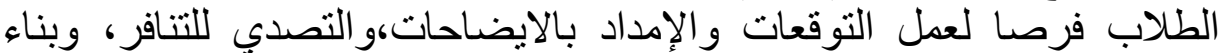

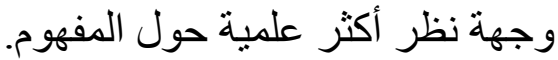

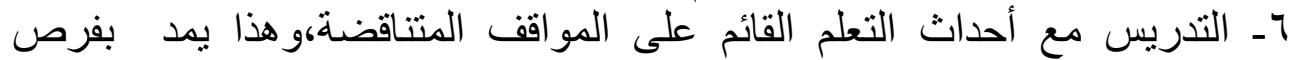

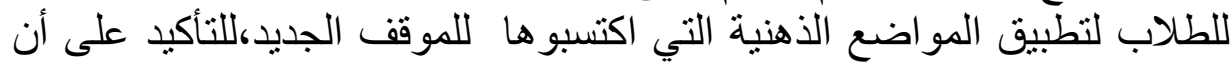
التغير المفاهيمي الناجح قد حدث.
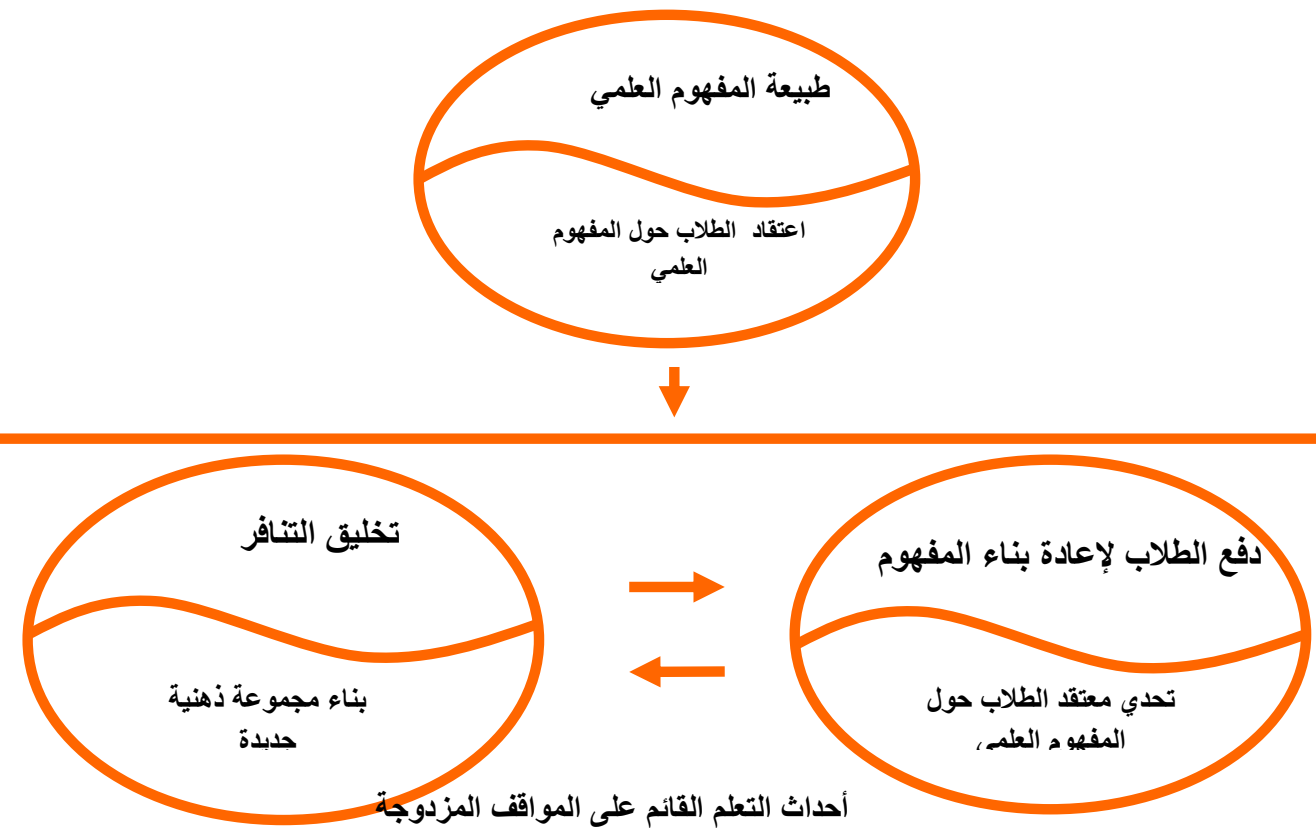

شكل () تركيب نموذج التعلم القائم على المواقف المزدوجة 


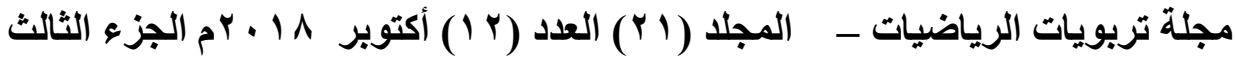

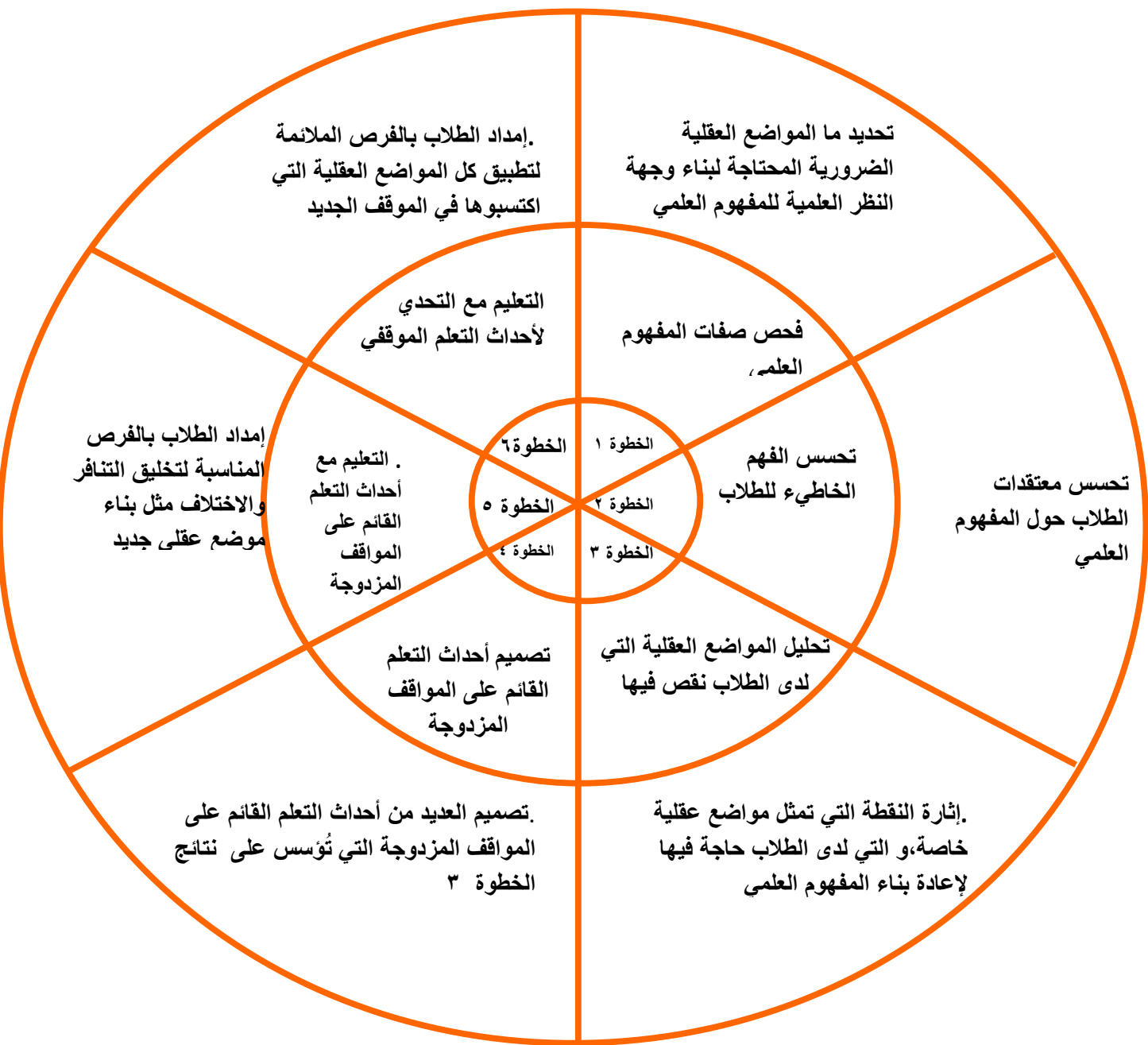

شكل (؛ ) خطوات نموذج التعلم القائم على المواقف المزدوجة

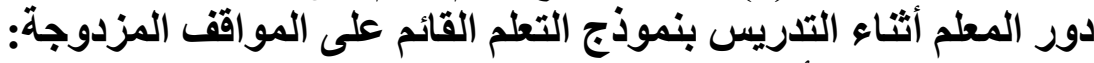

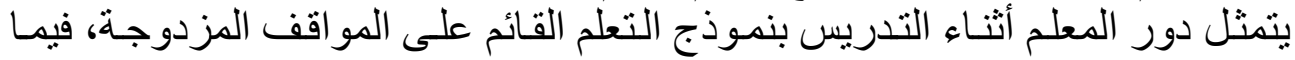
(Jessica; Jeffrey,2005,p3)

ـ تزويد التلاميذ بأسئلة وأحداث معينة، ويطلب منهم الكتابة أو التعبير عن أفكار هم من منظور هم المعرفي. 


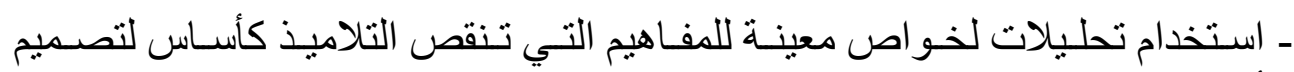

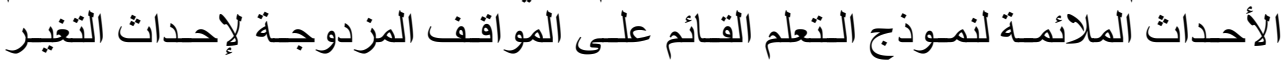
المفاهيمي. ـ التدخل باستمر ار مع التلاميذ، وطلب منهم التعبير بالكتابـة أو الرسم عن معتقداتهم قبل وبعد كل حدث. ـ تجهيز أحداث متحدية، للتأكد من حدوث اثن التغير المفاهيمي لدى التلاميذ.

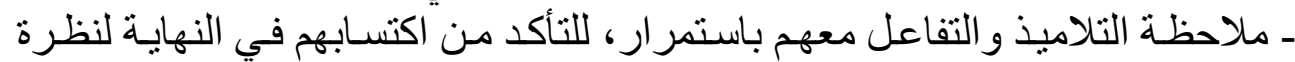
أكثر علمية.

تثالثا: مهارات القرن الحاد الحادي والعشرين:

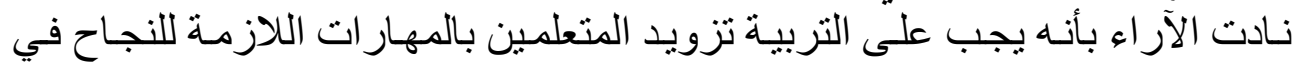

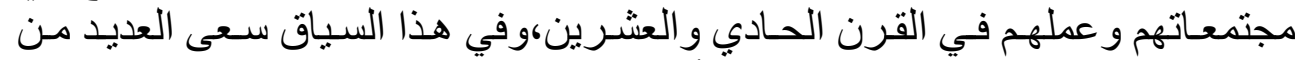

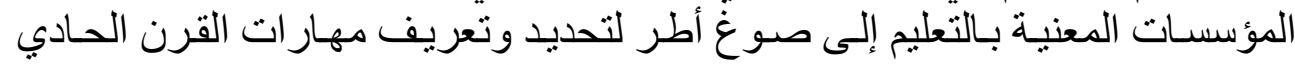

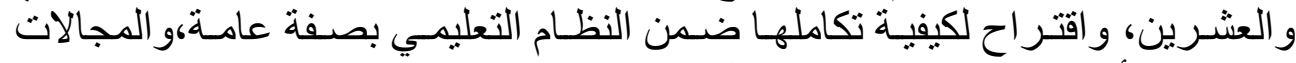

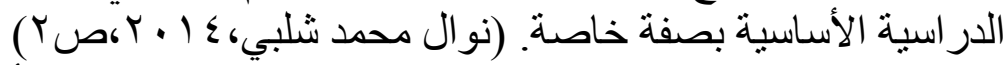

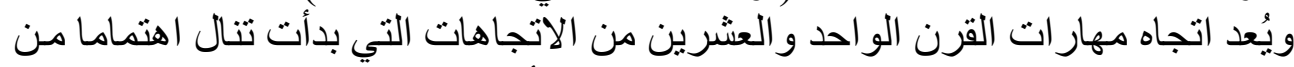

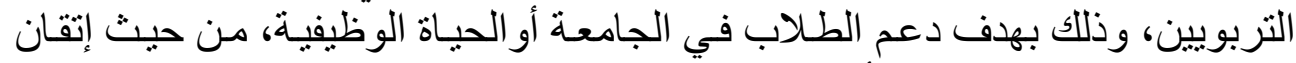

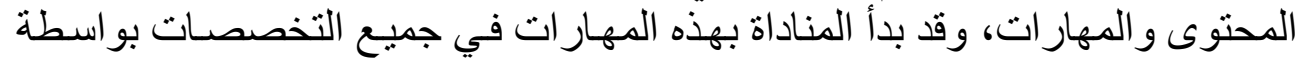

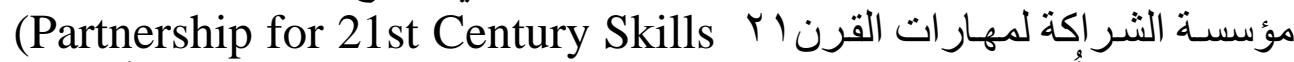

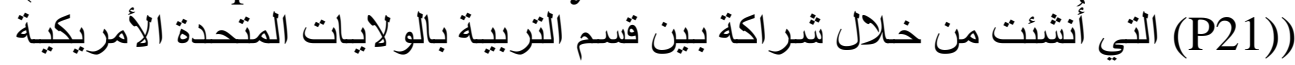

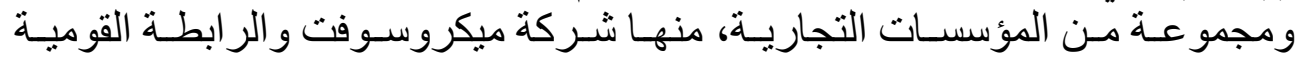

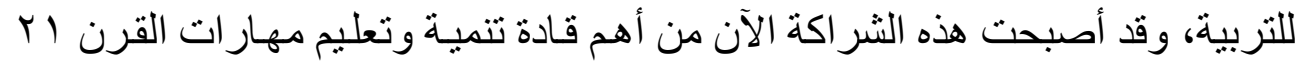

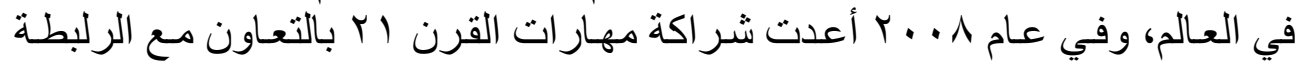

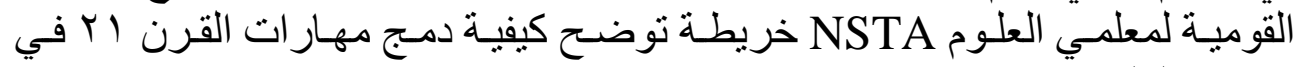
تدريس العلوم من

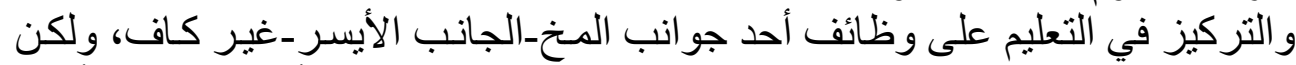
يجب توظيف مهار ات و قدر ات لم توضع في الاعتبـار كمهار ات أساسية في التأهيل

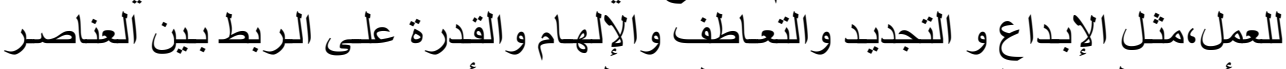

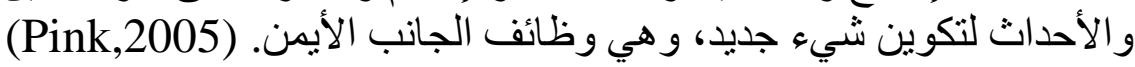

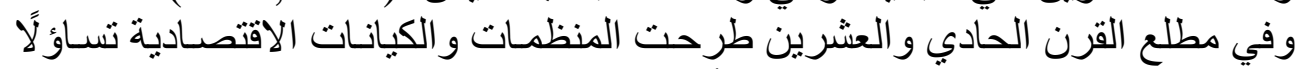

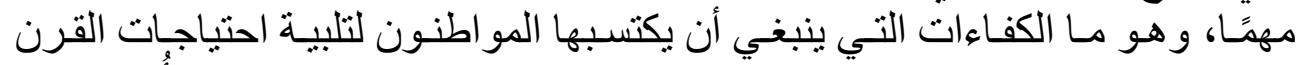

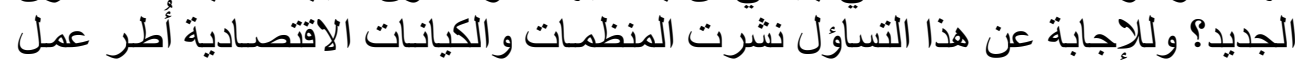

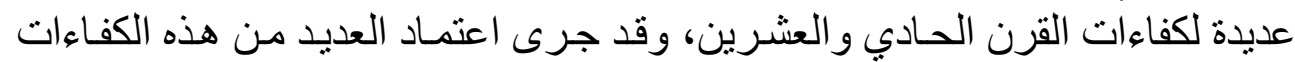




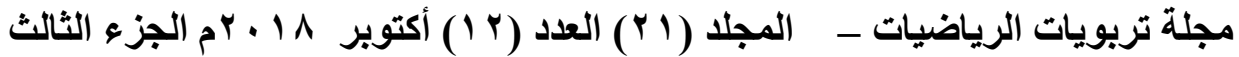

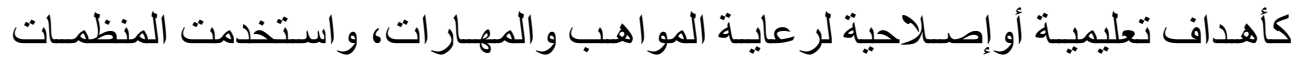

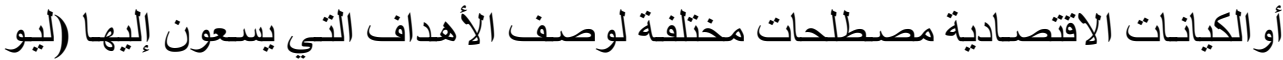

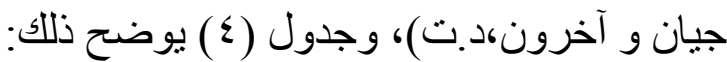

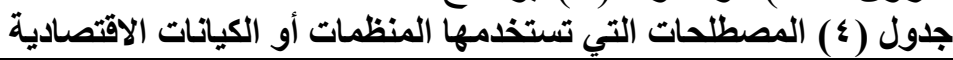

\begin{tabular}{|c|c|}
\hline المصطلحات التي تستخدمها & المنظمات أو الكياتات الاقتصادية \\
\hline مهارات القرن الحادي والعشرين. & بالولايات المتحدةدة. مـن أجلـ مهـارات القـرن الحسادي و العشـرين \\
\hline كفاءات القرن الحادي والعشرين. & منظمة التعاون الاقتصادي والتمية بسنغافورة. \\
\hline الكفاءات الأساسية. & 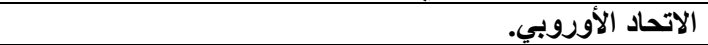 \\
\hline القدرات العامة. & إستراليا. \\
\hline المهارات العامة. & هونج كونج بالصين. \\
\hline الكفاءات الرئيسة. & تايوان الصينية،والبر الرئيس للصين. \\
\hline الت التطليم من أجل المستقبل. & مؤسسة قطر. \\
\hline
\end{tabular}

دواعي مهارات القرن الحادي والعشرين:

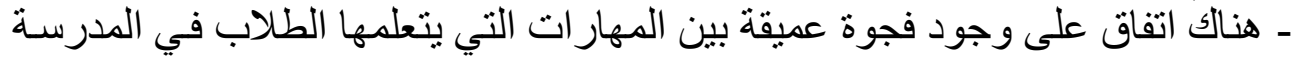

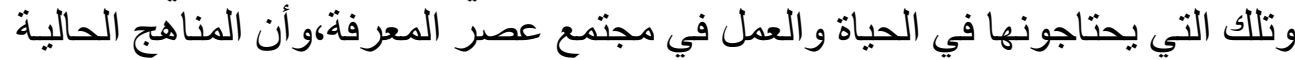

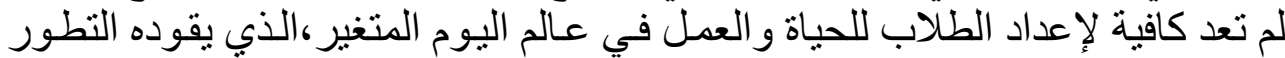

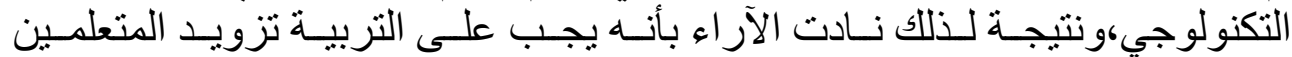

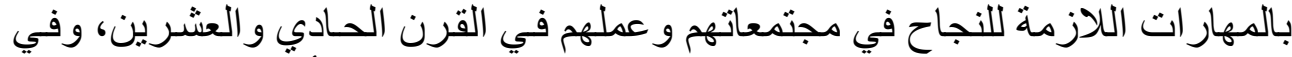

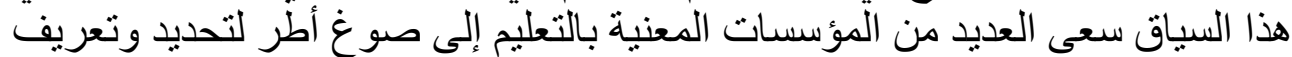

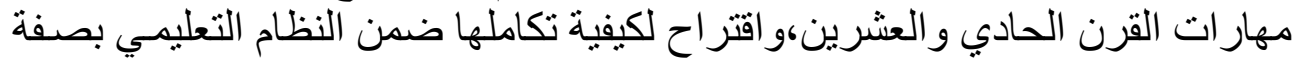

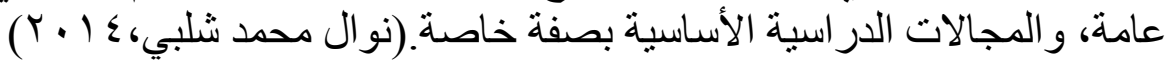

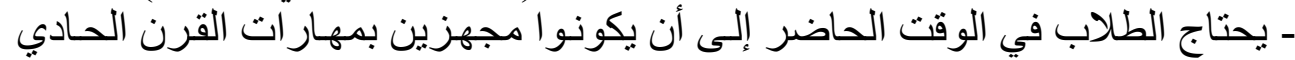

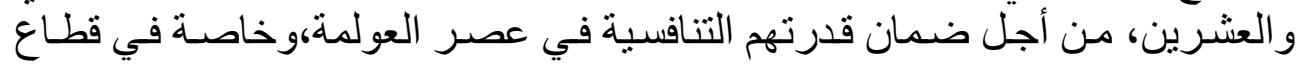

العلوم و التكنولوجيا.(Wan Husin ,et al,2016) ـ ت تمثل دو اعي مهار ات القرن الحسادي و العشـرين فيما يلي (Century skills as a :vision for K-12 Education,2007) ـ أظهر التقييم العالمي مدى تخلف مستويات التعليم في مصر عن المستويات العالمية.

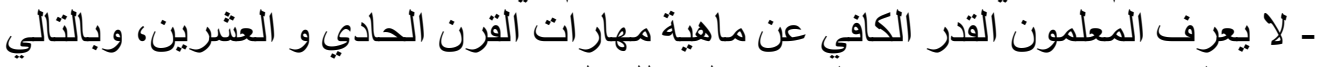

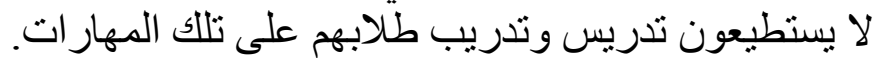

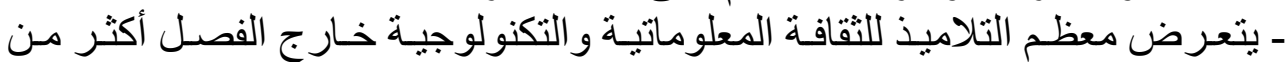

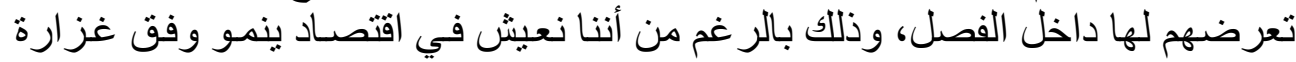
المعلومات و التكنولوجيا المعاصرة. 
ـ تشكو الهيئات و المؤسسات الثقافية و الصناعية بأن خريج المرحلة الثانوية و الجامعية غير مُعد لواقع و متطلبات ميدان العمل اليوم.

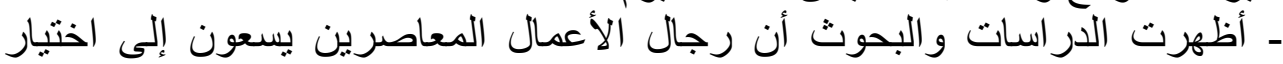

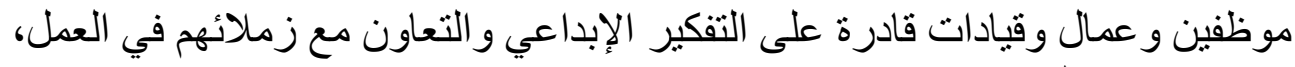
و إيجابيين، ويملكون و وعيا كونياد

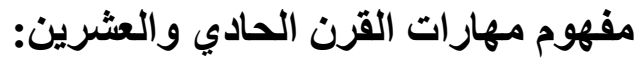

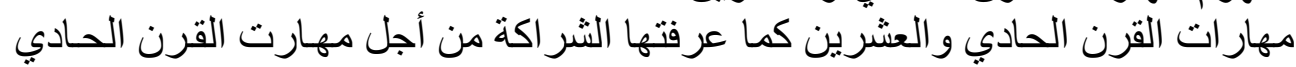

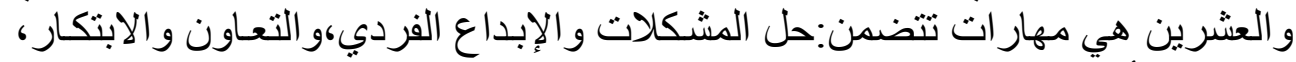

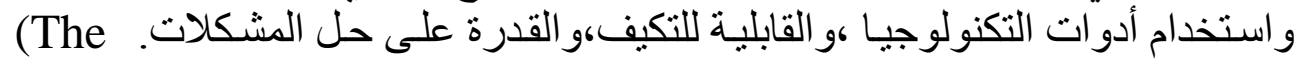
Partnership for 21st Century Skill, 2006,p21)

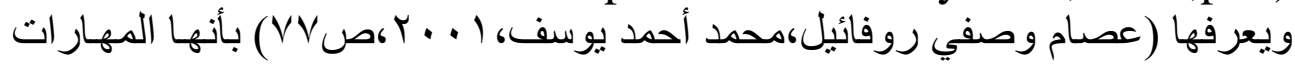

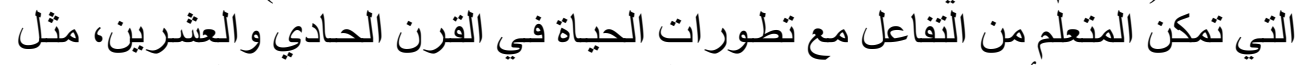

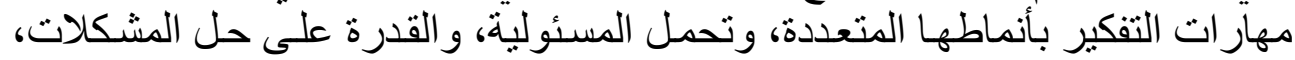

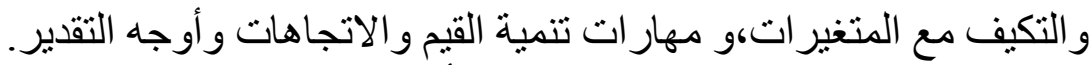

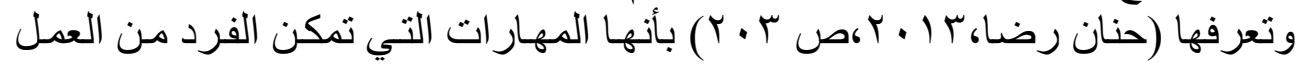

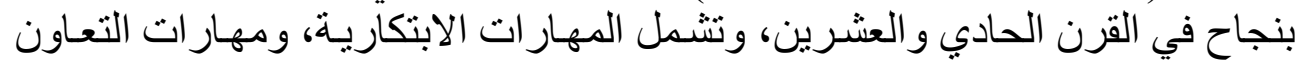

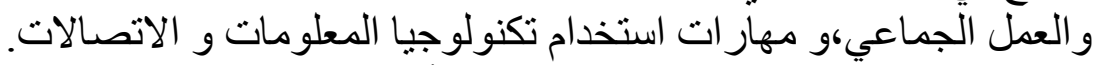

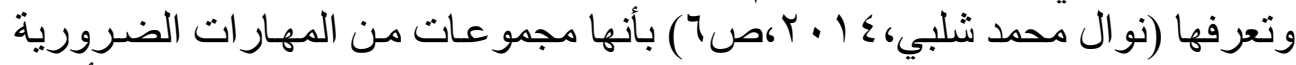

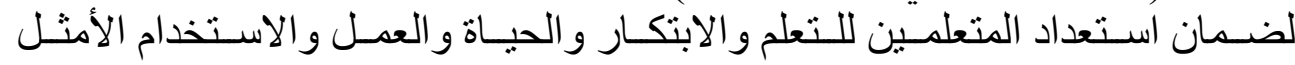

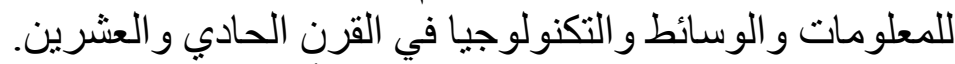

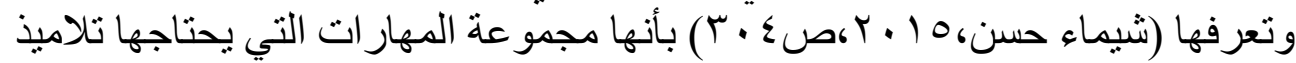

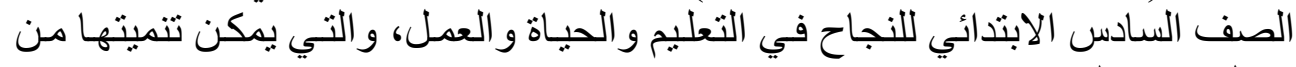
خلال منهج الرياضيات.

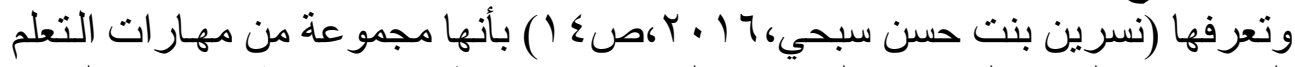

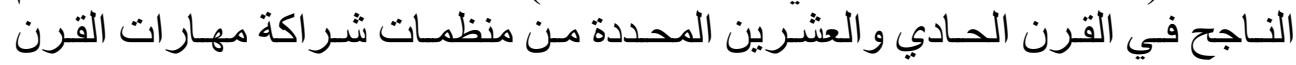

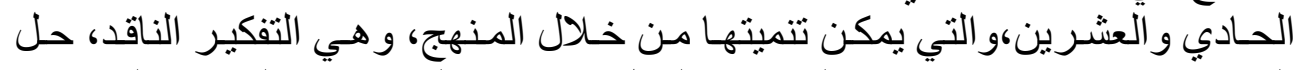

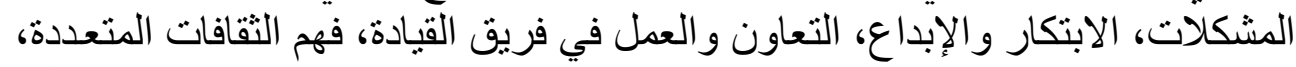

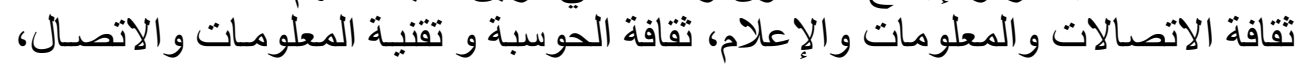

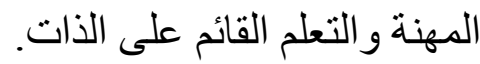

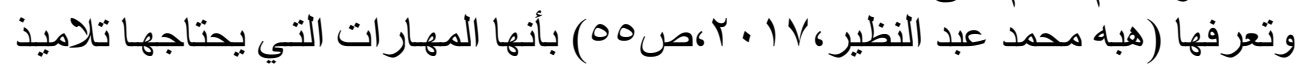

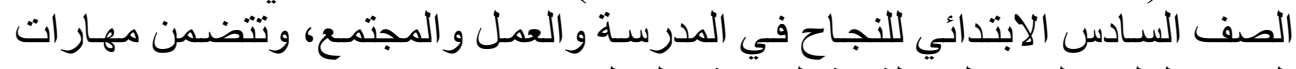
التفكير العليا والتو اصل و الثقافة الرقية فية والعمل و الإنتاج. 
أهداف تنمية مهارات القرن القرن الحادي والعثرين:

تتمثل فيما يلي: (Partnership fr 21st Century Skills,2009e)

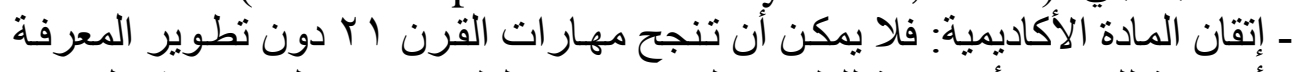

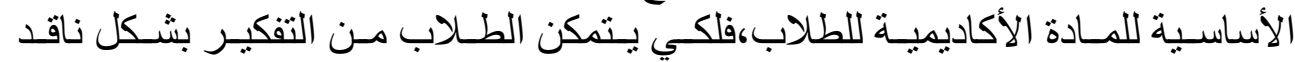

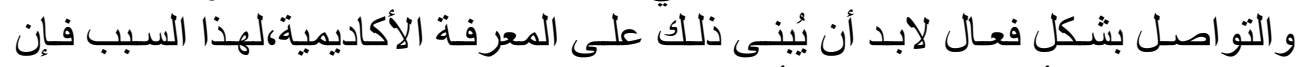

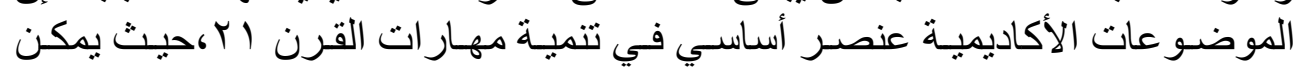

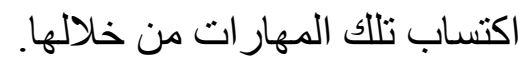
ـ مخرجات مهار ات القرن آ ب تهدف إلى جلى جعل الطلاب قادرين على التفكير الناقد،حل

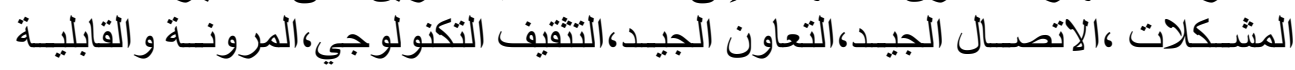

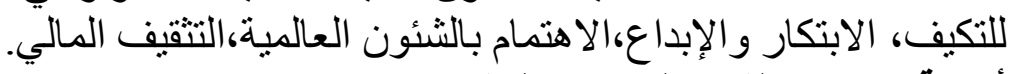

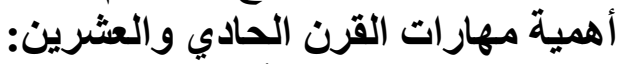

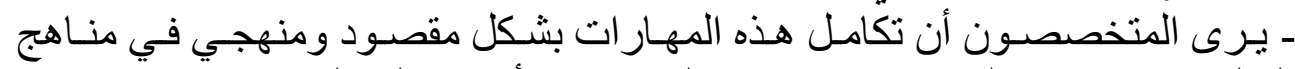
التعليم سوف يمكن التربويين من إنجاز العديد من الأهداف التي لم يتمكنواً من تحقيقها فئها

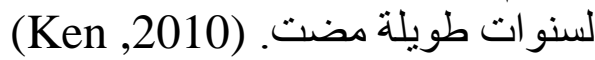

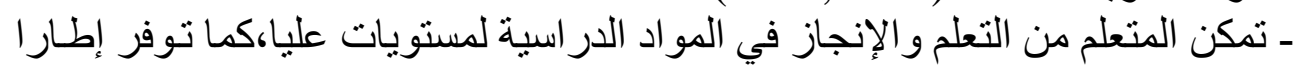

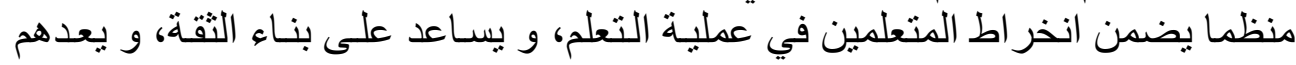

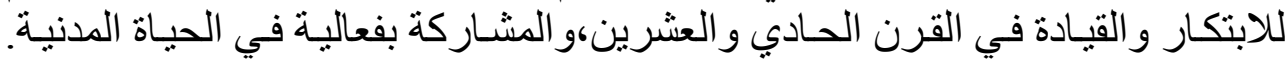

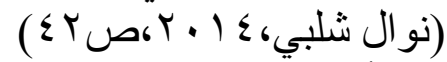

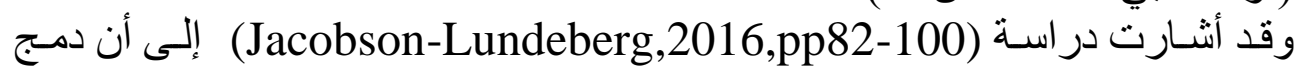

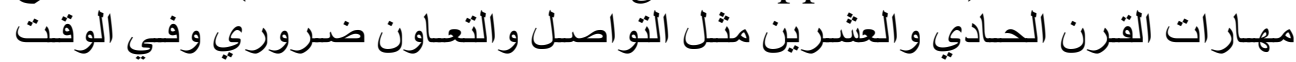

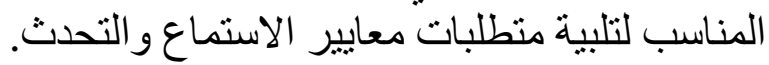

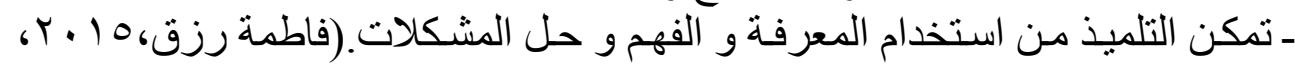

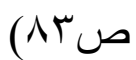

تصنيف مهارات القرن الحادي والعثرين:

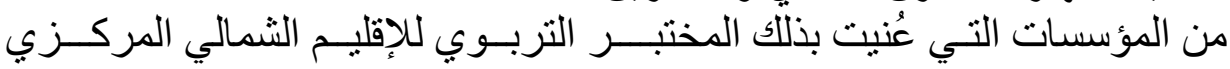
The North Central Regional Educational Laboratory(NCREL)

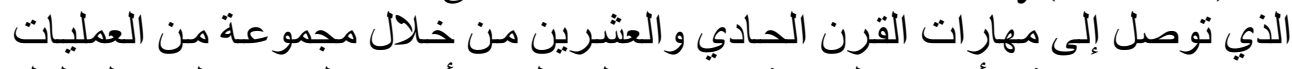

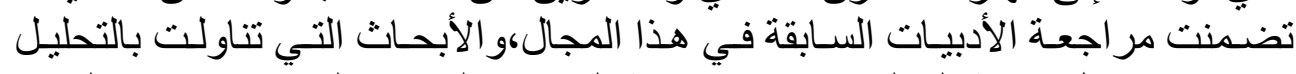

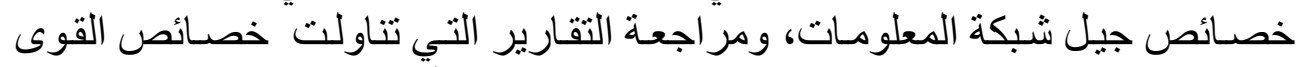

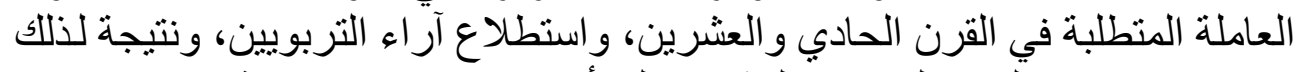

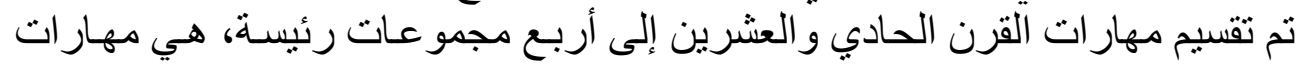


العصـر الرقمـ، مهـار ات التفكيـر الإبـداعي، مهـار ات الاتصــال الفعّـال، ومهـار ات الإنتاجية العالية. (Metiri Group;NCREL,2003)

ووضـعت منظمـة التعـاون و التنميـة الاقتصـادية Economic Cooperation and Development-OECD

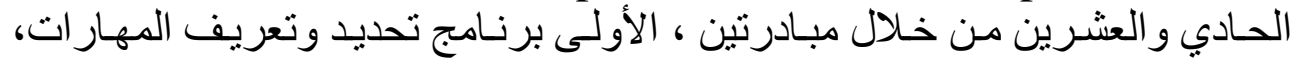

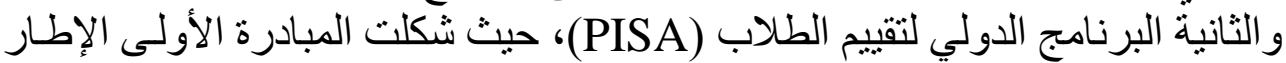

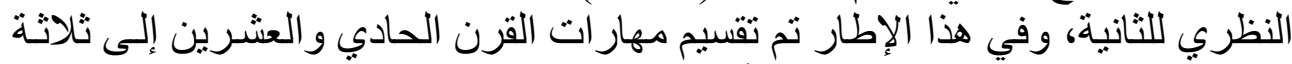

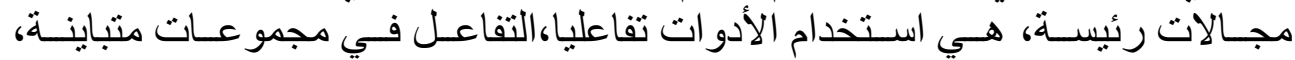

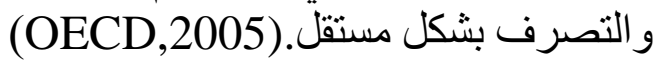
كما ترى (The Partnership for 21st Century Skill,2006,p21) بأنها

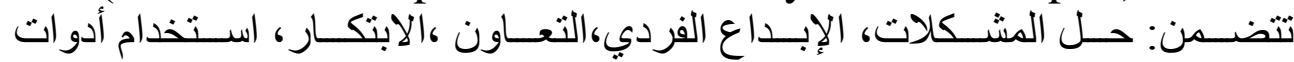

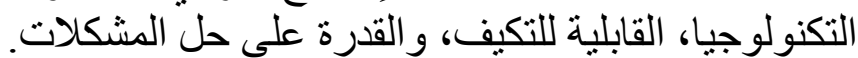

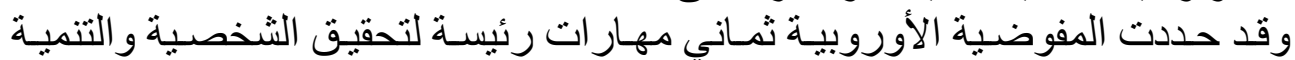

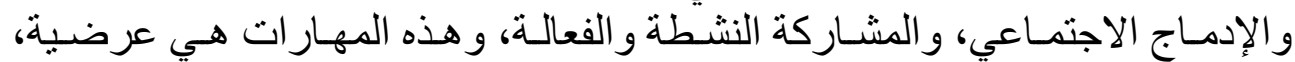

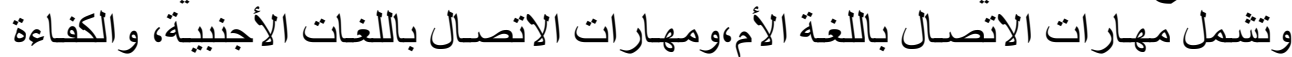

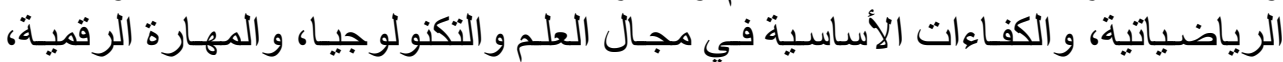

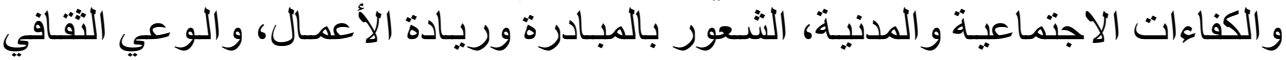
والتعبير وتعلم التعلم. (EC.2008)

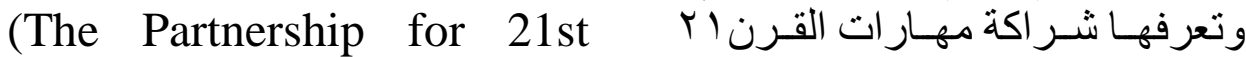
و بأنها المهار ات التي يحتاجها الطلاب للنجاح في المدرسـة و العمل

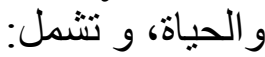

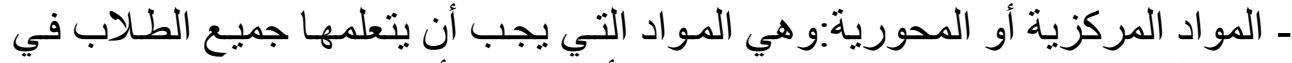

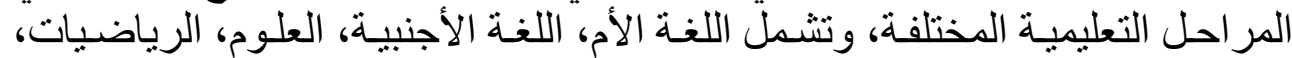

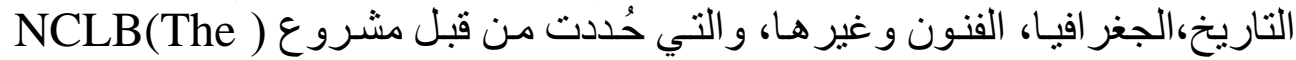
No Child Left Behind Act

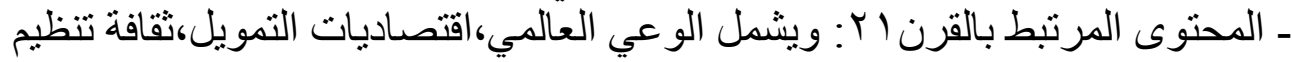

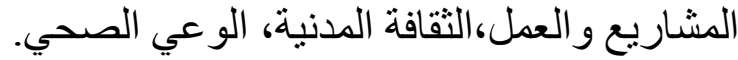

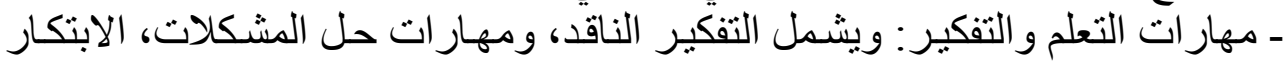

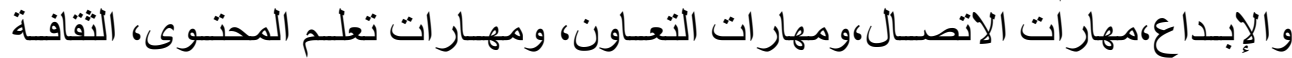

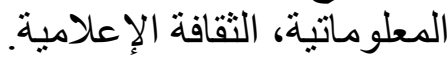
ـ ـثقافة تكنولوجيأيا المعلومات و الاتصاهة. 
ـ المهارات الحياتية: وتشمل القيادة،الأخلاق،المساءلة،القدرة على التكيف، الإنتاجية

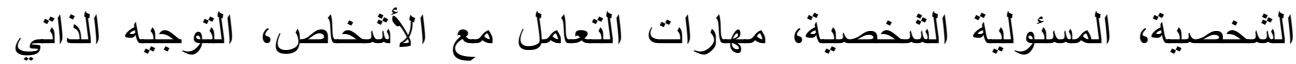
و المسئولية الاجتماعية.

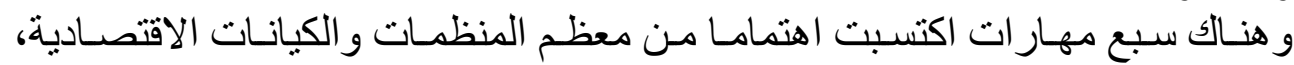

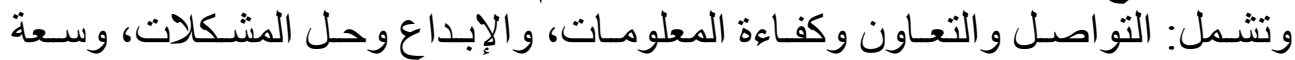

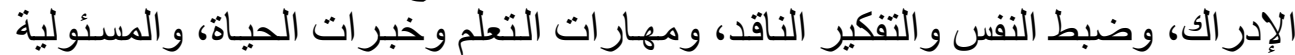

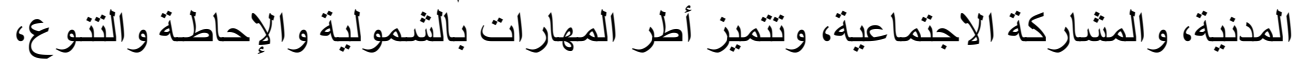

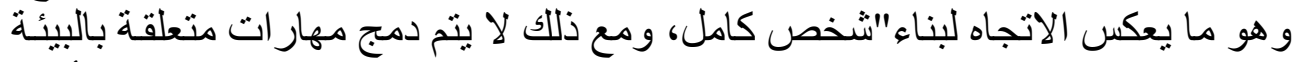

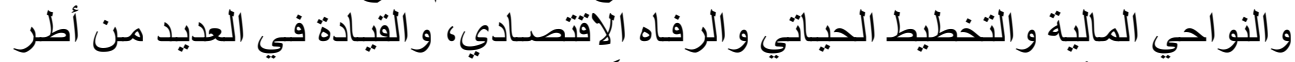

العمل، برغم أهميتها في تطوير التعليم مستقبلًا. (The World Bank,2015)

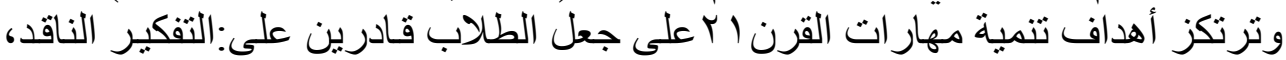

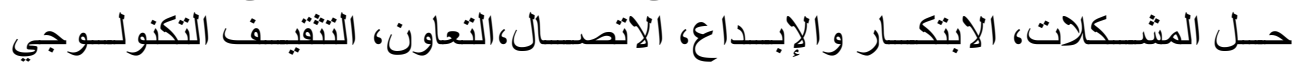

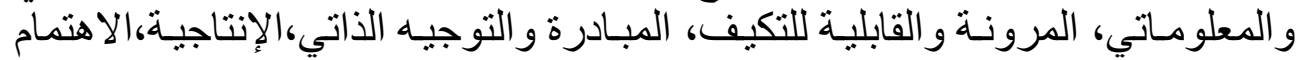
بالثـئون العالميـة،التثقيف الإعلامسي. Partnership for 21st Century

Skills,2009)

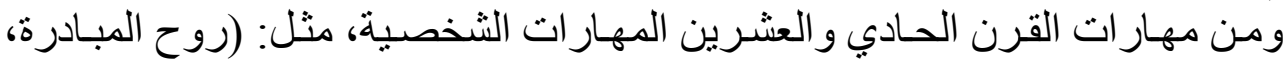

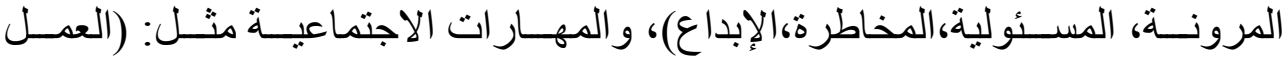

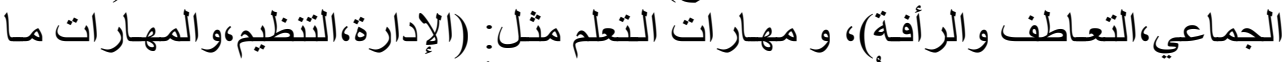

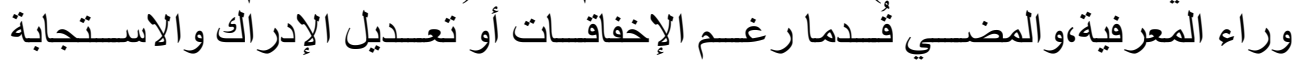

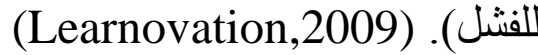
ويرى (Senechal,2010,p5) أنه على المدارس للبقاء ليس لديهم خيار سوى تعليم

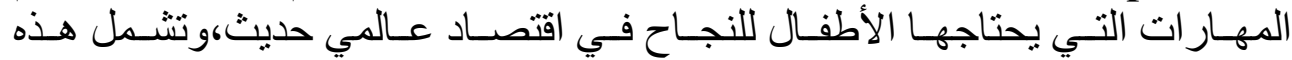

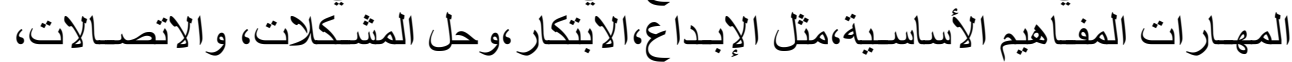

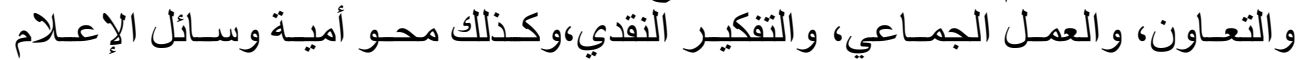

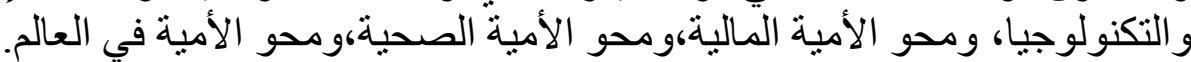

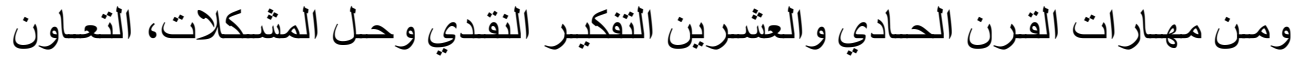

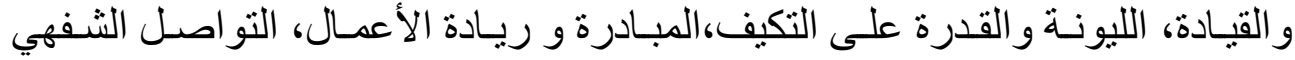

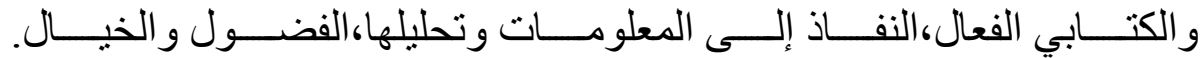
(Wagner,2010,p4)

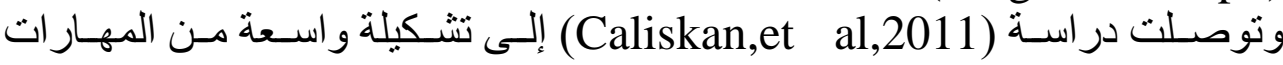
المتقدمة، منّل نظام التفكير،و الإدارة الذاتية،و الإبداع،الاتصال و التفكير الناقد. 


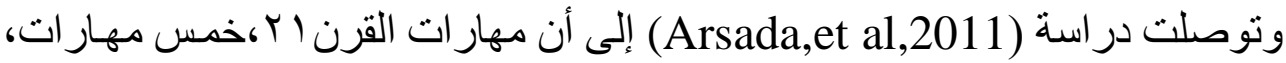

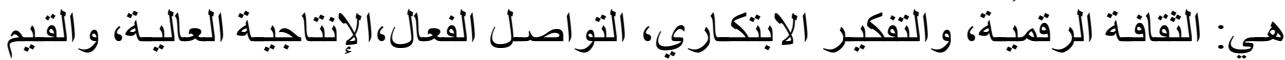

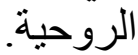

وتوصلت دراسة (Gut,2011,pp37-157) إلى أن مهار ات القرن آب، هي: محتوى

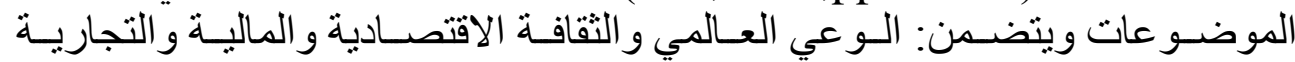

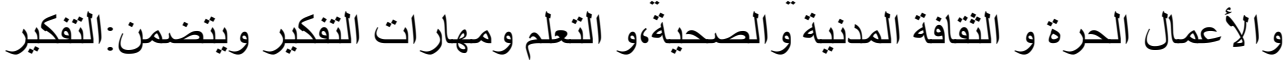

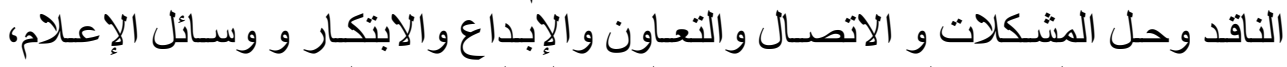

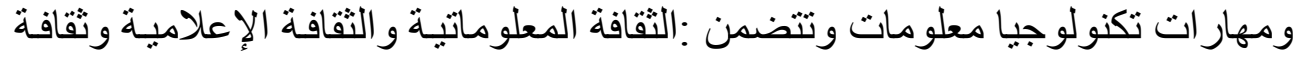

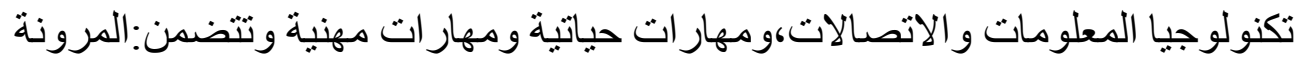

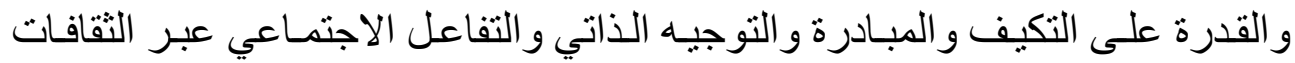
و والإنتاجية و المساءلة و القيادة و المسئولية.

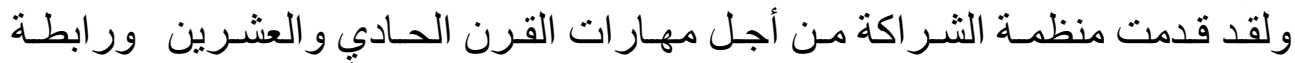

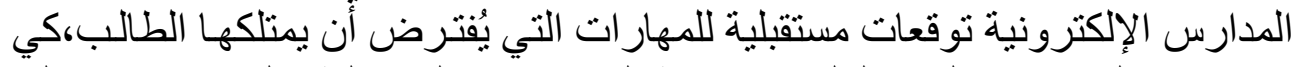

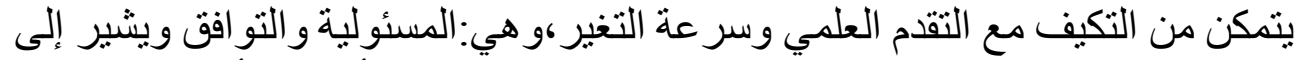

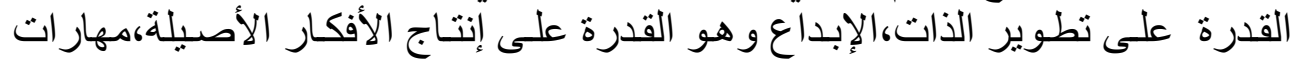

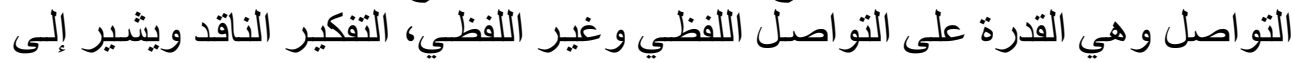

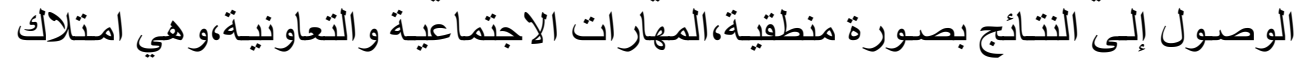

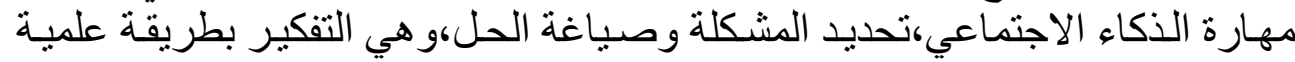

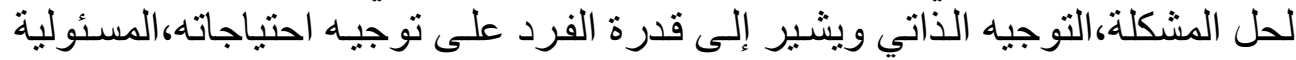

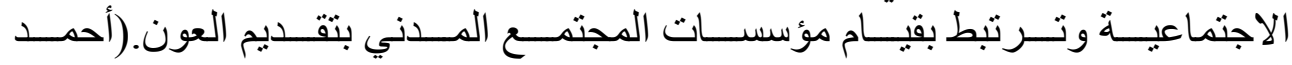

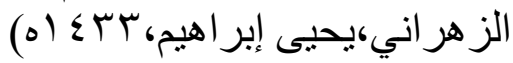

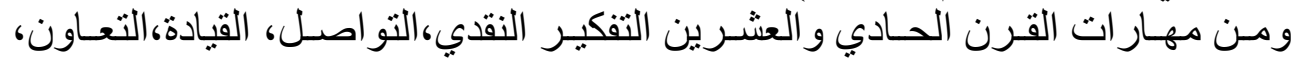

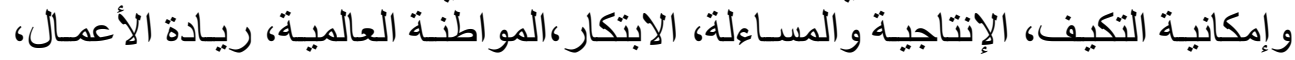

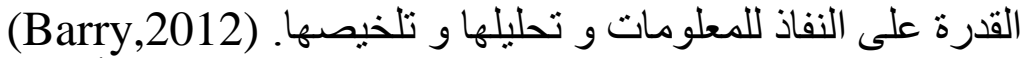

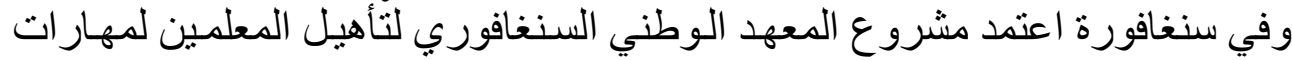

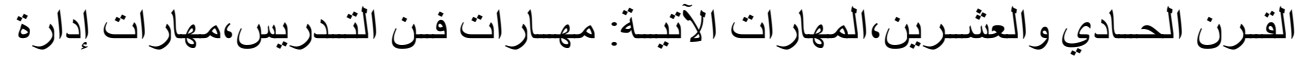

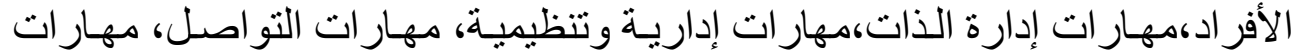

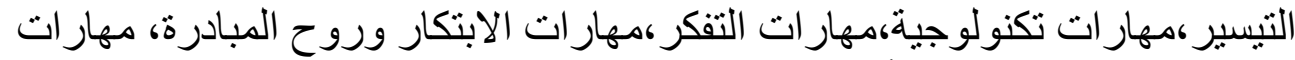

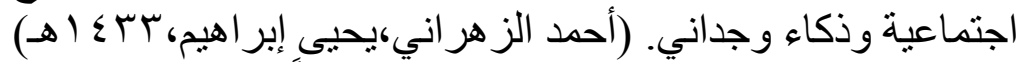

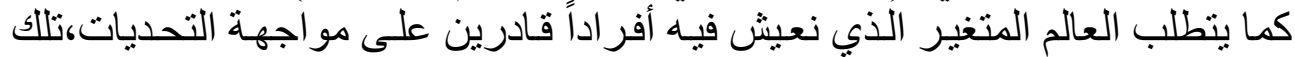

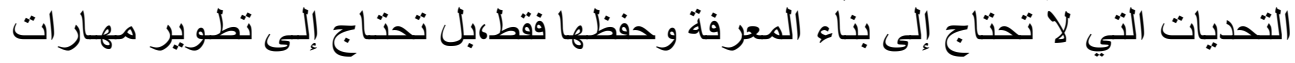


التفكير العليا، مثل مهار ات التفكير الناقد والقدرة على اتخـاذ القرار وحل المشكلات

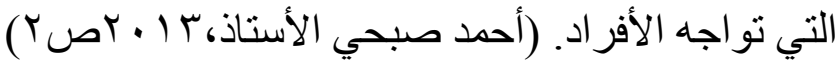

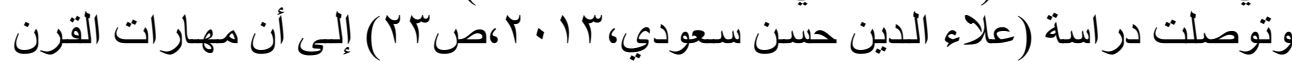

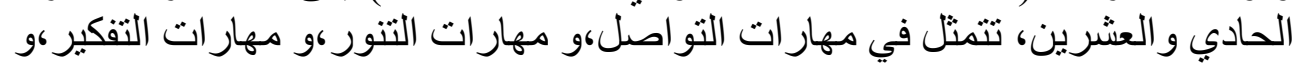

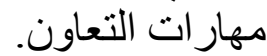

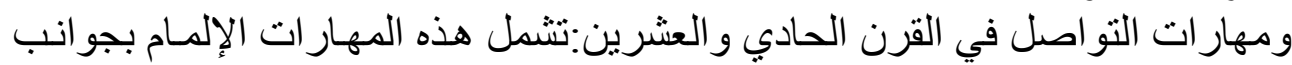

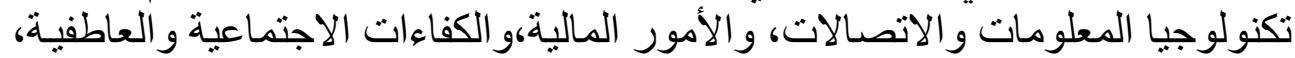

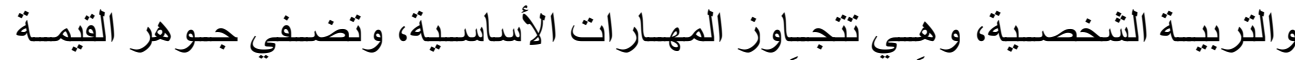

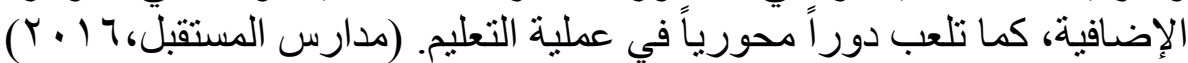

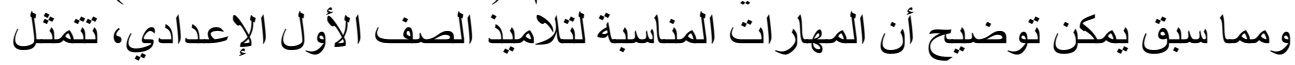

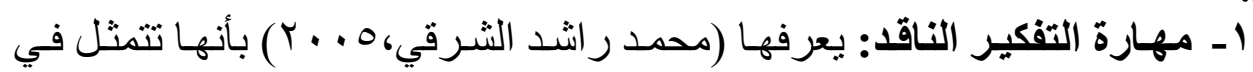

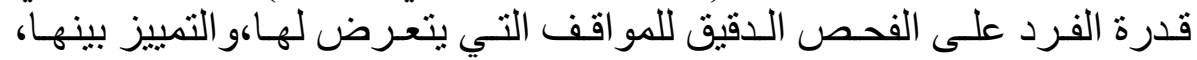

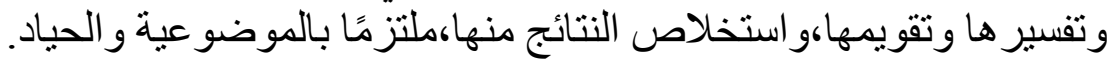

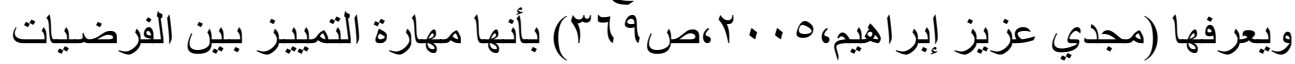

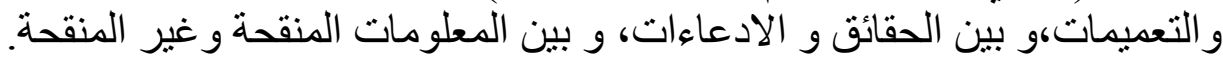

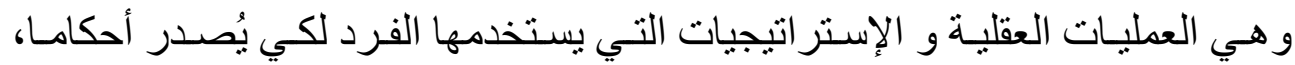

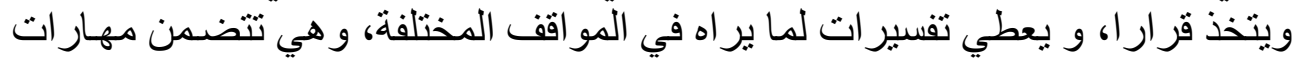

بعينها.

و تمثل أحد مهار ات التفكير العلياهو التي ثُعنى بتقويم الحججهوبقدرة الفرد على التنظيم الذاتي للقيام بمهار ات التقويم،و التحليل،ورات الاستنتاج. (Astleitner,2002)

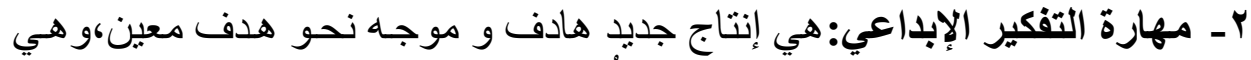

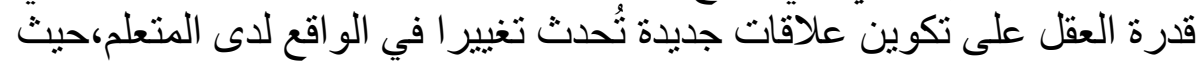

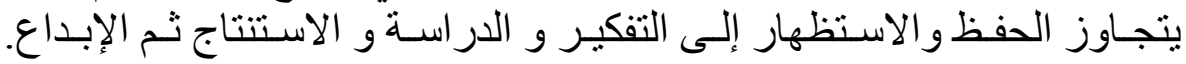

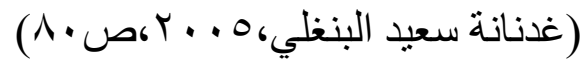

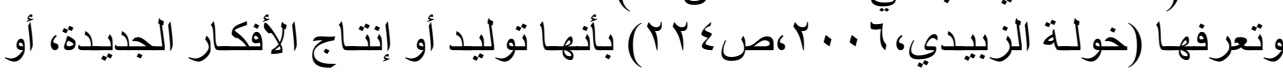
إيجاد الحلول الجديدة للتحديات.

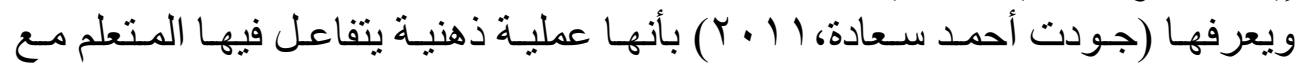

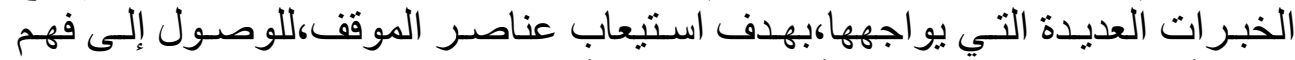

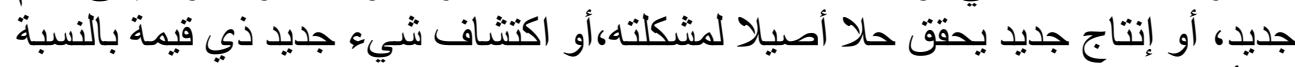
له، أو للمجتمع الذي يعيش فيه. 


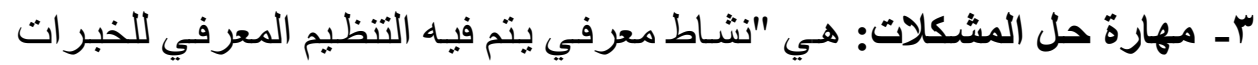

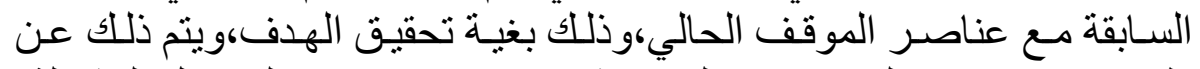

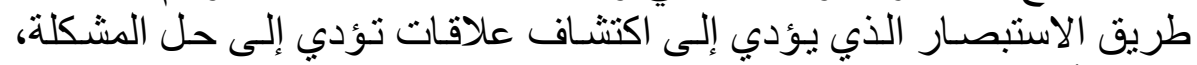

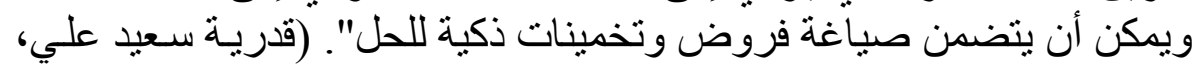
(r.. 0

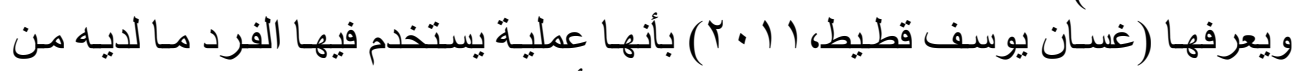

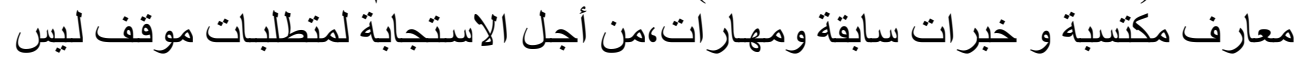

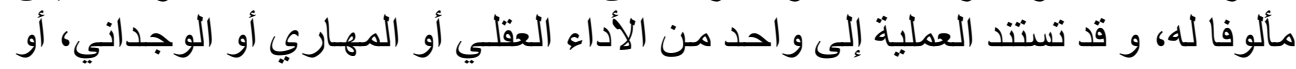

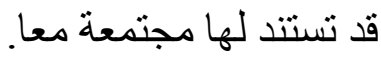

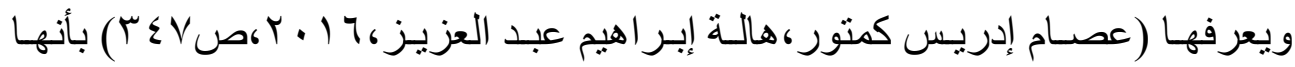

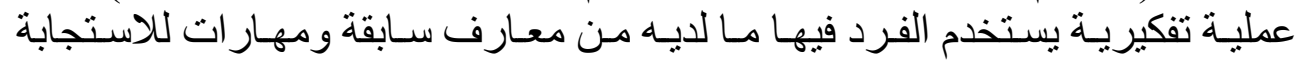

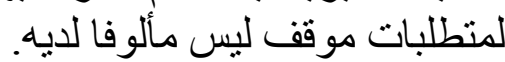

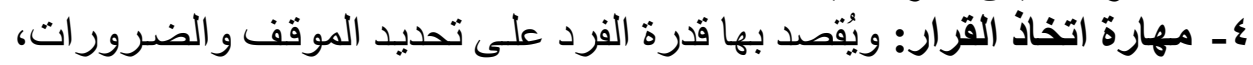

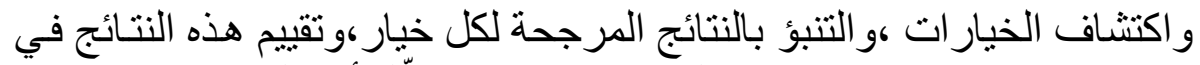

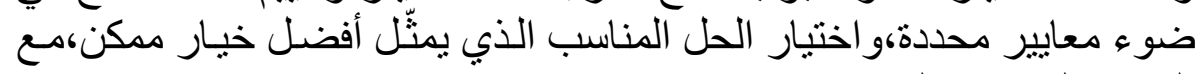

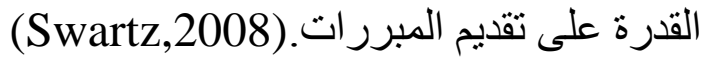

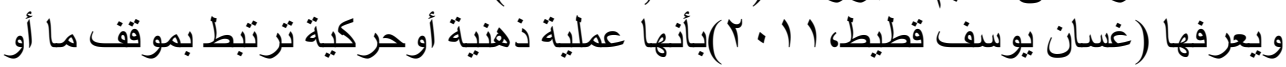

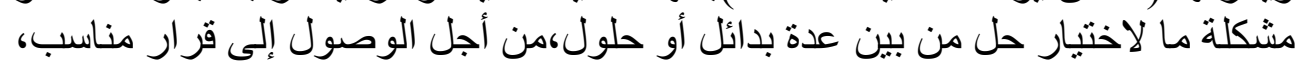

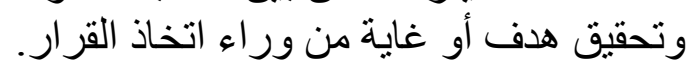

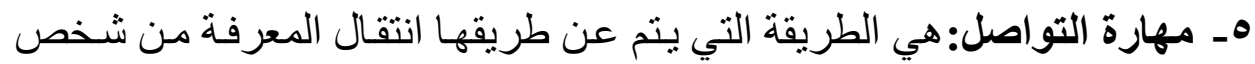

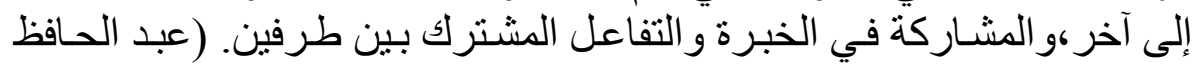

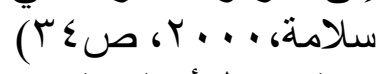

التغيرات التي تطرأ على المناهج في ضوع ضوع مهارات القرن الحادي والعشرين:

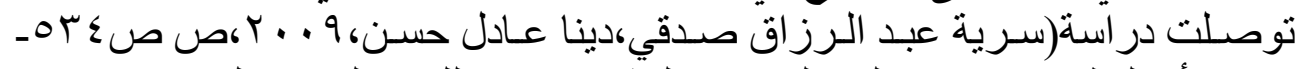

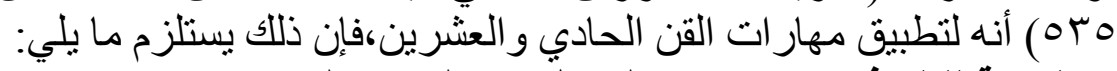

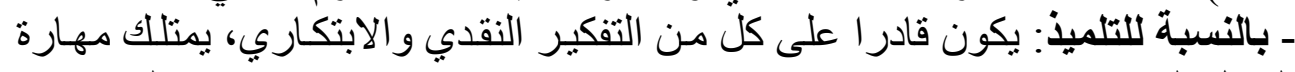

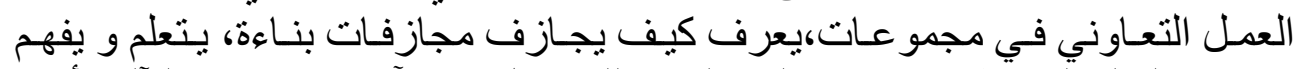

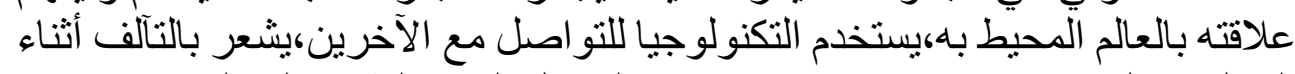

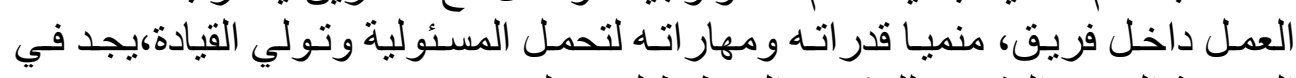
المدرسة الدعم و التشجيع للتفكير و التخطيط لمنيط لمستقبله.

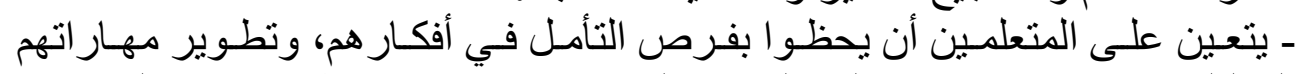

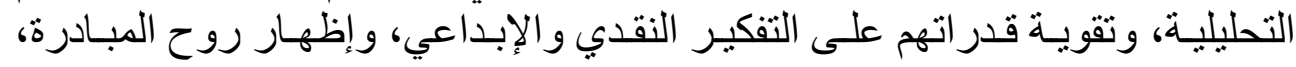


و القدرة على تقديم مساهمات و مناظير جديدة،وبناء قدر ات جديدة،وتعزيز الاستقلالية

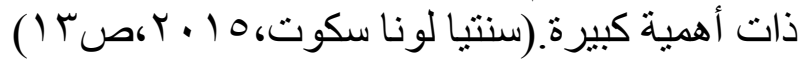

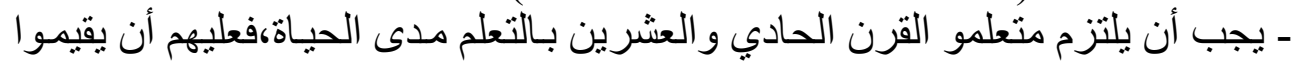

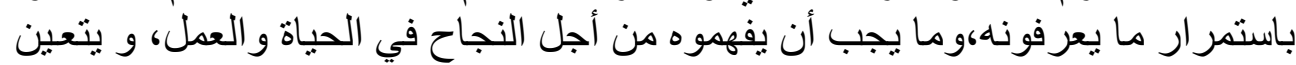

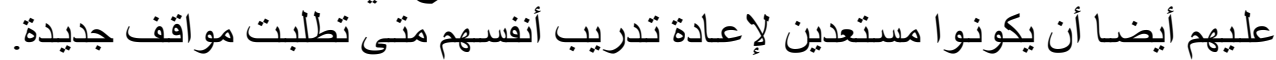

(Redecker,et al.,2011)

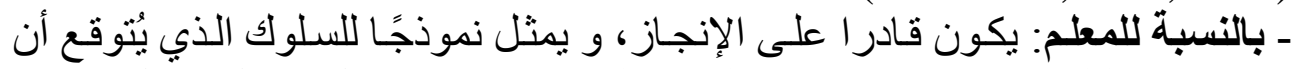

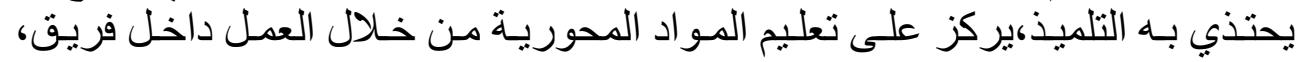

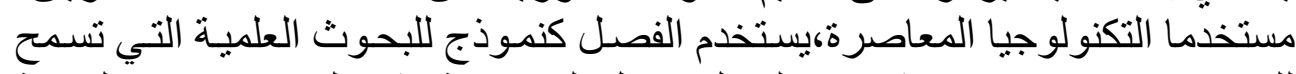

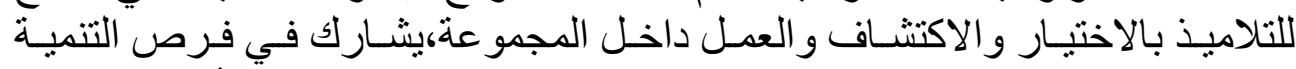

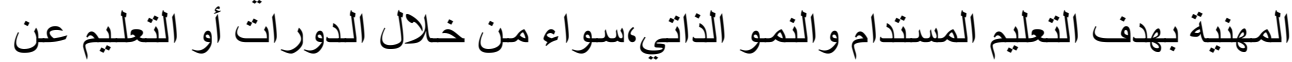

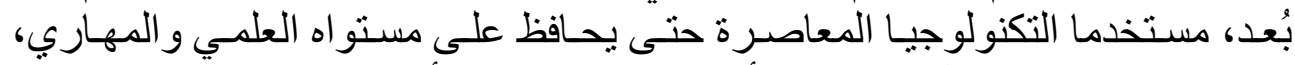

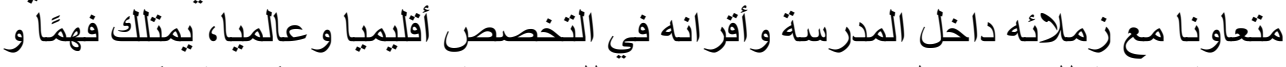

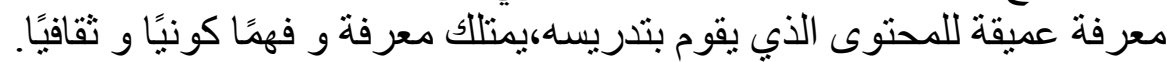

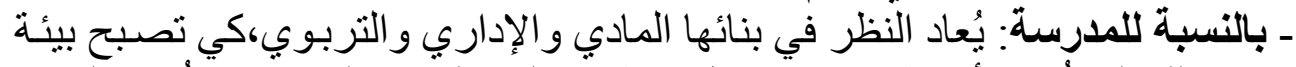

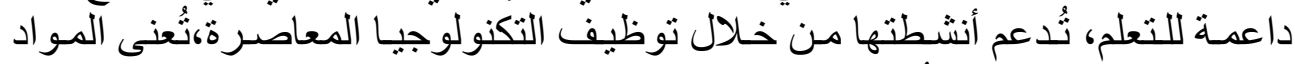

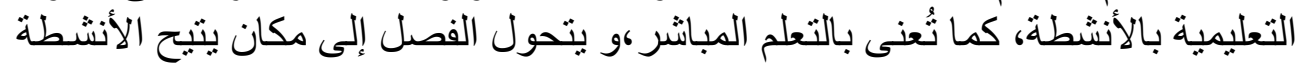
و العروض الجمينة بالنية.

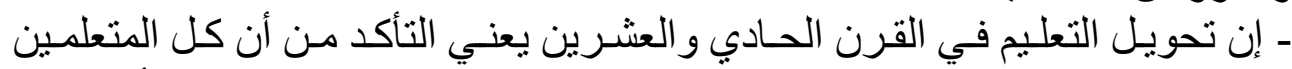

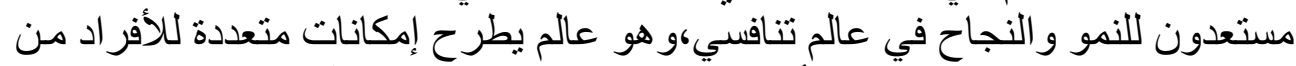

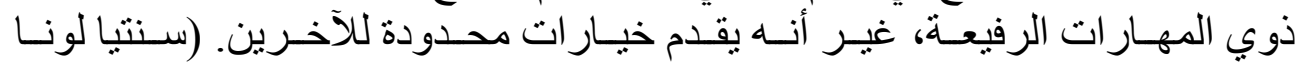

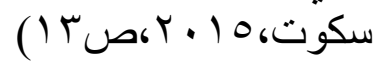

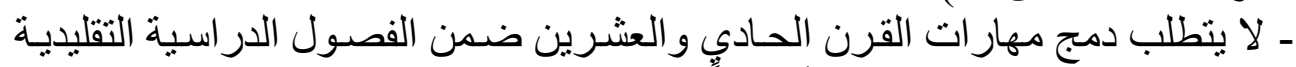

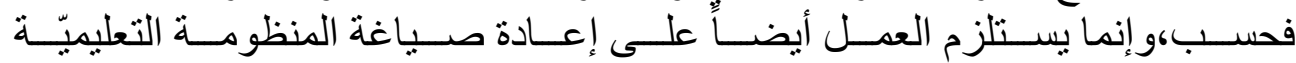

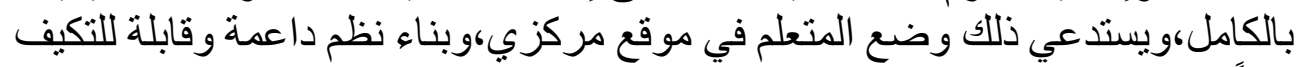

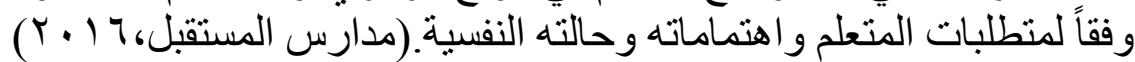

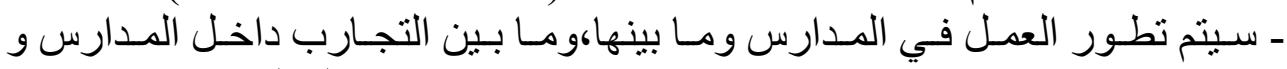

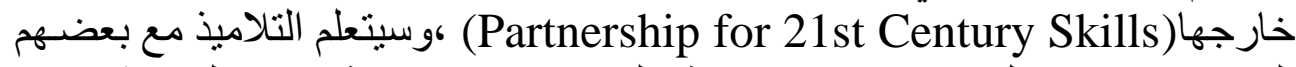

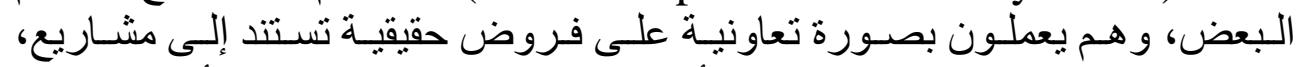

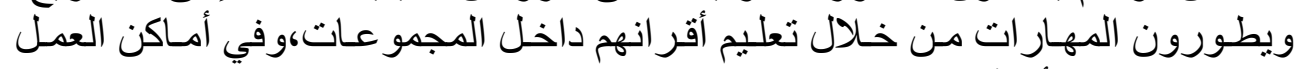

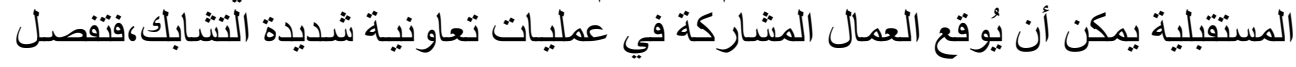


بينهم وبين زملائهم مسـافات كبيرة،و يكونون في أمـاكن بعيدة كل البُعد عن الموقع المادي لمصادر المعلومات. (Facer,2009)

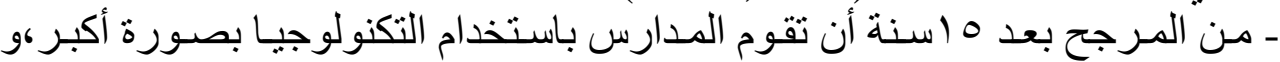

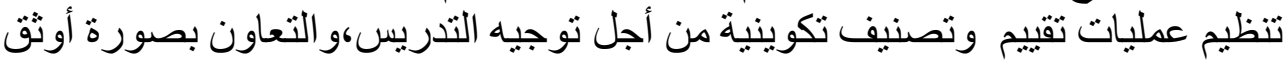
مع قطاع التكنولوجيا و الجامعات،فتصبح أكثر تكيفا مع حاجات الأفر اد و اهتماماتهر. ) Leis, 2010)

- يعتبر كل من التعلم التخصي و التعاون والتو اصل و التعليم غير النظامي و الإنتاجية

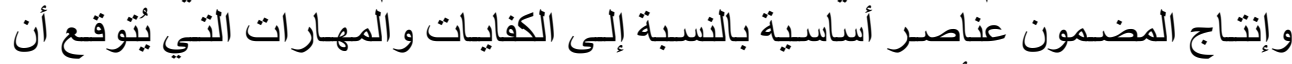
يطور ها المتعلمون و أسلوب تعليم هذه المهار ات.(Redecker;Punie,2013)

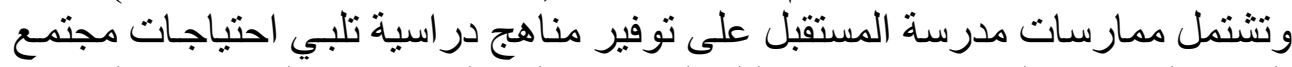

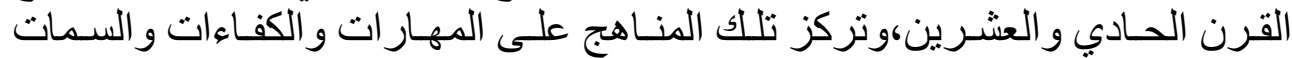

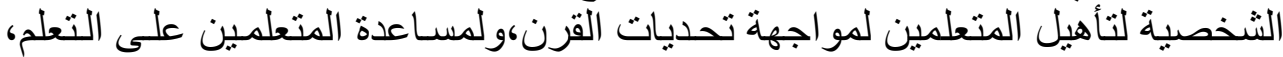

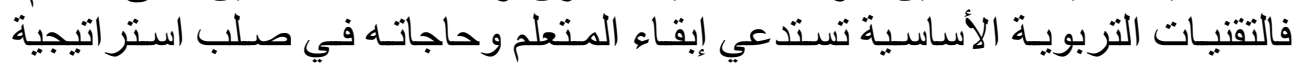

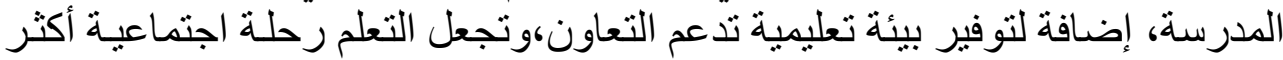

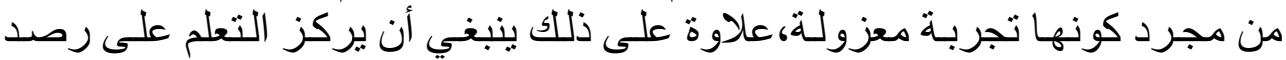

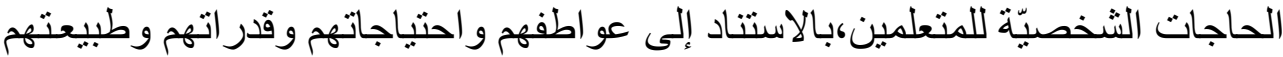

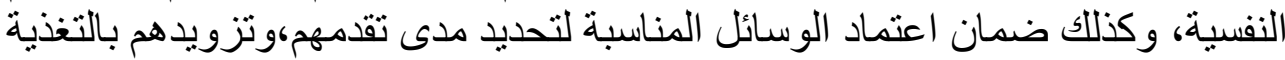

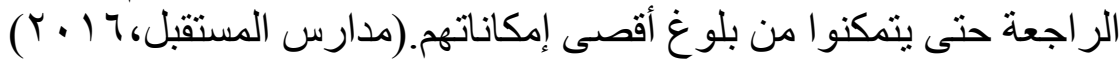

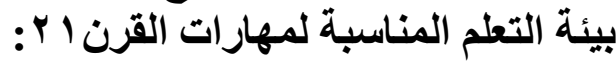

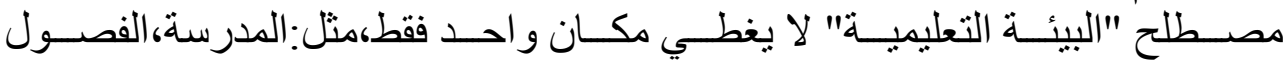

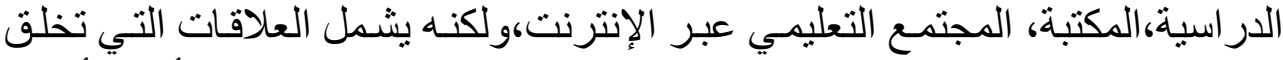

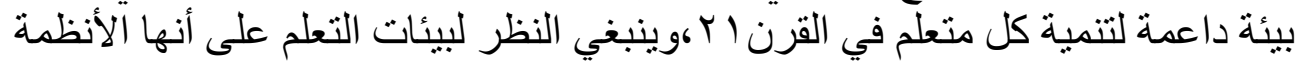

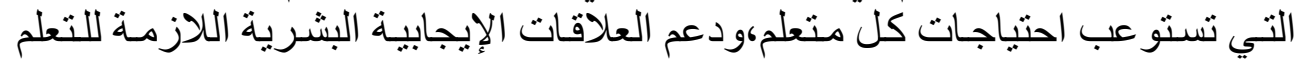

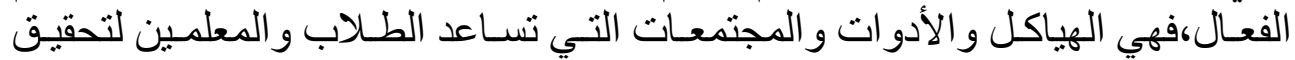

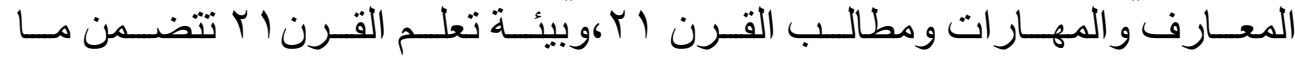
يلي(Partnership fr 21st Century Skills,2009c):

ـ خلـق ممارسـات التعلم في البيئـات الماديـة التي تـدعم تـدريس وتعلم مهـار ات

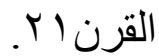

ـ دعم مجتمعـات التعلم المهنيـة التـي تمكن المعلمـين مـن التعـاون وتبـادل أفضـل

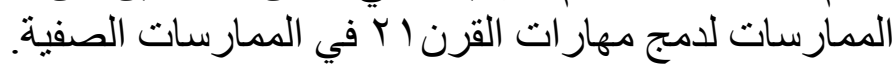




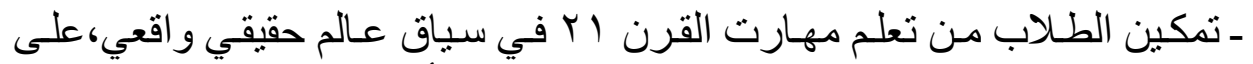

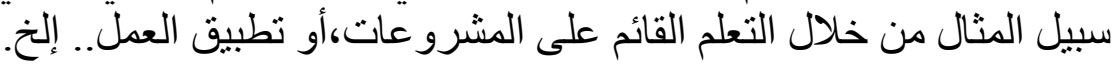

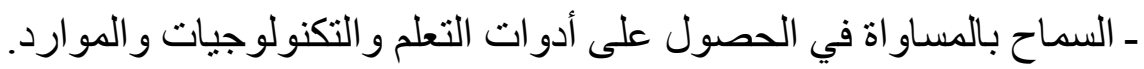
ـ توفير تصميمات للتعلم للقرن ا Y في صورة مجمو عات أو تعلم فردي.

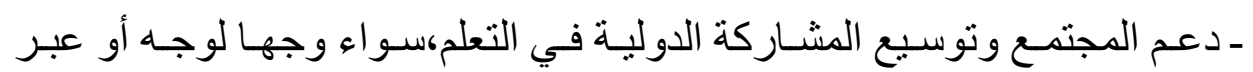
الإنترنت. ويعيش طفل القرن الحادي و العشرين في عـالم رقمـي متغير طُور ببر اعة الإنسـان

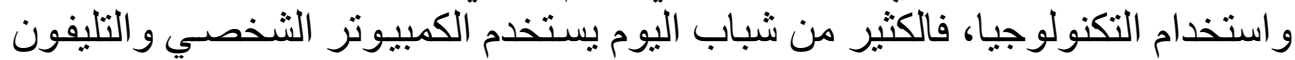

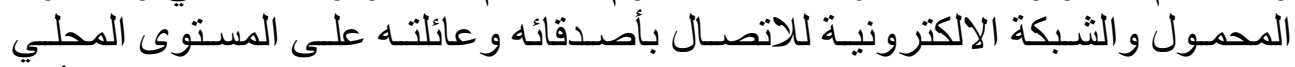

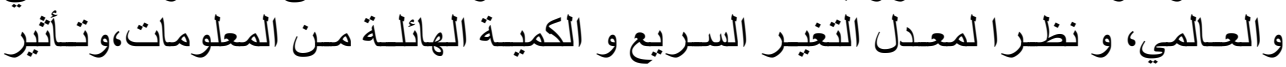

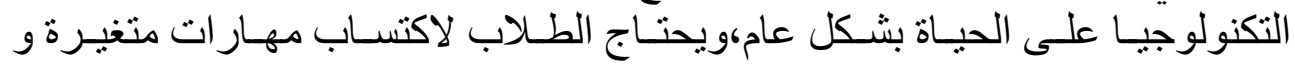

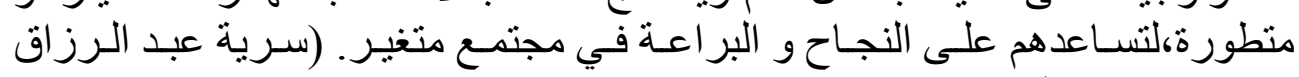

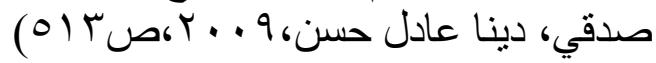

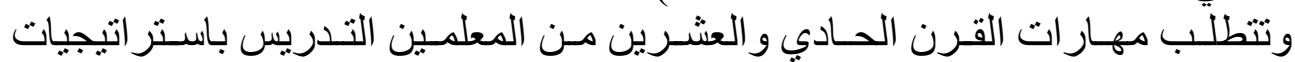

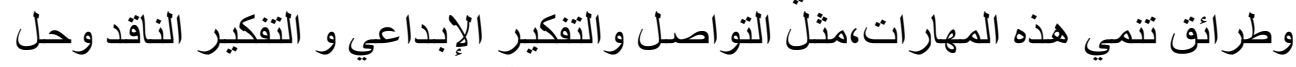

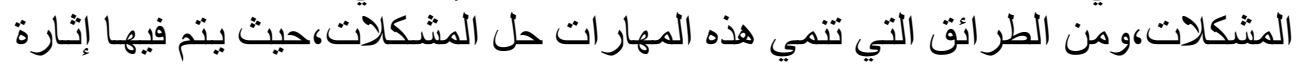

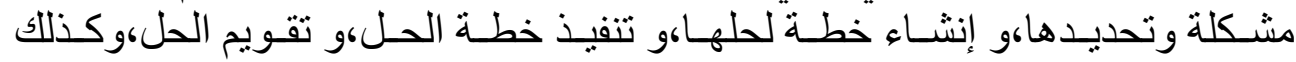

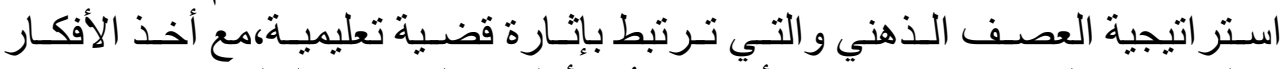

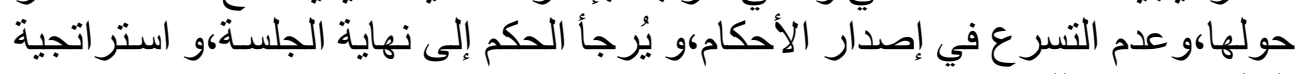

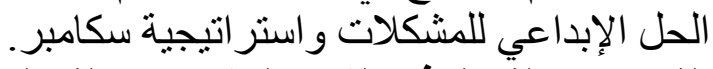
الفرق بين الفصل في القرن العشرين و الفصل في القرن الحادي و العثرين: 
جدول (•) الفرق بين الفصل في القرن العشرين والفصل في القرن الحادي والعشرين

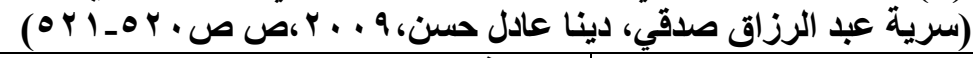

\begin{tabular}{|c|c|}
\hline الفصل في القرن الحادي و العشرين. & الفصل في القرن العشرين. \\
\hline مبني على المخرجات. & مبني على الوقت. \\
\hline نسبئن عميع ماذا يقرفل الطالب؟ماذا يستطيع عمله؟ماذا يجب بعد & مبني على تذكر الحقائق المنفصلة. \\
\hline يُصمم التعليم على مستويات بلوم العليا(تحليل ،تركيب،تقويم). & 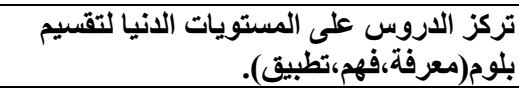 \\
\hline يعتمد على البحث. & يعتمد على الكتب. \\
\hline التعلم نثط. & التعليم سلبي. \\
\hline العالم(فصون كوني). & جدران. \\
\hline قائم على المتعلم(المعلم ميسر و مدرب). & قائم على المعلم(فهو مركز الانتباه ). \\
\hline قدر كبير من الحرية للطلاب. & القليل من الحرية أو معدومة. \\
\hline 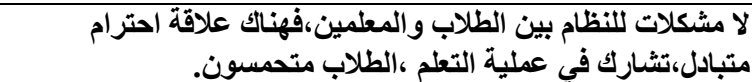 & مشكلات النظام:المعلمون لا يثقون في طلابهم \\
\hline مناهج متكاملة و منظمة. & مناهج مفتتة. \\
\hline المر احل مبنية على ما تم تعلمه. & متوسط مرحلي (المعدل بالمرحلة). \\
\hline توقعات عليا. & توقعات دنيا. \\
\hline تخصدية. أنواع التقويم،وهي ذاتي،تقويم الأقران،التقويم الحقيقي،لقاءات & غيرهم. \\
\hline المنهج التذريسي يهتم بتت & تُ تُهمل الفرو \\
\hline كونية للألفية الجدايدة. الحادي و العشرين، & 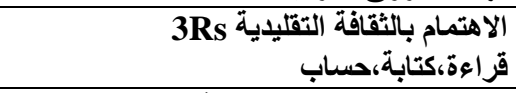 \\
\hline
\end{tabular}

خصائص المناهج في القرن الحادي والعثرين:

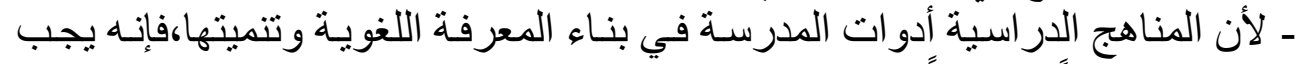

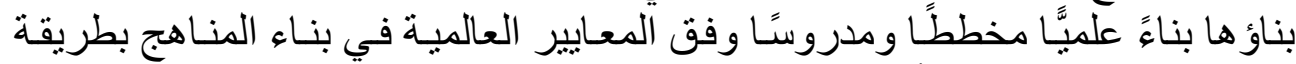

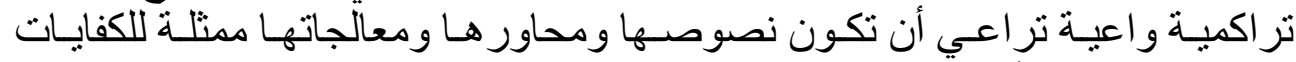

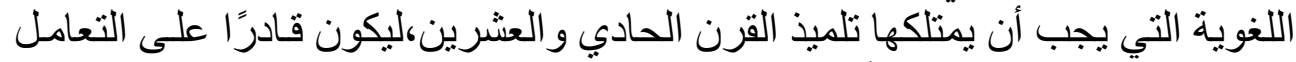

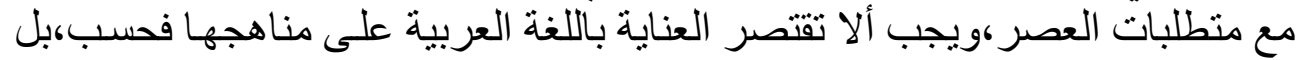

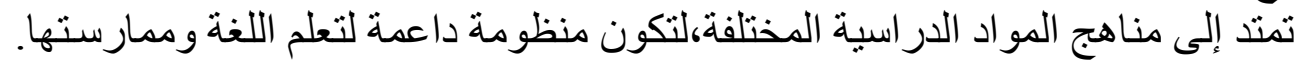

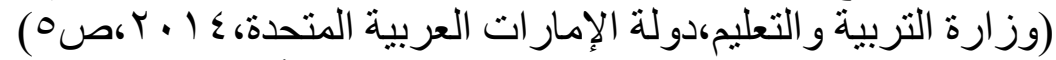

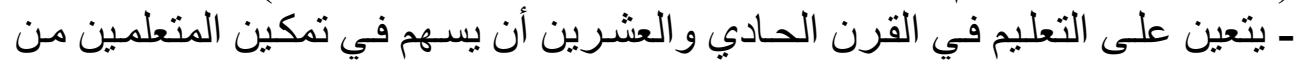

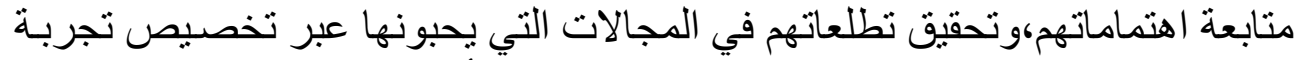

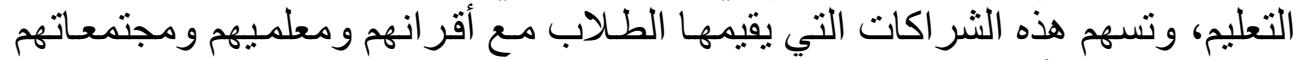

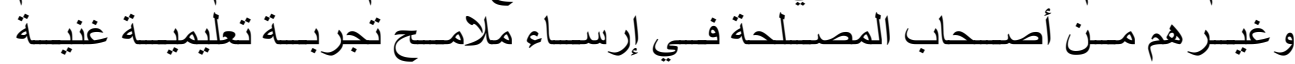

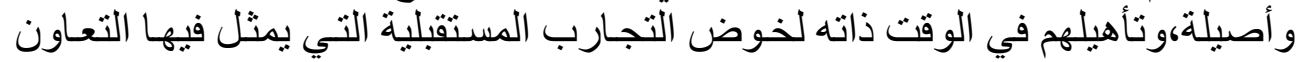




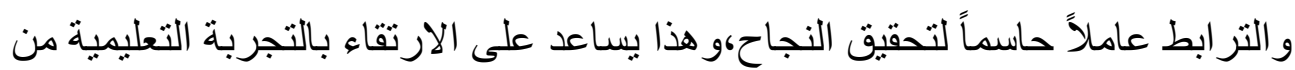

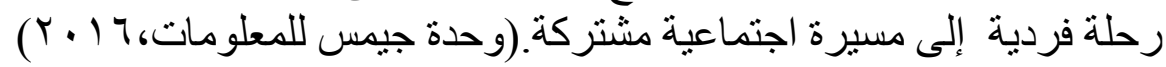

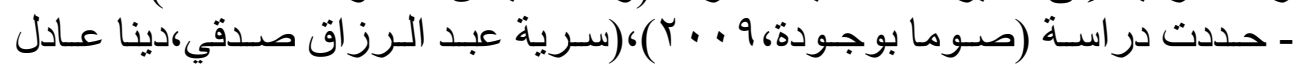

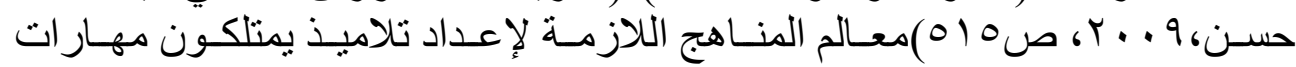

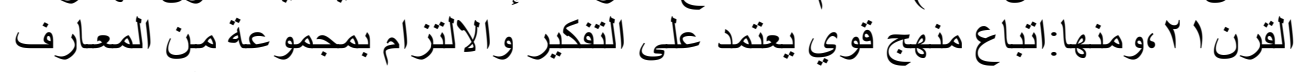

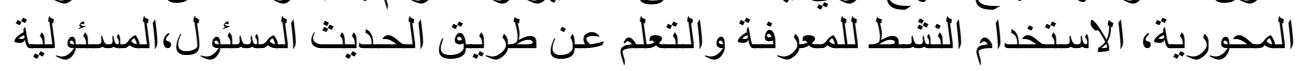

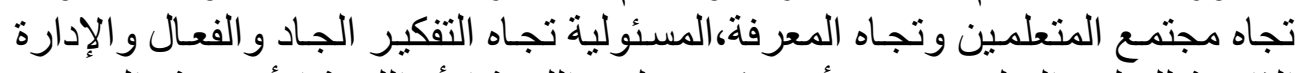

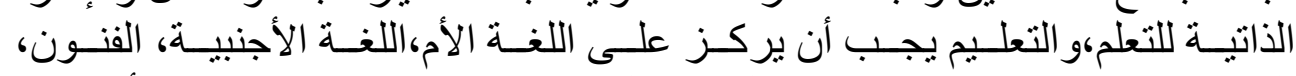

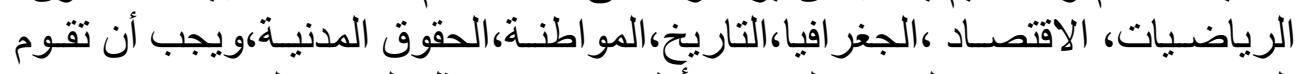

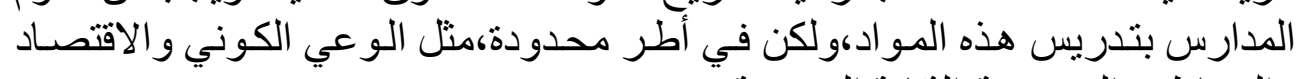
و المخاطرة المحسوبة، الثقافة البصرية الدورية. أدوار المعلم في ضوء المع مهارات القرن الحادي والعشرين:

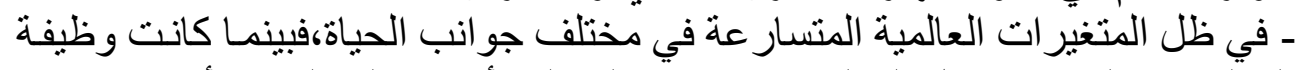

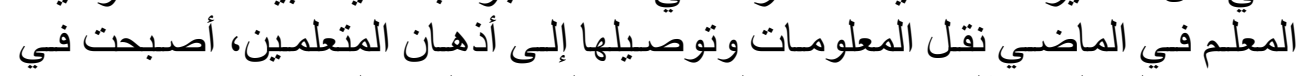

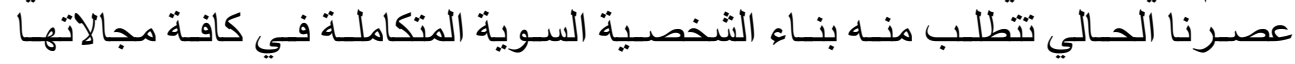

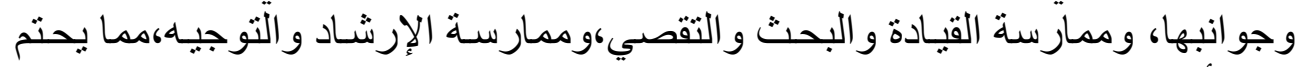

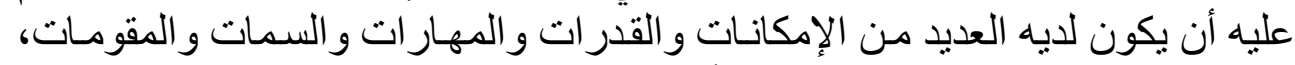

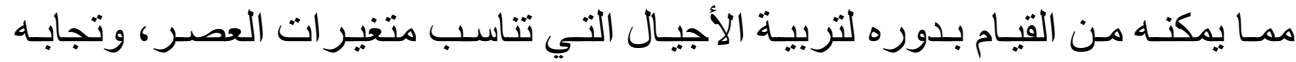

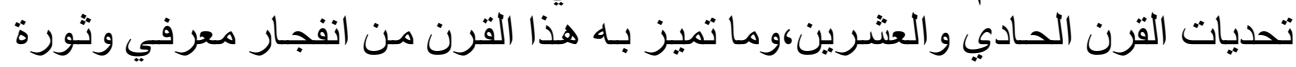

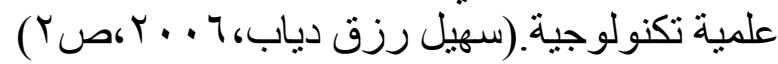

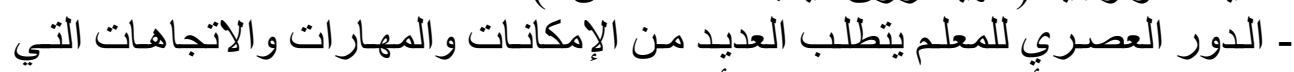

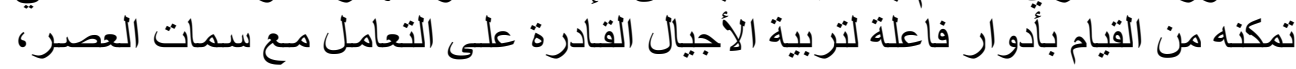

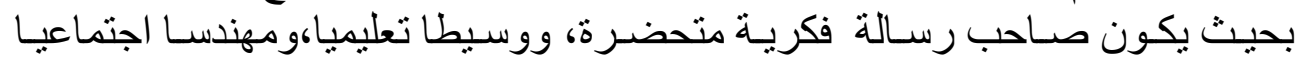

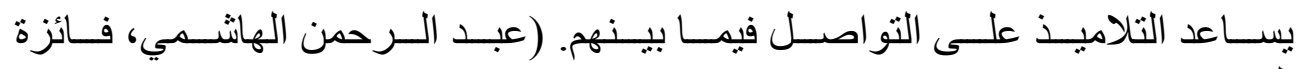

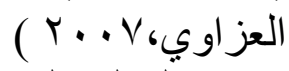
- يقف ألمعلم على رأس القائمين على عمليات التعلم،كونه المحور الأساسي في إدارة

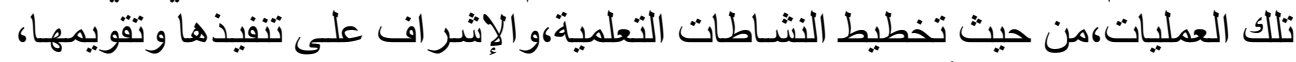

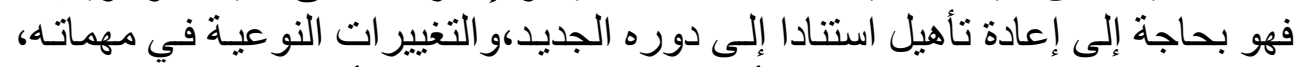

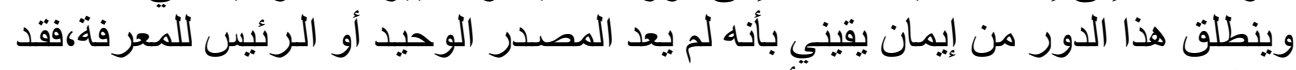

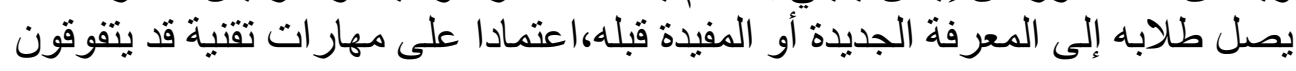

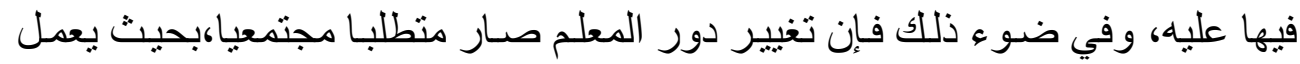


على إغناء المو اقف التعلّمية بالمثير ات المناسبة،ويناقش ويحاور طلبتهـه باعتبـاره قائدا

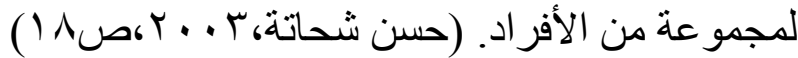

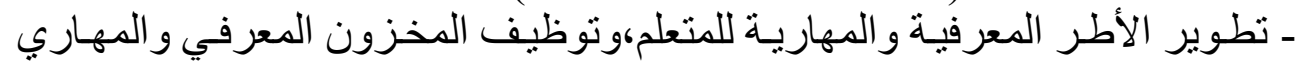

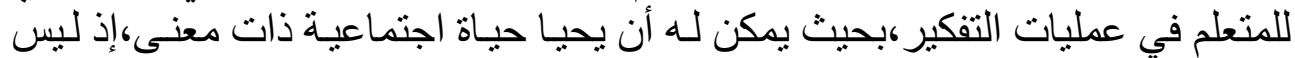

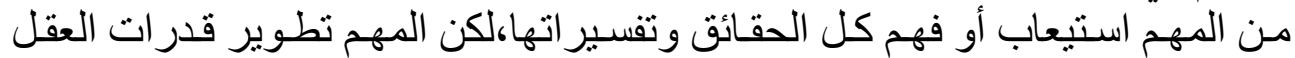

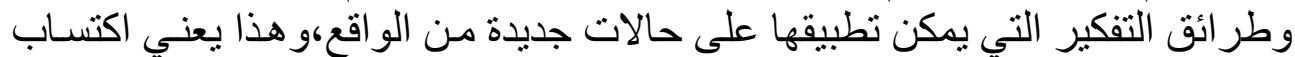

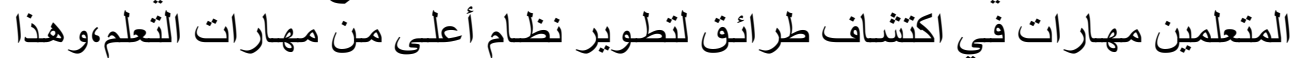

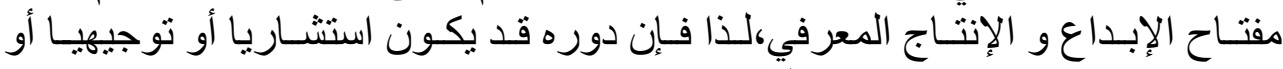

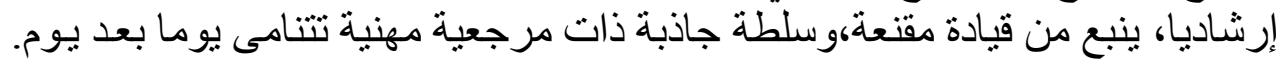

(Peterson,2003)

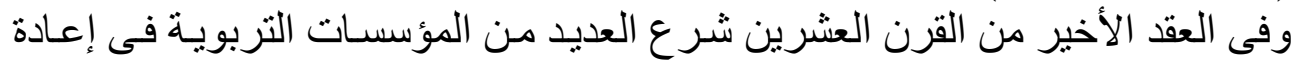

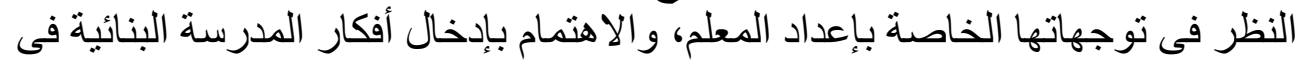

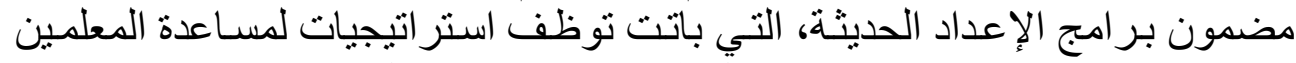

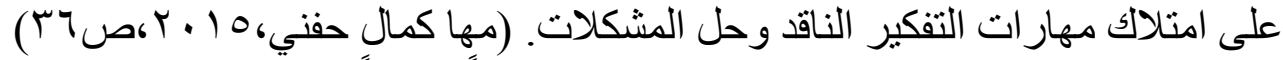

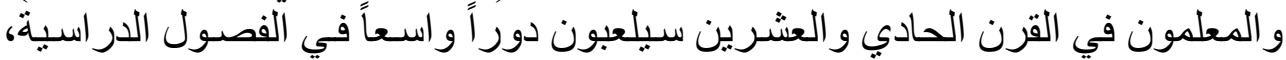

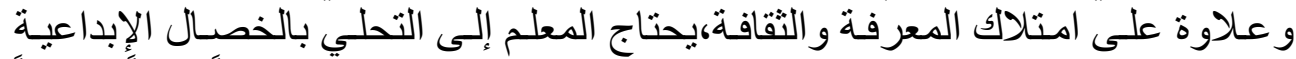

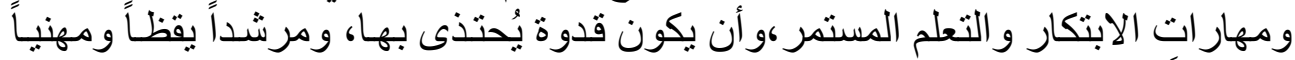

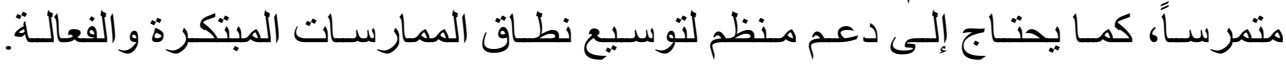

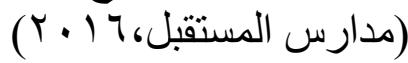

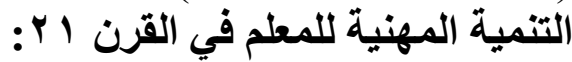

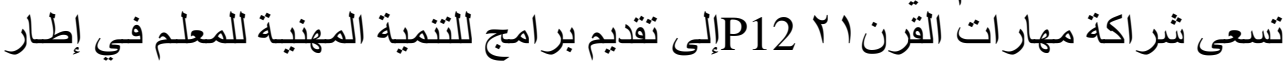

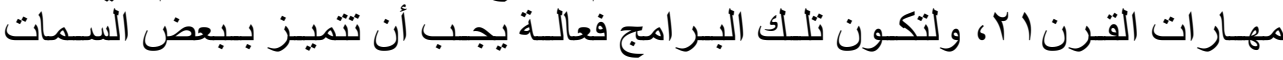
الرئيسة،منها: (Partnership for 21st Century Skills,2009d)

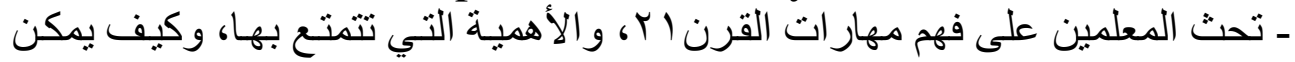
دمجها في عملية التدريس اليومية فئمين. ـ تيسر التعاون بين جميع المشاركين بها من معلمين ومديرين التهائ ومدربين و غير هم.

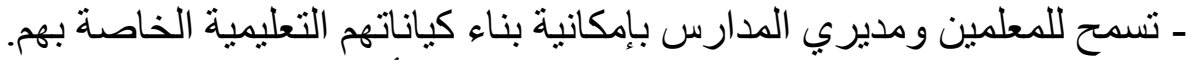

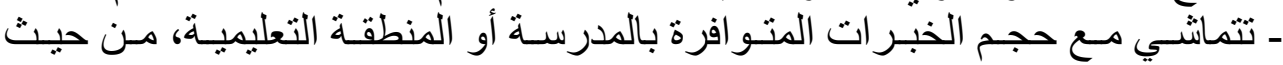

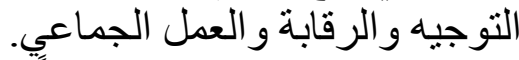

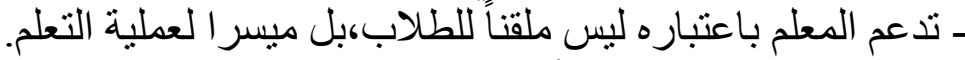

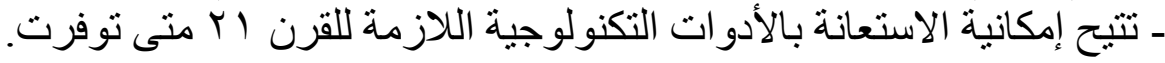


وقد أوصت شر اكة مهار ات القرن إب بمجمو عة من الإرشادات و الإجر اءات اللازمـة

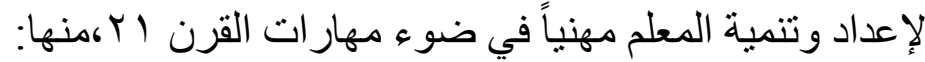

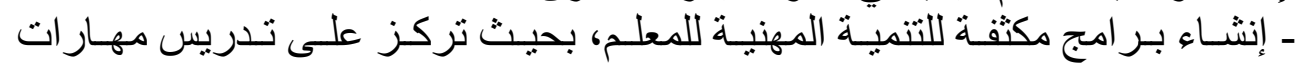

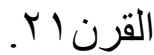

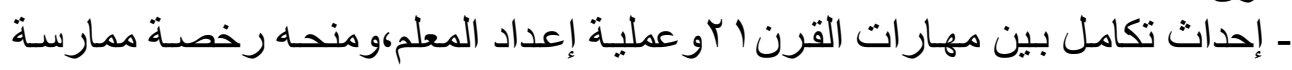
المهنة. ـ التعاون مع الإداريين و المعلمين لدعم التعليم المهني المتميز و القائم على علاقات تعاونية. - إنشاء فرق عمل قيادية على مستوى الإدارة التعليمية، لمتابعة الجهود المبذولة لتنمية

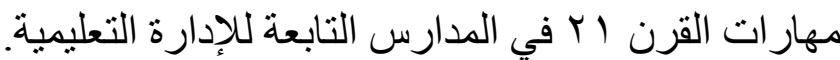

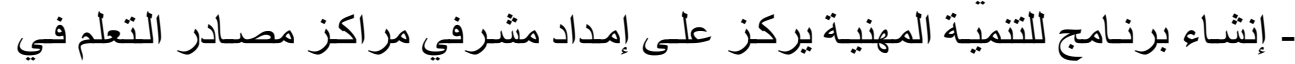

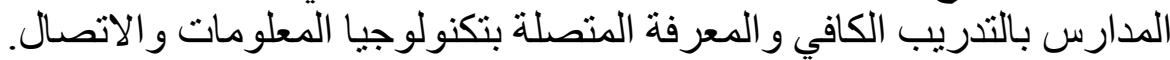

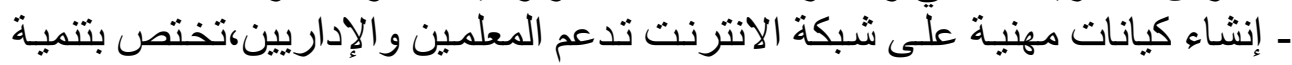

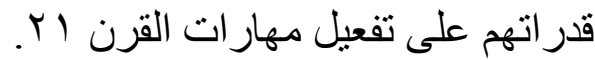

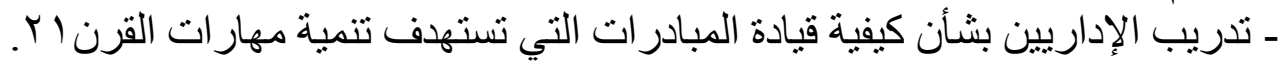

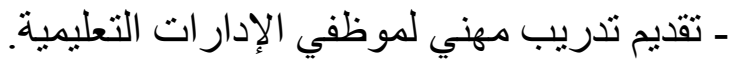

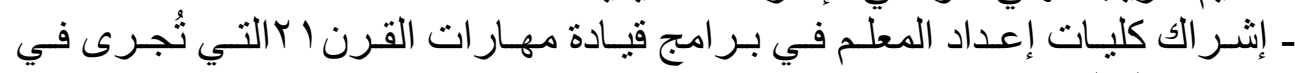
الإدار ات التعليمية. ـ دمج معايير التدريس ومهار ات القدات القرن ا ب، كلضمان أن المعلم بـات قادرًا على تدريس

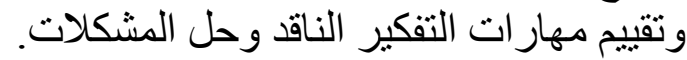

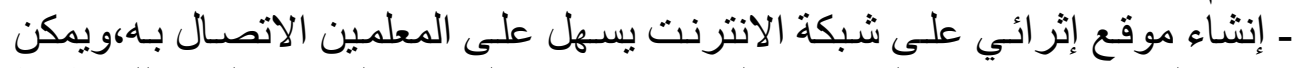

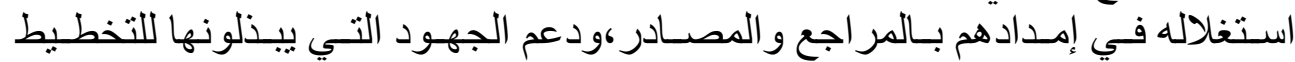
و التوصل الفعال لمهار ات القرن ابكي صفوفهم الدار اسية. ( Partnership for 21st (Century Skills,2009d

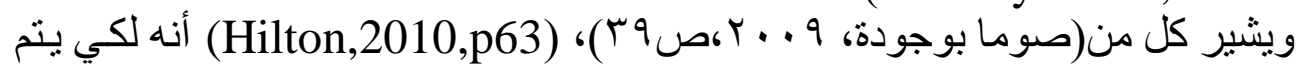

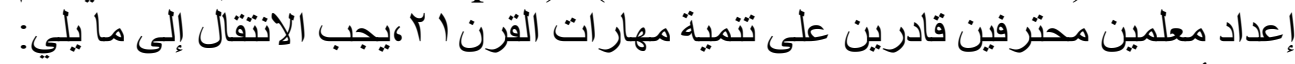

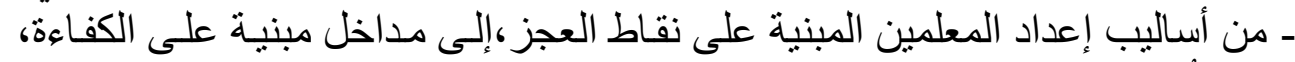

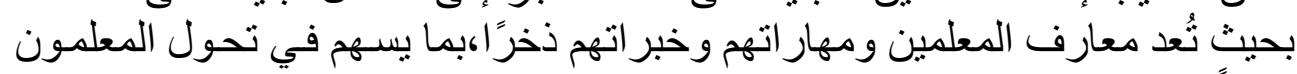

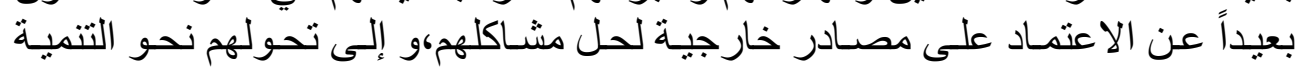

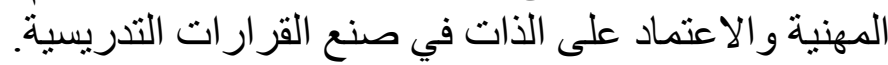

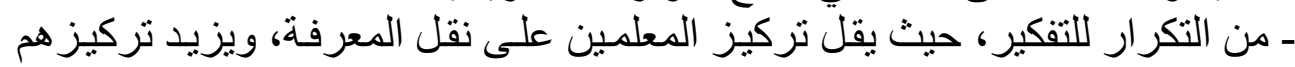

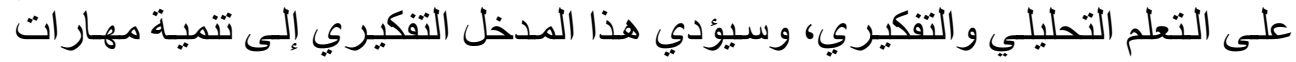


المعلمين في حل المشكلات وتحديد احتياجات الطلاب،و إجر اء أبحاث مصممة لتطوير

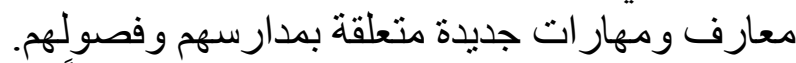

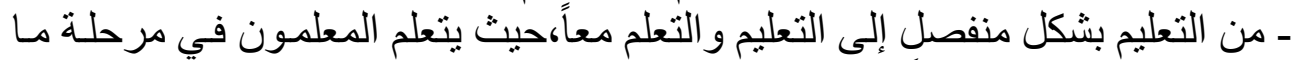

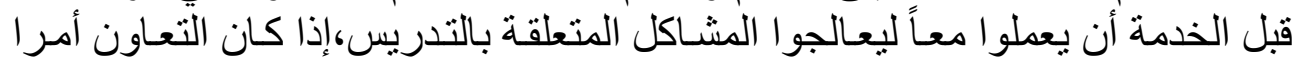

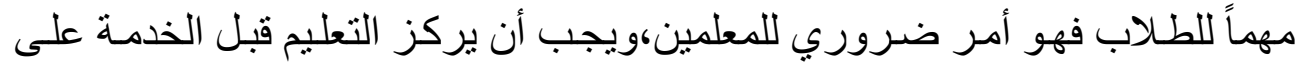

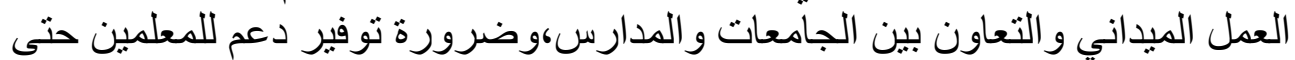

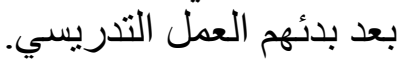

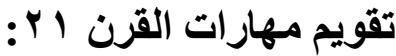

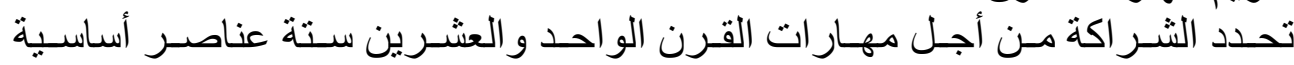

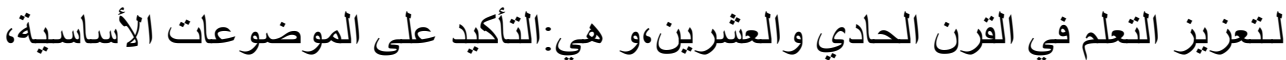

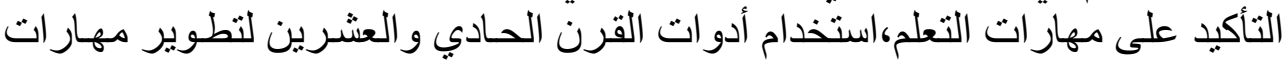

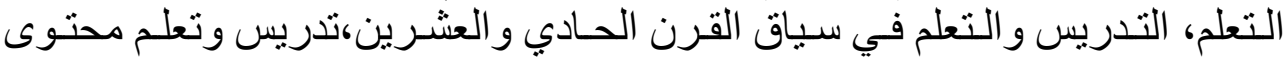

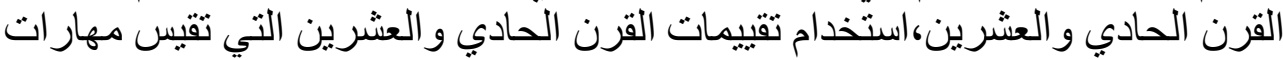
القرن الحادي و العشرين.

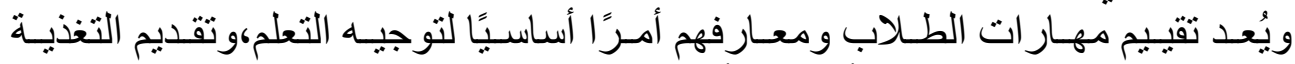

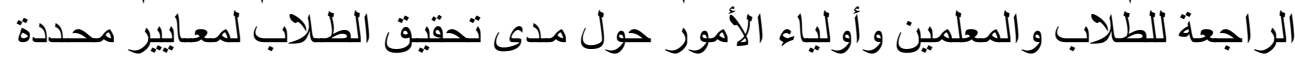

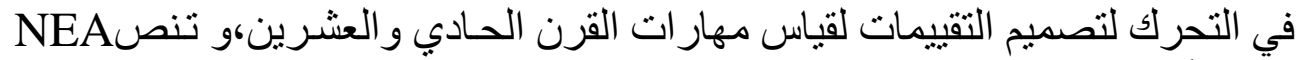

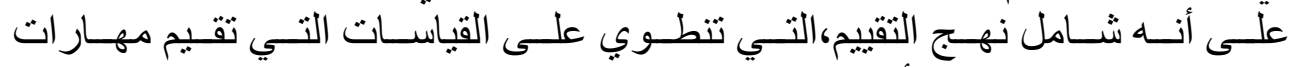

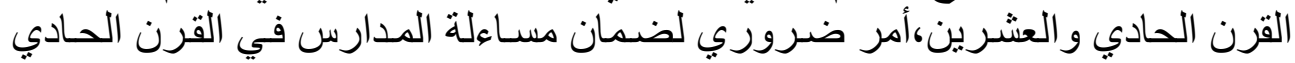

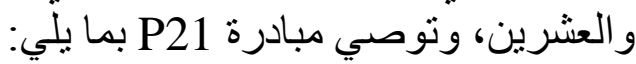
ـ تعتمد نظم التقييم على مقاييس متعددة لقدر ات الطلاب، التهي التي تشمل مهار ات القرن الحادي و العشرين.

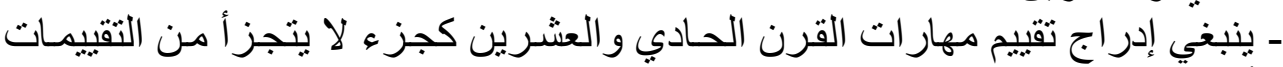

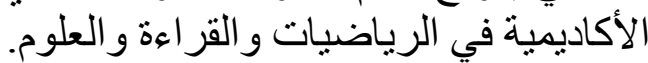

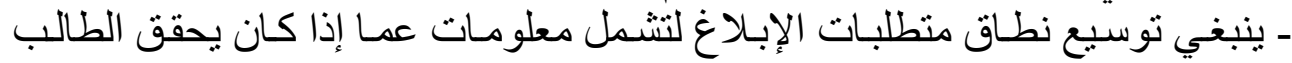
مهار ات القرن الحادي و العشرين.

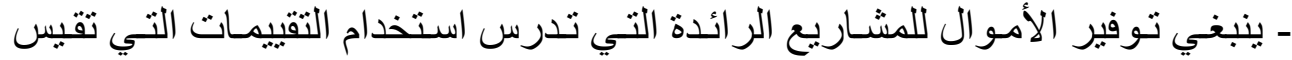

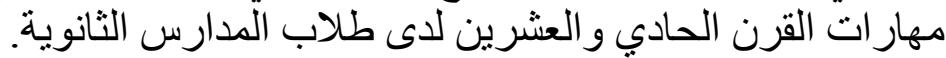

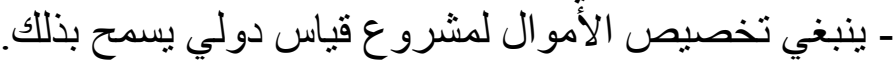

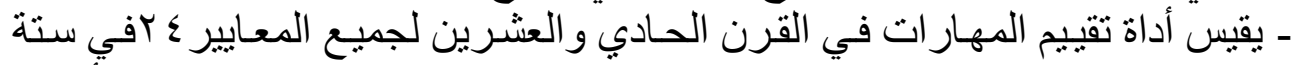

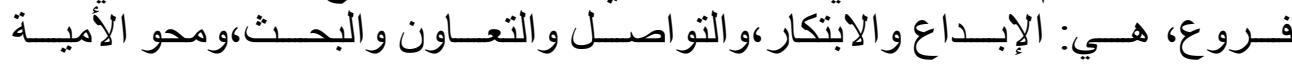

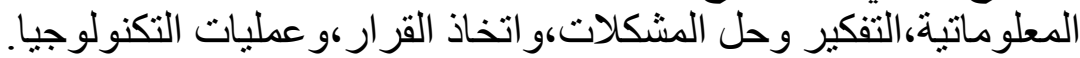




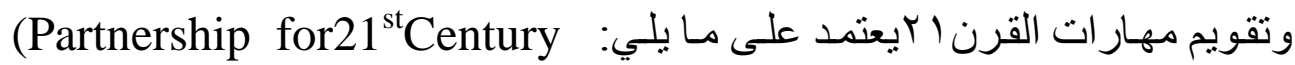
Skills,2009a)

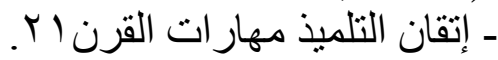

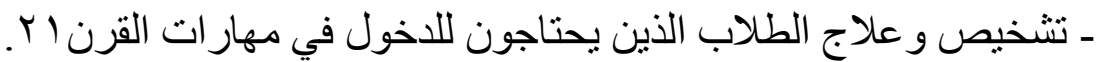

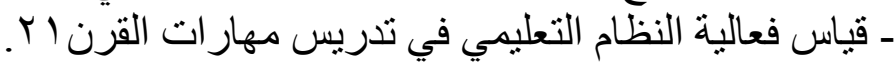

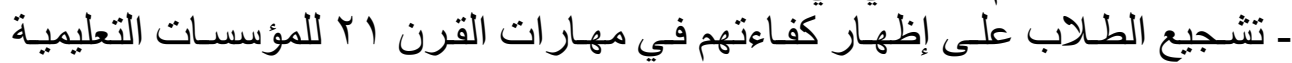
و المهنبين.

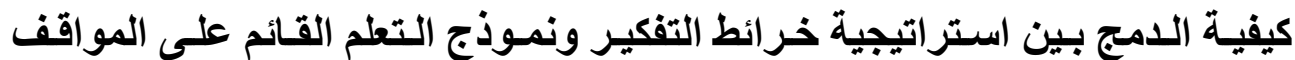

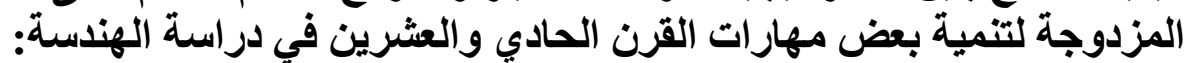

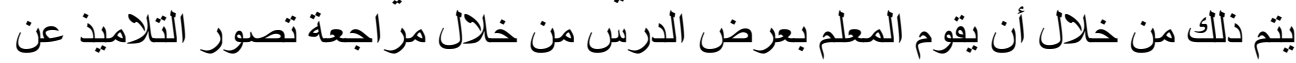

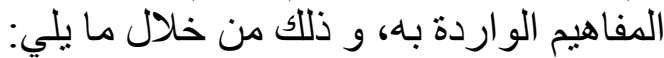

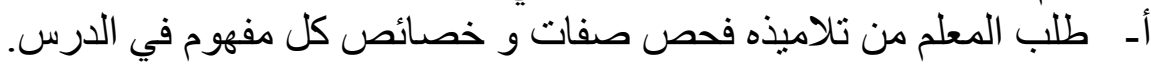

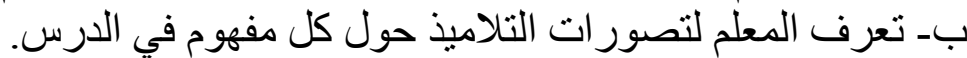
جـ تعرف المعلم لأسباب تصور تصورات التلاميذ الخطأ حول كل مفهوم في الدرس.

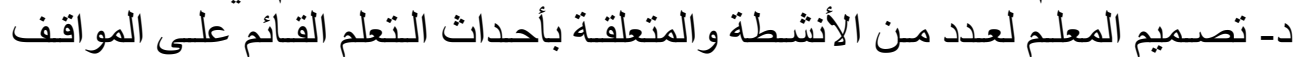

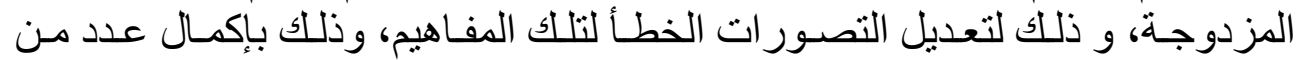

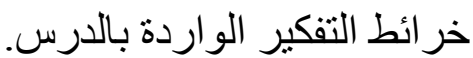

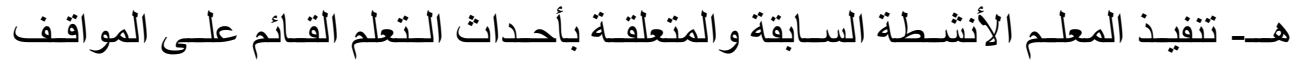

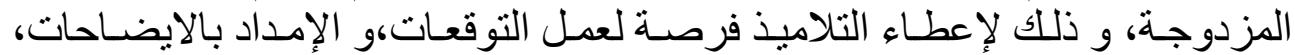
و التصدي للتنافر ، و بناء وجهة نظر ألتر أكثر علمية حول المفاهيم السابقة.

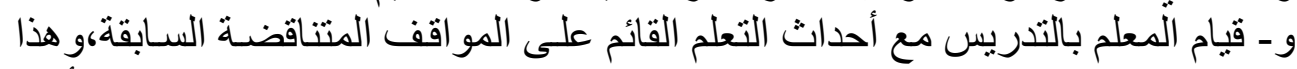

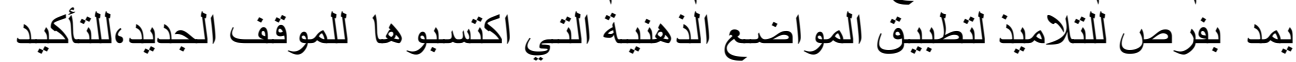

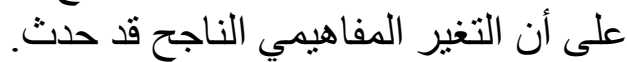

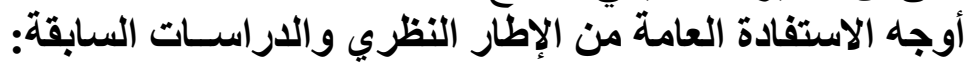

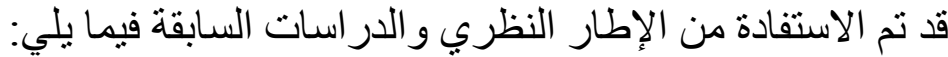

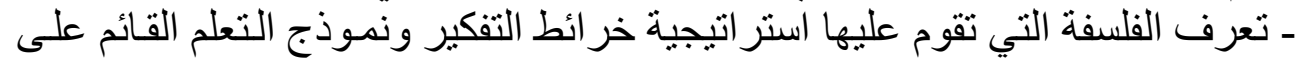
المو اقف المزدوجة في تتمية مهار ات القرن الحادي و العشرين.

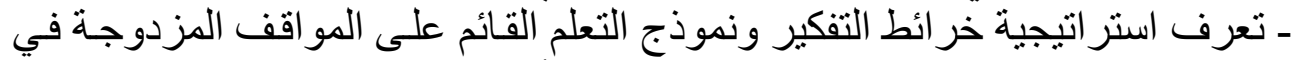

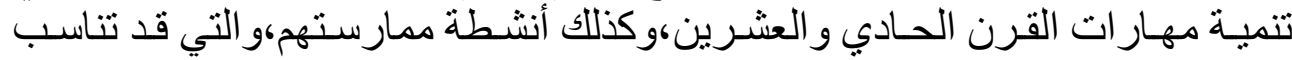

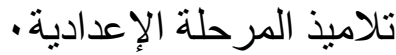




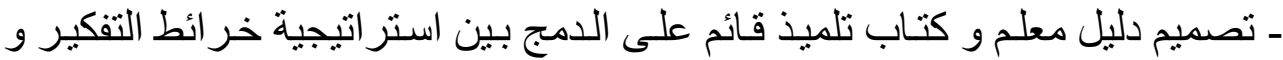

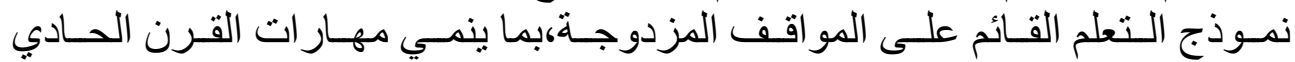
و العشرين. ـ اختيار التصميم التجريبي المناسب للبحث. التمان. ـ اختيار الأساليب الإحصائية المناسبة للإجابة عن أسئلة البحثث.

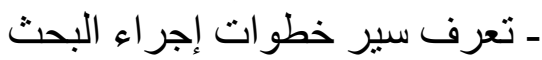

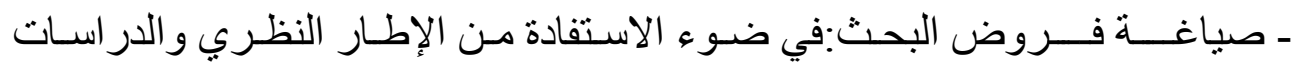

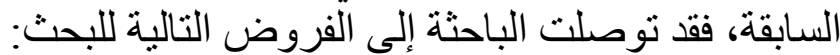

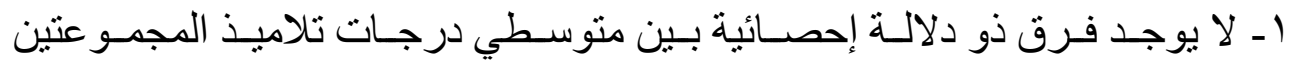

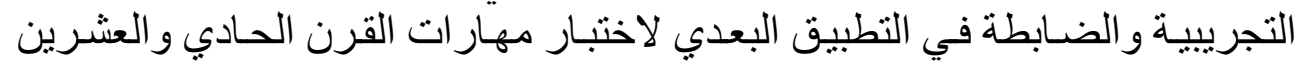

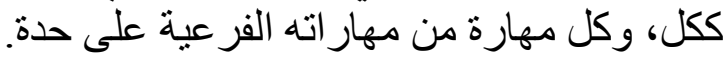

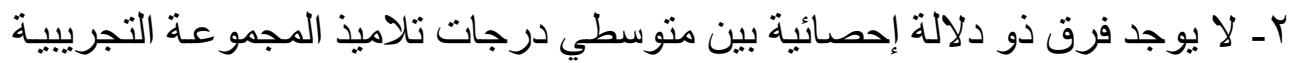

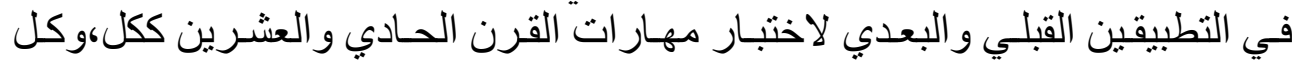

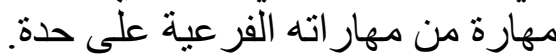

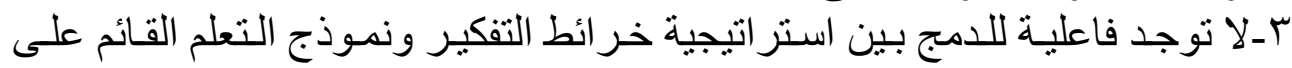

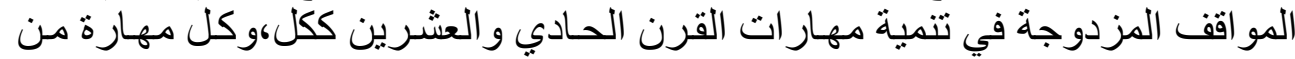

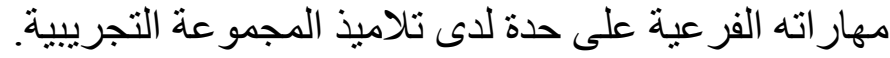

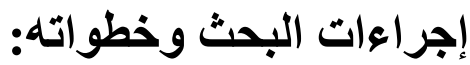

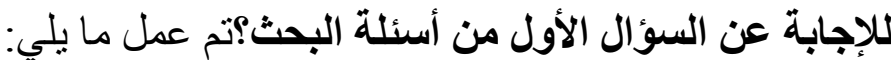

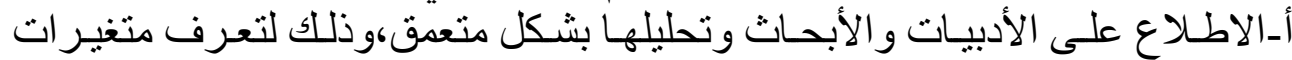

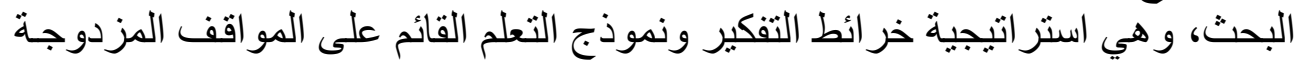

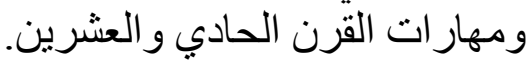

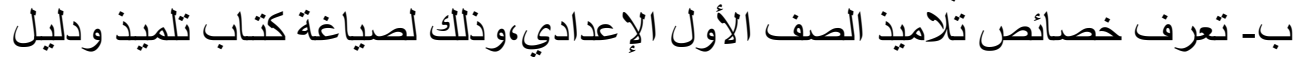

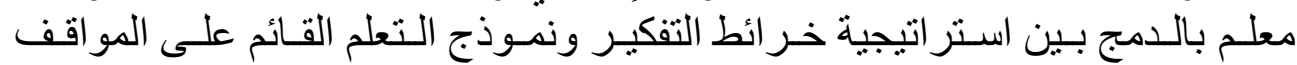

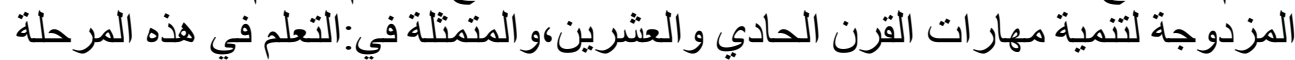

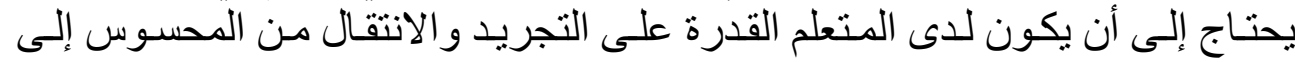

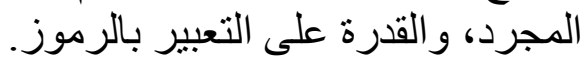

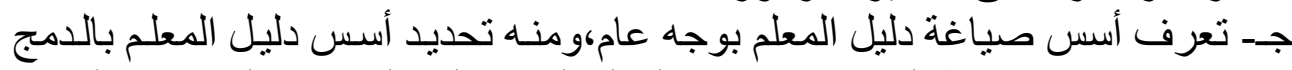

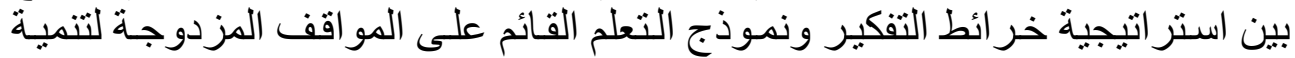
مهار ات القرن الحادي و العشرين لائ تلاميذ الصف الصف الأول الإعدادي. 


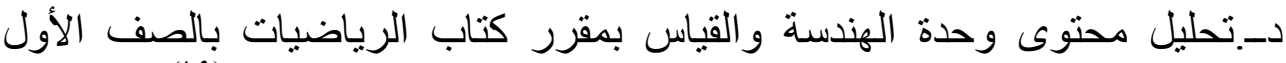

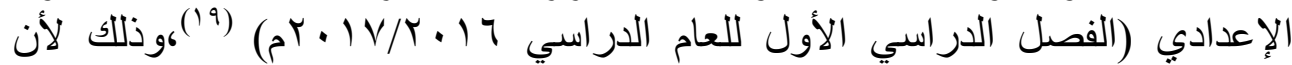

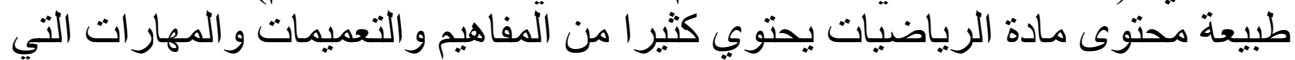

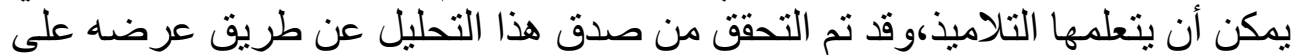

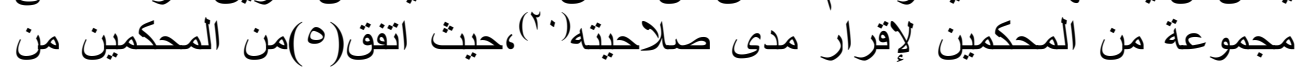

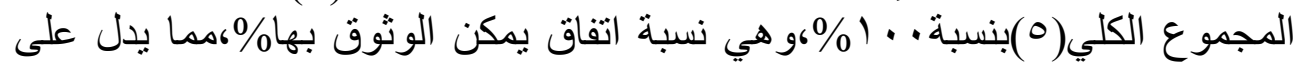

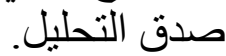
وقد تم التأكد من ثبات التحليل عن طريـق إعادته مرة أخرى،وقد تم استخدام معادلة

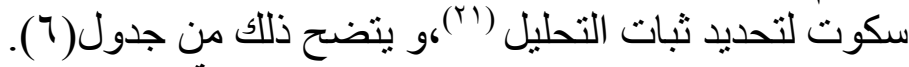

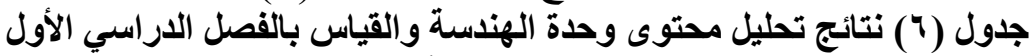

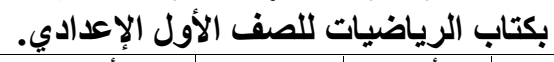

\begin{tabular}{|c|c|c|c|c|c|c|c|}
\hline $\begin{array}{c}\text { /\%+\%) } \\
\dot{r}(Y\end{array}$ & $\begin{array}{c}+\mathbf{l}+ \\
\%\end{array}$ & أ \%ب-\% & ب\% & \%أ & الثانية & الأولى & / وقت التحليل \\
\hline $1 \cdot r \wedge . \leqslant \wedge \leqslant q$ & $7 \leq .1 \leq$ & $1 . Y \Lambda_{-}$ & $\begin{array}{c}\text { rr.vi } \\
\%\end{array}$ & $\begin{array}{c}\mu . \varepsilon r \\
\%\end{array}$ & ro & rr & مفاهيم \\
\hline $1.09 .1 \mathrm{VV}$ & 70.99 & • & $\%$ YY.VI & \% rY.r人 & ro & rq & تعميمات \\
\hline lror..91r & $v \cdot . v V$ & 1.71 & $\%$ \% & $\%$ & rv & $\mathrm{r \Lambda}$ & مهارات \\
\hline rrrq.vq. & $r \ldots$ & 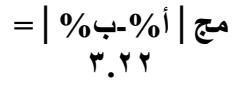 & $\%$ & $\%$ & $1 \cdot V$ & 1.0 & المجموع \\
\hline
\end{tabular}

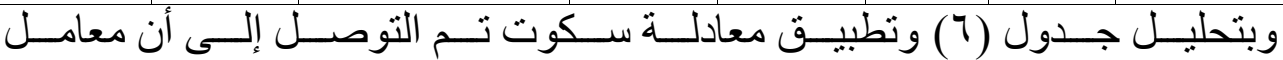
التبات=(90. 9 • )،و هذه النسبة مرتفعة،مما يؤدي إلى الثقة في أن التحليل يتميز بدرجة عالية من الثبات.

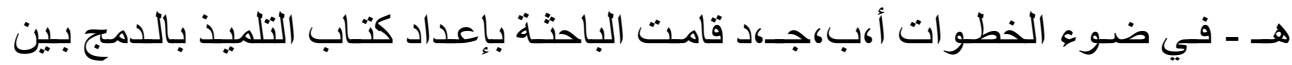

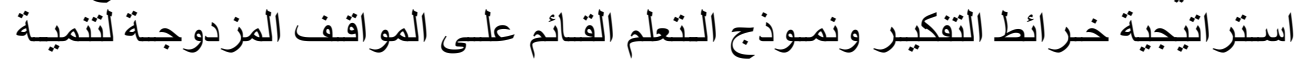

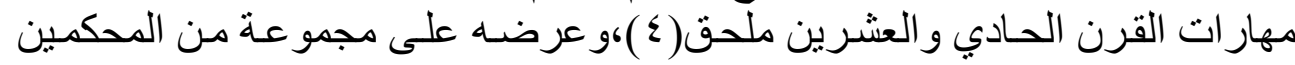
لتحديد مدى صدقه.

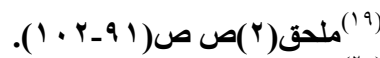

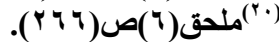

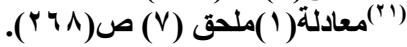




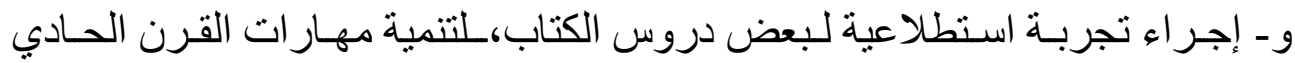

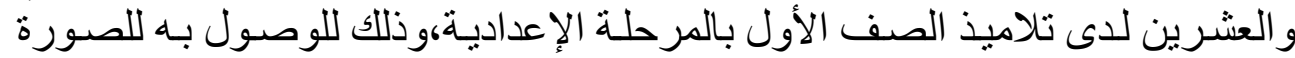

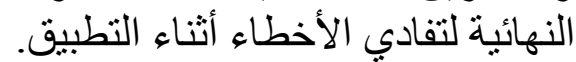

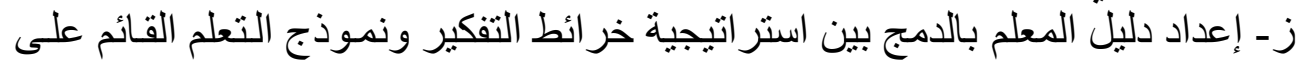

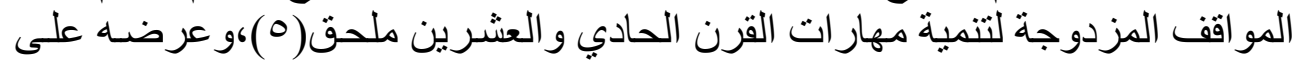

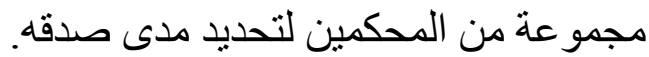

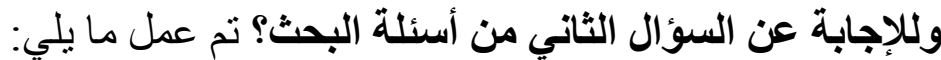

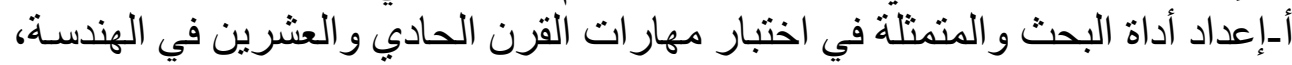

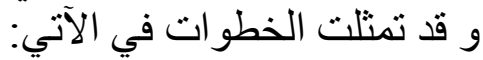

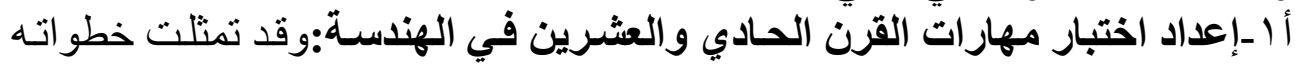

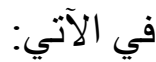
أ أُ أتحديد الأتهف من الاختبار:كان الهدف من الاختبار هو تحديد مدى امتلاك تلاميذ

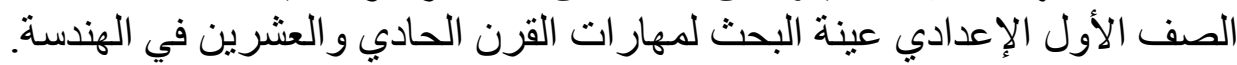

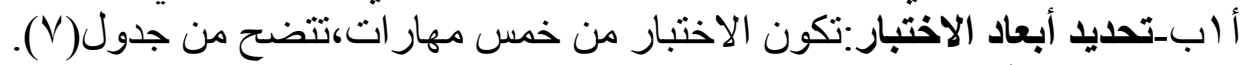

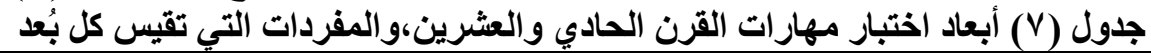

\begin{tabular}{|c|c|c|}
\hline المجموع - الموع & أَرقام المفردات & 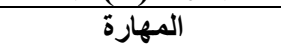 \\
\hline مفردات - مفرات & $(0) \cdot(\xi) \cdot(\Gamma) \cdot(r) \cdot\left({ }^{\prime}\right)$ & 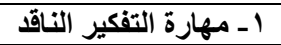 \\
\hline آمفردات & $(1) \cdot(1 \cdot) \cdot\left(q^{(}\right) \cdot(\wedge) \cdot(\mathrm{V}) \cdot(\mathrm{Y})$ & 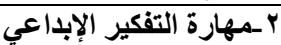 \\
\hline 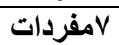 & $(1 \wedge) \cdot(1 V) \cdot(17) \cdot(10) \cdot(1 \varepsilon) \cdot(1 Y) \cdot(1 Y)$ & ب آـمهارة حل المشكلات \\
\hline ז'مفردات & $(Y \xi) \cdot(Y Y) \cdot(Y Y) \cdot(Y))(Y \cdot) \cdot(1 q)$ & ع ـ-مهارة اتخاذ القرار \\
\hline 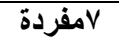 & 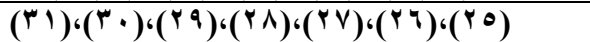 & مـ مهارة التواصل \\
\hline آل امفردة & & المجموع \\
\hline
\end{tabular}

أ أجـتحديد نوع مفردات الاختبار:قد تمثلت المفردات في(الاختيار من

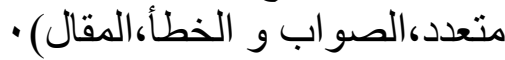
أ أدـصياغة مفردات الاختبار: تكون الاختبـار من مجمو عـة من المفردات،تتمثل في

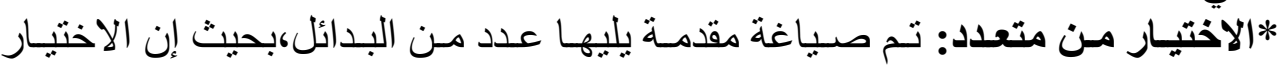
الصحيح موزع عشو ائيا. *الصواب و الخطأ:تم فيها صياغة عبارة عائة إما صـائبة أو خاطئة،و المطلوب من التلميذ الحكم على صحتها أو خطنئها

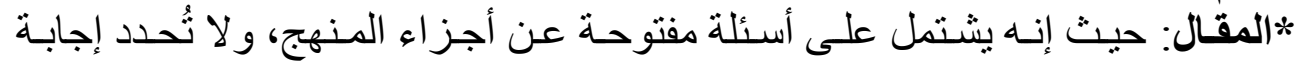

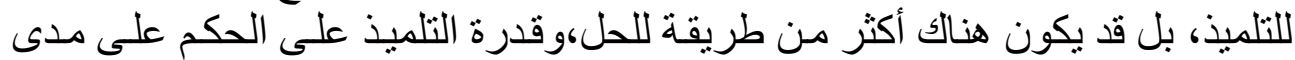
مناسبة الحل الموجود للمسألة. 


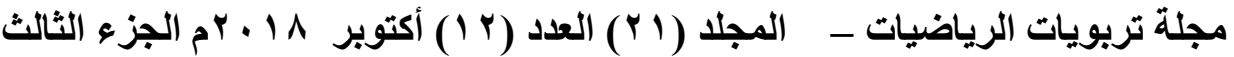

\section{أ (هـتحديد الأوزان النسبية لكل موضوع والمتضمنة بالاختبار :ويتضح ذلك من جدول}

جدول (^) الأوزان النسبية لكل موضوع من موضوعات وحدة الهندة و القياس بالصف الأول الإعدادي،واعوالمتضنة منوفي بالاختبار.

\begin{tabular}{|c|c|c|c|c|c|}
\hline النسبي لكليهما الوزن & الوزن النسبي لعدد & لعدد الحصص النسبي & الصفحات & الحصص & البيان \\
\hline$\% 10.940$ & $\% 17 . \leqslant V$ & $\% 10 . r \wedge$ & Y.A. & $r$ & 1 ـمفاهيم هندسية \\
\hline$\% \mid r . \cdot \wedge 0$ & $\% 17 .\{V$ & $\% \vee . \vee$. & Ү.^. & 1 & r ـ التطابق \\
\hline$\%$ YI.人1 & $\%$ \% . Y & $\% 10 . \mu \wedge$ & $\varepsilon . \wedge$. & $r$ & rا_تطابق المثلثات \\
\hline$\%$ \% . 07 & \% rr.ro & $\% r \cdot . V V$ & r.A. & $\varepsilon$ & צ ـأيام الأسبوع \\
\hline$\%$ \%r.7r & $\% \backslash 7 . \& V$ & $\% r \cdot . V V$ & Y.A. & $\varepsilon$ & •ـ إنشاءات هندسية \\
\hline$\% 1 \ldots$ & $\%$ & $\% 1 \ldots$ & V اصفحة V & rا حصة & المجموع \\
\hline
\end{tabular}

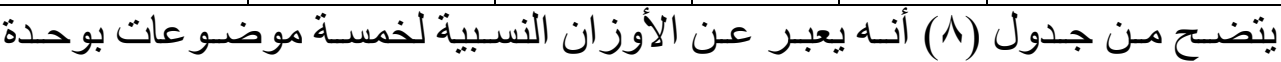

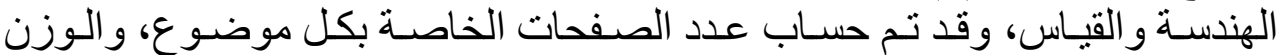

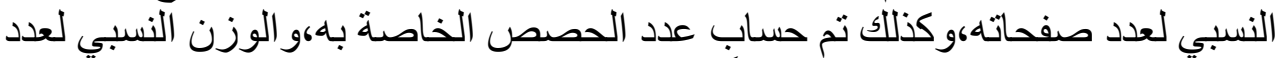

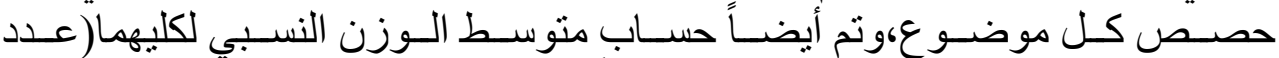

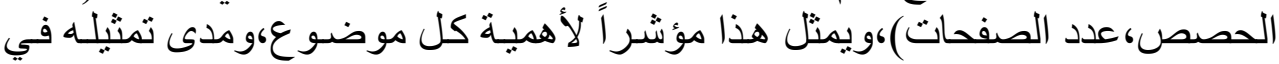

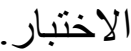
أ أو -إعداد جدول مو اصفات اختبار مهار ات القرن الحادي و العشرين(وفقاً للأوزان

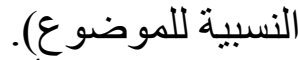
جدول (9) توزيع أبعاد اختبار مهارات القرن الحادي والعشرين على كل درس من دروس وحدة

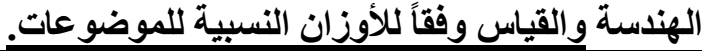

\begin{tabular}{|r|r|r|r|r|r|r|}
\hline & & & & \\
\hline & & & & \\
\hline
\end{tabular}




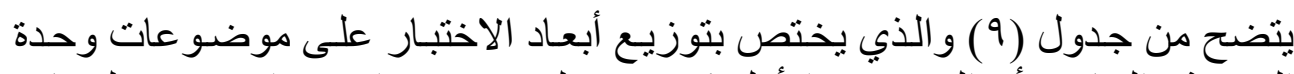

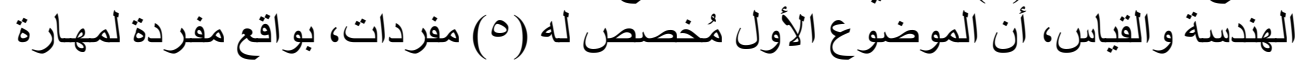

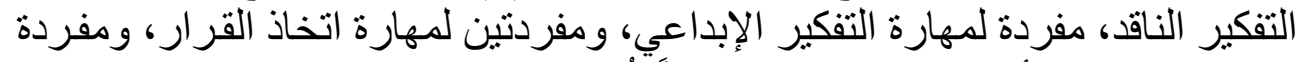

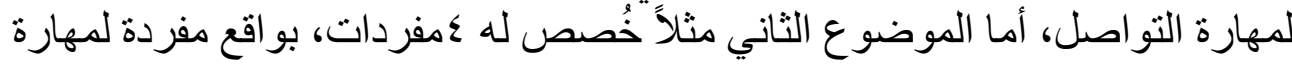

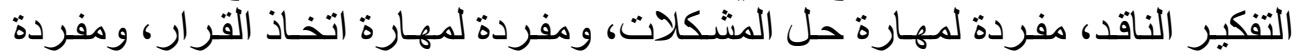

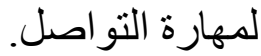
أ الز-صياغة مفردات الاختبار: تكون الاختبار من مجموعة من المفرداردات تتمثل في

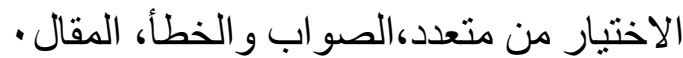

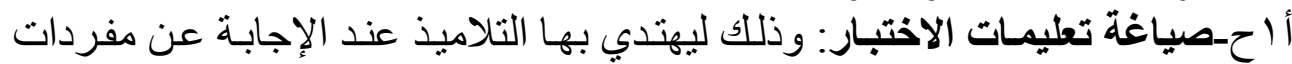

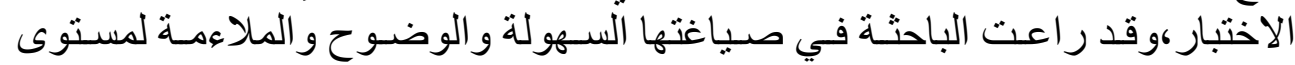
التناميذ.

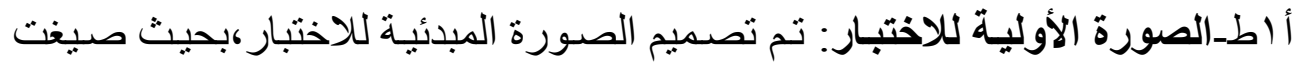

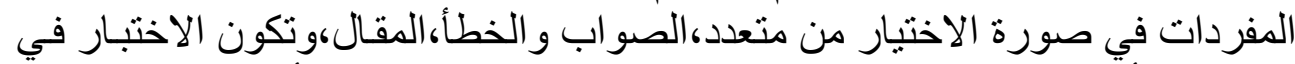

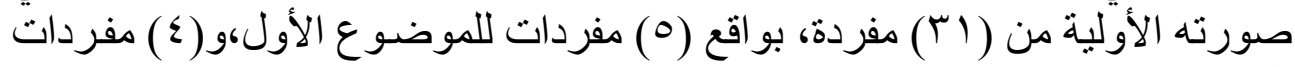

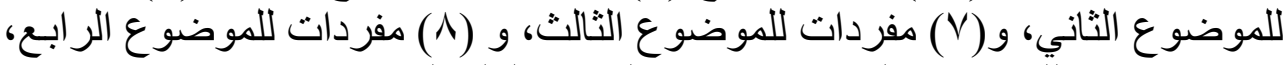

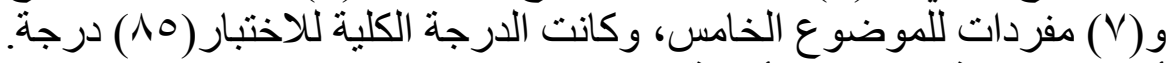

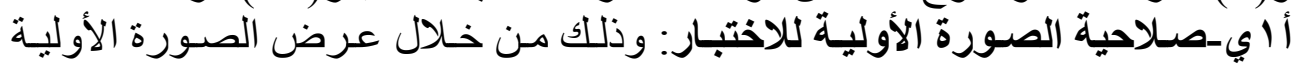

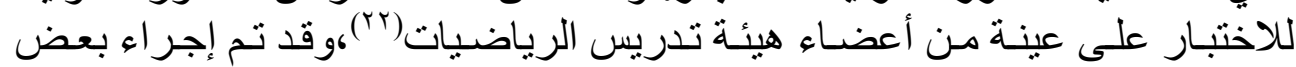

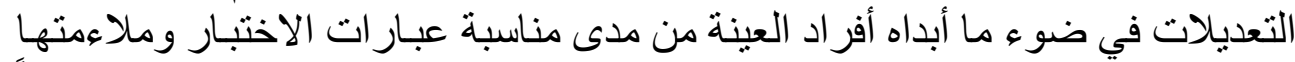

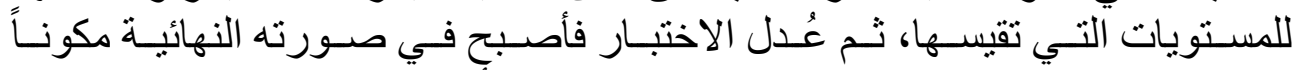

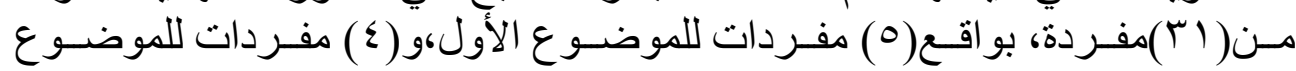

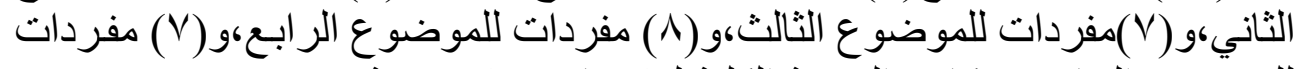

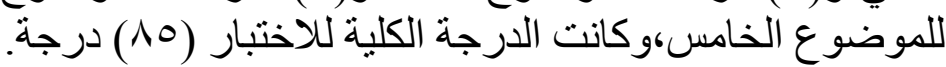

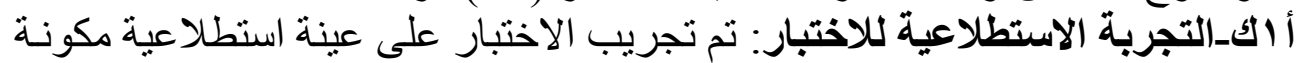

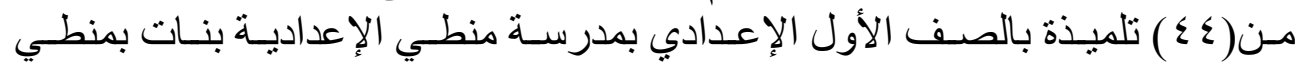

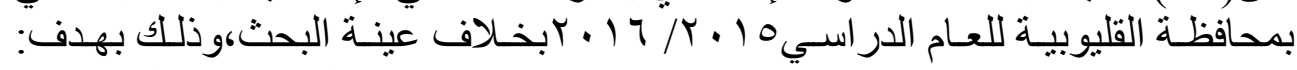

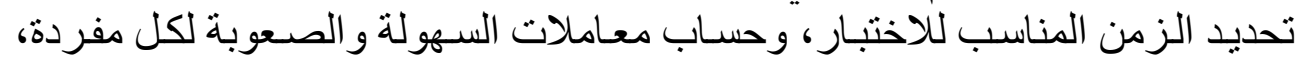

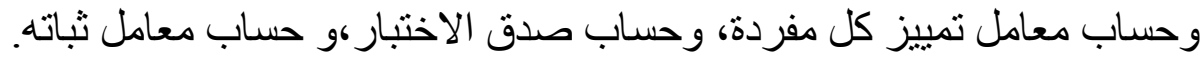

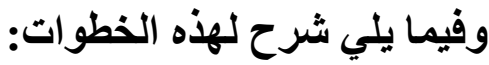




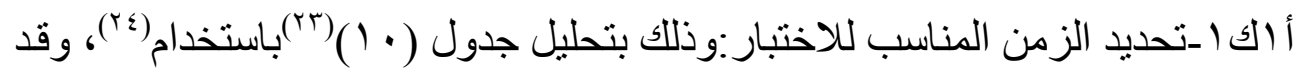
بلغ متوسط الأزمنة (9V) دقيقة، أي ما يقرب الزبن من الساعتين إلا الثلث.

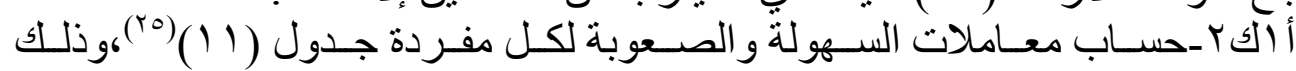

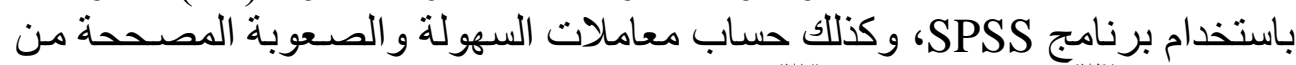

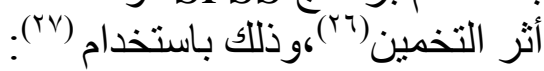

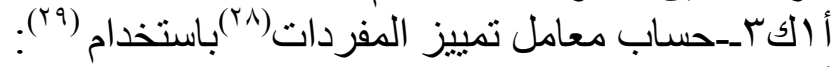

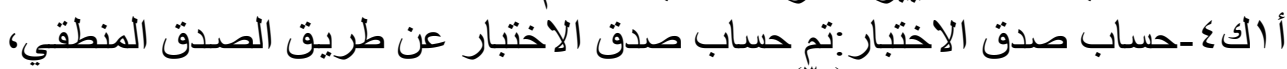

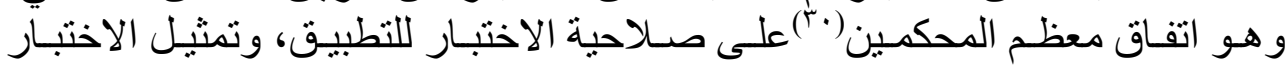

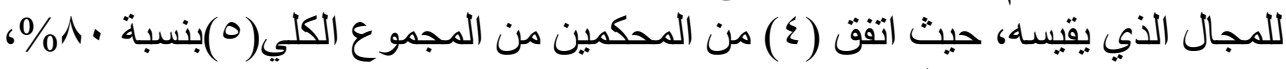

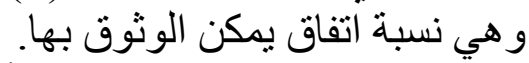
وقد تم حساب صدق الاختبار أيضاً عن طريق التهاق تعيين معامل الاتساق الداخلي

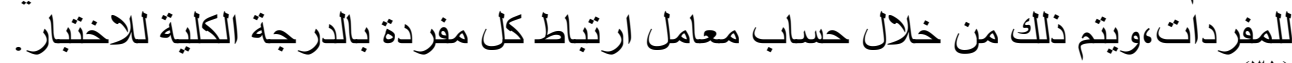

أ الكهـحسـاب ثبـات الاختبـار :تم حسـاب ثبـات الاختبـار باسـتخدام معادلـة جتمــان

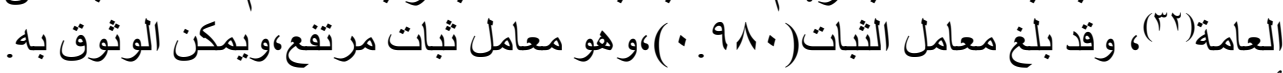

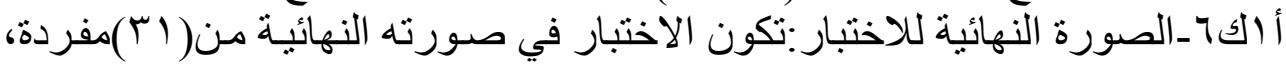

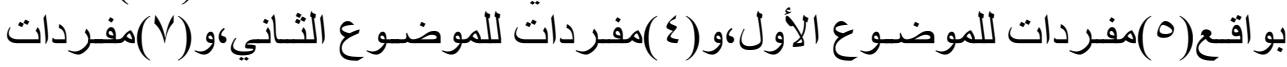

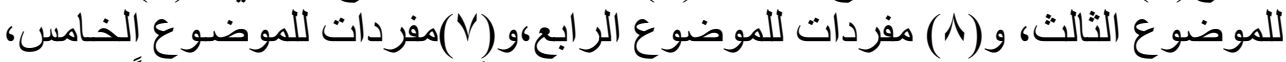

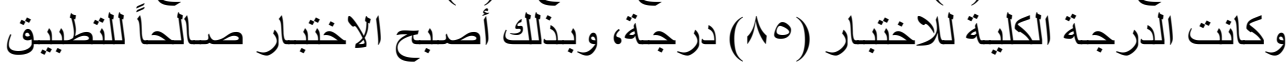
على عينة البحث.

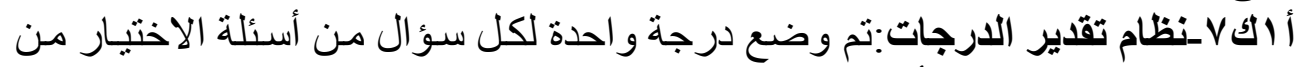

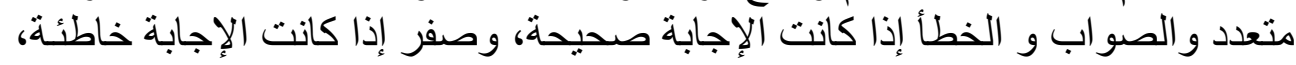
و عدد من الدرجات بساوي عدد الخطو ات للأسئلة المقالية. منهجية البحث: البرجات

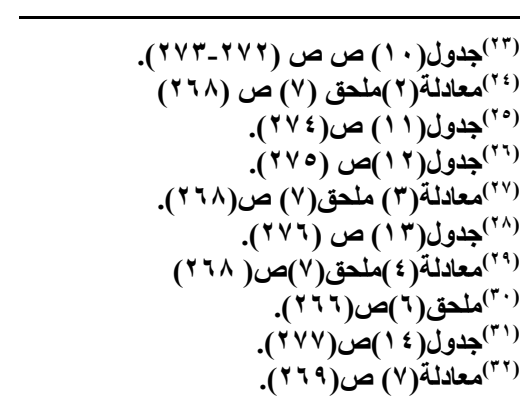


بـالتصميم التجريبي وعينة البحث:استخدم البحث الحالي التصميم التجريبي القائم

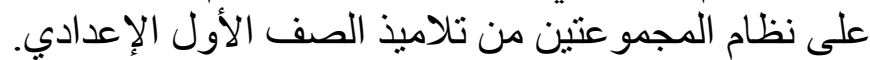

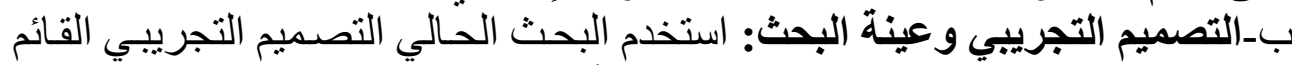

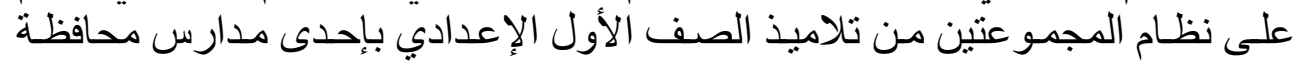

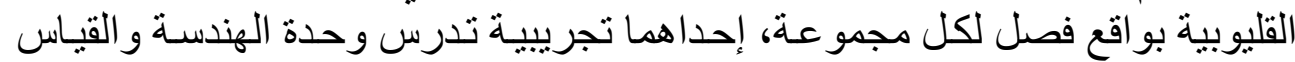

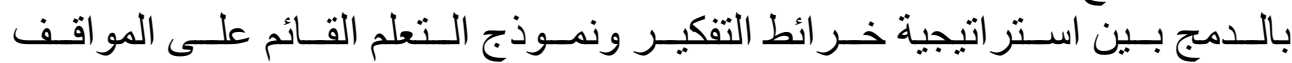

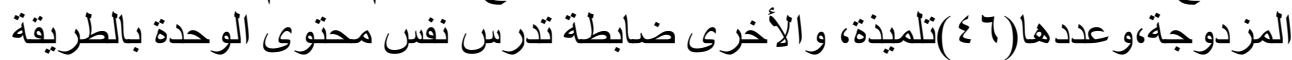

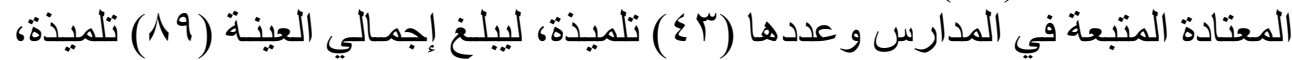

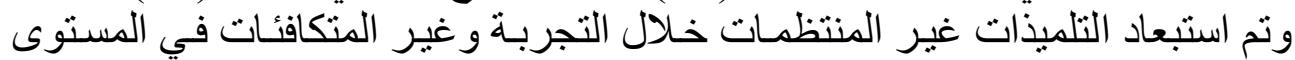

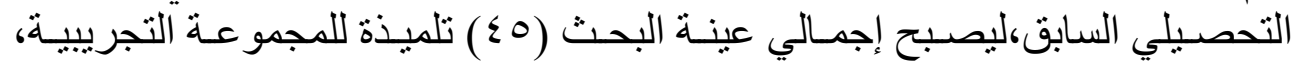
و(1) تلميذة للمجمو عة الضابطة.

جدول (0 1 ) عينة البحث التجريبية

\begin{tabular}{|c|c|c|c|}
\hline العدد & المجموعة & الفصل & اسم المدرسة \\
\hline$\leqslant 0$ & تجريبية & $1 / 1$ & منطي الإعدادية بنات بمنطي \\
\hline$\xi 1$ & 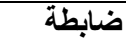 & $r / T$ & \\
\hline$\Lambda \tau$ & مجمو عتان & فصلان & المجمو \\
\hline
\end{tabular}

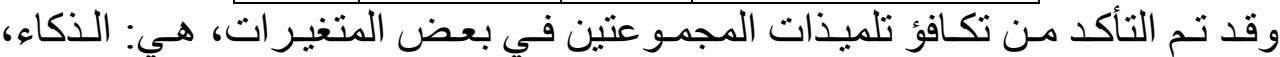

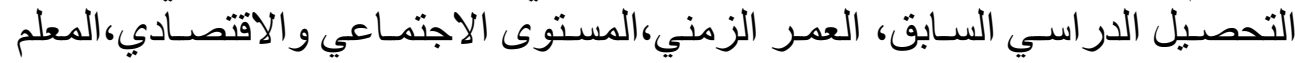
القائم بالتدريس.

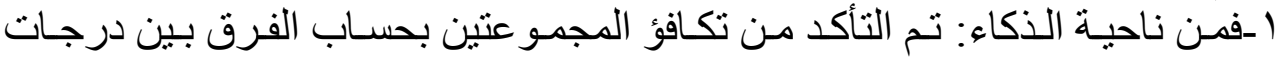

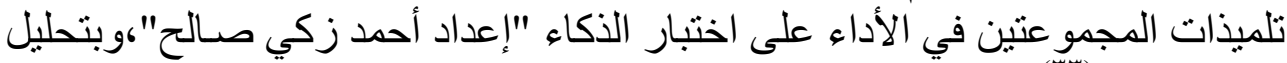

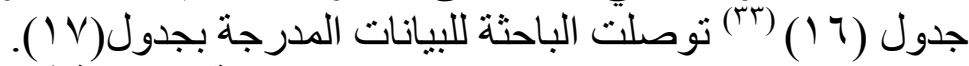
جدول (IV ) الفرق بين المجموعتين التجريبية والضابطة في اختبار الذكاء.

\begin{tabular}{|c|c|c|c|c|c|}
\hline مستوى الدلالة & ت & $\varepsilon$ & b & $\dot{ن}$ & المجموعة \\
\hline \multirow[t]{2}{*}{ غير دالة } & \multirow[t]{2}{*}{$\because \leqslant V$} & V.VVO & $\leqslant 1 . \cdot 19$ & $\leqslant 0$ & التجريبية \\
\hline & & $9 . \wedge 4 \%$ & $\$ 1 . \ldots$ & $\leqslant 1$ & الضابطة \\
\hline
\end{tabular}

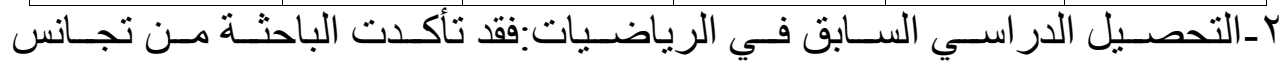

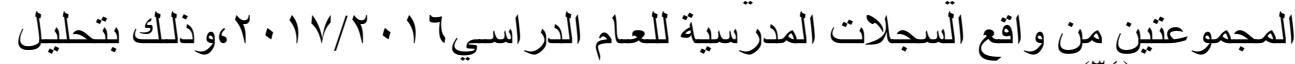

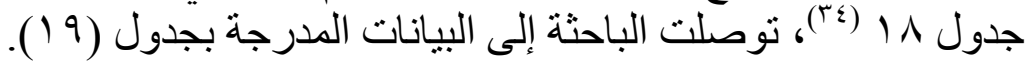




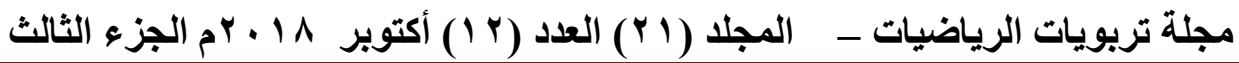

جدول (9 9 () الفرق في التحصيل الدراسي السابق بين المجموعتين الضابطة والتجريبية.

\begin{tabular}{|c|c|c|c|c|c|c|}
\hline مستوى اللالالة & ت & $\varepsilon$ & P & ن & درجة الاختيّار & المجموعة \\
\hline \multirow[t]{2}{*}{ غير دالة } & \multirow[t]{2}{*}{1.041} & 1.994 & $4 . .804$ & $\leqslant 0$ & \multirow[t]{2}{*}{0.} & التجريبية \\
\hline & & $\Lambda . Y \leqslant Y$ & $r r . \wedge r q$ & «1 & & الضابطة \\
\hline
\end{tabular}

من جدول (9 (1) يتبين أن الفرق ليس دال إحصائيا

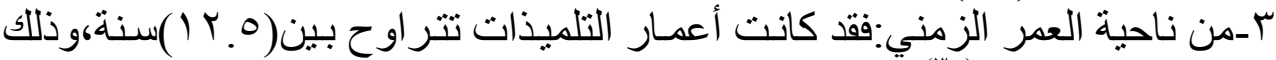

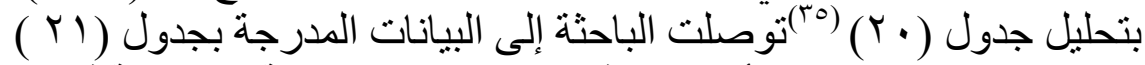
جدول (Y ا Y الفرق بين أعمار تلميذات المجموعتين التجريبية و الضابطة في العمر الزمني.

\begin{tabular}{|c|c|c|c|c|c|}
\hline مستتوى الدلالة & 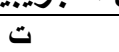 & $\varepsilon$ & 5 & $\dot{ن}$ & المجموعة \\
\hline \multirow[t]{2}{*}{ غير دالة } & \multirow{2}{*}{$\cdot \wedge \wedge \theta_{-}$} & .099991 & Tr.\&Y. & $\leqslant 0$ & التجريبية \\
\hline & &.$r \ldots l$ & $1 Y . \leqslant \vee \wedge$ & « & الضابطة \\
\hline
\end{tabular}

بتحليل جدول (Y (Y) يتبين أن هذا الفرق ليس دال إحصائياً

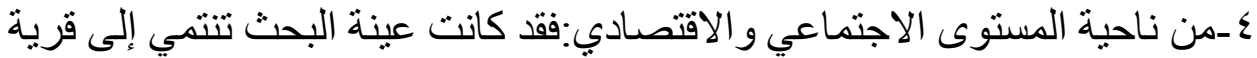

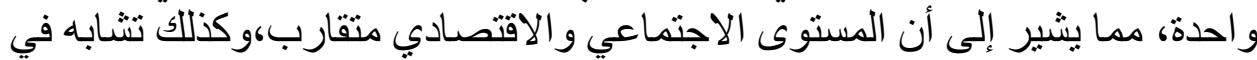
الخبر ات التعليمية السابقة.

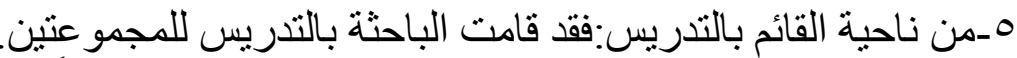

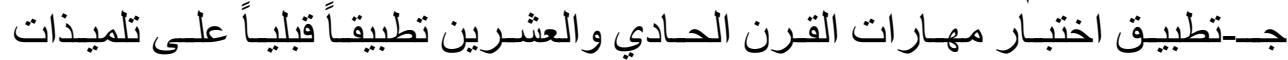

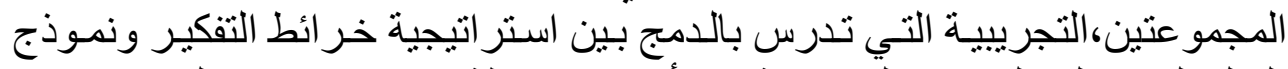

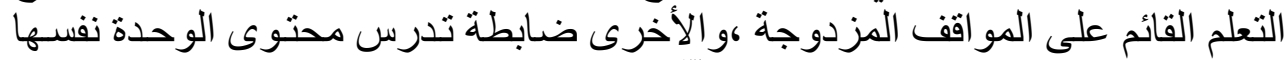

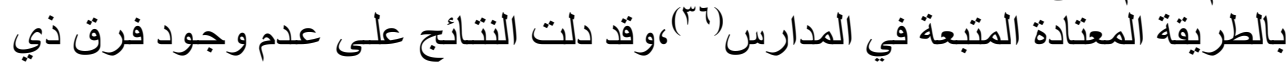

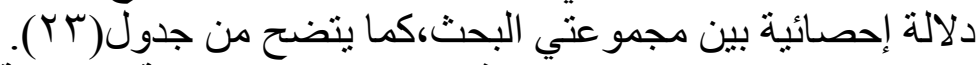

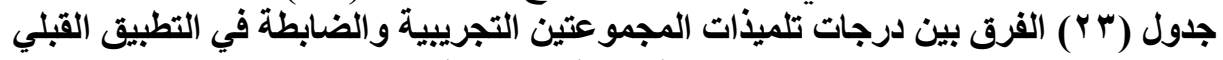
لاختبار مهارات القرن الحادي و العشرين.

\begin{tabular}{|c|c|c|c|c|c|c|c|}
\hline الاختبار ككل & التواصل & اتخاذ القرار & حـ & التفكيــــــ & التفكيـــر & المهارة & \\
\hline $1.7 \ldots$ & 1.719 & 1.719 & $1 . \wedge 7 V$ & $1 . \vee \vee \wedge$ & $1.0 \mathrm{VA}$ & م & \multirow[t]{4}{*}{ التجريبية } \\
\hline \&.Yrq & $\cdot \wedge \vee \varepsilon$ & $1.1 \cdot \varepsilon$ &. .179 & $\cdot .9 V \leq$ & $\cdot . \wedge q Y$ & $\varepsilon$ & \\
\hline $.9 r \Lambda_{-}$ & $1.91 V_{-}$ & $\cdot 0 \cdot \Lambda_{-}$ & $\because \vee v 0$ & $.0 \leqslant 9$ & I.YVY- & قيمة ت & \\
\hline غير دالة & غير دالة & غير دالة & غير دالة & غير دالة & غير دالة & مستوى الدلالة & \\
\hline $9 . \% 9$. & $r_{.} \cdot \leq q$ & 1.1 .0 & $1 . \wedge 0 \leqslant$ & $1 . \wedge \vee \wedge$ & 1.1 .0 & م & \multirow{2}{*}{ الضابطة } \\
\hline 4.091 & $\cdot \wedge>0$ & $1 . \ldots 0$ & $\because V Y V$ & $.7 \vee \wedge$ & $\because V \leqslant q$ & $\varepsilon$ & \\
\hline
\end{tabular}


دـالتدريس للمجمو عة التجريبية بالدمج بين استر اتيجية خر ائط التفكير و نموذج التعلم

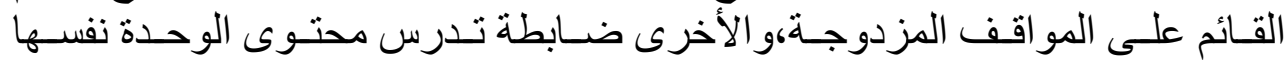

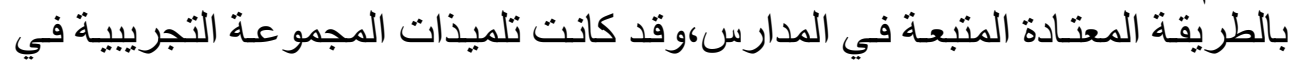

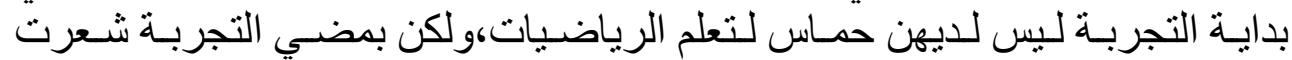

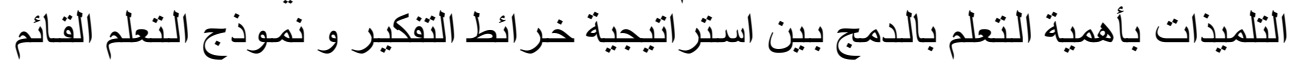

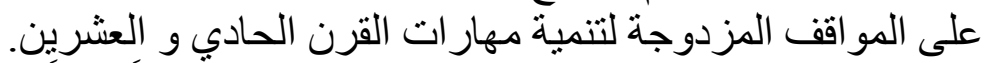
هـ-تطبيق اختبار مهار ات القرن الحادي و العثرين تطبيقاً بعدياً.

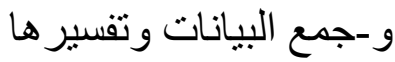

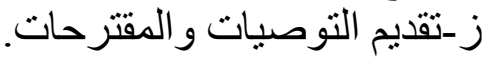
نتائج البحث وتوصياته ومقترحاته:

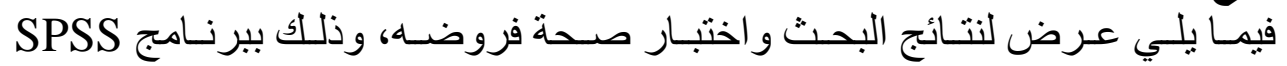

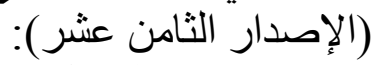

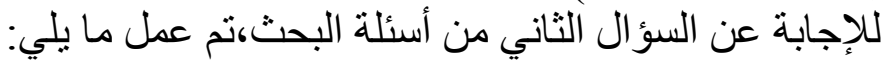

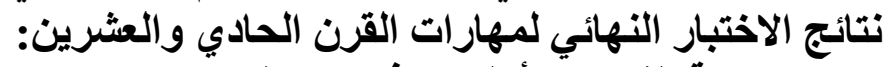

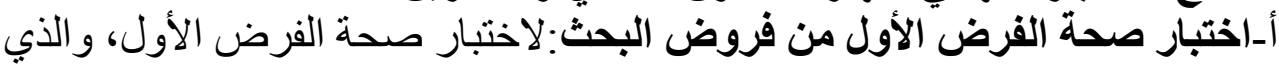

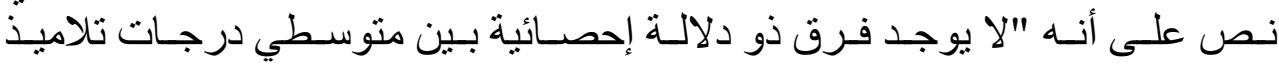

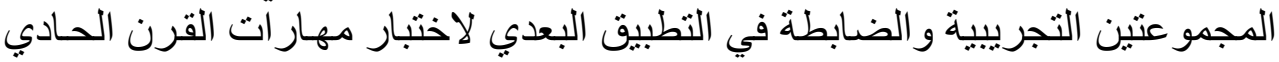

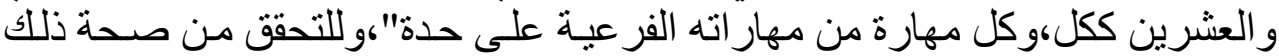

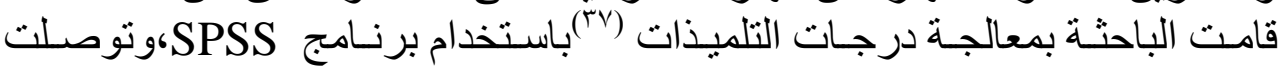

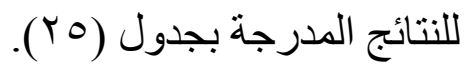
جدول (ه Y) الفرق بين درجات تلميذات المجموعتين التجريبية والضابطة في التطبيق البعدي لاختبار مهارات القرن الحادي و العثرين.

\begin{tabular}{|c|c|c|c|c|c|c|c|}
\hline الاختبار ككل & التواصل & القراذ & المشكلات & الإبداعير & التفاقير & المهارة & \\
\hline $01.0 \mathrm{rr}$ & Ir.IVA & س.OH & $1 \cdot . \wedge \wedge 9$ & אr.rT & $1 \cdot .7 \ldots$ & r & \multirow[t]{4}{*}{ التجريبية } \\
\hline 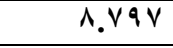 & 1.990 & .740 & r.rvT & r.rvo & $1 . r \wedge 7$ & $\varepsilon$ & \\
\hline$V .1 V \varepsilon$ & $0 . r \leqslant r$ & r.VYo & $\varepsilon .1 \leq \varepsilon$ & $7.71 \%$ & $\varepsilon . \& Y Y$ & قيمة ت & \\
\hline 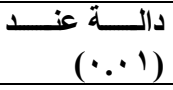 & 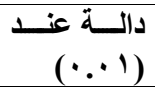 & دالـة عنــ & 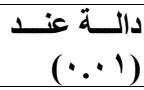 & 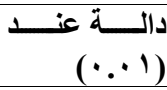 & دالـة عنــ & مسلــتوى & \\
\hline$\varepsilon \cdot . V Y r$ & $1 \cdot . r \leqslant r$ & r.9V7 & $1.01 Y$ & 1.0rv & 9.479 & 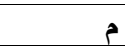 & \multirow{2}{*}{ الضابطة } \\
\hline$\varepsilon .1 Y r$ & $1.71 \mathrm{r}$ & $\because \vee \bullet \wedge$ & 1.019 & $1 . V \leq 1$ & 1.199 & $\varepsilon$ & \\
\hline
\end{tabular}

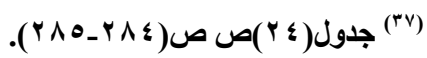




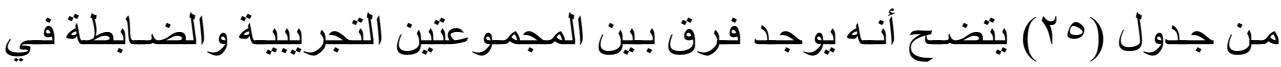

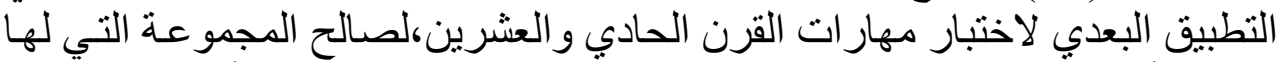

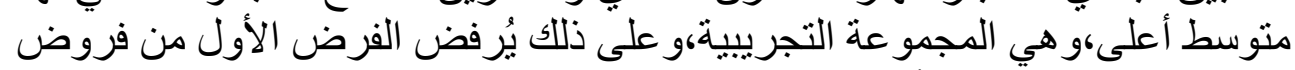

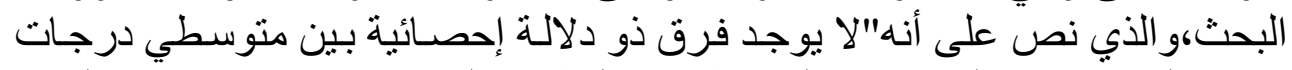

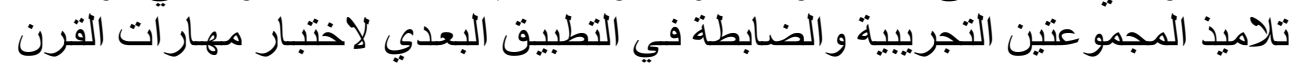

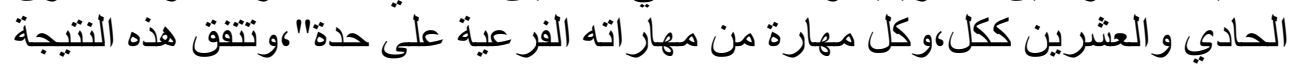

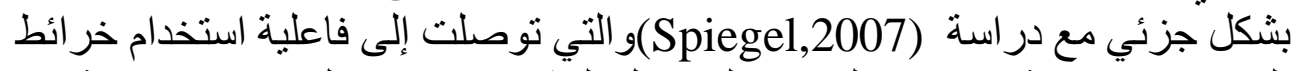

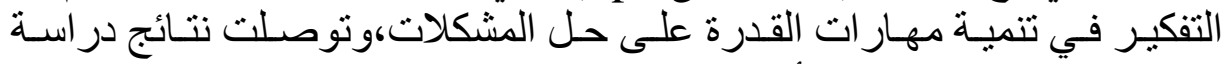

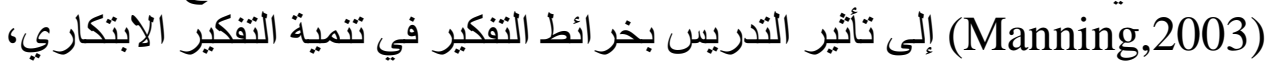

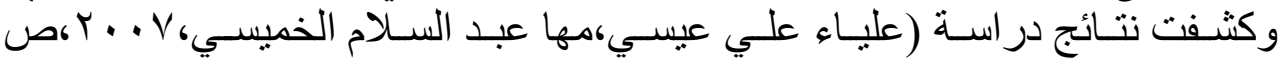

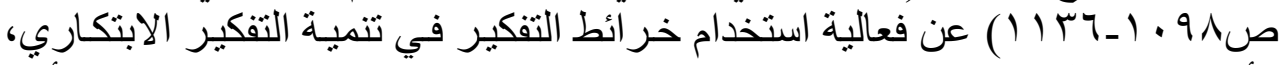

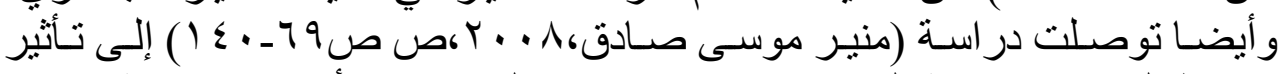

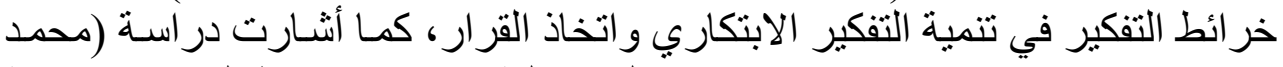

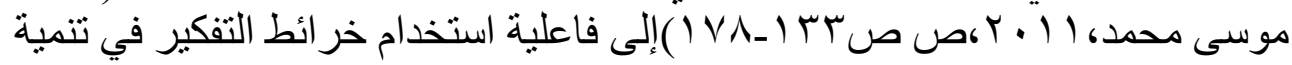

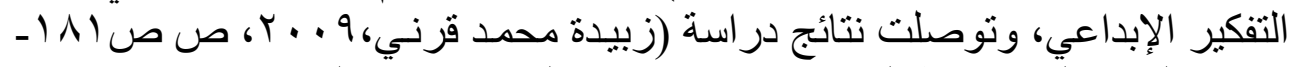

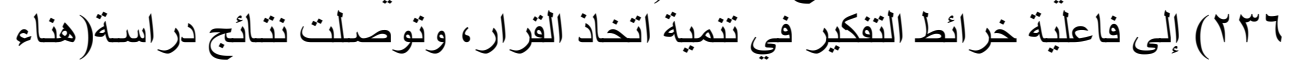

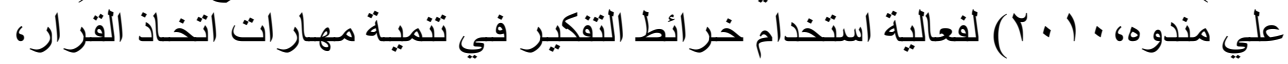

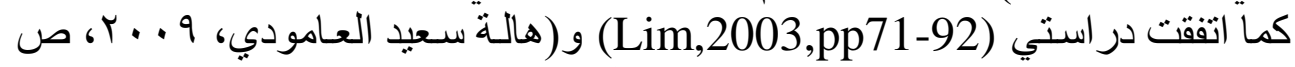

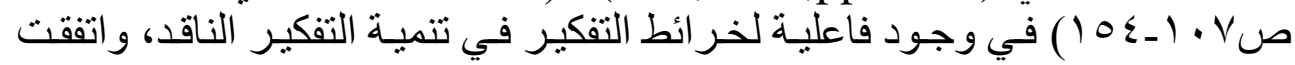

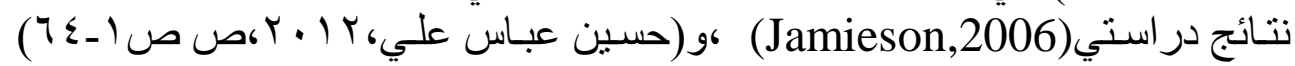

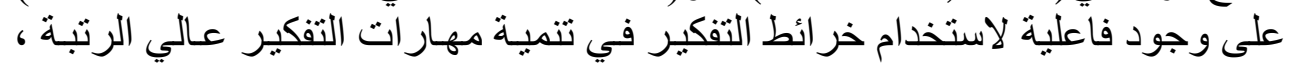

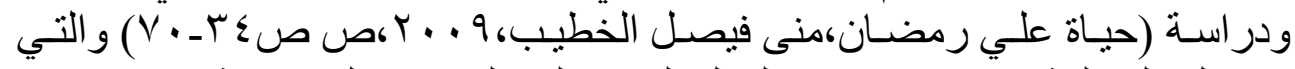

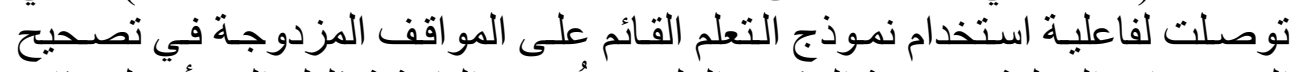

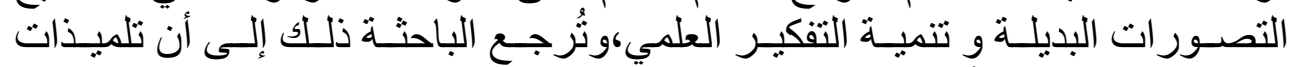

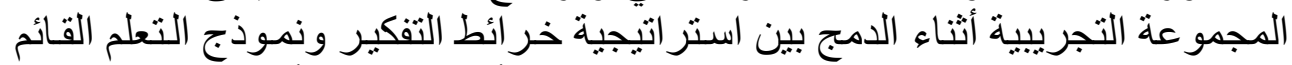

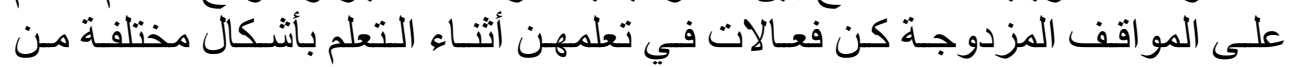

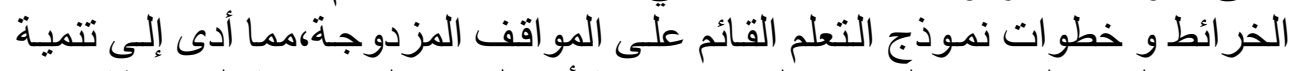

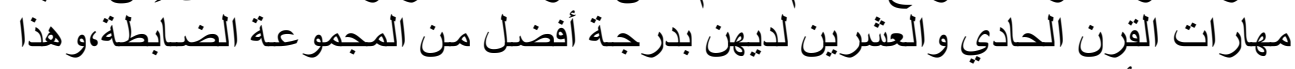

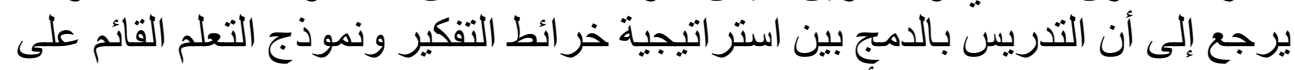

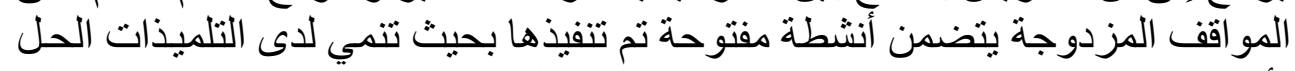

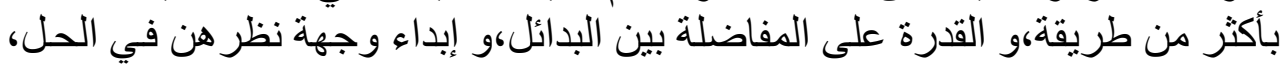


و نقل أفكـار هن للآخرين،مهـا سـاعد على تتميـة مهـار ات القـرن الحـادي و العشـرين

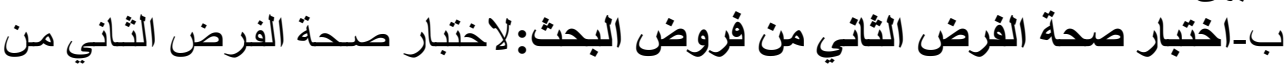

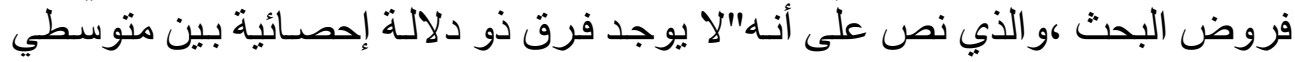

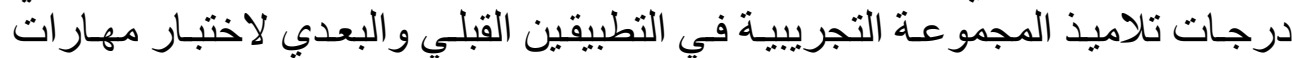

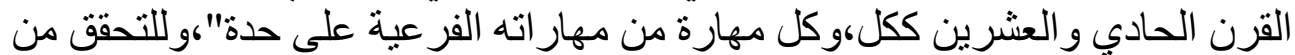

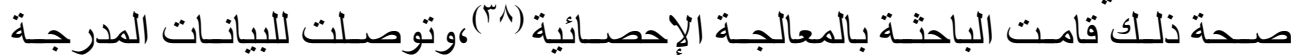

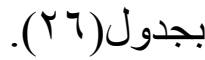

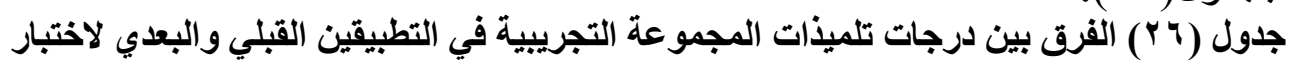
مهارات القرن الحادي و العشرين.

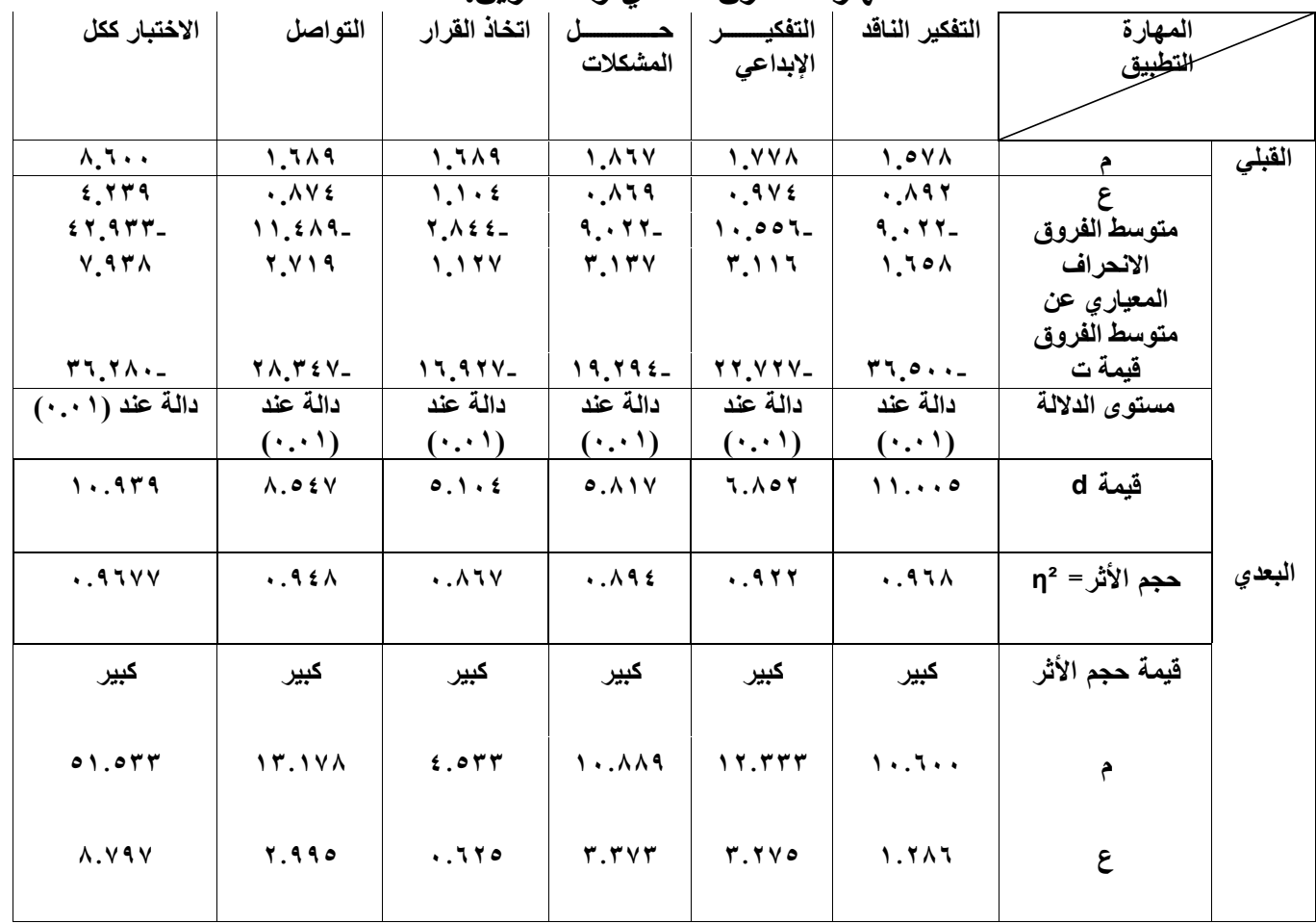

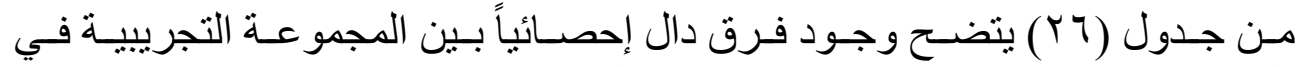

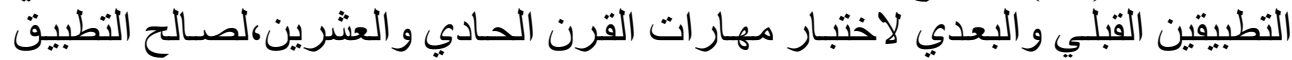

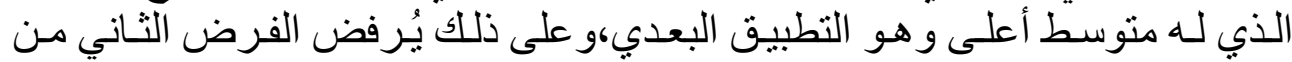


فروض البحث، و الذي نص على أنه"لا يوجد فرق ذو دلالة إحصـائية بين متوسطي

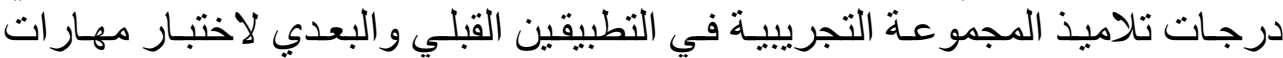

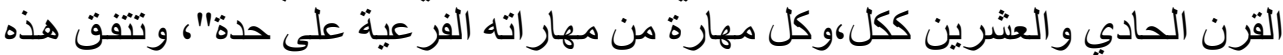
النتيجة بشكل جزئي مع در اسة (Spiegel,2007) و التي توصلت كئت إلى فاعلية استخدام

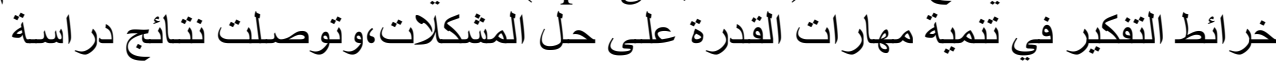
وكanning,2003)

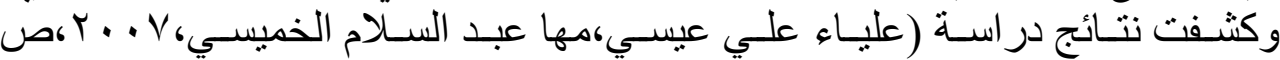

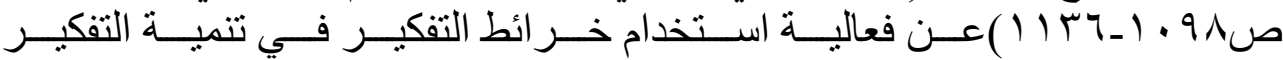

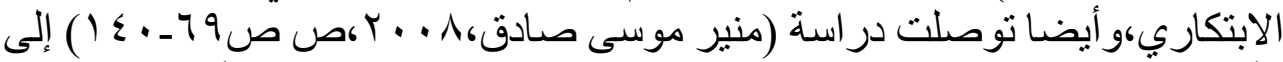

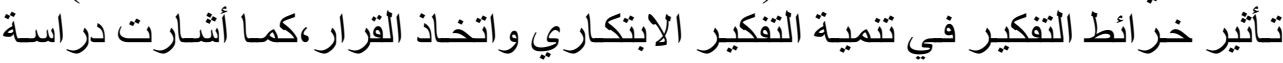

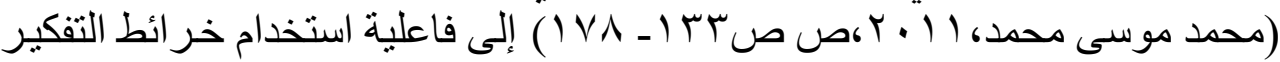

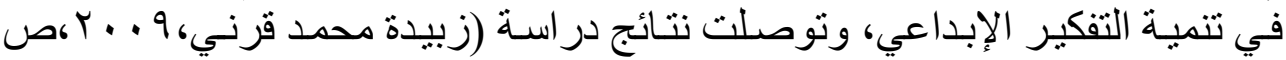

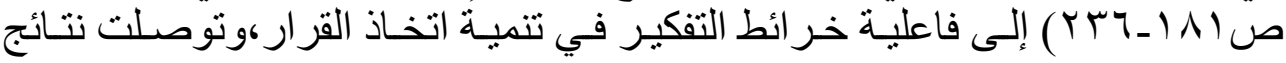

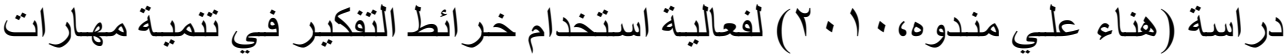

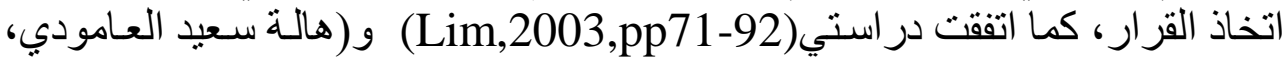

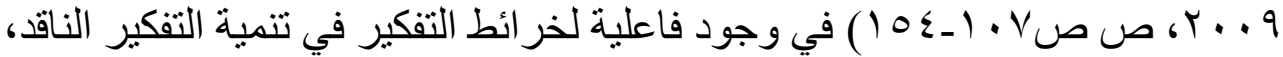

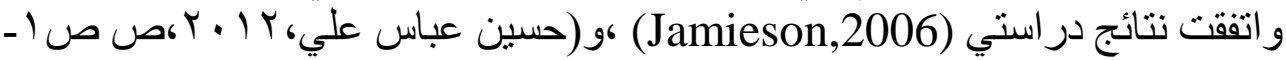

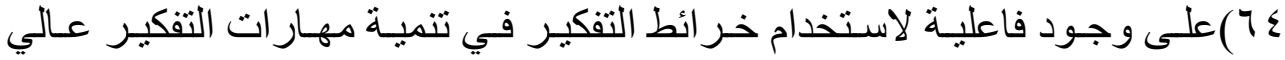

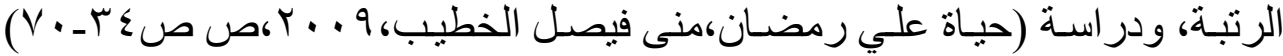

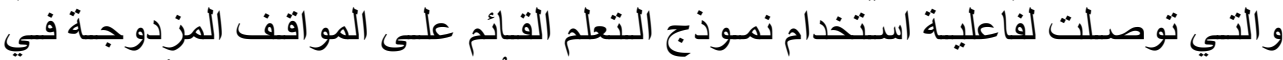

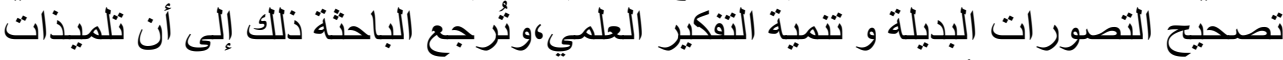

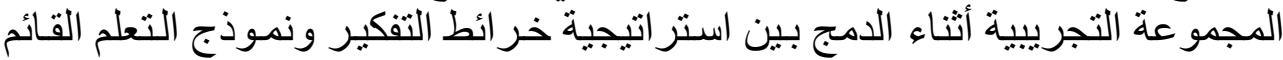

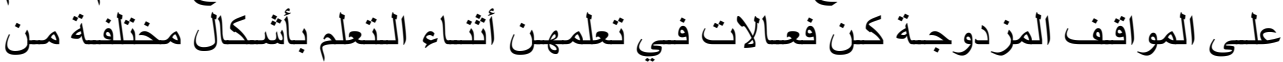

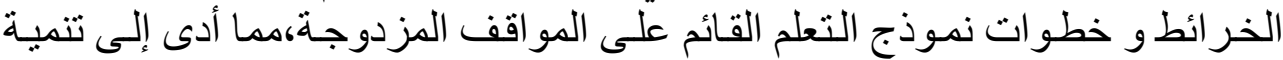

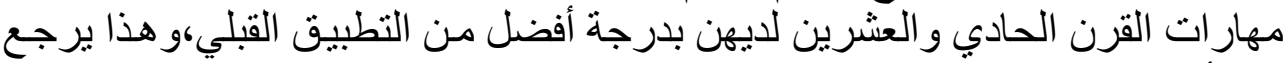

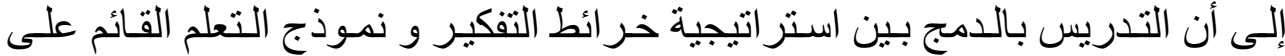

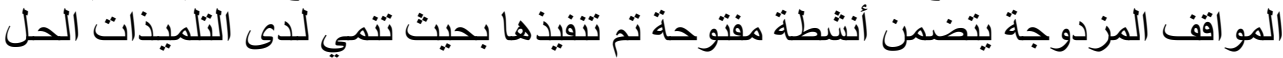

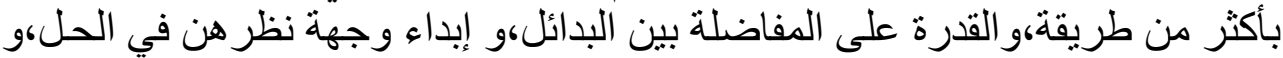

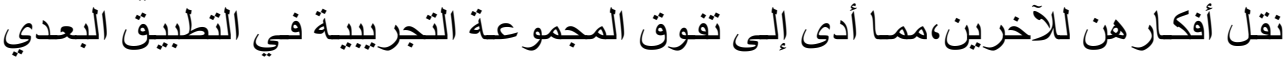

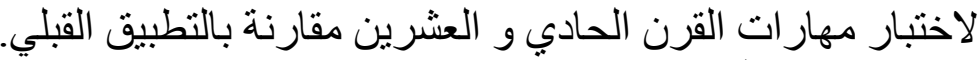

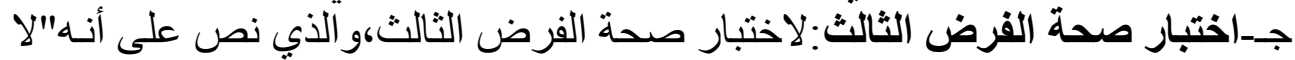

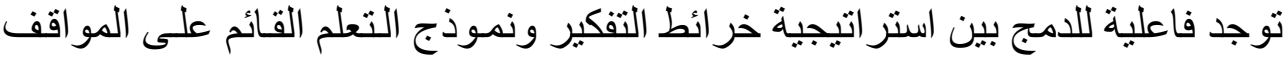


المزدوجة في تنميـة مهار ات القرن الحسادي والعشـرين ككل،وكل مهارة مـن مهار اتـه

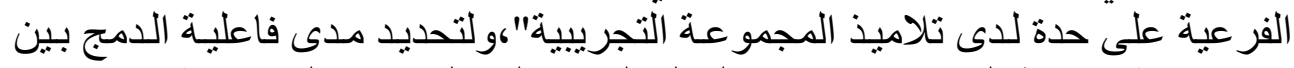

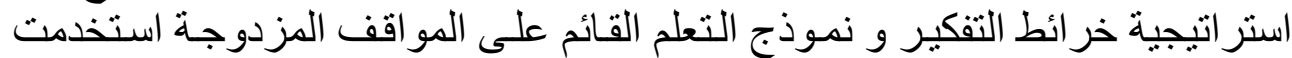

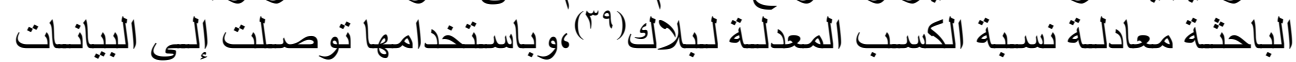

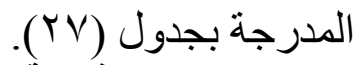
جدول (YV) مدى فاعلية الدمج بين استراتيجية خرائط التفكير ونموذج التعلم القائم على المواقف فئف

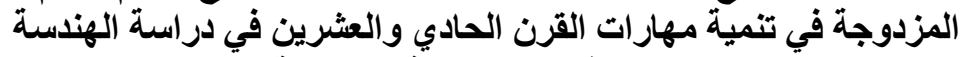
لاى تلميذات المجموعة التجرئ والتيبية.

\begin{tabular}{|c|c|c|c|c|c|c|c|}
\hline ككل الاختبار & التواصل & القرار & المشكلات حل & الإبداعير & التاقدير & & \multirow{3}{*}{ القبالي } \\
\hline$\wedge .7 \ldots$ & 1.719 & 1.719 & $1 . \wedge 7 V$ & $1 . \vee \vee \wedge$ & $1.0 \mathrm{VA}$ & المتوسط & \\
\hline Ao & YI & 7 & YI & $Y \varepsilon$ & ir & الارجة العظمي & \\
\hline $01.0 \mathrm{rr}$ & Ir.IVA & \&.OHr & $1 \cdot . \wedge \wedge 9$ & Ir.rur & $1 \cdot .7 \ldots$ & المتوسط & \multirow[t]{2}{*}{ البعدي } \\
\hline 10 & YI & 7 & YI & $Y \varepsilon$ & ir & الارجة العظمى & \\
\hline $1.9 \mathrm{~V}$ & $1.1 \leqslant r$ & $1.1 \% \varepsilon$ & $.99 \cdot 1$ & .910 & $1 . \leqslant \wedge \leqslant$ & \multicolumn{2}{|c|}{ نسبة الكسب المعدلة } \\
\hline
\end{tabular}

من جدول (YV) يتضـح أن نسبة الكسب المعدلة التي حققها الدمج بين استر اتيجية

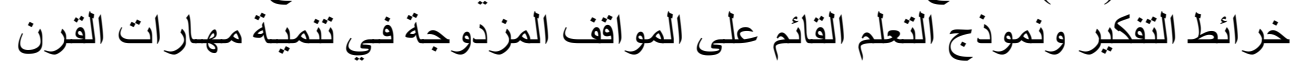

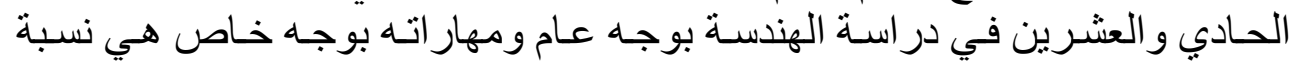

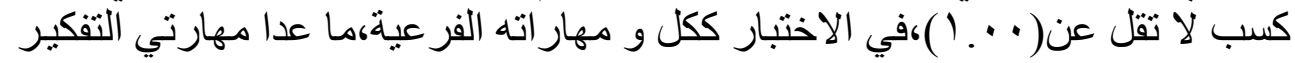

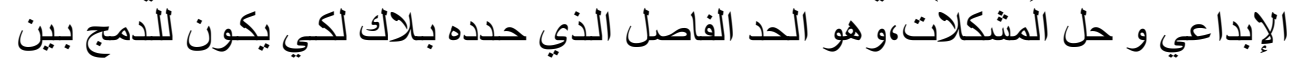

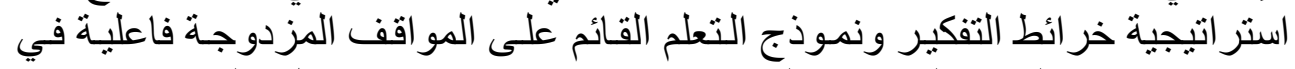

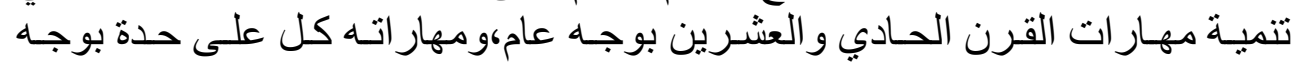
خاص.

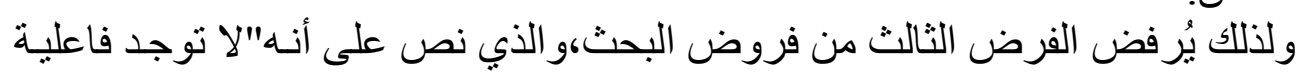

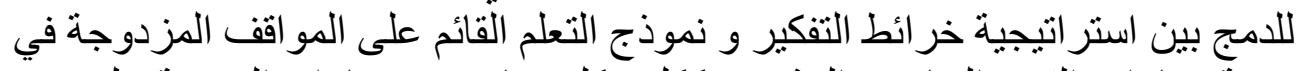

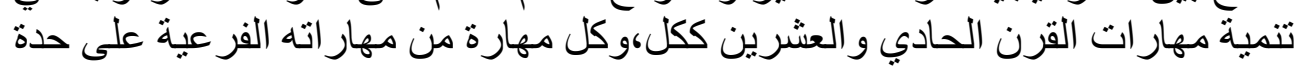

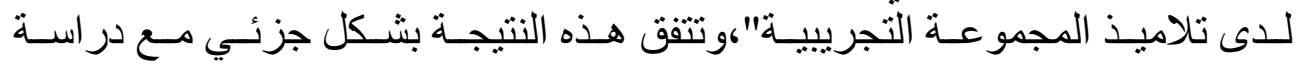

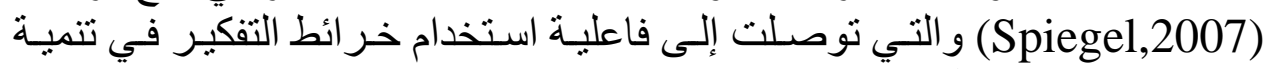

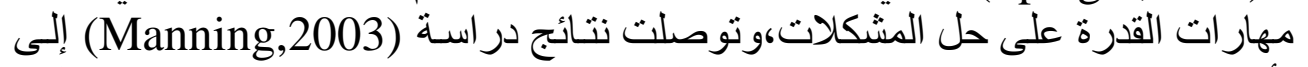

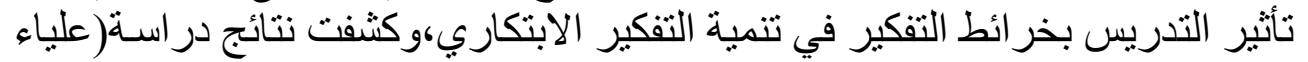

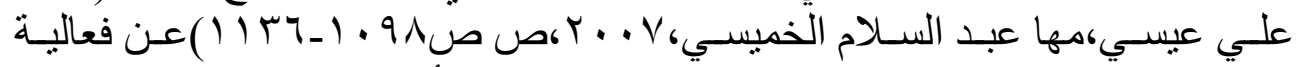

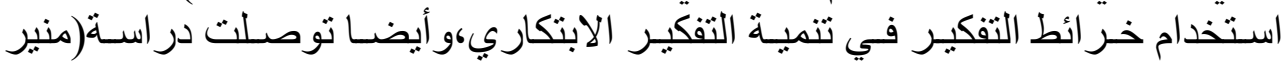




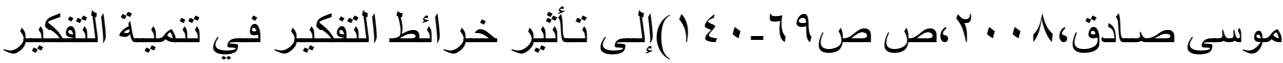

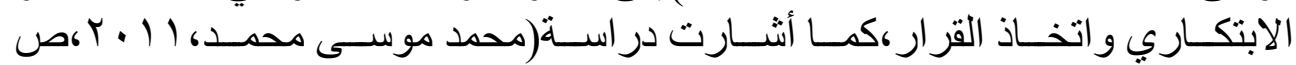

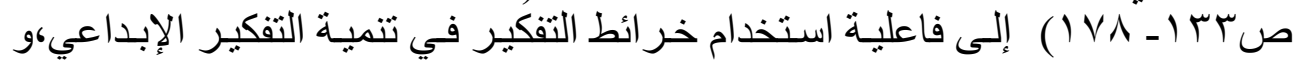

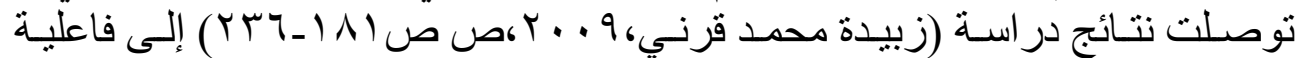

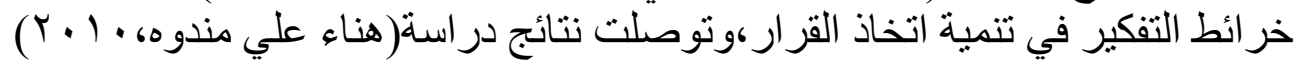

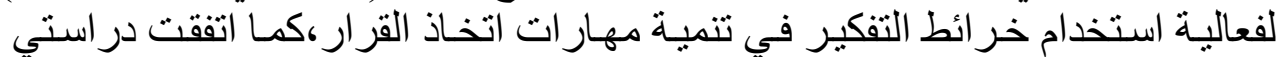

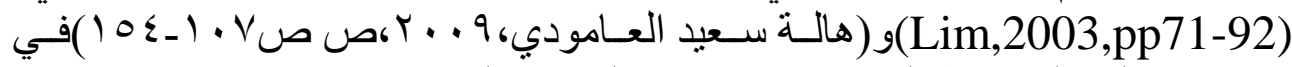

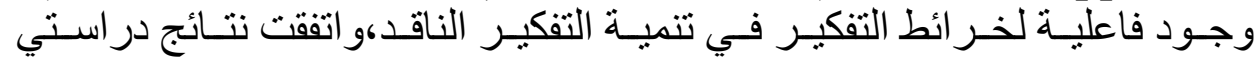

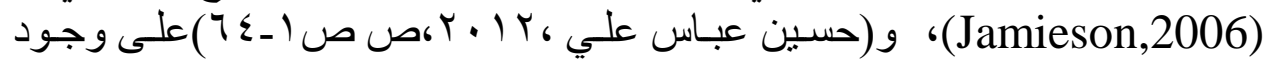

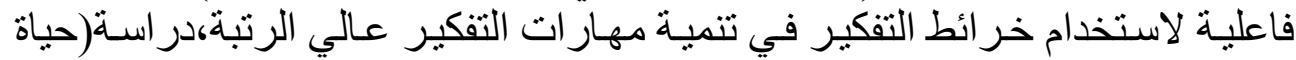

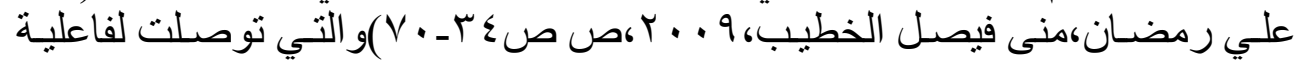

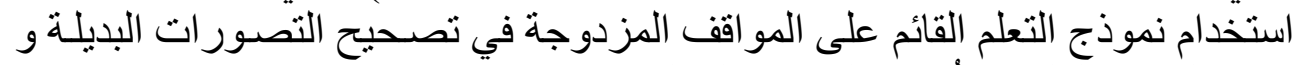

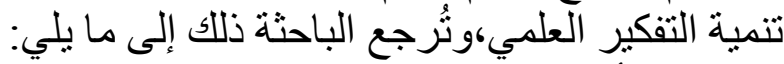

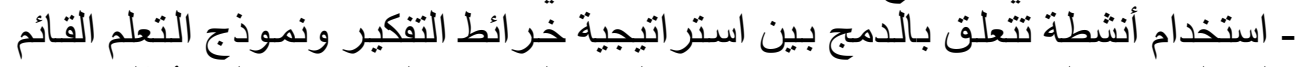

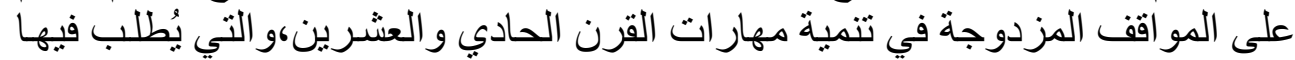

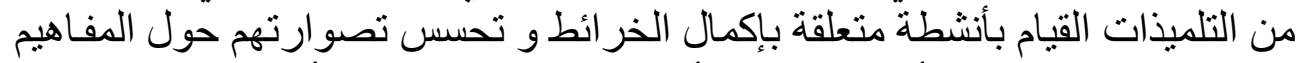

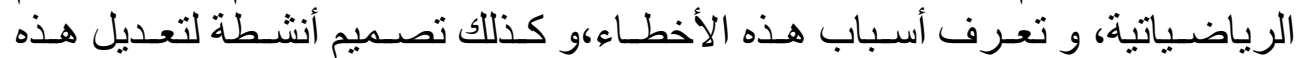

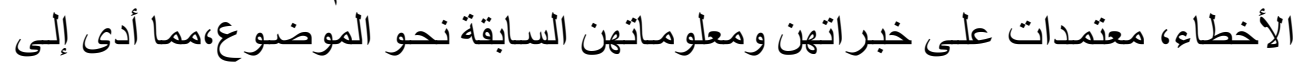

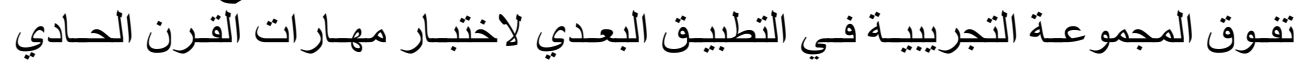
و العشرين مقارنة بالتطبيق القبلي.

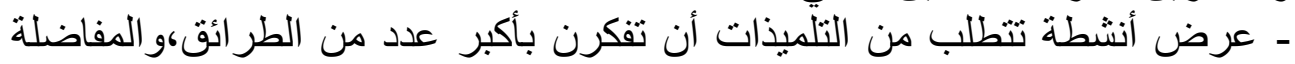

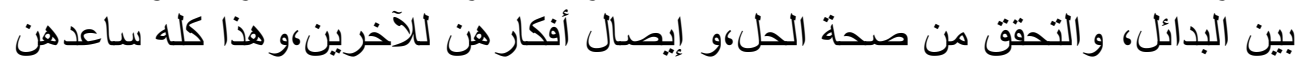

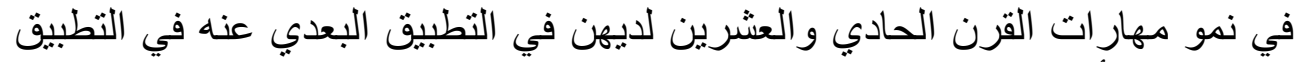

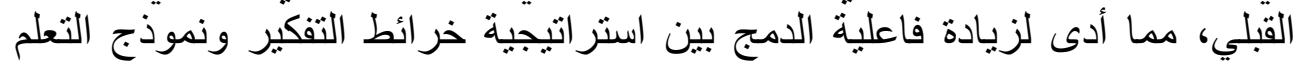

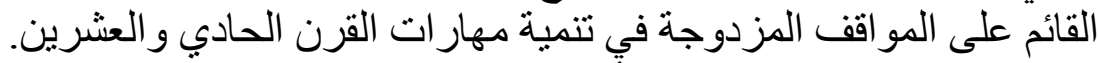

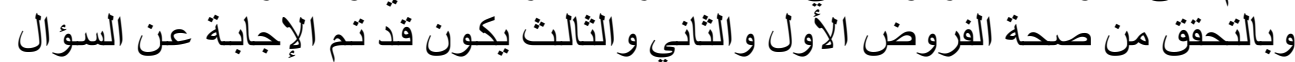

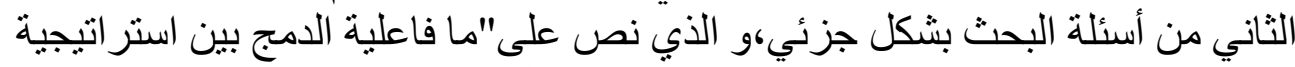

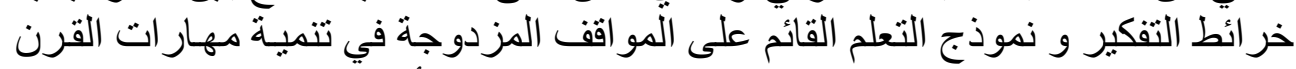
الحادي و العثرين في در اسة الهندسة لدى تلاميذ الصفي الصف الأول الإعدادي ؟ ثانيا:توصيات البحث: ـ الاهتمام بمهار ات القرن الحادي و العشرين،وتوفير مو اقف للتلاميذ بستطيعون من خلالها تتمية مهار اتهم. 


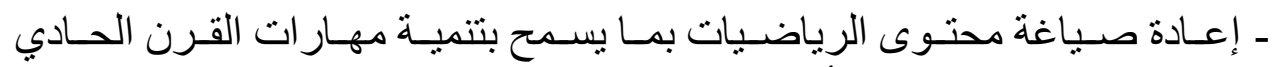
و العثرين لتلاميذ الصف الأنساغ الأول الإعدادي.

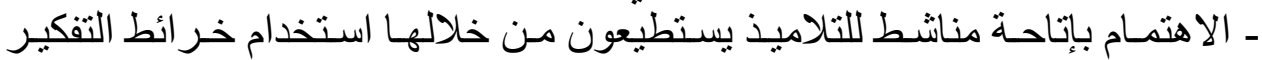

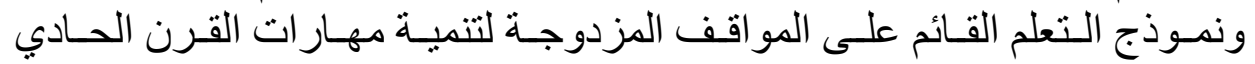
و العشرين.

\section{ثالثًاً:مقترحات البحث:}

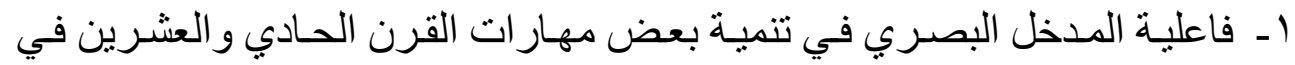

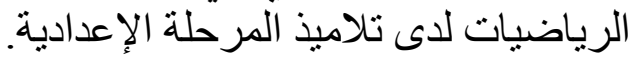

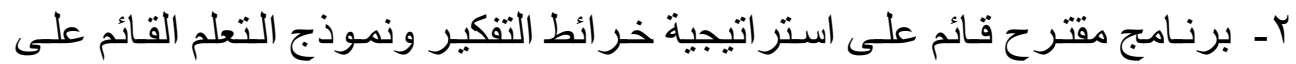

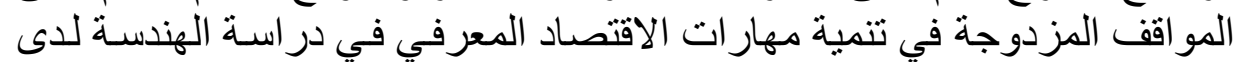

$$
\text { تلاميذ المرحلة الإعدادية. }
$$

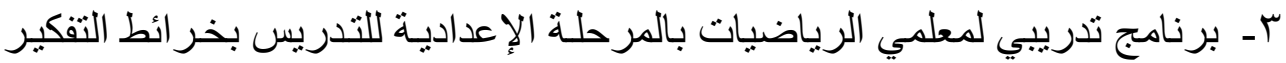

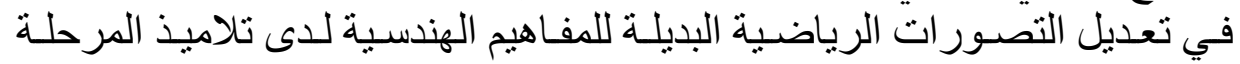

$$
\text { الإعبدادية. }
$$

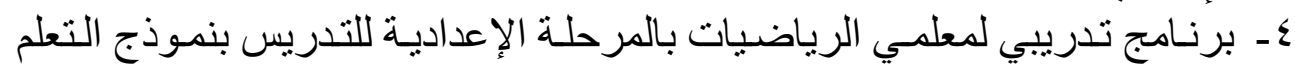

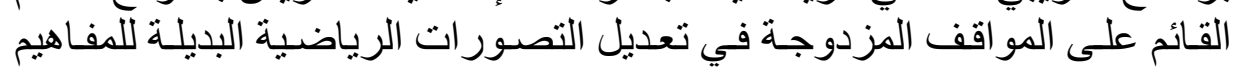
الهندسية لدى تلامبذ المرحلة الإعدادية.

\section{المراجع باللغة العربية واللغات الأجنبية:}

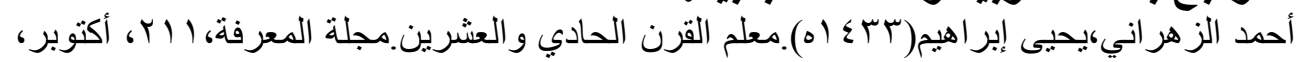
وزارة التربية والتعليم السعودية. الإية.

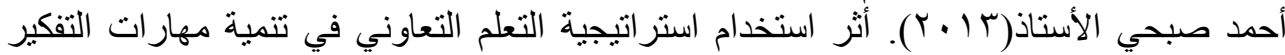

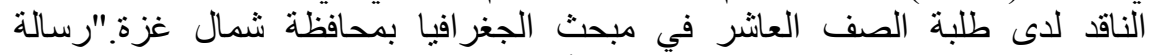

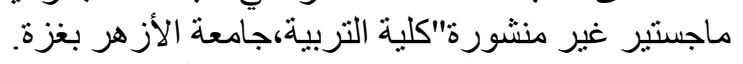

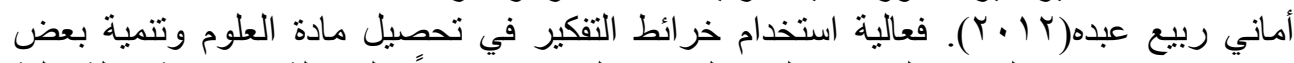

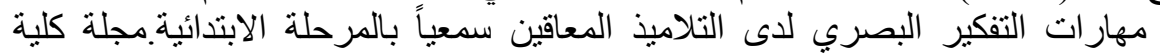

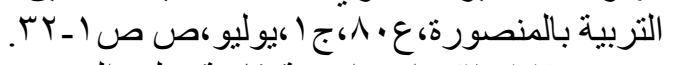

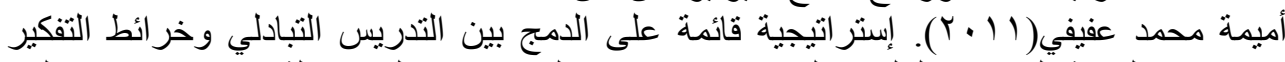

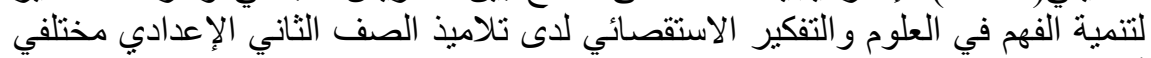

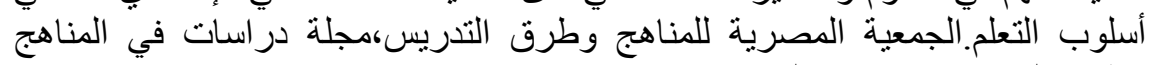

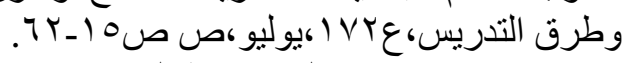

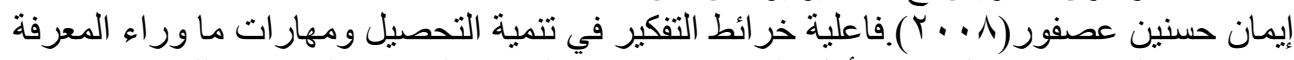

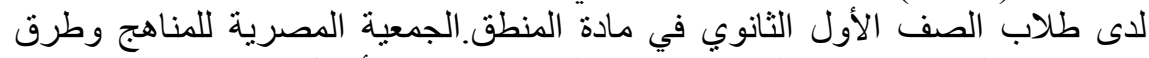

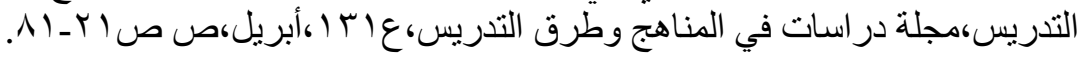




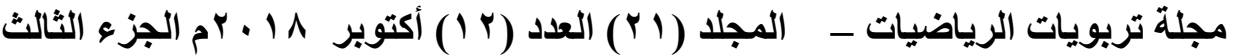

إيمان حسنين عصفور( (1 • ب).فاعلية خر ائط التفكير في تتمية التحصيل ومهار ات ما ور اء المعرفة

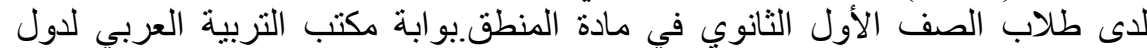

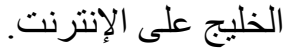

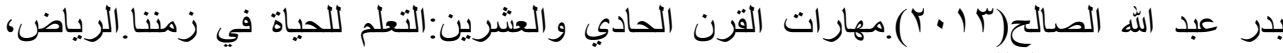

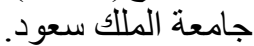
ثناء محمد حسن(9 ج . ؟).فاعلية خر ائط التفكير في تنمية التحصيل والتنظيم الذاتي للتعلم والاتجاه

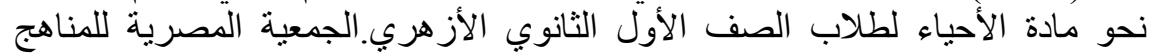

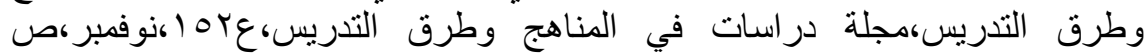

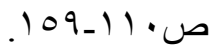

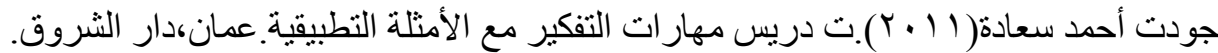

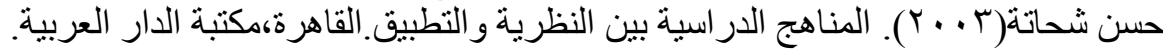

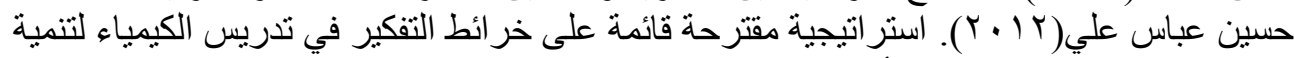

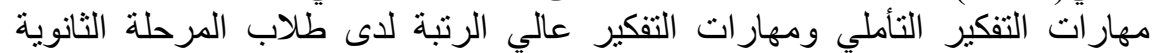

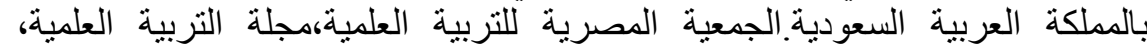

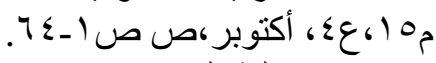

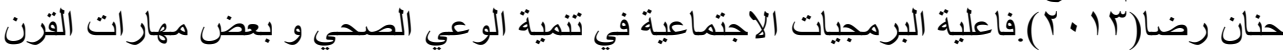

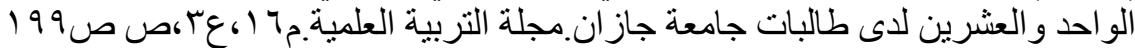

$$
\text { rV.- }
$$

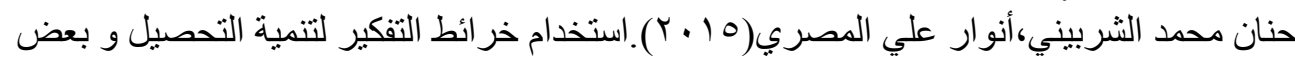

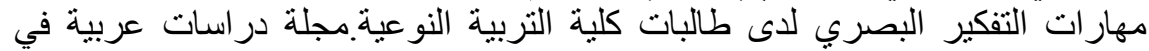

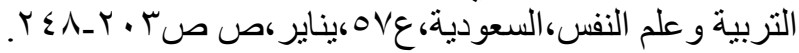

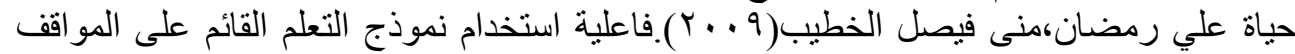
المزدوجة (DSLM)في تصحيح التصورات البديلة و تنمية التفكير العلمي في مادية

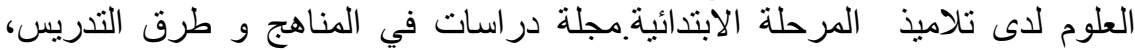

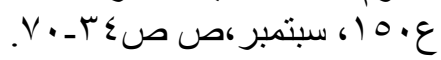

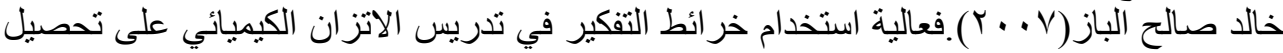

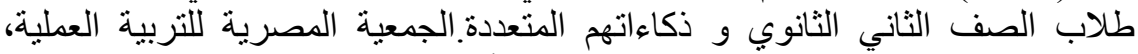

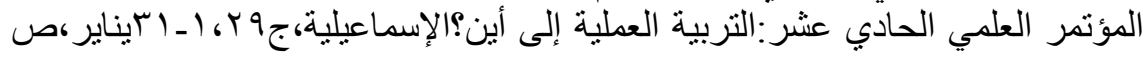

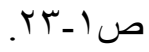

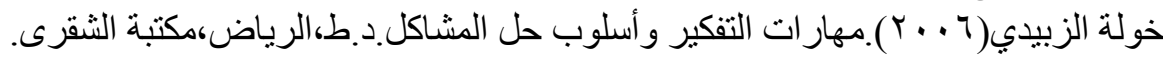

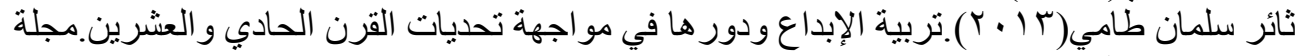

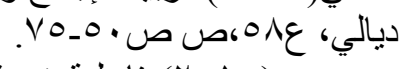

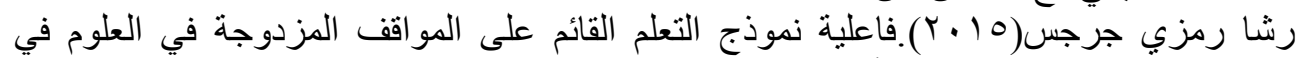

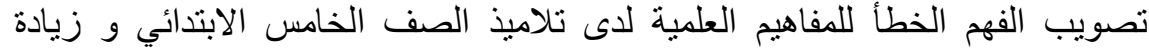

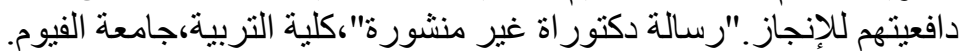

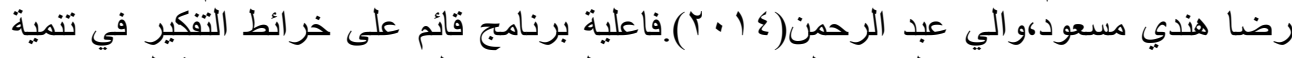

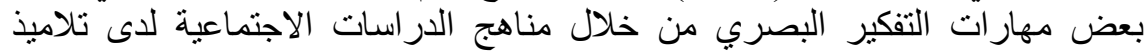




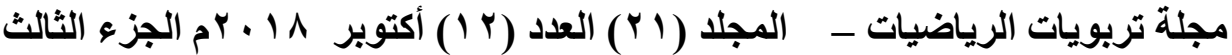

الصف الخامس الابتدائي. الجمعية المصرية للاراسات الاجتماعية،مجلة الجمعية

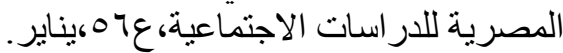

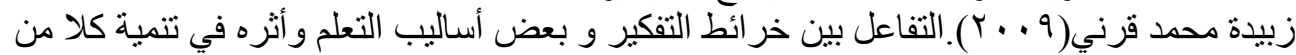

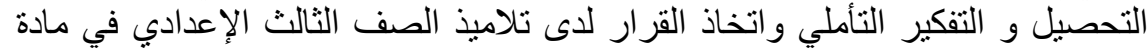

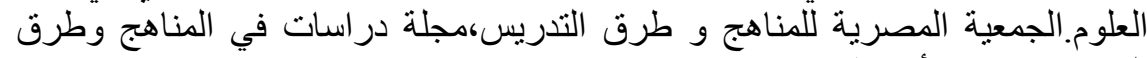

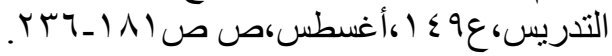

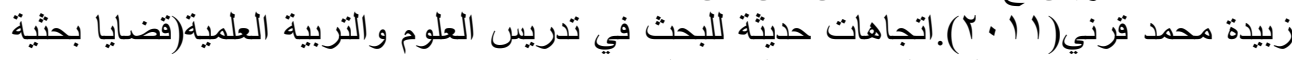

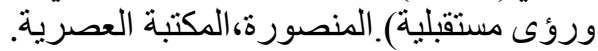

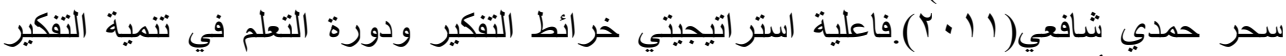

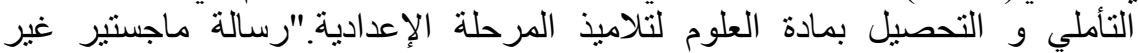

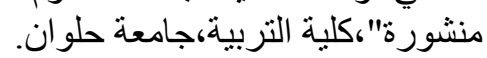

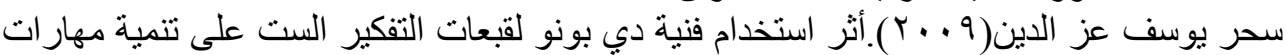

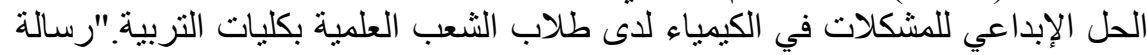

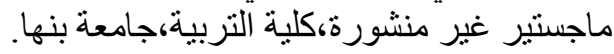

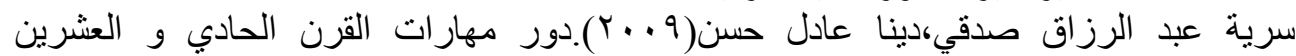

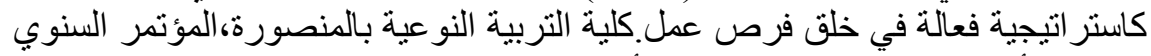

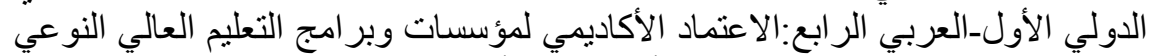

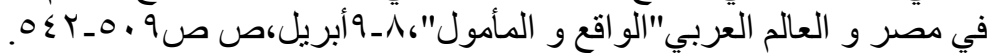

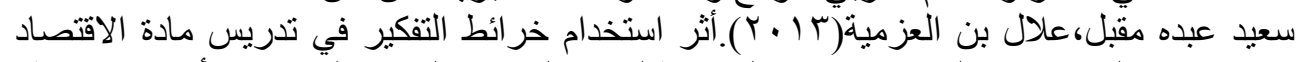

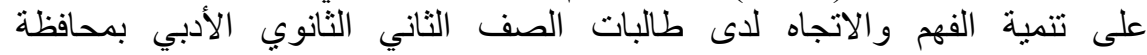

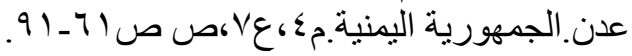

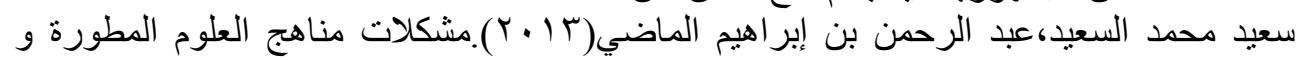

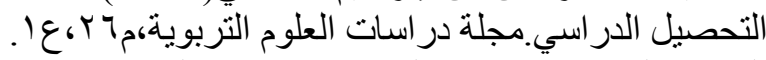

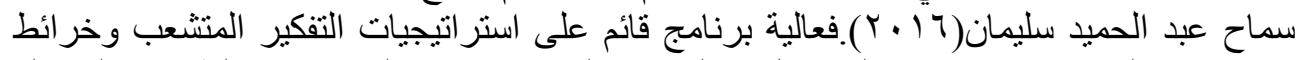

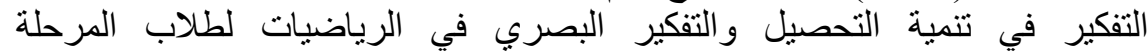

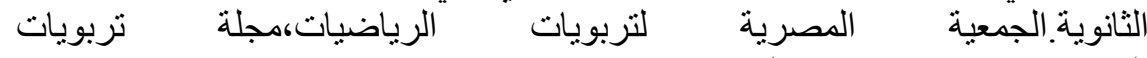

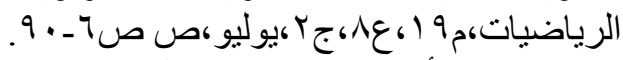

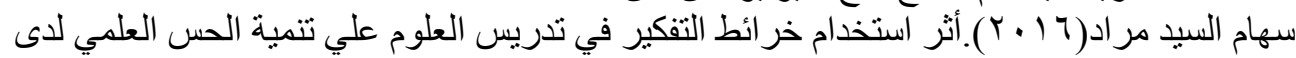

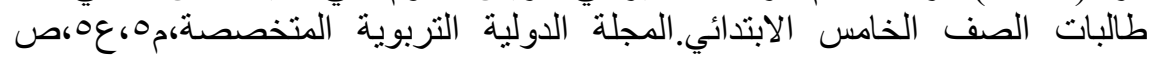

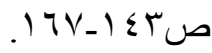

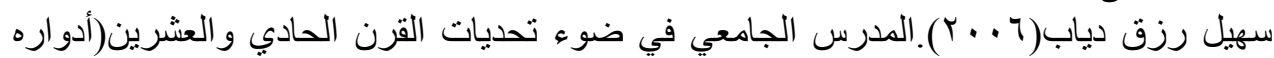

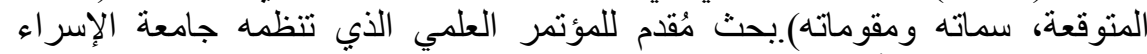

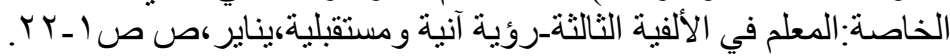

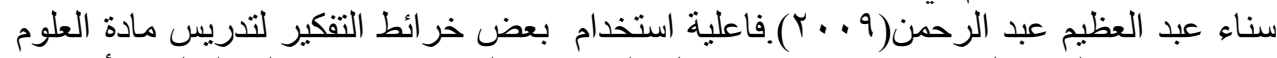

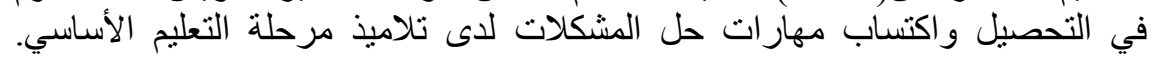

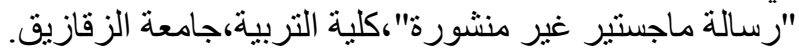




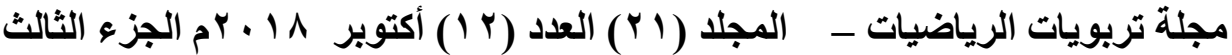

سنتيا لونا سكوت(0) ( ب).بحث ونظرة استشر افية بشأن التعليم-اليونسكو.منظمة الأمم المتحدة

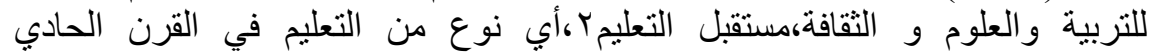

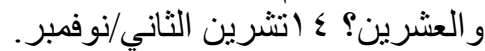

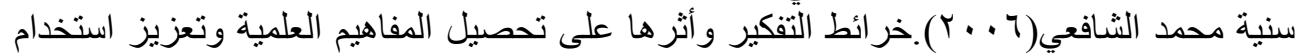

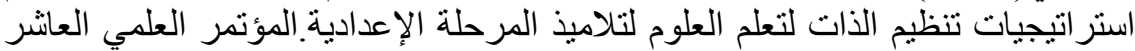

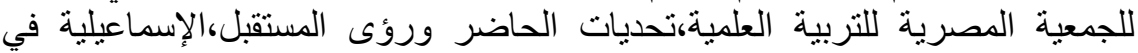

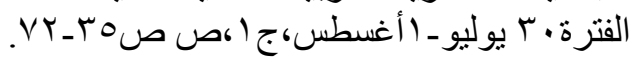

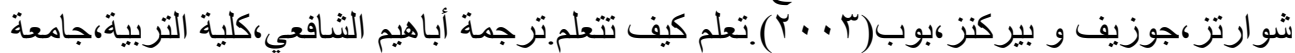
الملك سعود.

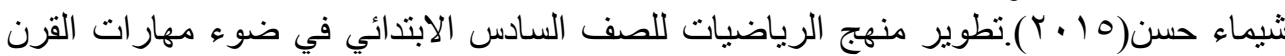

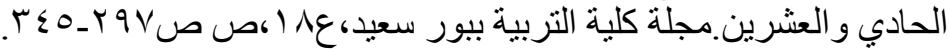

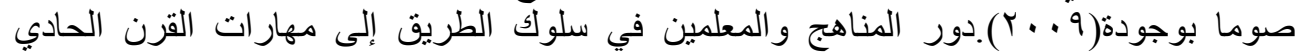

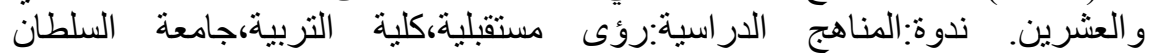

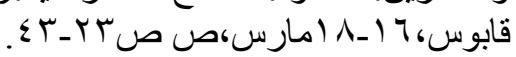

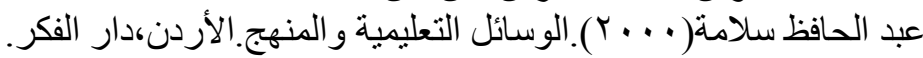

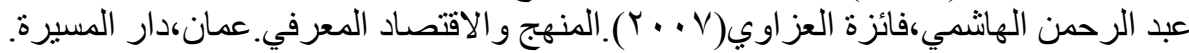

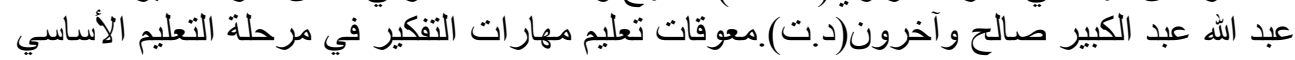

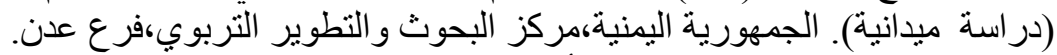

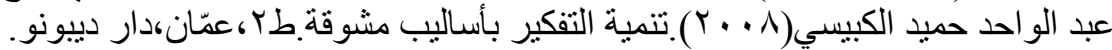

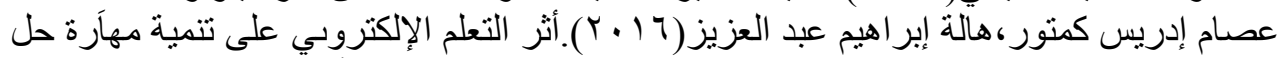

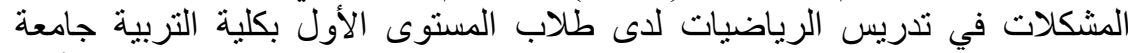

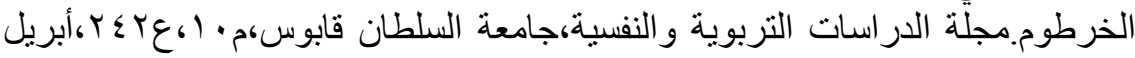

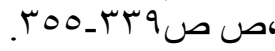

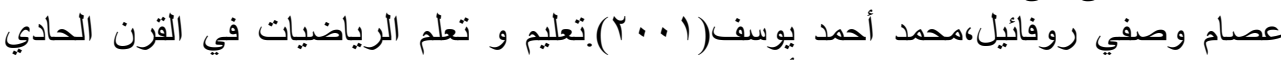

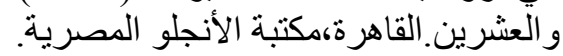

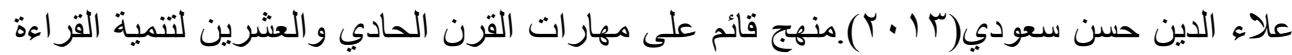

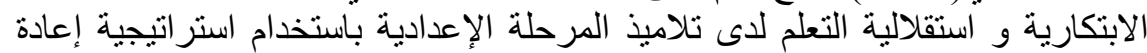

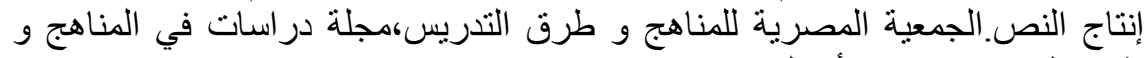

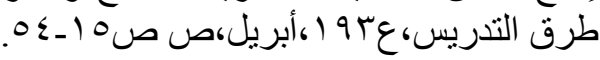

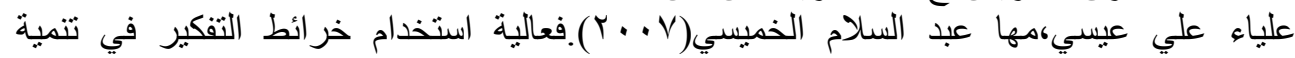
التحصيل والتفكير الابتكاري في مادة العلوم لاعى تلاميذ الصفيذ الصفئ السادس الإبتدائي.

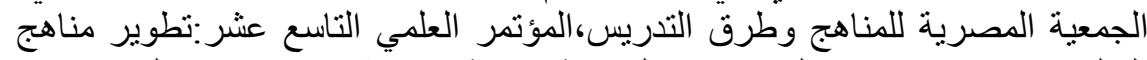

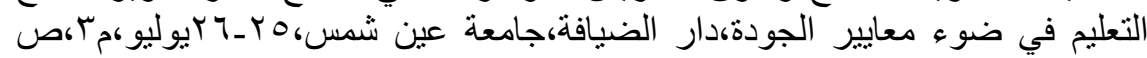

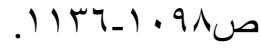
غدنانة سعيد البنغلي(0 . . ب).مدى استخدام معلمي الدر اسـات الاجتماعية لمهار ات التفكير في تدريس

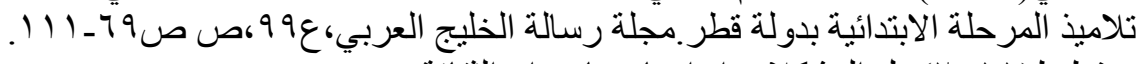
غسان يوسف قطيط(1) ( • (Y)حل المشكلات إبداعيا.عمان،دار الثقافة. 


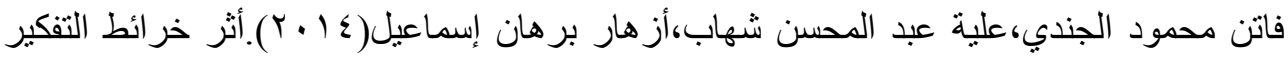

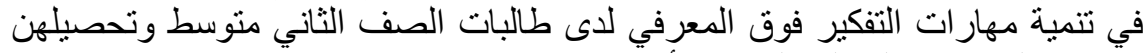

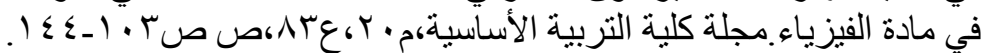

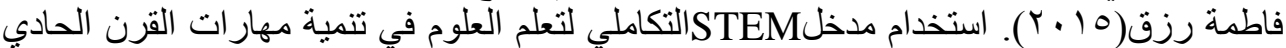

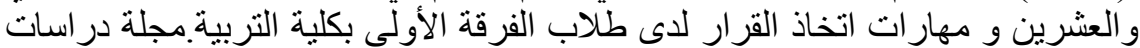

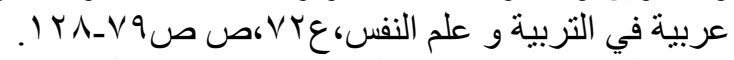

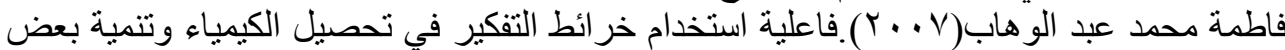

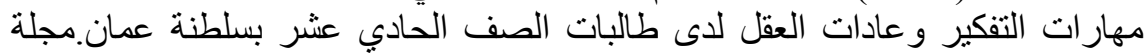

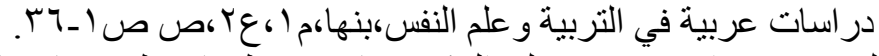

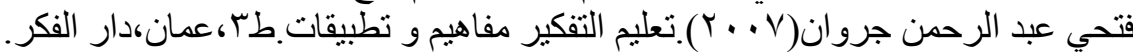

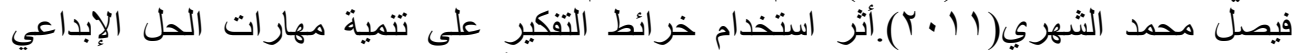

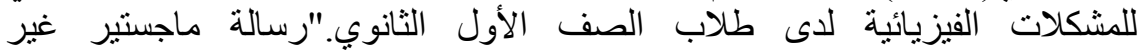

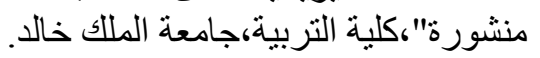

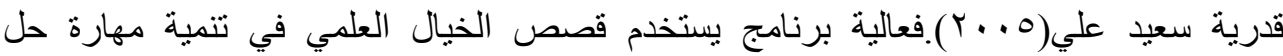

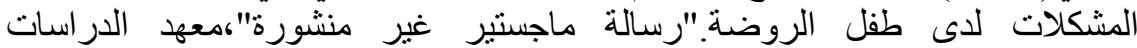

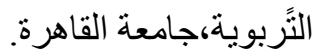

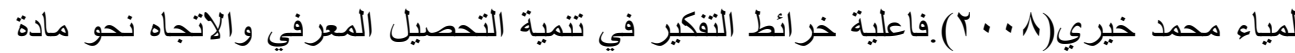

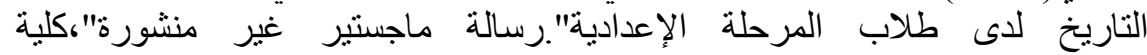

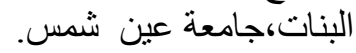

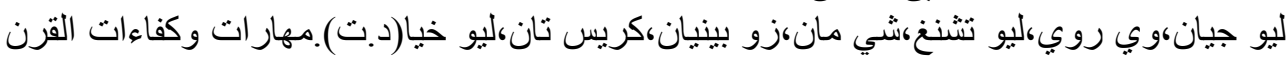

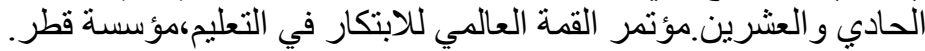

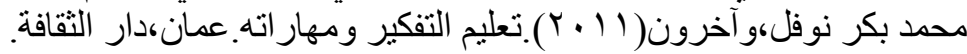

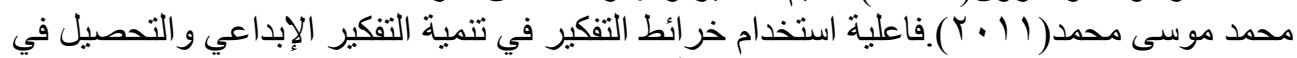

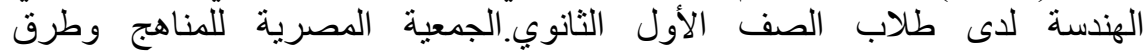

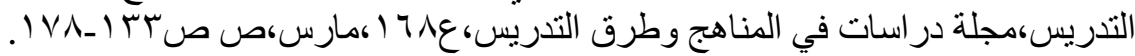

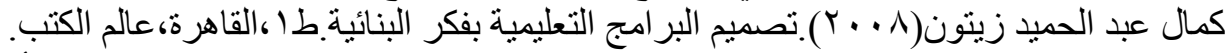

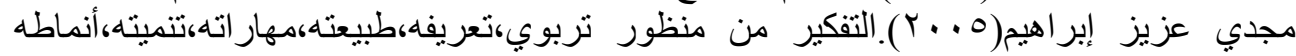

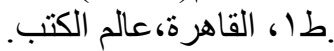

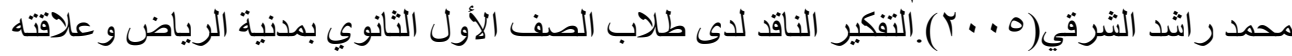

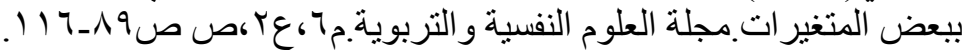

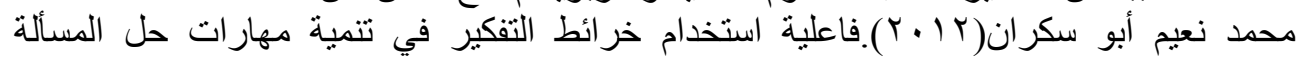

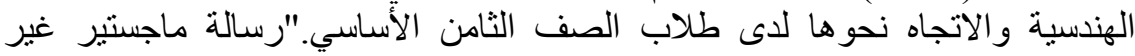

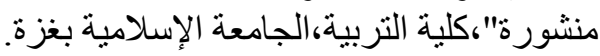

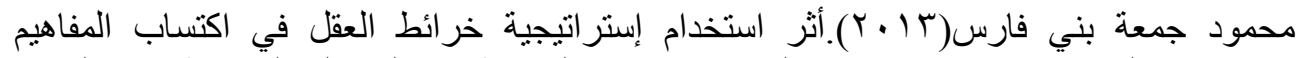

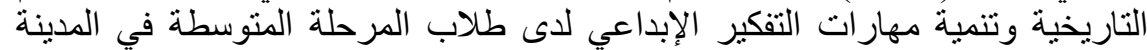

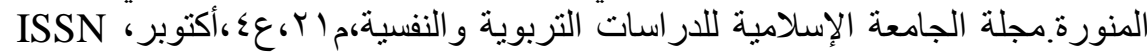

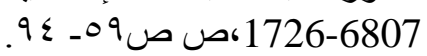


مدارس المستقبل(T 1 • (Y).وحدة جيمس للمعلومات.فبر اير.

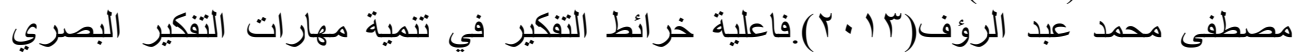

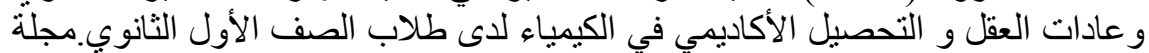

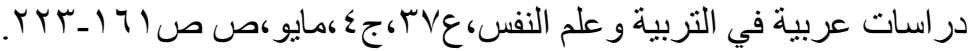

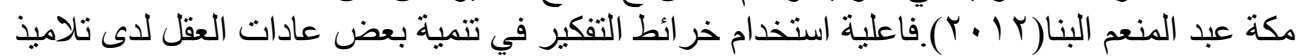

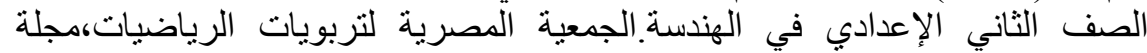

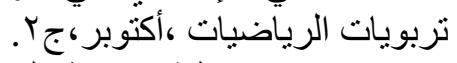

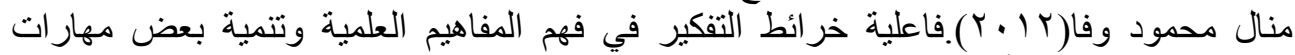

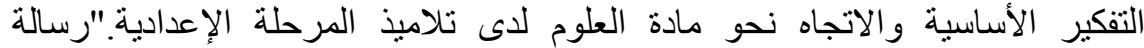

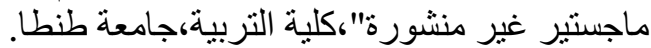

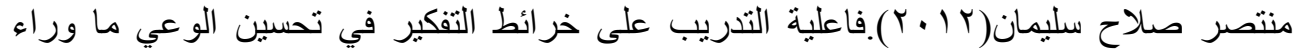

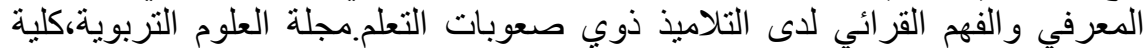

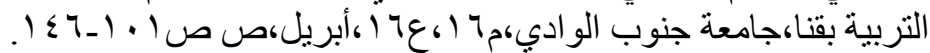

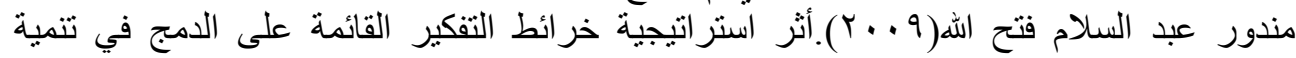

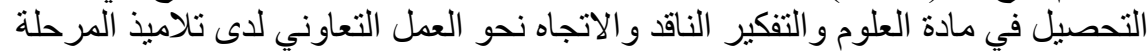

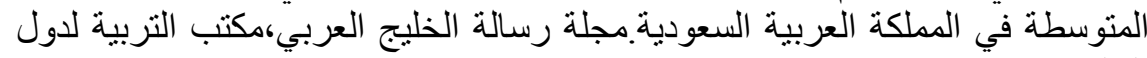

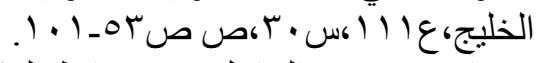

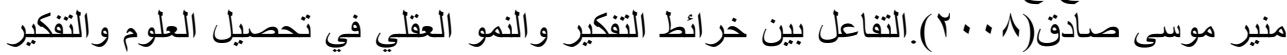

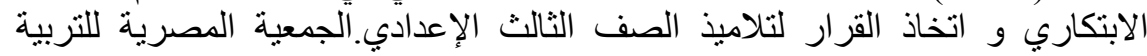

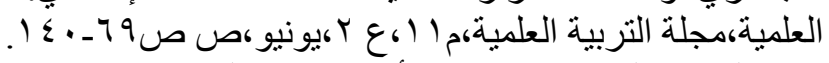

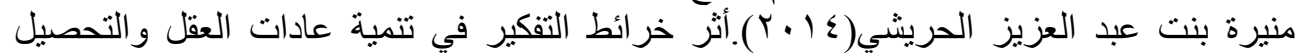

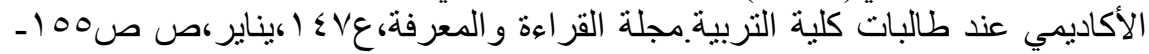

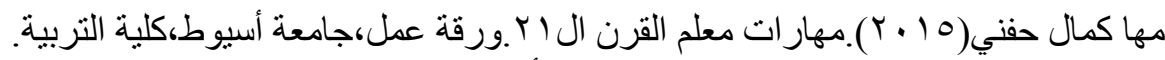

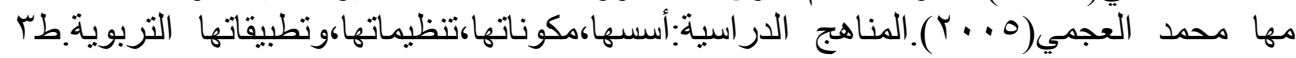

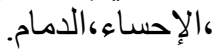

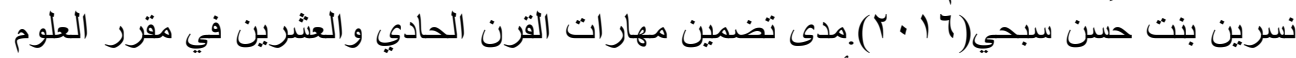

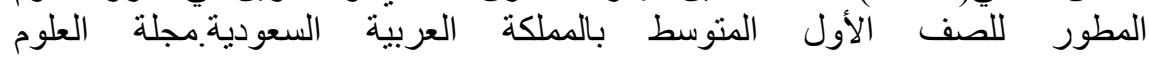

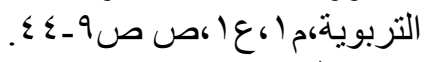

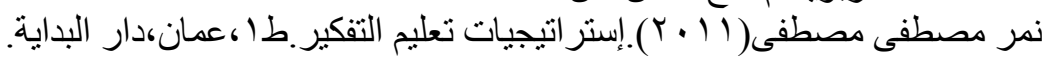

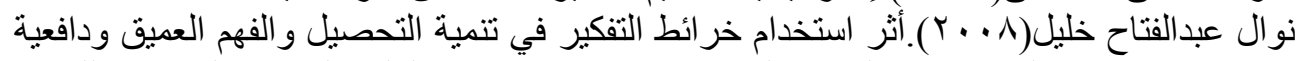

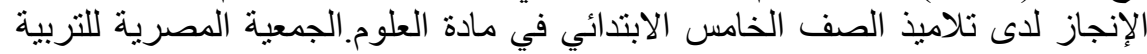

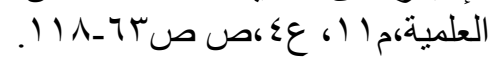

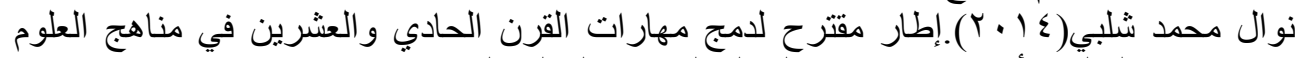

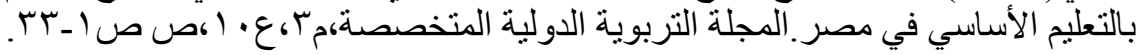




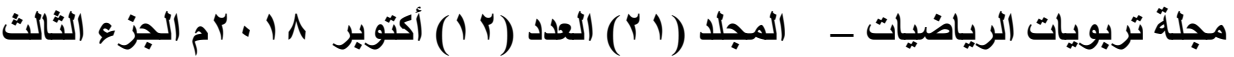

هادي كطفان الثون، علي عادل تركي،أحلام حمبد الجنابي(7 ( • ب).فاعلية خر ائط التفكير القائمة

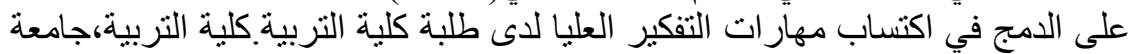

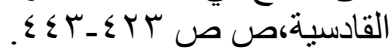

هالة سعيد العامودي(q . . ب).فاعلية الخرائط العقلية لتدريس الكيمياء في تنمية التفكير الناقد

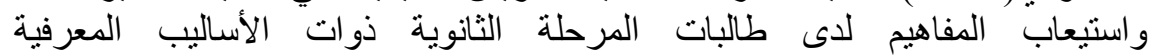

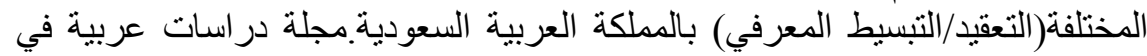

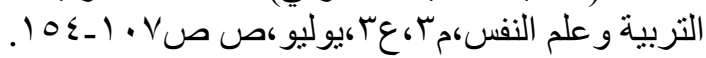

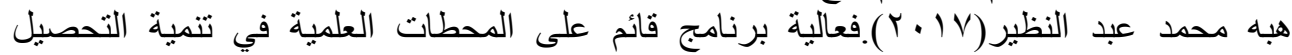

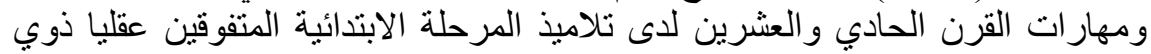

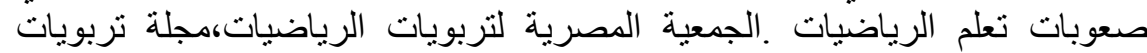

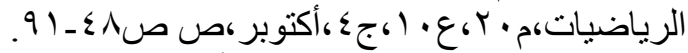

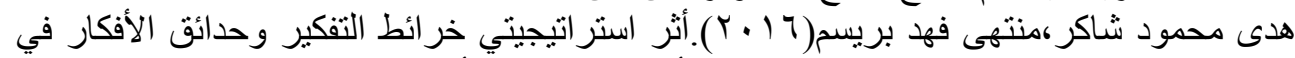

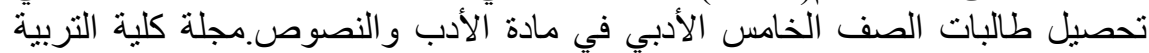

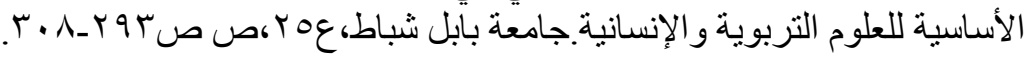

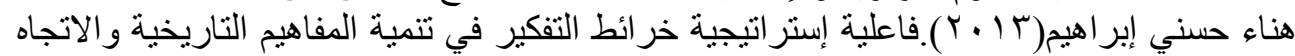

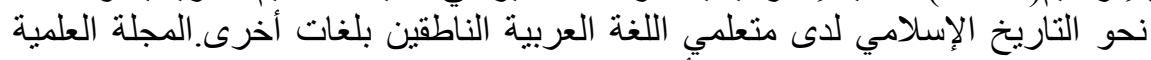

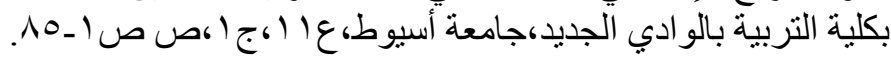

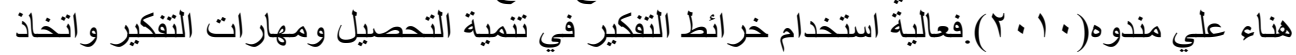

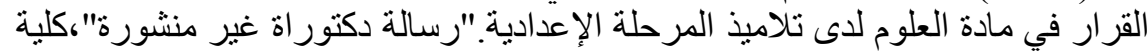

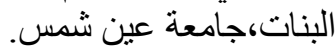

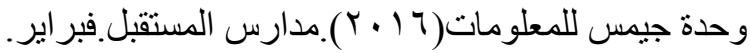

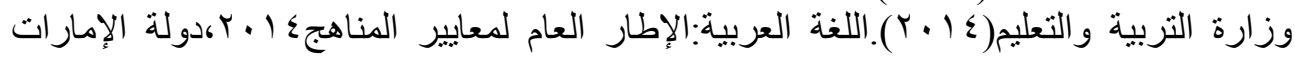
العربية المتحدة.

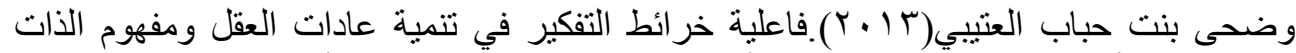

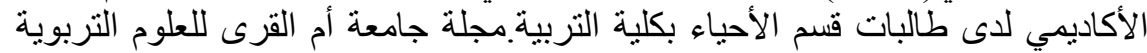

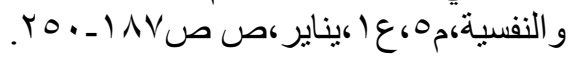

Akpinar,E.(2007).The Effect of Dual Situated Learning Model on Students' Understanding of Photosynthesis And Respiration Concepts.Journal of Baltic Science Education, Vol.6,No.3 ,ISSN1648- 3898,pp.16-26.

Akpinar,E.;Ergin,O.(2007).Dual Situated Learning Model and Science Teaching .Elementary Education Online,vol6,no3,pp390-396.

Arsada,N.;Osmana,K.;Tuan,M.(2011)Instrument Development for21st Century Skills in Biology.Procedia Social and Behavioral Sciences 15. www.sciencedirect.com.8-Bell.

Astleitner,H.(2002).Teaching Critical Thinking.Journal of Instructional Psychology,vol 29,no2,pp53-76. 
Barry,M.(2012).What Skills will you need to Succeed in the Future? Phoenix Forward(online).Tempe,AZ,University of Phoenix.1

Bell,D.V.J(2016).Twenty Frist Century Education:Transformative

Education for Sustainability and Responsible Citizenship.Journal

of Teacher Education for Sustainability,vol.18,no.1,pp.4856,DOI: 10.1515/jtes-2016-0004.

Blank,R.K. et. al(2001).New Tools for Analyzing Teaching,Curriculum and

Standards in Mathematics \& Science.

https://secure.wceruw.org/seconline/Referen ce/SECnewToolsreport.pdf.

Bell,S.(2010).Prject-Based Learning fr the 21st Century:Skills for the

Future",Clearing Huse.A Journal Educational Strategies,Issues and Ideas,v83 ,n2,pp39-43.

Buold,J.(2003).Mind Maps a Classroom Exercises.Journal of Economic Education,Vol.35,No.4.

Burden.B.;Silver.J.(2006).Thinking Maps in Action,Teaching Thinking \&Creativity, pp38-42.

Buxton,M.(2005).How Can Thinking Maps in Pact upon the Learning to Learn Agenda?inet on Line Conference Paper:Learning to Learn,Djanogly Cit Academy Nottingham,pp1-18.

Bybee,W.R.(2010).The Teaching of Science:21st Century Perspectives.NSTA press.

Caliskan,H.;Kumtepe,E.;Aydin,C.;Kumtepe,A.(2011)Integration of 21st

Century Skills into Science Instruction:A Case Of Early Childhood Teacher Education .International Conference, The Future of Education, Florence,Italy,16-17June.

Century Skills as a vision for K-12 Education(2007).What Should Schools and Districts do?Ken Kay,President,Partnership for 21st Century Skills,FETC, Orlando, Florida,Granary25.

Diaz,A(2010).The Relationship between Thinking Maps ${ }^{\circledR}$ and Florida Coprehensive Assessment Test ${ }^{\circledR}$ Reading and Mathematics Scores in Two Urban Middle Schools.Doctoral Dissertation Submitted to the College of Education at the University of Central Florida Orlando, Florida. www.ju.edu jo/ar/arabic/home.aspx

EC.(2008).Lifelong Learning for Creativity and Innovation.A Background Paper.Slovenia:Slovenian EU Council Presidency. 
Facer,K.(2009).Educational,Social and Technological Futures:A Report from the Beyond Current Horizons Programme.Berkshire,UK,FutureLab.

Gallagher,M.L.(2011).Book IV:Integrating and Sustaining Habits of Mind,Using Visual Maps to assess Student Thinking,Thinking Foundation.East Carolina University.Journal of

Family\&Consumer Sciences Education,29(2),Fall/Winter.

Gut,D.M.(2011)Integrating 21st Century Skills into the Curriculum.Explorations of Educational Purpose,v13,pp137-157. Hamzah,M.S.;Md Zain,A.N.(2010).The Effect of Cooperative Learning With DSLM on Conceptual Understanding and Scientific Reasoning among form Four Physics Students With Different Motiivation Levels.Bulgarian Journal of Science and Education Policy (BJSEP), Vol4,No2,pp275-310.

Hilton,M.(2010).Exploring the Intersection of Science Education and21 st Century Skills:A Workshop Summary",National Academy of Sciences, http://www.nap.edu/catalog/12771.html.

Holzman,S.(2004).Thinking Maps:Strategy-Based Learning for English Language Learners(and Others)Annual Administrator Conference13th "Closing the achievement Gap for El Students",Sonoma county office of Education,California Department of Education,pp.1-8.

Holzman,S.(2004).Thinking Maps:Strategy-Based Learning for English Language Learners(and Others)Annual Administrator Conferencel3th,Sonoma Country Office of Education.California Department of Education,pp1-8.

Hortencia,P.( 2007).Building Bridges for Second Language Learners International Conference,Thinking Maps,13-14July,Incorporated. Hyerle,D.(1996).Thinking Maps:Seeing Is Understanding Education.Leadership ,V.53,N.4,pp85-89.

$\begin{array}{ccccr}\text { Hyerle,D.(2000).A Field Guide } & \text { to } & \text { Using } & \text { Visual } \\ \text { Tools.Alexandria,VA:Association } & \text { for } & \text { Supervision } & \text { and } \\ \text { Curriculum Development. } & & & \end{array}$

Hyerle,D.(2000).A field Guide to Using Visual Tools,Association for Supervision and Curriculum Development (ASCD)pres.Alexandria,Virginia.

Hyerle,D.(2004).Designs for Thinking Represents Thinking Maps.Inc. 
Hyerle,D.( 2004).Student Successes With Thinking Maps.School Based Research,Results and Models Using Visual Tools, Corwinpress ‘SAGE.Pub. Hyerle,D.(2004)Student Successes with Thinking Maps:Seeing is Understanding.Educational Leadership,53,4,pp85-98.

Hyerle,D.(2004).Thinking Maps:As a Transformational Language for Learning. WWW. Thinking Maps.Com.

Hyerle,D.;Curtis,S.;Alper,L.(Eds.)(2004).Student Successes with Thinking Maps: School-Based Reaearch:Results and Models for Achievement Using Visual Tools ,VA:Association for Supervision and Curriculum Development.

Hyerle,D.(2007).Student Successes With Thinking Maps.School Based Research,Results,and Models for Achievement Using Visual Tools. http:Iwww.corwinpress.com.

Hwa,T.H.;Karpudewan,M.(2017).Green Chemistry-Based Dual-Situated Learning Model:An Approach that Reduces Students'MisConceptions on Acids and Bases. In:Karpudewan M.,Md Zain A.,Chandrasegaran A(eds)Overcoming Students' MisConceptions in Science.Springer International Publishing AG.Part of Springer Nature, 1 March,ISBN 978-981-10-3435-0.

Jacobson-Lundeberg,V.(2016).Pedagogical Implementation of 21st Century Skills.Educational Leadership and Administration:Teaching and Program Development,v27,pp82-100,Mar.

Jamieson,S.(2006).Thinking Maps for G\&T Learners-Birchwood Community High School,Warrington.The Academy for Gifted and Talented Youth.

Jessica,O.;Jeffrey,O.(2005).Throwing Paper Wads in the Chemistry Classroom:Really Active Student Learning.Journal of College Science Teaching,35,3,Nov-Dec.

John,C.;Cecilia,M.(2003).Abduction and Analogy in Scientific Model Construction .Science Education,3,pp97-105.

Ken,K.(2010).21st Century Skills:Why They Matter,What They Are,and How We Get There?

Learning Prep School(2007).Thinking Maps http: Ilwww.LearningPrep org. Learnovation.(2009).Inspiring Young People to Become Lifelong Learners in 2025.Vision Paper1.Brussels, MENON,pp.1-12. 
Leis,M.(2010).Challenges for the Future of Learning until 2030:Foresight on Learning,Innovation and Creativity.Presentation at LearnTec,Karlsruhe,DE.

Liao,Y.W.;She,H.C.(2009).Enhancing Eight Grade Students' Scientific Conceptual Change and Scientific Reasoning through a WebBased Learning Program .Educational Technology\&Society, 12 ,4,pp228-240.

Lim,S.(2003).Developing Reflective and Thinking Skills by Means of Semantic Mapping Strategies in kindergarten.Teacher Education,Early Child Development and Care,Vol.173,No.1,pp.71-92.

Manning,C.(2003).Improving Reading Coprehension through Visual Tools .Master of Education in Eastern Nazarene College.

foundation,org.www.Thinking Metiri Group;NCREL(2003).EnGauge21st Century Skills:Literacy in the Digital Age.Chicago,IL:NCREL pict.sdsu.edu/engauge21st.pdf.

Miller,R.D.(2009).Developing 21st Century Skills Through the Use f Student Personal Learning Networks,Ed.D.Nrthcentral University. United States-Arizna. http://search.prquest.cm/dcview/305177755? accuntid=37552.

OECD(2005).21st Century Learning Research.Innovation and Policy.

Partnership for 21st Century Skills(2007).The Intellectual and Policy Foundations of the 21st Century Skills Framework.Washington DC,Partnership for 21st Century Skills.

Partnership for 21st Century Skills(2009a).Assessment f 21st Century Skills", http://www.p21.rg.

Partnership for 21st Century Skills(2009b).Curriculum and Instruction:A 21st Century Skills Implementation Guide http://www.p21.org.

Partnership for 21st Century Skills(2009c).Learning Envirnments:A 21st Century Skills Implementatin Guide", http://www.p21.rg.

Partnership for 21st Century Skills(2009d).Professional Development:A 21st Century Skills Implementation Guide http://www.p21.org.

Partnership for 21st Century Skills(2009e).21st Century Skills Standards. http://www.p21.org.

Peterson,A.D(2003).Schools Across Frontiers:The Story of The International Baccalaureate and The United World Colleges.USA:Carus Publishing Company ,ISBN0. $\_-90.0_{-} \wedge 1$ Y. 


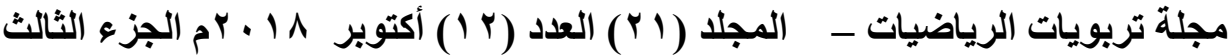

Piercy,D.(2007).Thinking Maps:The Cognitive Bridge to Literacy.Alexandria,AV, ASCD.

Pink.D.H.(2005).A whole New Mind,the Penguin Group.New York,USA.

Posner, G et al.(1982).Accommodation of a scientific Conception:Toward a theory of Conceptual Change.Science Education,66,2,pp211-227.

Redecker,C.;Ala-

Mutka,K.;Leis,M.;Leendertse,M.;Punie,Y.;Gijsbers,G.;Kirschner, P.;Stoyanov,S.;Hoogveld,B.(2011).The Future of Learning:Preparing for Change .Luxembourg.Publications Office of the European Union.

Redecker,C.;Punie,Y.(2013).The Future of Learning2025:Developing a vision for Change.Learning,Vol.1,pp.3-17.

Reubell,S.(2009).What are the Benefits of Thinking Maps?

Russel,L.(2010).The Impact of Thinking Maps on the Reading Coprehension of Elementary School Students.Doctor of Education,United States-Texas University.

Senechal,D.(2010).The Most Daring Education Reform act of all.American Educator,34,1,pp4-16.

Senthilkumar,R.D.(January2016).ICT Enabled Situated Learning Model in the Development of Metacognitive Skills.International Journal of Engineering Science and Innovative Technology(IJESIT),Vol5,no1,ISSN:2319-

5967ISO9001:2008,pp 76-80.

She,Hsiao-Ching Promotiing Students'Scientific Conceptual Change through Dual-Situated Learning Model.

She,H.C.(2001).Dual Situated Learning Model:An Instrumental Approach Toward Scientific Conceptual Change.Proceedings of 2001 SinoJapanese Symposium on Science Education(Taipei,Taiwan,ROC:National Science Council).131,139,3.

She,H.C.(2002).Concepts of Higher Hierarchical Level Required more Dual Situational Learning Events for Conceptual Change:A Study of Students' Conceptual Changes on air Pressure and Buoyancy.International Journal of Science Education, V24, no9,pp981-996. 
She,H.C.(Feb2004).Fostering Radical Conceptual Change through DualSituated Learning Model.Journal of Research in Science Teaching,v41,n2,pp142-164.

She,H.C.;Liao,Y.W.(2010).Bridging Scientific Reasoning and Conceptual

Change through adaptive Web-Based Learning.Journal of

Research in Science Teaching, 47,1,pp91-119.

Sherwin,S.(2004).Thinking Maps.New York,University of Syracuse Inc.

Spiegel,L.(2007).The Metcognitive School:Creating acommunity where

Children and Adult Reflect on their Work.The New Hampshire

Journal Education, vol11,Plymouth State College Center for

Professional Educational Partnership.

Srisawasdi,N.;Kroothkeaw,S.;Educ,J.C.(2014).Supporting

Students'Conceptual Development of Light Rfraction by

Simulation-Based Open Inquiry with Dual-Situated Learning Model.Beijing Normal University and Springer-Verlag Berlin Heidelberg,1,1,pp49-79,DOI 10.1007 /s40692-014-0005-y.

Stevens,R.(2012).Identifying 21st Century Capabilities,International Journal of Learning and Change.6,3,pp123-137.

Sunseri,A.B.(2011).The Impact of Thinking Maps on Elementary Students' Expository Texts,San Francisco,California,May.

Swartz,R.(2008).Energizing Learning.Educational Leadership,vol65,no5,pp26-31.

Sylvia,P.(2007).Thinking Maps through The Eyes of School Leaders

International Conference.Thinking Maps,13-14 July,Incorporated.

The Partnership for 21st Century Skills(P21) is a national Organization that advocates for 21st Century Readiness for Every Student. P21

Advocates for Local,State and Federal Policies that Support 21st Century Learning Standards for Every School.

The Partnership for 21st Century Skill(2006).Framework for 21st Century Learning.

The Partnership for 21st Century Skill Designed in Cooperation with The National Science Teachers Association(2009).21 Century Skills Map.

http://www.p21.org/storage/documents/21st cskillsmap_science.pdf.

The World Bank.(2015).Countries and Economies http://data worldbank.org/ country. 
Thinking Maps,INC(2004)Thinking Maps Information https://Thinking map.Ivordpress.com/category 17/8/2017.

Thinking Maps Organization(n.d).Retrieved on March 20,2017, from Thinking Maps,13-14July,Incorporated. ThinkingMaps/index.htm

Tseng,C.H.;Tuan,H.L.;Chin,C.C.;Chang,J.C.(n.d).Investigating the Relation between Students'Motiivation and Concept Learning in a digital Learning Context.

Wagner,T.(2010).Overcoming The Global Achievement Gap(online).Cambridge ,Mass,Harvard University.

Wikipedia,Site(2007)Cognitive Map. WWW. Wikipedia .org.

Wan Husin,W.N.F.;Mohamad Arsad,N.;Othman, O.;Halim,L.;Rasul,M.S.; Osman,K.;Iksan,Z.(2016).Fostering Students' 21st Century Skills through Project Oriented Problem Based Learning(POPBL)in Integrated STEM Education Program.Asia-Pacific Forum on Science Learning and Teaching, v17,n1,Article3,Jun.

Yvtte,J.(2002).Closing The Gap by Connecting Culture,Language and Cognition .ED,D,National Urban Alliance. 